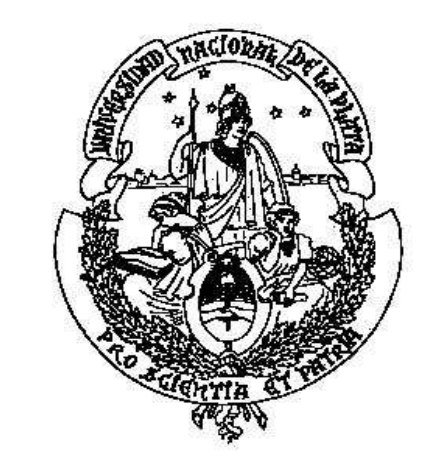

Universidad Nacional de La Plata

Facultad de Ciencias Astronómicas y Geofísicas

\title{
Propiedades del gas molecular asociado con estrellas Wolf Rayet de nuestra galaxia
}

\author{
Por: Lic. Nicolás Duronea \\ Director: Dr. Edmundo Marcelo Arnal \\ Tesis presentada para optar al grado de Doctor en \\ Astronomía
}




\section{Índice general}

1. Introducción 1

1.1. Evolución de estrellas de gran masa . . . . . . . . . . . . . . 1

1.2. Estrellas Wolf-Rayet . . . . . . . . . . . . . . 6

1.3. Vientos estelares y su interacción con el medio interestelar . . . 8

1.4. Burbujas interestelares y su evidencia observacional . . . . . . . 15

1.4.1. Observaciones en el óptico . . . . . . . . . . . . . 15

1.4.2. Observaciones en el continuo de radio . . . . . . . . . . . 17

1.4.3. Observaciones en la línea de $21 \mathrm{~cm}$ del HI . . . . . . . . . 20

1.4.4. Observaciones en infrarrojo . . . . . . . . . . . 24

1.4.5. Observaciones en líneas moleculares . . . . . . . . . . 25

1.5. Nubes moleculares y formación estelar inducida . . . . . . . . . 31

1.6. Objetivos de esta Tesis . . . . . . . . . . . . . . . . . 35

1.7. Bibliografía . . . . . . . . . . . . . . . 37

2. Descripción del instrumento, observaciones y bases de datos utilizados 43

2.1. Radiotelescopio de disco simple . . . . . . . . . . . . . . . 43

2.1.1. Principales parámetros de un radiotelescopio . . . . . . . 43

2.1.2. Interpretación de las señales recibidas por un radioteles-

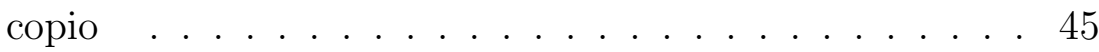

2.1.3. Señal y ruido . . . . . . . . . . . . . . . . 47

2.2. Instrumento utilizado y observaciones realizadas . . . . . . . . 48

2.3. Bases de datos utilizadas . . . . . . . . . . . . . . . 50

2.4. Bibliografía . . . . . . . . . . . . . . 52

3. Tratamiento de los datos y parámetros derivables de las observaciones

3.1. Observaciones de ${ }^{12} \mathrm{CO} \ldots \ldots \ldots \ldots$. . . . . . . . . . . . . . . . . . . 53

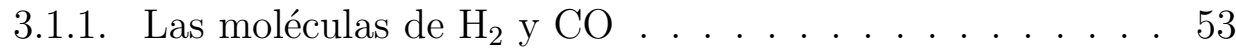

3.1.2. Reducción de los espectros y confección de los cubos de datos . . . . . . . . . . . . . . 56

3.1.3. Análisis del cubo de datos y detección preliminar de las estructuras moleculares relacionadas con las estrellas WR 57 
3.1.4. Cálculo de los principales parámetros asociados a las nubes moleculares . . . . . . . . . . . . . 59

3.2. Observaciones de HI . . . . . . . . . . . . . . . . . 62

3.3. Observaciones infrarrojas . . . . . . . . . . . . . . . 64

3.4. Observaciones en continuo de radio . . . . . . . . . . . 65

3.5. Bibliografía . . . . . . . . . . . . . . . . 69

4. El gas molecular asociado a WR $16 \quad 71$

4.1. Descripción de la zona y antecedentes . . . . . . . . . . . . . 71

4.2. Búsqueda y análisis de las componentes moleculares asociadas

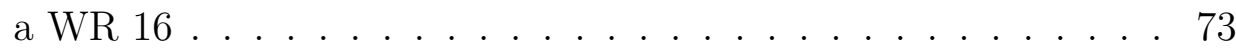

4.3. La nebulosa infrarroja . . . . . . . . . . . . . . . . . 84

4.4. Análisis y discusión . . . . . . . . . . . . . . . . . 85

4.4.1. Características del AME y la subcomponente A1 . . . . 86

4.4.2. El Anillo Molecular Interno . . . . . . . . . . . . . . 97

4.5. Resumen y conclusiones . . . . . . . . . . . . . . . . . 109

4.6. Bibliografía . . . . . . . . . . . . . . . . 111

5. El complejo MIE en los alrededores de WR 18

5.1. La nebulosa NGC 3199 . . . . . . . . . . . . . . . . . . . 112

5.2. Resultados observacionales . . . . . . . . . . . . . . . . . 114

5.2.1. Emisión general de CO . . . . . . . . . . . . . 114

5.2.2. Distribución espacial del CO . . . . . . . . . . . 116

5.3. Emisión de HI . . . . . . . . . . . . . . . . . . . . . . . . 126

5.4. NGC 3199 en IR . . . . . . . . . . . . . . . . . . . . . . 128

5.5. Emisión del gas ionizado . . . . . . . . . . . . . . . . . . 129

5.6. Análisis y discusión . . . . . . . . . . . . . . . . . . . . . 131

5.6.1. El gas ionizado asociado a NGC 3199 . . . . . . . . . 131

5.6.2. Emisión del polvo en NGC 3199 . . . . . . . . . . . . . 140

5.6.3. Movimiento de WR 18 . . . . . . . . . . . . . . . 141

5.6.4. Componentes moleculares y atómicas asociadas a NGC

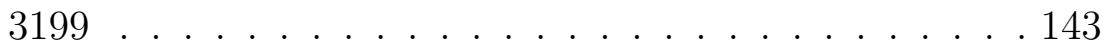

5.7. Resumen y conclusiones . . . . . . . . . . . . . . . 146

5.8. Bibliografía . . . . . . . . . . . . . . . . . 148

6. Las nebulosas ópticas alrededor de WR 55 y WR 68 . 149

6.1. RCW 78, morfología y antecedentes. . . . . . . . . . . . . . . . 149

6.2. Observaciones de CO de NANTEN . . . . . . . . . . . . 152

6.3. La nebulosa RCW 78 en el continuo de radio e infrarrojo . . . . 162

6.4. Análisis y discusión . . . . . . . . . . . . . . . . . . . . . 164

6.4.1. La componente molecular entre $\sim-58 \mathrm{y}-45 \mathrm{~km} / \mathrm{seg} . .164$

6.4.2. La "barra" $\mathrm{H} \alpha \ldots \ldots$. . . . . . . . . . . . . 177

6.4.3. La estructura B . . . . . . . . . . . . . . . . . . 179 
6.5. El modelo propuesto para CM234. ¿Es posible encontrar este tipo de estructuras alrededor de otras estrellas WR? . . . . . . . 183

6.5.1. La nebulosa óptica alrededor de WR 68 . . . . . . . . . . 183

6.6. Resumen y conclusiones . . . . . . . . . . . . . . . . . 188

6.7. Bibliografía . . . . . . . . . . . . . . . . . . 190

7. El gas molecular asociado a las regiones HII RCW 121 y RCW 122. Su relación con las estrellas WR 87, WR 89, WR 91 y el cúmulo abierto HM 1

7.1. Resumen . . . . . . . . . . . . . . . . . . . . . . 192

7.2. Algunos conceptos adicionales del análisis realizado a la componente molecular asociada a RCW 121 y RCW 122 . . . . . . . 194

8. El gas molecular detectado en los alrededores de las estrellas WR 14, WR 75 y WR 103

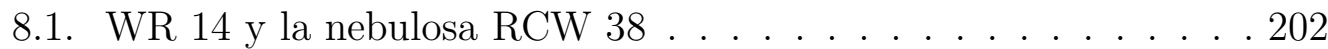

8.2. WR 75 y la nebulosa RCW $104 \ldots 206$

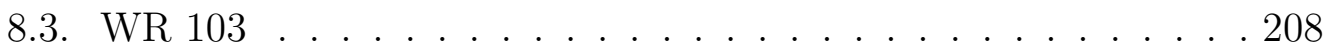

8.4. Bibliografía . . . . . . . . . . . . . . . . 211

9. Resumen general y Conclusiones 212

9.1. Resumen . . . . . . . . . . . . . . . . . 212

9.2. Conclusiones . . . . . . . . . . . . . . . . . . . . 214

9.3. Trabajos a futuro . . . . . . . . . . . . . . . . 215 


\title{
Capítulo 1
}

\section{Introducción}

\author{
"...Dios mío, está lleno de estrellas...!!" \\ David Bowman, "2001: Odisea del espacio" \\ Arthur C. Clarke
}

"...me pregunto si las estrellas se iluminan con el fin de que algún día, cada uno pueda encontrar la suya..."

"El Principito"

Antoine de Saint-Exupéry

\subsection{Evolución de estrellas de gran masa}

La deposición localizada de grandes cantidades de energía por parte de las estrellas de gran masa produce notables cambios en el medio interestelar (MIE) que las rodea. Al evolucionar, estas estrellas afectan el MIE, cambiando su fase a través de la disociación del material molecular e ionización del gas neutro debido a su alta tasa de emisión de fotones UV, y luego inyectándole energía mecánica, primero por medio de los vientos y luego al explotar como supernovas. También contribuyen al enriquecimiento químico del MIE

En esta Tesis Doctoral se considerarán como "estrellas de gran masa" a aquéllas que en la fase de Secuencia Principal tienen una masa comprendida entre $\mathrm{M}>10 \mathrm{M}_{\odot}$, así como sus descendientes (supergigantes de todos los tipos espectrales y estrellas Wolf-Rayet (WR)).

Durante mucho tiempo se pensó que la evolución estelar de las estrellas de alta masa podía ser explicada sólo con la opacidad debida a los electrones libres y una sencilla ecuación de estado, con lo cual la estrella dejaba la Secuencia Principal (SP) y luego de pasar por la fase de supergigante, explotaba como supernova de tipo II. En las últimas décadas, algunas conclusiones obtenidas de las observaciones, llevaron a hacer algunas modificaciones al esquema evolutivo anterior (Maeder, 1991). Hoy en día se admite que: 
- Las estrellas de gran masa pierden gran parte de la misma durante su evolución, a través de los vientos estelares. Dados los valores para las tasas de pérdida de masa actuales, todas las estrellas de Población I con masas iniciales mayores a $25 M_{\odot}$, terminan sus vidas sólo con $5-10 M_{\odot}$. Así los vientos estelares cumplen un rol fundamental en la evolución estelar.

- Las estrellas Wolf-Rayet (WR), son consideradas como estrellas que se han "evaporado" debido a sus vientos y han dejado su núcleo expuesto, lo cual ofrece la posibilidad de ver en forma directa los productos de la nucleosíntesis. Estas estrellas, escasas y de corta vida, son uno de los proveedores importantes de masa y energía al MIE.

- Se han encontrado grandes diferencias entre el número relativo de estrellas $\mathrm{O}$, supergigantes azules y rojas y WR en galaxias con distinta metalicidad (Z). Esto se debería principalmente al hecho de que la tasa de pérdida de masa dependería fuertemente de Z, por lo que la evolución de estrellas de gran masa no sería la misma en galaxias de distinto Z .

- Una consecuencia directa de lo anterior es que las estrellas progenitoras de las supernovas, y por ende las supernovas, son distintas en galaxias con distinto Z. Esto sucede principalmente para supernovas tipo II y supernovas tipo Ib que son las que de acuerdo a los modelos evolutivos actuales podrían originarse de supergigantes rojas y WR, respectivamente.

- La producción de elementos químicos, depende fuertemente de la tasa de pérdida de masa y de la metalicidad final. A altos valores de Z, los fuertes vientos se llevan el He antes de que éste pueda ser convertido en elementos pesados. A pequeños valores de Z, los vientos son débiles y la mayor parte del He se convierte en elementos pesados.

Es sabido que los efectos de metalicidad ejercen influencia en la estructura estelar a través de las opacidades debidas a los procesos ligado-libre y ligado-ligado de los electrones. En el caso de estrellas de gran masa, este efecto es insignificante en el interior, ya que la principal fuente de opacidad es la dispersión de electrones. Sólo en las capas exteriores es donde los efectos de metalicidad afectan a la opacidad.

Las estrellas (principalmente las de mayor masa) expulsan a lo largo de toda su vida, buena parte de sus capas externas a través de los vientos estelares. La tasa de pérdida de masa $(\dot{M})$ se define como el cambio de masa con el tiempo, entonces

$$
\dot{M}=\frac{d M}{d t}
$$

Modelos de vientos para estrellas O (Abott, 1982a; Kudritzki et al., 1987; Leitherer \& Langer, 1991) sugieren una dependencia de $\dot{M}$ con Z : 


$$
\dot{M} \sim Z^{\alpha} \quad \text { donde } \alpha=1,0-0,5
$$

En el caso de estrellas WR, Langer (1989) sugiere que $\alpha=2$.

Las consecuencias de las distintas tasas de pérdida de masa en la evolución estelar fueron estudiadas por Chiosi \& Maeder (1986). En este trabajo se destacan los siguientes puntos:

- Para valores típicos de $\dot{M}\left(\dot{M}<8 \times 10^{-6} M_{\odot} /\right.$ año $)$, las consecuencias de los vientos estelares en la secuencia principal (SP) son pequeñas; el tiempo de vida en SP es: $t(S P) \sim q M / L$ donde q es la fracción de masa del núcleo de una estrella de masa $\mathrm{M}$ y luminosidad L. El resultado sobre t(SP) es pequeño : sólo un incremento del 5 al $10 \%$.

- Durante la etapa de quema de He, los efectos son mayores. El tiempo de vida en la fase de quema de $\mathrm{He}(\mathrm{t}(\mathrm{He}))$ se divide entre la fase de supergigante azul (BSG), supergigante roja (RSG) y WR.

$$
t(H e)=t(B S G)+t(R S G)+t(W R)
$$

El balance entre estas tres fases depende fuertemente de $\dot{M}$.

Los efectos antes mencionados, llevan a tres secuencias evolutivas diferentes, de acuerdo a la masa inicial:

$$
\begin{aligned}
M>M_{1} & =O \rightarrow O f \rightarrow B S G \rightarrow L B V \rightarrow W R \mapsto S N \\
M_{1}>M>M_{2} & =O \rightarrow B S G \rightarrow Y S G \rightarrow R S G \rightarrow W R \mapsto S N \\
M_{2}>M & =O \rightarrow R S G(\text { con o sin lazo de Cefeida }) \mapsto S N
\end{aligned}
$$

Donde BSG, YSG, RSG significan supergigante azul, amarilla y roja respectivamente, LVB variable luminosa azul y SN supernova. Los valores de $M_{1}$ y $M_{2}$ son aproximadamente: $M_{1}=50 \pm 10 M_{\odot}$ y $M_{2}=35 \pm 5 M_{\odot}$. Estos valores podrían ser mayores para poblaciones con menor metalicidad.

Leitherer, Robert \& Drissen (1992) identificaron las cuatro fases de pérdida de masa más importantes durante la evolución:

- Fase OB: Las propiedades del viento estelar están determinadas por la presión de radiación. La pérdida de masa durante esta fase no provoca grandes consecuencias en la evolución, a menos que $M>50 M_{\odot}$. Junto con la fase WR, esta fase es la que transmite mayor cantidad de energía y momento al MIE. 
- Fase $L B V$ : Esta es muy corta ( 10 $10^{4}$ años). Las tasas de pérdida de masa son muy altas $\left(\sim 10^{-4} M_{\odot} /\right.$ año $)$ y las velocidades del viento de alrededor de $200 \mathrm{~km} / \mathrm{seg}$. Desde el punto de vista del MIE, esta fase no es muy importante debido a su corta duración.

- Fase RSG: Estas estrellas tienen altas tasas de pérdida de masa $\left(10^{-6} M_{\odot}\right.$ /año), pero bajas velocidades del viento $(10 \mathrm{~km} / \mathrm{seg})$ y por lo tanto la energía mecánica inyectada al MIE es menor que en la fase OB. Aun así, esta fase es muy importante desde el punto de vista evolutivo.

- Fase WR: Son estrellas azules muy luminosas, con líneas anchas de emisión de C, N y O en la zona del óptico y UV. Estas estrellas tienen tasas de pérdida de masa muy altas $\left(10^{-5} M_{\odot} /\right.$ año $)$, así como una elevada velocidad de sus vientos $(2000-3000 \mathrm{~km} / \mathrm{seg})$. Las estrellas WR tienen un gran impacto sobre el MIE.

La evolución de las abundancias químicas superficiales en estrellas de gran masa fue estudiada por varios autores (Noels \& Gabriel, 1981; Maeder, 1983; Prantzos et al., 1986); en forma sintética, se distinguen 5 estadíos en la misma:

1. Abundancias iniciales (cósmicas), $C / N \simeq 4, O / N \simeq 10$.

2. Enriquecimiento de N.

3. Equilibrio $\mathrm{CNO}$ con presencia de $\mathrm{H}$, con $C / N \simeq 0,02$ y $O / N \simeq 0,1$. El contenido de $\mathrm{H}$ en la superficie es bajo. Esta es la composición típica de las estrellas LBV y WR de tipo WN tardíos (WNL)

4. Equilibrio $\mathrm{CNO}$ con poco o nada de H. Esta composición es típica de estrellas WR de tipo WN tempranas (WNE).

5. Productos de la combustión parcial de He: He, C, O, como se ven en estrellas WR de tipo WC y WO.

En la Figura 1.1 se muestra el cambio en las abundancias químicas superficiales con la masa para distintos valores de metalicidad (Maeder, 1991).

De acuerdo a lo expuesto anteriormente, está claro que la masa final en la evolución de una estrella (previa a la explosión de supernova) está íntimamente ligada a la masa inicial, a la tasa de pérdida de masa y por ende a la metalicidad Z. En la Figura 1.2 se muestra la relación entre la masa inicial y la masa final (en el momento de la explosión como supernova) para distintas metalicidades $(\mathrm{Z}=0,4,0,02,0,002,0,005)$. En este gráfico también se muestra esta relación en el caso de una tasa de pérdida de masa nula (masa inicial = masa final) y en el caso de una tasa de pérdida de masa constante durante la fase WR. 

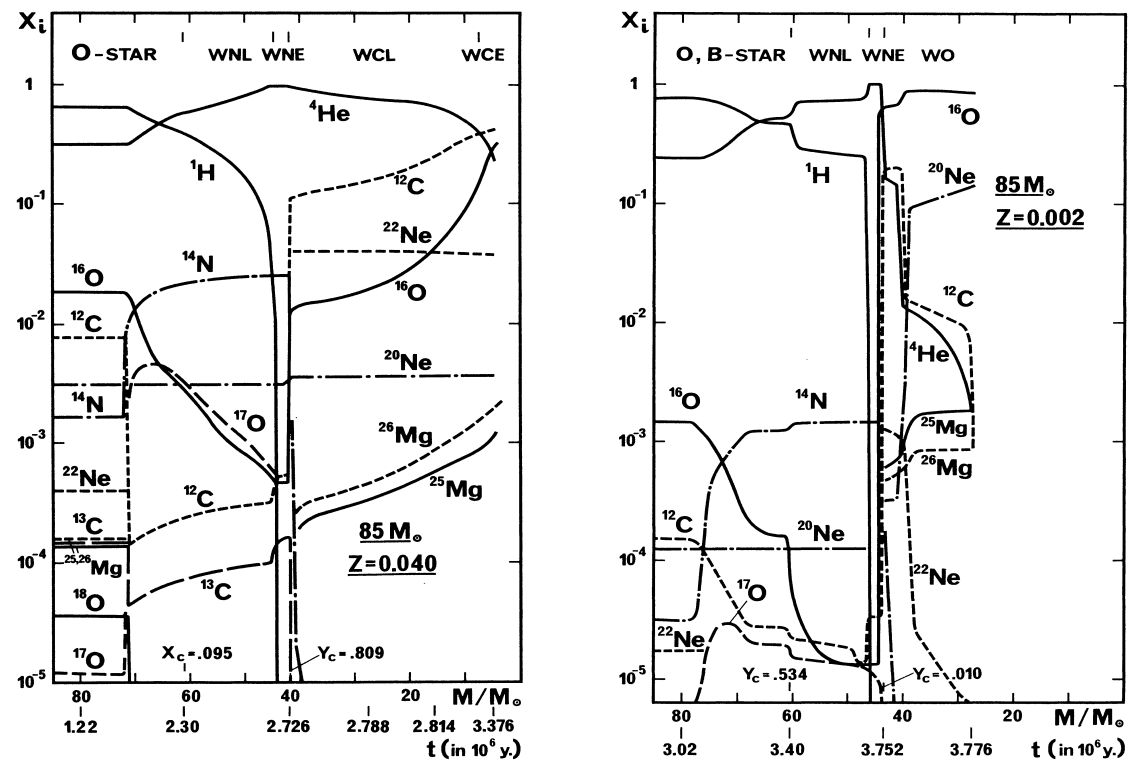

Figura 1.1: Cambio en las abundancias superficiales (en fracciones de masa) en términos de la masa remanente para una masa inicial $M=85 M_{\odot}$ con $\mathrm{Z}=0.04$ (izquierda) y Z $=0.002$ (derecha) (Maeder, 1991)

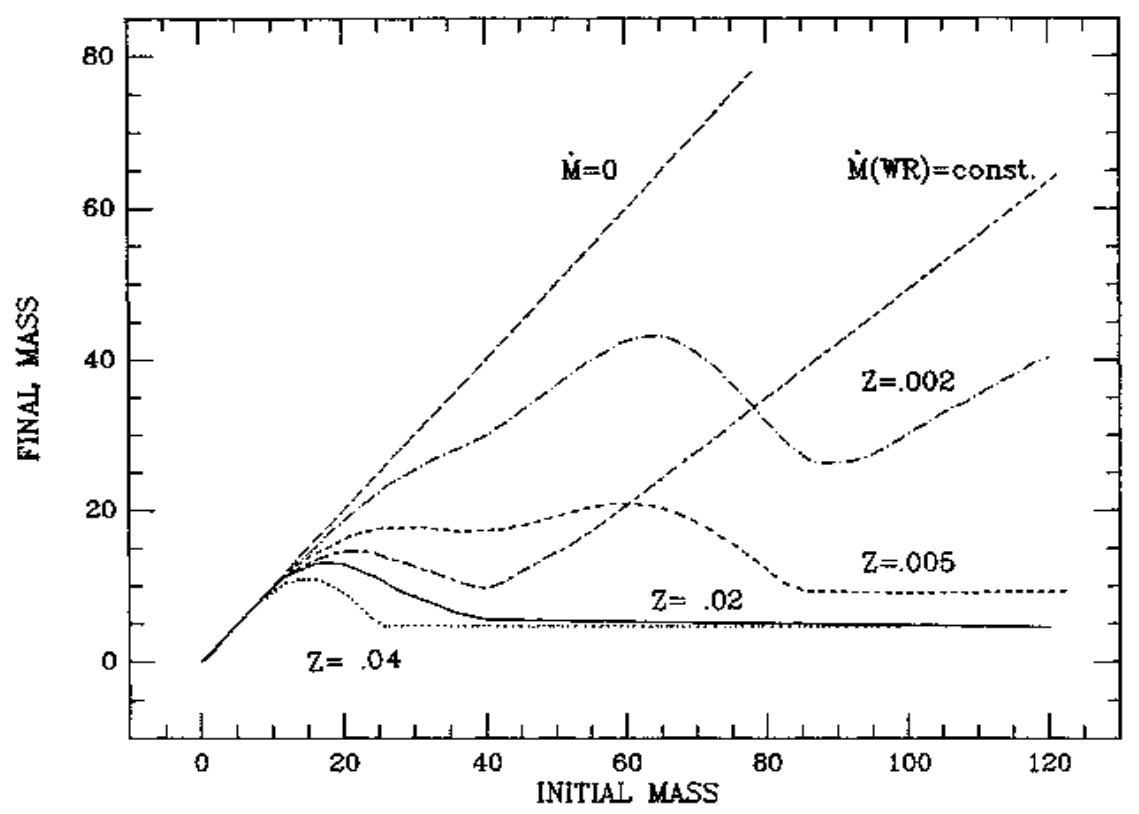

Figura 1.2: Relación entre las masas finales (en el momento de la explosión como supernova) y las masas iniciales como función de la metalicidad (Maeder, 1991) 


\subsection{Estrellas Wolf-Rayet}

De acuerdo a lo mencionado en la sección anterior, las estrellas Wolf-Rayet parecen ser el último eslabón en la cadena evolutiva de la estrella, previo a la explosión como supernova. Estas estrellas, que se supone están en la etapa de quema de He, han perdido sus capas externas debido a sus fuertes vientos y han dejado su núcleo expuesto, lo que permite ver los productos de la nucleosíntesis a través de las líneas de emisión presentes en su espectro.

Las estrellas WR se dividen básicamente en tres grupos o secuencias: WN, WC y WO las cuales presentan fuertes líneas de N, C y O respectivamente. Dentro de cada grupo puede haber subgrupos.

La primera clasificación espectral fue llevada a cabo por Beals (1938). Esta se basaba en la comparación de las intensidades de distintas líneas. Las estrellas fueron separadas en dos secuencias paralelas: N y C. Sumadas a las líneas de HeI y HeII (común en ambas secuencias), se observaban NiII NIV y Nv, mientras que para la secuencia del C se observaban CiI, Cin y Civ.

Las secuencias del $\mathrm{N}$ y $\mathrm{C}$ fueron desdobladas en cuatro y tres subclases respectivamente: WN5, WN6, WN7 y WN8 para la de $\mathrm{N}$ mientras que para la de C fueron WC6, WC7 y WC8. El interés en comprender la evolución estelar y en explicar los diferentes anchos en las líneas de emisión, llevaron a reconsiderar la clasificación hecha por Beals. Así Hiltner \& Schild (1966) y Smith (1968), realizaron modificaciones a este sistema. El primer trabajo introduce subclasificaciones de acuerdo al ancho de las líneas, mientras que en el segundo se hace un análisis más exhaustivo de las mismas, extendiendo los tipos espectrales e introduciendo nuevas subclases. Además, considera en el análisis a las estrellas binarias y plantea una posible clasificación fotométrica para las estrellas WR.

Es común dividir el grupo WN en dos subgrupos: WNE para las WN2-4.5 y WNL para las WN6-9 con las WN5 que se encuentran entre las WNE y las WNL. De la misma manera para el grupo WC: WCE para las WC4-6 Y WCL para las WC8-9 y las WC7 para ambos grupos. Smith et al. (1996) realizaron una clasificación tridimensional de estas estrellas utilizando (1) el cociente de líneas HeII 5411/HeI 5875 (como indicador primario de ionización), (2) el ancho a mitad de intensidad (FWHM) y el ancho equivalente (EW) de las líneas 4686 y 5411 del HeII como indicadores del ancho e intensidad, respectivamente y (3) la oscilación en el decremento de Pickering (causado por la coincidencia de las líneas de la serie de Balmer con la segunda línea de la serie de Pickering) como indicador de la presencia de $\mathrm{H}$.

Los modelos de evolución estelar sugieren una secuencia evolutiva dentro de la fase $\mathrm{WR}$ de la siguiente manera: $\mathrm{WN} \mapsto \mathrm{WC} \longmapsto \mathrm{WO}$. Así, las estrellas $\mathrm{WN}$ se consideran las estrellas WR menos evolucionadas.

La distribución de las estrellas WR en la Vía Láctea fue estudiada originalmente por Roberts (1962), Smith (1968, 1973), Moffat \& Isserstedt (1980), 
Gomez et al. (1981). Van der Hucht et al. (1981) publicaron el "Sixth Catalogue of WR Stars" en el que se calculan parámetros como el índice de color corregido por enrojecimiento $\left((b-v)_{0}\right)$, manitud visual absoluta $\left(M_{v}\right)$, magnitud visual aparente corregida por enrojecimiento $\left(v_{0}\right)$, distancia $(\mathrm{d})$, distancia al plano galáctico (z) etc, para las 159 estrellas WR galácticas conocidas hasta ese entonces. Más tarde, Hidayat et al. $(1982,1984)$, hicieron una revisión de este trabajo y realizaron un estudio completo de la distribución de las estrellas WR galácticas. En estos trabajos, la estructura espiral delineada por éstas fue más notoria que en trabajos anteriores para los que se contaba con menos datos. A continuación se muestra la distribución de las estrellas WR en la galaxia en función de sus coordenadas galácticas y de su distancia con respecto al plano galáctico (Figura 1.3, panel superior e inferior, respectivamente).
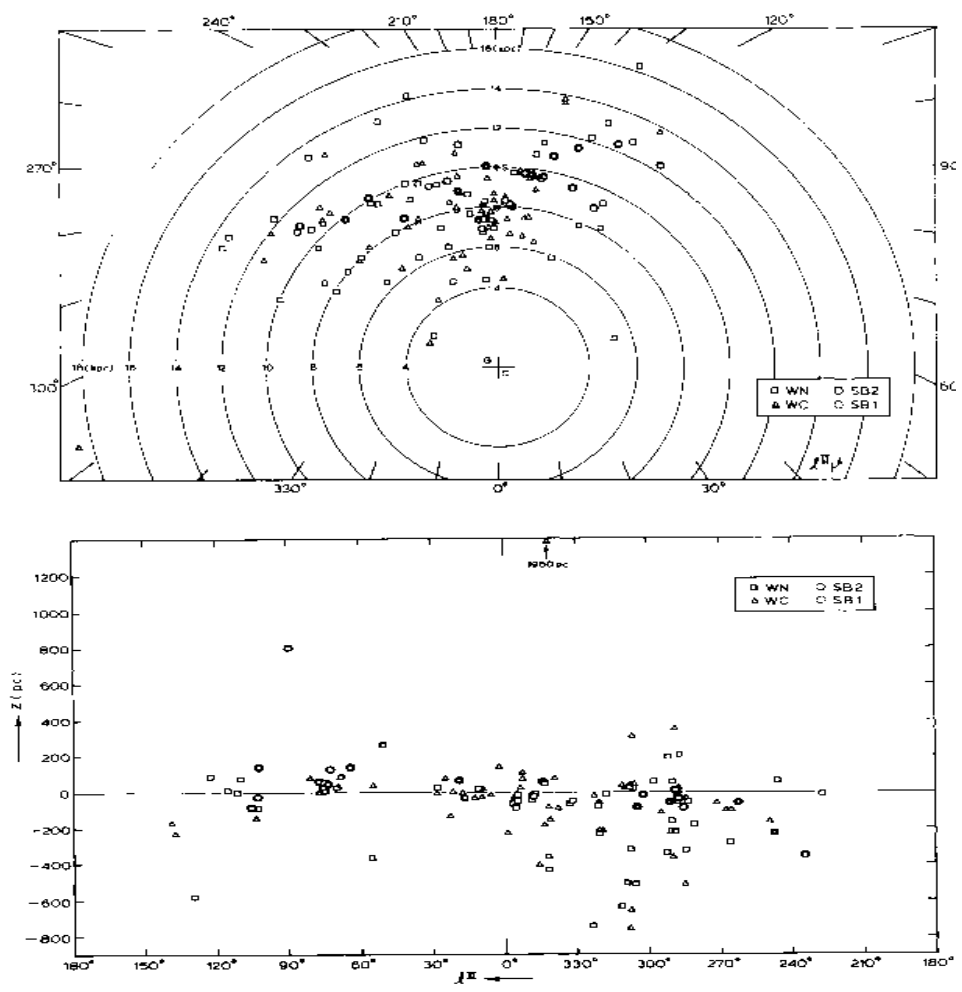

Figura 1.3: Panel superior Distribución de las estrellas WR galácticas proyectadas en el plano de la galaxia. Las coordenadas galácticas están dadas en la periferia. Las distancias desde el centro galáctico están dadas en kpc. La posición del centro galáctico está indicada por + G.C. y la posición del Sol está indicada por + S. Panel inferior Distribución $(1, z)$ de las estrellas WR galácticas (Hidayat et al., 1982)

La última compilación de estrellas WR incluye 227 estrellas individuales en nuestra galaxia (van der Hucht, 2001), a la que se han agregado 72 nuevas estrellas WR de Población I (Van der Hucht, 2006). 


\subsection{Vientos estelares y su interacción con el medio interestelar}

Como ya se dijo, las estrellas de gran masa provocan notables cambios en el MIE que las rodea, ionizándolo, poniéndolo en movimiento, y cambiando su abundancia química.

Al formarse la estrella de gran masa, el MIE se ioniza casi instántaneamente, debido a la copiosa cantidad de fotones ultravioleta (UV) emitidos por la estrella. Considerando una distribución homogénea de HI y una emisión isotrópica de fotones, alrededor de la estrella se forma una esfera de gas ionizado con $T \sim 10^{4} K$, la cual está separada del gas neutro por un frente de ionización (FI) que se expande a una velocidad que depende de la cantidad de fotones ionizantes que arriban al mismo por unidad de tiempo y área. El FI alcanza un determinado radio que se define como radio de Strömgren $\left(R_{s}\right)$, en el que el número de ionizaciones por unidad de volumen y tiempo igualan al número de recombinaciones por unidad de volumen y tiempo. Suponiendo que el número de electrones y de protones es el mismo, este radio es igual a:

$$
R_{s}=\left(\frac{3 S_{*}}{4 \pi n_{0}^{2} \beta}\right)^{\frac{1}{3}}
$$

donde $\beta$ es el coeficiente de recombinación hacia niveles excitados (no se considera el nivel fundamental), $S_{*}$ es la tasa de emisión de fotones de la estrella en el continuo de Lyman y $n_{0}$ la densidad ambiente inicial. Debido a la diferencia de temperaturas y presiones, la región ionizada se expande a una velocidad que es supersónica respecto de la velocidad del sonido en el gas neutro, generando de esta forma una onda de choque.

Es en este medio ionizado, donde los vientos estelares se manifiestan; estos vientos barren el material ionizado circundante generando una estructura conocida como burbuja interestelar (BI). El estudio de la estructura y dinámica de las BI, provee información sobre la interacción de los vientos estelares con el MIE y también sobre las condiciones iniciales de la región en que la explosión de supernova tendrá lugar.

Los primeros modelos teóricos realizados sobre la interacción del viento estelar y el MIE fueron llevados a cabo por Avedisova (1972), Dyson (1973), Castor et al. (1975) y Weaver et al. (1977). Estos modelos, a pesar de ser simples, sirvieron de base para modelos más realistas.

A continuación se presenta una versión del modelo de Castor et al.(1975) y Weaver et al.(1977) y posteriormente algunas de las modificaciones introducidas al mismo.

Este modelo está basado en las siguientes suposiciones:

- La densidad del MIE es constante, con un valor $\rho=\mu m_{H} n_{0}$ donde $\mu$ es 
el peso molecular medio, $m_{H}$ es la masa del átomo de hidrógeno y $n_{0}$ la densidad ambiente inicial.

- La estrella se encuentra en reposo respecto del MIE.

- El viento estelar es isotrópico.

- La luminosidad del viento $\left(L_{w}=1 / 2 \dot{M} v_{w}^{2}\right)$ es constante, siendo $v_{w}$ la velocidad del mismo.

- No existen campos magnéticos.

Haciendo estas suposiciones, el material circumestelar tiene una evolución en la que pueden distinguirse 4 fases:

1. Fase de expansión libre: Dura sólo unos pocos cientos de años hasta que la cantidad de MIE barrido logra frenar la expansión. En esta etapa se forma una cavidad de sólo $0,1-1$ pc.

2. Fase adiabática: Esta fase es también muy corta (algunos miles de años). Durante la misma, el viento estelar interactúa con el MIE y comienza a formar una estructura en la que se distinguen cuatro zonas distintas (ver Figura 1.4), a saber:

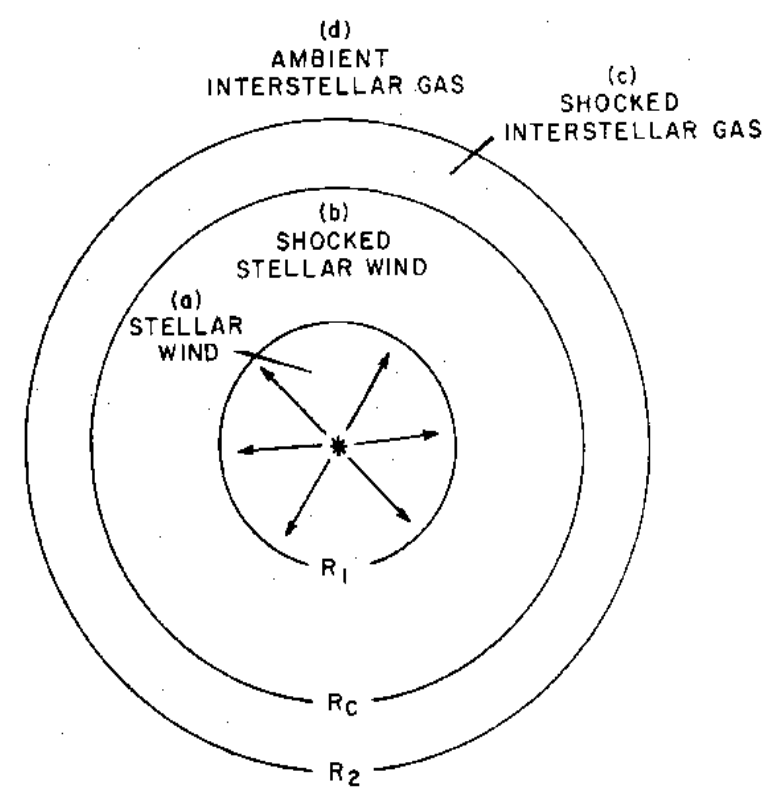

Figura 1.4: Representación esquemática de las cuatro zonas distinguibles del MIE alrededor de la estrella durante la fase adiabática. Ver texto para la explicación de cada una de las zonas. 
a) Una minúscula zona central donde el viento se expande libremente y a velocidades supersónicas $\left(v_{w} \sim 2000 \mathrm{~km} / \mathrm{seg}\right)$. La densidad del viento varía como $1 / r^{2}$ y $T \sim 10^{4} K$.

b) Una región de viento estelar chocado y desacelerado, cuya temperatura es de $10^{6}-10^{7} \mathrm{~K}$, separada de la región a) por un frente de choque interno $\left(R_{1}\right)$.

c) Cáscara de MIE barrido, que puede estar completamente ionizada por la estrella central o puede tener una capa externa de $\mathrm{H}$ neutro o molecular, si el frente de ionización queda atrapado en la misma.

La temperatura es de $\sim 10^{4} K$ o $\sim 100 K$, dependiendo de si el gas está ionizado o neutro, respectivamente. Esta región está separada del viento estelar chocado, por una discontinuidad de contacto $\left(R_{c}\right)$ y del medio ambiente interestelar sin perturbar por un frente de choque $\left(R_{2}\right)$.

d) MIE circundante sin perturbar.

La estructura de la BI durante esta etapa fue estudiada en detalle por Avedisova (1972) y Falle (1975).

La BI se expande tan rápido que las pérdidas radiativas en el gas no tienen tiempo de afectar ninguna parte del sistema, y la dinámica del mismo puede ser descripta como la de un flujo adiabático.

Despreciando los efectos de la gravedad y adoptando simetría esférica para los flujos, se encontró que:

$$
\begin{gathered}
R_{2}=\alpha\left(\frac{L_{w} t^{3}}{\rho_{0}}\right)^{\frac{1}{5}} \\
R_{c}=0,86 R_{2} \\
v\left(R_{c}\right)=0,86 V_{2}
\end{gathered}
$$

Siendo $\mathrm{V}_{2}$ la velocidad de $\mathrm{R}_{2}$. Para la región b), la relación $R_{1} / R_{c}$ no se mantiene constante con el tiempo:

$$
R_{1}=C t e \frac{R_{c}^{\frac{3}{2}}}{\left(v_{w} t\right)^{\frac{1}{2}}}
$$

Los cálculos de Weaver et al. (1977), muestran que en esta etapa, de la energía total liberada por el viento $\left(L_{w} t\right)$, el $40 \%$ es convertida en energía cinética, mientras que el $60 \%$ restante, en energía térmica del gas. 


\section{Fase de expansión radiativa o 'barredora de nieve'}

(snowplow): Como ya se mencionó, esta fase comienza cuando las pérdidas energéticas por radiación comienzan a hacerse importantes. Estas pérdidas causan el colapso de la región de gas interestelar chocado (región c)), que pasa a transformarse en una delgada cáscara isobárica, mientras que la región de viento interestelar chocado (región b)), todavía conserva la energía.

El gradiente de temperatura generado entre la zona de viento caliente y la cáscara fría es tan grande, que comienza a producirse el transporte convectivo de calor mediante electrones. Debido a esto, la superficie interna de la cáscara se evapora y el material fluye hacia la región caliente, aumentando la masa de dicha región. En la Figura 1.5 puede verse la variación de la temperatura y la densidad del material circumestelar con el radio para $\mathrm{t}=10^{6}$ años, una luminosidad del viento $L_{w}=1,27 \times 10^{36}$ $\mathrm{erg} / \mathrm{seg}$ y una densidad inicial $n_{0}=1 \mathrm{~cm}^{-3}$ (Weaver et al., 1977).

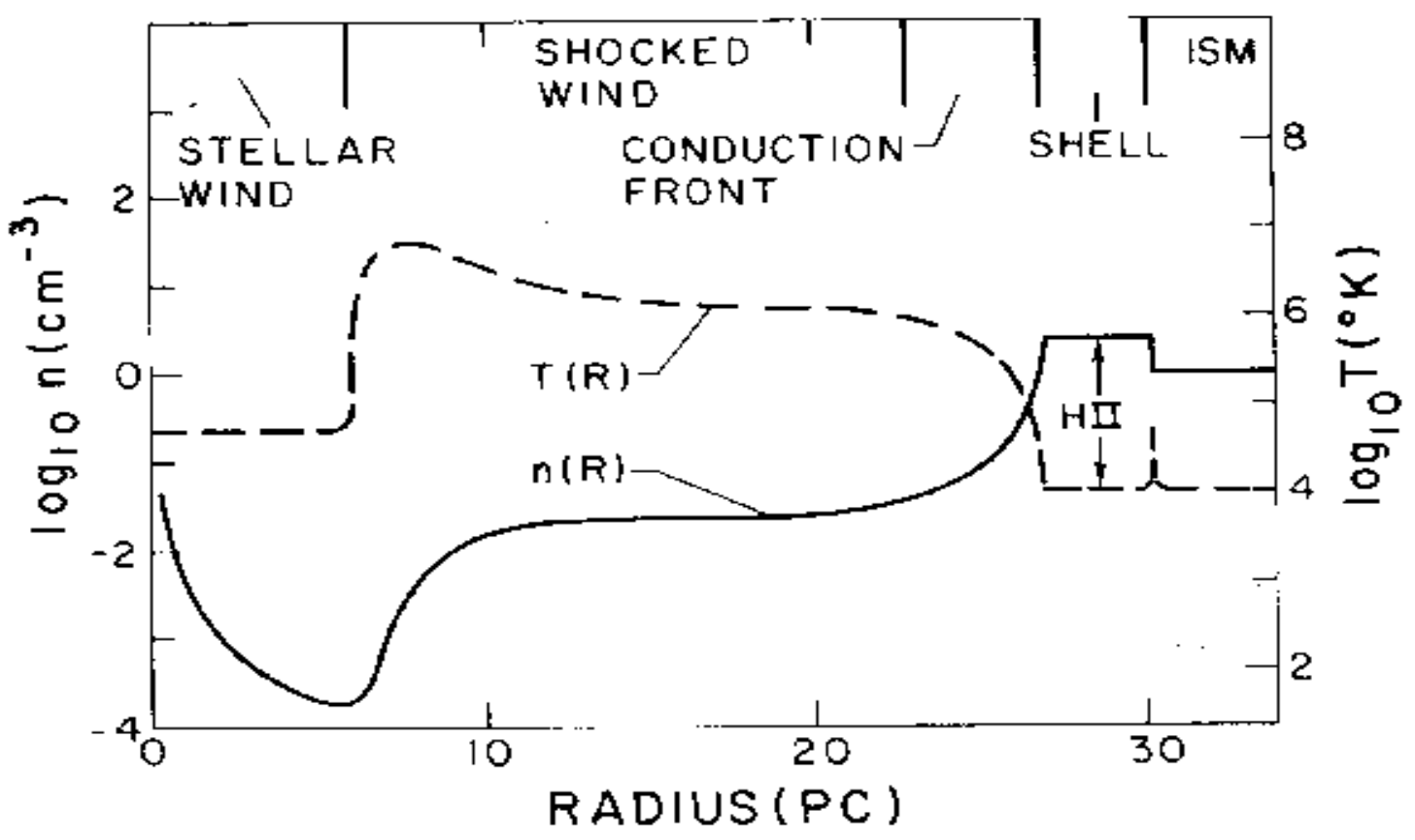

Figura 1.5: Variación de la temperatura y densidad con el radio para $t=10^{6}$ años, $L_{w}=$ $1,27 \times 10^{36} \mathrm{erg} / \mathrm{seg}$ y $n_{0}=1 \mathrm{~cm}^{-3}$ (Weaver et al., 1977)

En trabajos posteriores (McCray, 1983; Lamers \& Casinelli, 1999), la fase snowplow fue subdividida, de acuerdo a la cantidad de energía por radiación perdida por el material de la zona b) : 
- Fase de conservación de energía: el material de la zona b) se mantiene caliente y no sufre pérdidas significativas por radiación. La presión está determinada por la energía cinética del material incidente. Para esta fase encontramos que:

$$
\begin{gathered}
P_{\text {int }} \quad \alpha \quad \frac{L_{w} t}{R^{3}} \\
R=28\left(\frac{L_{36}}{\mu n_{0}}\right)^{\frac{1}{5}} t_{6}^{\frac{3}{5}} \\
v=17\left(\frac{L_{36}}{\mu n_{0}}\right)^{\frac{1}{5}} t_{6}^{-\frac{2}{5}}
\end{gathered}
$$

siendo $\mathrm{R}$ el radio de la cáscara en pc, $\mathrm{v}$ la velocidad de la cáscara en $\mathrm{km} / \mathrm{seg}, \mathrm{L}_{36}$ la luminosidad en unidades de $10^{36} \mathrm{erg} / \mathrm{seg}, \mathrm{y} \mathrm{t}_{6}$ el tiempo en unidades de $10^{6}$ años. La transición entre esta fase y la fase de conservación de momento ocurre a un tiempo $t=t_{\text {rad }}$ dado en años por:

$$
t_{\text {rad }}=15,5 \times 10^{6} \quad\left(L_{36}^{8} n_{0}^{2}\right)^{\frac{1}{6}}
$$

- Fase de conservación de momento: El material de la zona b) se enfría radiativamente, y por ende, esta zona se hace más fina. El viento impacta directamente sobre la cara interna de la cáscara, y de este modo hay una transferencia directa del momento del viento sobre la cáscara, lo que provoca la expansión.

El radio en pc y la velocidad en $\mathrm{km} / \mathrm{seg}$ de la cáscara son ahora:

$$
\begin{gathered}
R=16\left(\frac{L_{36}}{v_{3} n_{0}}\right)^{\frac{1}{4}} t_{6}^{\frac{1}{2}} \\
v=7,9\left(\frac{L_{36}}{v_{3} n_{0}}\right)^{\frac{1}{4}} t_{6}^{-\frac{1}{4}}
\end{gathered}
$$

siendo $v_{3}$ la velocidad del viento en unidades de $10^{3} \mathrm{~km} / \mathrm{seg}$.

La duración de la fase snowplow dependerá del tiempo que el viento persista. Para una estrella de gran masa es $\sim(3-10) \times 10^{6}$ años. Debido a su duración esta etapa es la de mayor interés observacional. 
4. Desaparición: La velocidad de la BI alcanza valores comparables a las velocidad de turbulencia del MIE y la burbuja se confunde con el mismo, perdiendo su identidad dinámica.

Es importante destacar que la evolución de la burbuja está definida por la naturaleza del frente de choque interno $\left(R_{1}\right)$. Si éste es isotérmico, la expansión es mantenida por la inyección de momento, si por el contrario, el frente es adiabático, es la presión térmica la que produce la expansión. La evolución previamente explicada, corresponde al segundo caso.

Trabajos realizados por Koo \& McKee (1992), estudian la evolución de los dos tipos de burbujas en un medio ambiente uniforme. Se introduce también el concepto de "viento rápido" y "viento lento". Burbujas creadas por vientos lentos serían radiativas (Avedisova, 1977; Steigman, Strittmatter \& Williams, 1975) mientras que las burbujas creadas por los vientos rápidos serían adiabáticas (Castor et al. 1975, Weaver et al. 1977). En estos trabajos se estudia también la posibilidad que las burbujas rompan el disco galáctico, y la evolución de las mismas luego de la ruptura.

Como se verá mas adelante, la evidencia observacional acerca de la existencia de las BI puede encontrarse a varias longitudes de onda. En el rango óptico, se las puede observar como "nebulosas anillo". Estas estructuras fueron encontradas alrededor de muchas estrellas WR pero no así alrededor de estrellas $\mathrm{OB}$ o de otro tipo que también posean fuertes vientos capaces de crear una BI. Esto resultaba ser una incógnita hasta el trabajo de García Segura \& Mac Low (1995), en el que se desarrollaron soluciones analíticas y semianalíticas para vientos estelares rápidos y variables en el tiempo que se expanden dentro de un viento más lento y denso, proveniente de la fase RSG. En este modelo llamado The three wind model, se incluyen tres tipos de vientos: el primero (Figura 1.6, panel superior izquierdo) es un viento rápido y rarificado de la estrella en secuencia principal que barre el MIE, formando una BI de secuencia principal. La estrella permanece en esta fase durante algunos $10^{6}$ años. El segundo tipo comienza cuando la estrella evoluciona a RSG; este viento es denso y lento y se expande en el interior rarificado de la BI de secuencia principal (Figura 1.6, panel superior derecho). Esta fase dura sólo algunos $10^{5}$ años. El tercer tipo (Figura 1.6, panel inferior izquierdo), es un viento rápido de la fase WR. Este barre el viento lento de la fase anterior formando la nebulosa anillo. Finalmente, el anillo nebular se disgrega y el viento rápido se expande dentro de la burbuja generada en la fase de secuencia principal.

En este trabajo se considera también el apartamiento de la simetría esférica debido a una posible anisotropía del viento estelar. 

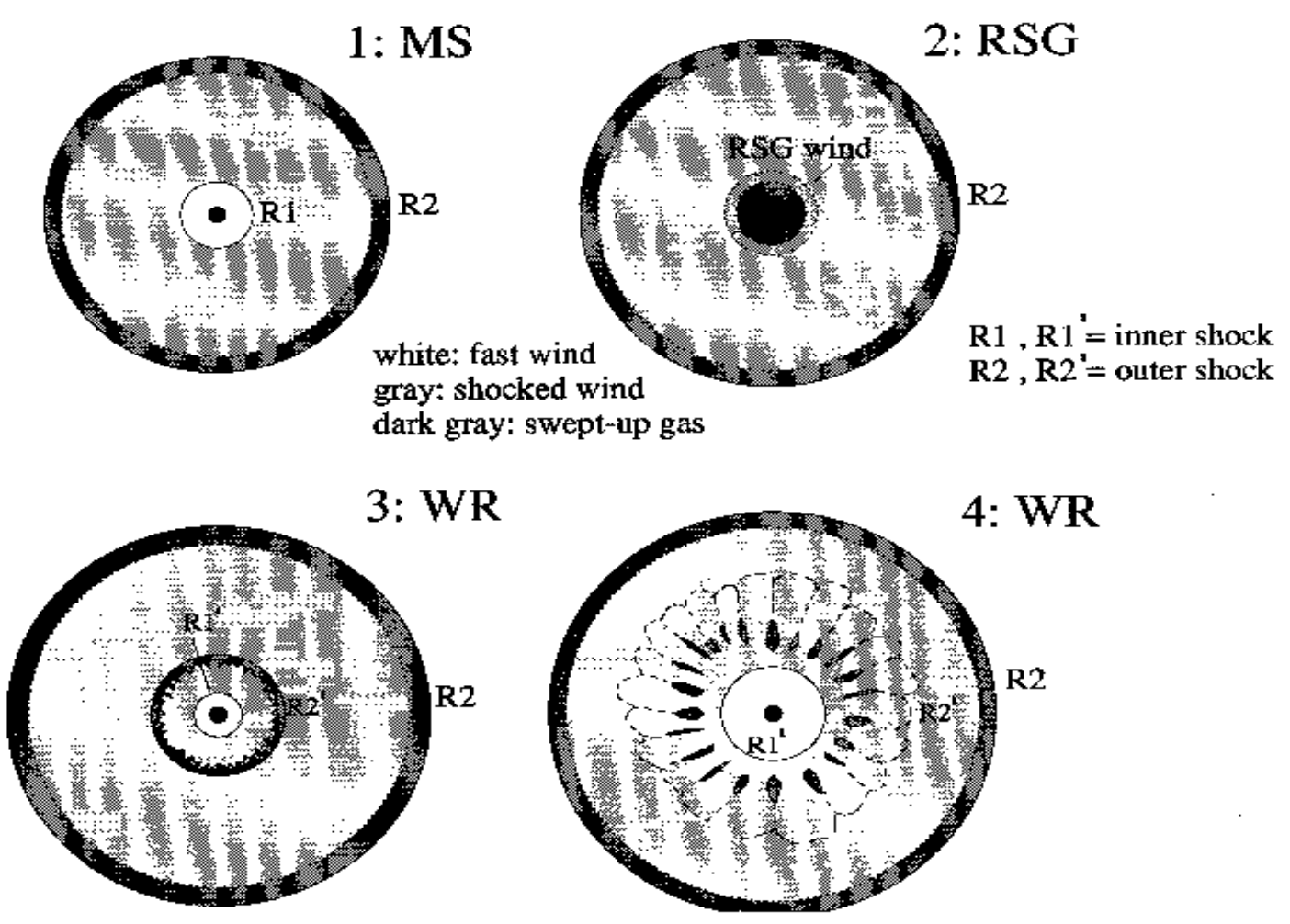

Figura 1.6: Modelo de los tres vientos (García-Segura \& MacLow, 1995a).

En una continuación del modelo de los tres vientos (García-Segura \& Mac Low 1995b), realizan un estudio de las BI con simulaciones hidrodinámicas, dando particular énfasis a las inestabilidades dinámicas de la cáscara y sus posibles consecuencias. Frayer et al. (2006) analizaron la influencia en la morfología y la energética del MIE alrededor de estrellas de gran masa que evolucionan desde la Secuencia Principal hasta la fase WR pasando por la fase RSG; el modelo desarrollado por estos autores permitió explicar algunas de las características observadas en las nebulosas anillo alrededor de estrellas WR tales como las altas luminosidades de emisión de rayos X, las temperaturas del plasma y el "abrillantamiento hacia el borde" observado en perfiles de emisión.

Es importante destacar que las teorías hasta aquí presentadas consideran el caso de estrellas simples, sin embargo las estrellas de gran masa aisladas no son muy comunes. La mayoría pertenecen a cúmulos o asociaciones, y es entonces donde los efectos acumulativos deben ser tenidos en cuenta. En estos casos, la teoría predice la formación de "superburbujas" con radios que pueden llegar hasta el kpc y muy bajas velocidades de expansión. Trabajos pioneros en este campo, fueron realizados por Heiles $(1979,1984,1987)$, en los que se 
estudió y catalogó varias de estas estructuras.

Otros motivos por los que la simetría esférica podría perderse, podrían ser:

- La estrella puede pertenecer a un sistema binario con lo cual se producirían irregularidades en la densidad de la cáscara, principalmente en la zona ecuatorial. Esta posibilidad fue estudiada por Livio \& Soker (1988).

- La existencia de gradientes de densidad en el MIE. El primer trabajo al respecto fue realizado por McKee et al. (1984). Los efectos que las distintas distribuciones de densidad tienen sobre la evolución de las BI fueron estudiados García-Segura \& Franco (1996).

- Elevada velocidad espacial de la estrella. Este efecto fue tenido en cuenta en el trabajo de Weaver et al. (1977)

- Rotación estelar (Owocki et al., 1994)

- Presencia de campos magnéticos (Stone \& Norman, 1992; Chevalier \& Luo, 1994; Rozyczca \& Franco, 1996)

\subsection{Burbujas interestelares y su evidencia ob- servacional}

Según lo mencionado anteriormente, el efecto de los vientos estelares sobre el MIE deviene en la formación de las BI. Estas son cavidades de muy baja densidad y alta temperatura, rodeadas por una cáscara o envoltura de gas interestelar barrido y gas estelar desacelerado; si el frente de ionización queda atrapado en la misma, la cáscara externa puede contener una contraparte de gas atómico o molecular.

Las BI pueden manifestarse en varias longitudes de onda del espectro electromagnético. En lo que sigue se presenta un breve resumen de los principales estudios realizados en la dirección de algunas estrellas WR de nuestra galaxia a distintas frecuencias. Muchos de estas estrellas serán estudiadas posteriormente en los siguientes capítulos de esta Tesis Doctoral.

\subsubsection{Observaciones en el óptico}

La manifestación más importante en este rango son las ya mencionadas "nebulosas anillo", que son nebulosas de emisión ubicadas alrededor de las estrellas. Las líneas de emisión más comunes son $H \alpha$ y OıI $(\lambda=5007 \AA)$. A modo de ejemplo en las Figura 1.7 se pueden ver dos nebulosas anillo (RCW 58 y RCW 104) alrededor de las estrellas WR 40 y WR 75, respectivamente obtenidas de Chu (1982), aunque estos objetos particularmente no pueden, según la autora, ser explicados como cáscaras en expansión. 
Desde que Johnson \& Hogg (1965) encontraron que S 308, NGC 2359 y NGC 6888 eran nebulosas de forma circular en cuyo centro se encontraba una estrella WR, búsquedas posteriores de objetos de esta clase en nuestra galaxia y en la Nube de Magallanes, llevaron a establecer a las "nebulosas anillo alrededor de estrellas WR" como una nueva clase de objetos.
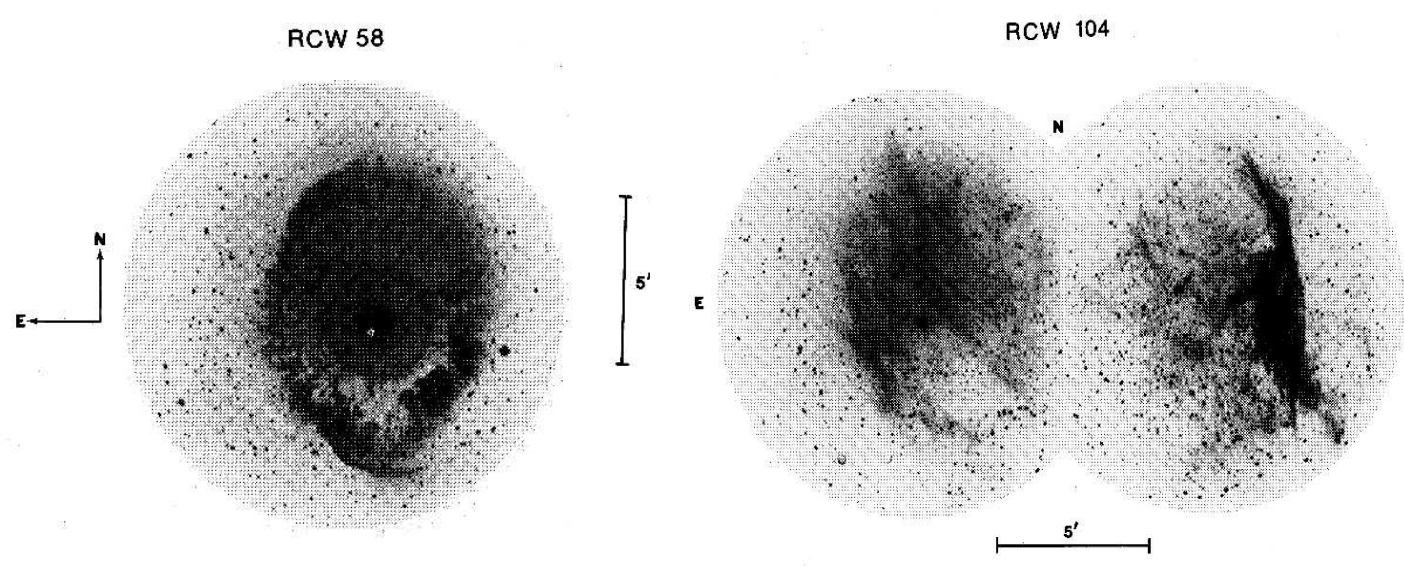

Figura 1.7: Panel izquierdo: Imagen en $\mathrm{H} \alpha$ de RCW58 tomada por Chu (1982). Esta nebulosa se encuentra asociada con la estrella WR 40 (HD 96548). Panel derecho: Imagen en $\mathrm{H} \alpha$ de RCW104 tomada por Chu (1982). Esta nebulosa se encuentra asociada a la estrella WR 75 (HD 147419).

Los primeros intentos por explicar los posibles mecanismos de formación de estas estructuras, fueron llevados a cabo por Chu y colaboradores (Chu, 1981, 1982a y b; Chu et al., 1982; Chu \& Treffers, 1981a y b; Chu, Treffers \& Kwitter, 1983; Treffers \& Chu, 1982a y b). Es así que Chu clasificó a las nebulosas anillo asociadas a estrellas WR en tres clases:

- Nebulosa tipo $\mathbf{W}$, creadas por el viento estelar y constituidas en mayor medida por el MIE barrido.

- Nebulosa tipo E, constituidas principalmente por material estelar.

- Nebulosa tipo R, son aquellas en las que la estrella WR central es sólo responsable de la ionización pero no de la forma. Su escala de tiempo dinámico es mayor que la duración de la fase WR.

Una de las dificultades de este sistema de clasificación es determinar si el material de la nebulosa tipo $\mathrm{W}$ es de origen estelar o interestelar. 
Marston, Chu \& García-Segura (1994a), Marston et al. (1994b) y Marston (1997), realizaron una búsqueda en los alrededores de estrellas WR galácticas y encontraron un total de 40 nebulosas anillo asociadas a las mismas. La existencia de material circumestelar y particularmente de múltiples anillos concéntricos, indican la evolución de las estrellas a través de tres fases, desde estrellas O de gran masa hasta la fase WR (García-Segura \& McLow, 1995). La existencia de nebulosas anillo de mayor extensión alrededor de estrellas WC respecto de las WN, parece corroborar la teoría de la secuencia evolutiva $\mathrm{WN} \mapsto \mathrm{WC}$.

Posteriormente, van der Hucht (2001) encontró que el número de nebulosas anillo alrededor de estrellas WR llegaba casi a 60 (casi un $25 \%$ de las 227 estrellas WR catalogadas), mientras que también se han encontrado algunas alrededor de estrellas Of. En la mayoría de los casos, las nebulosas tienen dimensiones inferiores a los 30 pc, sus velocidades de expansión varían entre 10 y $80 \mathrm{~km} / \mathrm{seg}$; las de mayor velocidad de expansión, son aquellas que muestran una mayor proporción de gas eyectado por la estrella (tipo E), que a su vez son las de menor extensión.

Pese a que en todos los casos de estrellas de gran masa, la temperatura efectiva es suficiente para ionizar la cara interna de la burbuja, la mayoría de las estrellas Of y WR no tienen asociada una nebulosa anillo. Esto puede deberse a una densidad del MIE circundante relativamente baja, a la absorción interestelar o a inhomogeneidades del MIE.

\subsubsection{Observaciones en el continuo de radio}

La región HII generada alrededor de la estrella puede ser observada en el continuo de radio como radiofuente térmica, debido a la emisión libre-libre generada por la dispersión de los electrones en el plasma.A partir de estudios llevados a cabo en forma independiente por varios investigadores se han detectado varias estructuras posiblemente relacionadas con estrellas de gran masa.

La región HII BG2107+49 fue observada en el continuo de radio a 21 y 74 cm (van der Werf \& Higgs, 1990). Esta es una estructura que fue descripta como una cabeza con una larga cola (ver Figura 1.8). Cabe destacar que la estrella responsable de esta estructura no fue individualizada.

Cappa et al. (1999), realizaron observaciones en HI y continuo de radio en $1465 \mathrm{MHz}$, alrededor de la nebulosa anillo NGC 2359 que rodea a la estrella HD 56925 (WR 7). La nebulosa consiste en una cáscara filamentosa y "streamers" de gas ionizado. La parte sur de la nebulosa es la conocida región HII S 298. En la Figura 1.9 se muestra la imagen de la nebulosa obtenida en $1465 \mathrm{MHz}$ y la superposición de ésta con la imagen de $\mathrm{H} \alpha$. Como puede observarse existe una notable correlación entre ambas imágenes. En este trabajo también se detectó por medio de observaciones en la línea de $21 \mathrm{~cm}$ del HI la interacción 


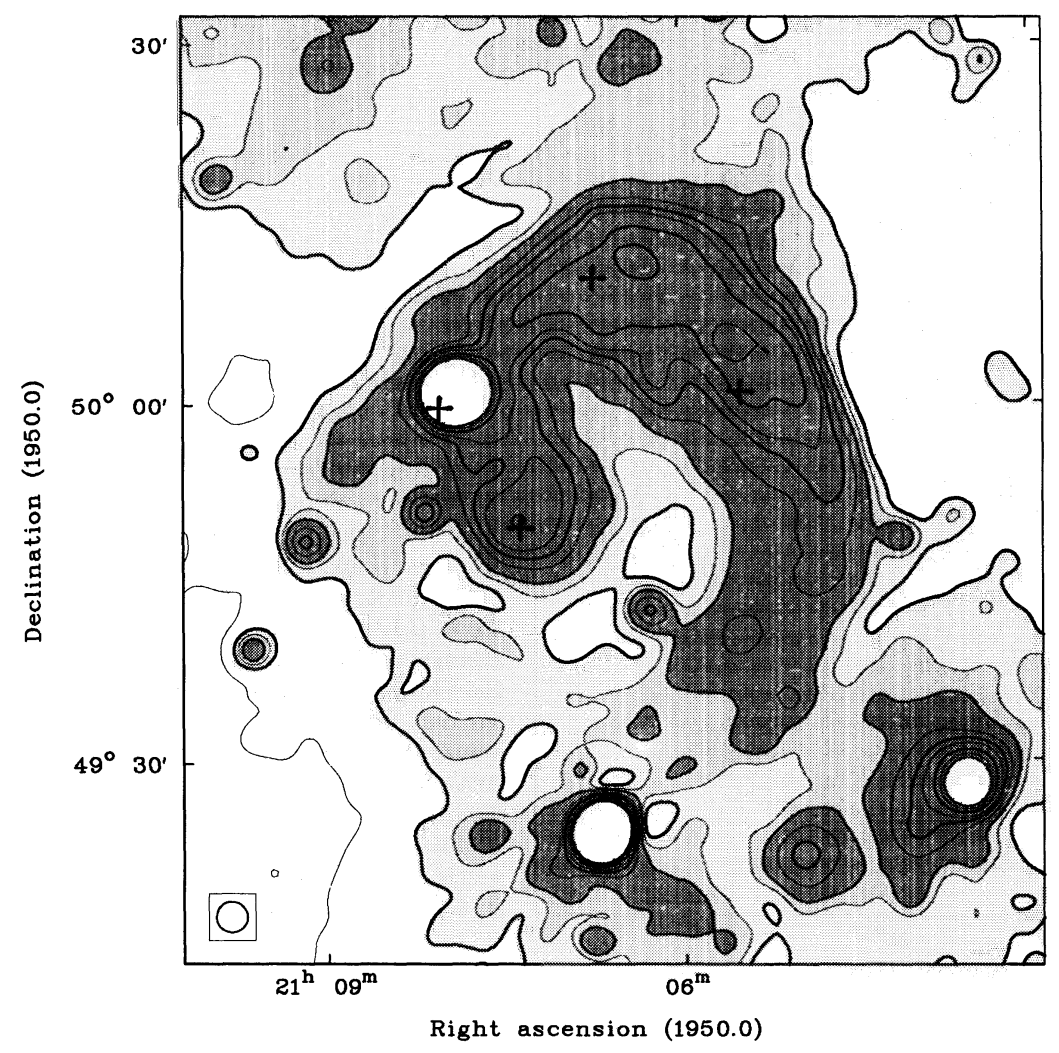

Figura 1.8: Región HII BG2107+49 (van der Werf \& Higgs 1990)

entre la nebulosa y el medio interestelar circundante. Como veremos más adelante, además de mostrar correlación espacial entre hidrógeno ionizado y el atómico, esta nebulosa presenta una excelente contrapartida molecular.

Cappa et al. (2002), llevaron a cabo un estudio del continuo de radio e IR de las nebulosas anillo asociadas a las estrellas WR 101 y WR 113. Existe una notable correlación entre las imágenes infrarrojas y de radio en estas nebulosas.

El gas ionizado de las regiones HII generadas por la estrella, puede ser también identificado en líneas de recombinación del hidrógeno y del helio. Cichowolski et al. (2001), estudiaron el MIE en los alrededores de WR 130 en HI, continuo de radio en 408 y $1420 \mathrm{MHz}$, y en la línea de recombinación $H 110 \alpha$. En este trabajo se identificó una estructura anular $(\mathrm{G} 68.1+1.1)$ en 

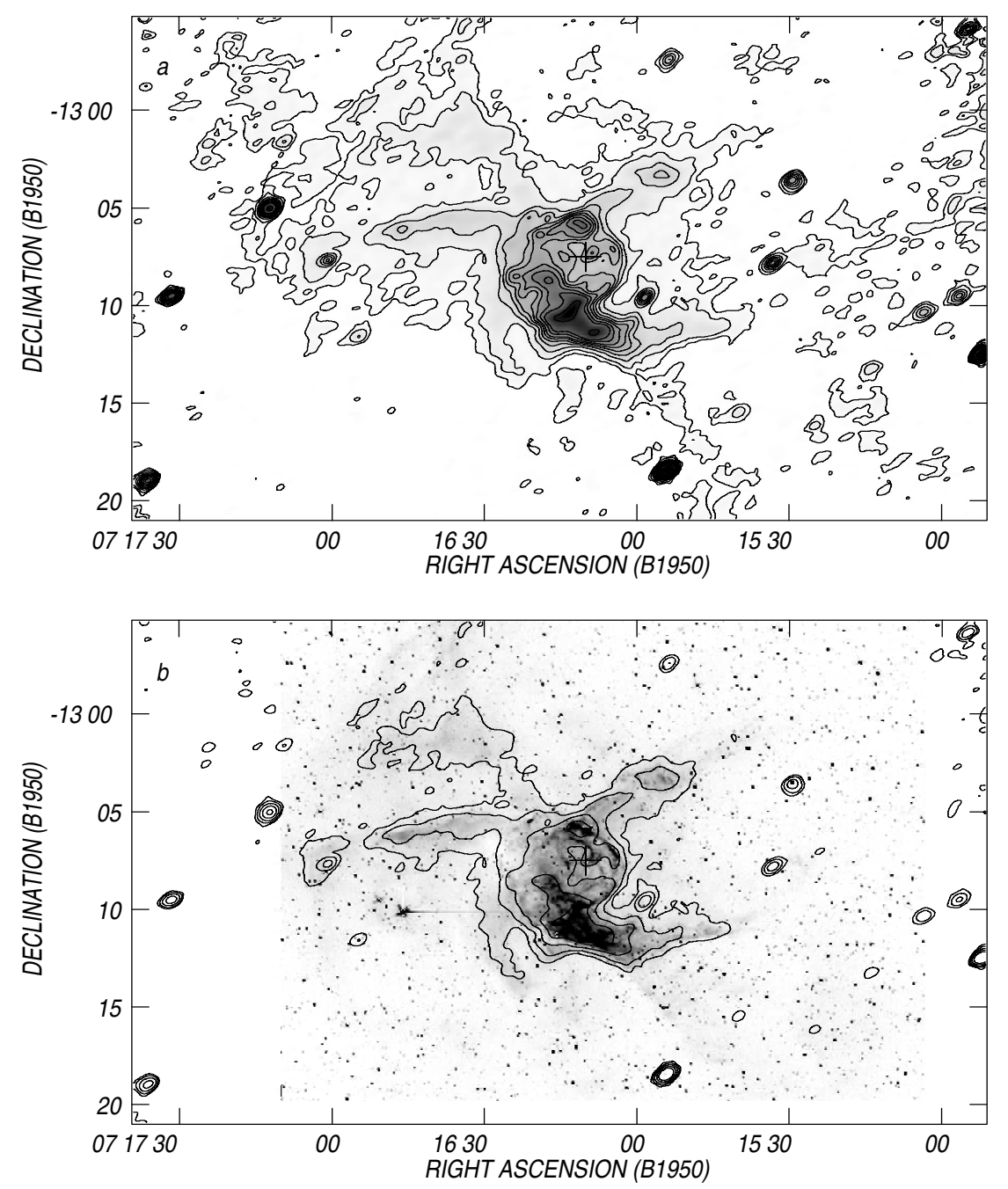

Figura 1.9: Panel superior: NGC2359 en $1465 \mathrm{MHz}$; Panel inferior: superposición de la imagen $\mathrm{H} \alpha$ y el continuo de radio (Cappa et al. 1999)

continuo de radio que presentaba además una excelente correlación con HI e IR (ver Figura 1.10). La estrella presenta una posición muy excéntrica dentro de la cavidad, debido tal vez a su elevada velocidad espacial. Mediante la aplicación de un modelo de rotación galáctica, las líneas de H110 $\alpha$ fueron utilizadas para la determinación de la distancia, con la cual se concluyó que G68.1+1.1 era la contrapartida en el continuo de radio de la región HII Sh 98. 


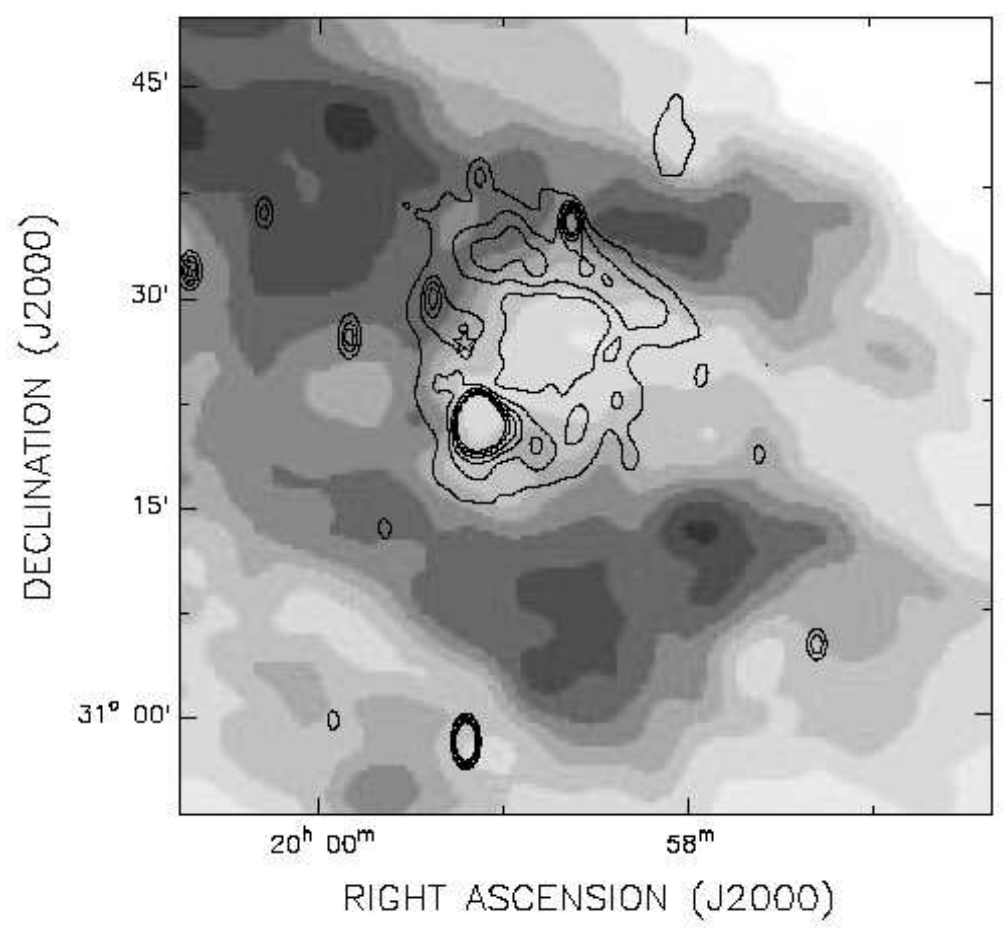

Figura 1.10: Superposición del continuo de radio a $1420 \mathrm{MHz}$ (contornos) con la imagen de HI (escala de grises) del MIE alrededor de WR130 (Cichowolski et al., 2001)

\subsubsection{Observaciones en la línea de $21 \mathrm{~cm}$ del HI}

Como se mencionó anteriormente, alrededor de la cavidad creada por el viento estelar, puede haber también una cáscara de hidrógeno neutro en emisión.

Las primeras BI en HI fueron detectadas por el grupo del IAR (Cappa \& Niemela, 1984; van der Bij \& Arnal, 1986). En el primer trabajo se detectó una cavidad de aproximadamente 100 pc de diámetro, alrededor de la estrella binaria $\theta$ Muscae (WR 48). En el segundo, la cavidad fue detectada alrededor de una estrella O7 de secuencia principal (HD 91824) y sus dimensiones alcanzan los 50 pc de diámetro. Desde entonces este grupo ha contribuido al estudio de estos objetos, particularmente en la línea de $21 \mathrm{~cm}$, con más de cincuenta trabajos publicados.

En los años siguientes, numerosas cavidades y cáscaras de HI fueron encontradas alrededor de estrellas WR galácticas. Cappa et al. (1986), utilizando la antena de 30m del IAR, analizaron la distribución del HI en los alrededores de WR17 y observaron la presencia de una cavidad no esférica de aproximadamente 50 pc de radio probablemente relacionada con la estrella. La edad dinámica de la estructura es de $3,5 \times 10^{6}$ años, lo cual indicaba la participación de un estadío previo a la fase WR en la formación de la misma. En una continuación a este trabajo, y usando también la antena del IAR, Cappa et al. (1988) estudiaron el HI alrededor de WR 90, y descubrieron una notable BI 
en expansión que era la contrapartida neutra de la nebulosa óptica RCW 114, rodeada de una delgada cáscara de HI; esta cavidad tiene un radio de 57 pc y al igual que en el caso anterior su edad dinámica supera por mucho al tiempo de vida de una estrella en la fase WR. Dado que en los casos mencionados hasta aquí las observaciones se realizaron con una resolución angular entre 30 y 40', sólo se pudieron analizar las propiedades globales del HI asociado a las estrellas observadas.

Observaciones de HI realizadas con mejor resolución angular, permitieron revelar la existencia de morfologías no predichas por los modelos teóricos. Dubner et al.(1990), utilizando el telescopio del Dominion Radio Astrophysical Observatory $(\mathrm{DRAO})\left(\mathrm{HPBW} \sim 1^{\prime}(E O) \times 1,2^{\prime}(N S)\right)$, analizaron el HI en los alrededores de la estrella WN7, HD 197406. Sus observaciones mostraron la existencia de una cáscara de 36' de diámetro (detectada también en el IR) y dentro de ésta una pequeña burbuja esférica de $6^{\prime}$ de diámetro concéntrica con la estrella; las edades dinámicas para éstas son $3 \times 10^{6}$ y $6 \times 10^{5}$ años, respectivamente. Arnal \& Mirabel (1991), realizaron un estudio del hidrógeno neutro alrededor de WR 125 utilizando observaciones de alta resolución angular obtenidas con el radiotelescopio de Arecibo (HPBW 3,3'); se observó la presencia de un pequeño hueco en la distribución de HI provocado tal vez por efectos de la ionización de la estrella, la cual se encuentra inmersa en una gruesa 'pared' perteneciente a una cáscara de HI aún mayor (60 pc de diámetro). Para explicar esto se propuso que WR 125 y la estrella progenitora del púlsar $P 1919+20$, habrían formado parte de un sistema binario, siendo esta última la responsable de la estructura más grande mencionada anteriormente. Arnal (1992), estudió la distribución del HI en los alrededores de seis estrellas WR galácticas (WR 3, WR 4, WR 5, WR 23, WR 132 y WR 140) usando datos obtenidos con el radiotelescopio de 100m del Max Planck für Radioastronomie $\left(\mathrm{HPBW} \sim 9^{\prime}\right)$. En todos los casos se observó la presencia de mínimos relativos en la densidad columnar de HI, los cuales son elongados y en la mayoría de los casos están rodeados en forma incompleta por HI en emisión; las estrellas se ubican siempre en una posición excéntrica con respecto al centroide de la BI.

Si bien muchas de la características mencionadas anteriormente no concuerdan con las predichas por los modelos teóricos, más extraños aún son las estructuras de "cáscaras con doble mínimo". La primera de éstas fue descubierta por Arnal \& Cappa (1996), quienes estudiaron el HI en la vecindad de WR 6 usando datos de resolución angular intermedia $\left(9^{\prime}\right)$. Observaron la presencia de una gran cavidad ovoide, dentro de la cual, son claramente identificables dos mínimos relativos en la distribución de HI (ver Figura 1.11 ). Se concluyó también que existía una relación física entre uno de estos mínimos y la nebulosa óptica S 308.

Morfologías similares (cáscaras con doble mínimo), fueron encontradas alrededor de WR 149 (Cappa et al., 1996) y WR 3 (Arnal \& Roger, 1997). Arnal (2001), mediante datos obtenidos con el interferómetro de DRAO (HPBW 

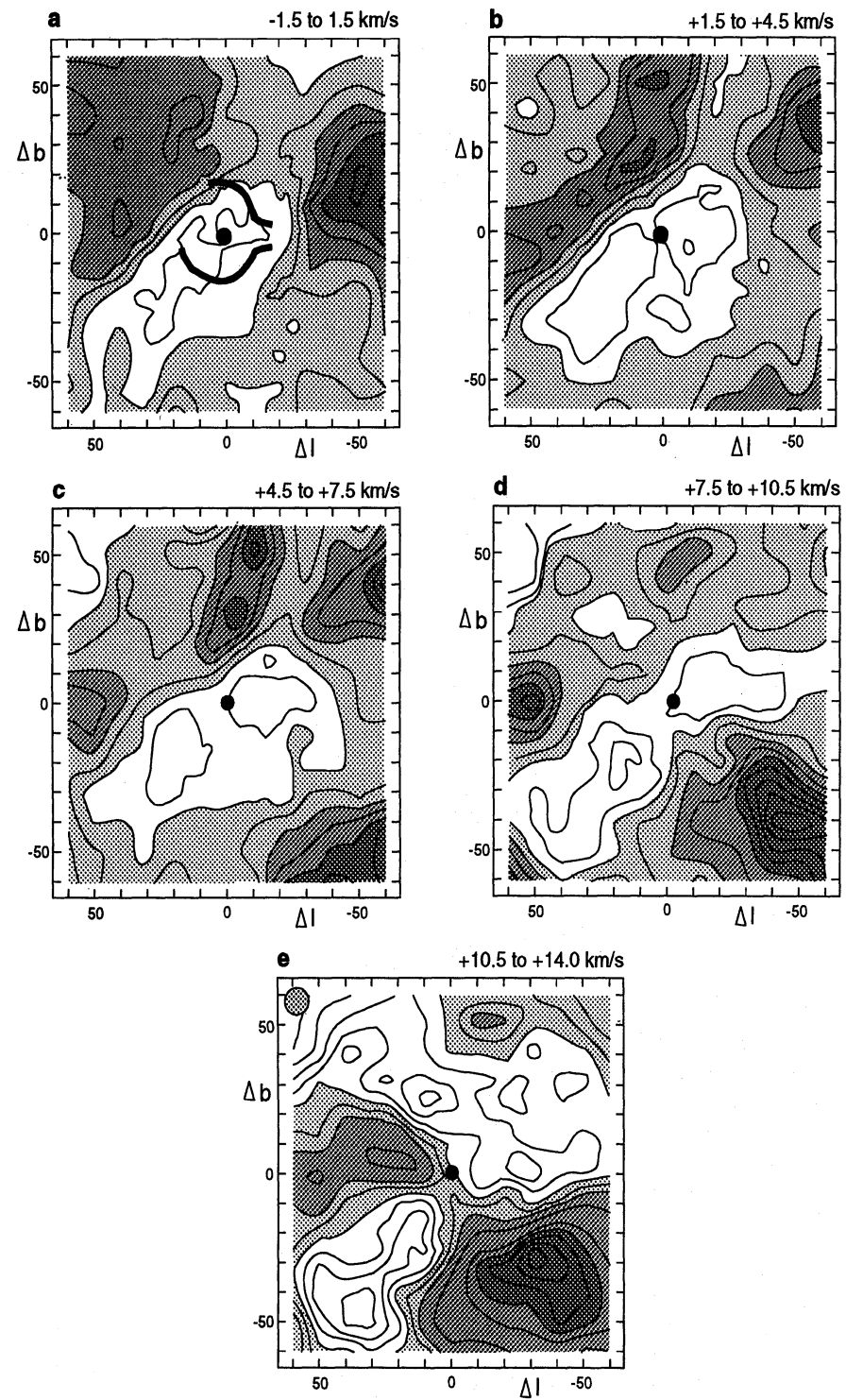

Figura 1.11: Imágenes de densidad columnal de HI en los alrededores de WR 6, integrados en intervalos de $3 \mathrm{~km} / \mathrm{seg}$, en el rango de velocidades en el que se encuentra la cavidad. La zona delimitada en la figura a) indica la posición de la nebulosa óptica S 308, y el círculo lleno la posición de WR 6 (Arnal \& Cappa, 1996)

$\left.2 \times 3^{\prime}\right)$ estudió el HI en los alrededores de WR 140, objeto que había sido estudiado anterioriormente con datos de menor resolución angular $\left(\mathrm{HPBW} \sim 9^{\prime}\right.$ ) (Arnal, 1992). Los datos de esta resolución permitieron detectar la presencia de un mínimo principal de aproximadamente $12 \times 8$ pc, cercano a la posición de la estrella, y dentro de este dos mínimos secundarios. En la Figura 1.12 se comparan las imágenes de HI en las vecindades de WR 140, obtenidas con distintas resoluciones angulares. 

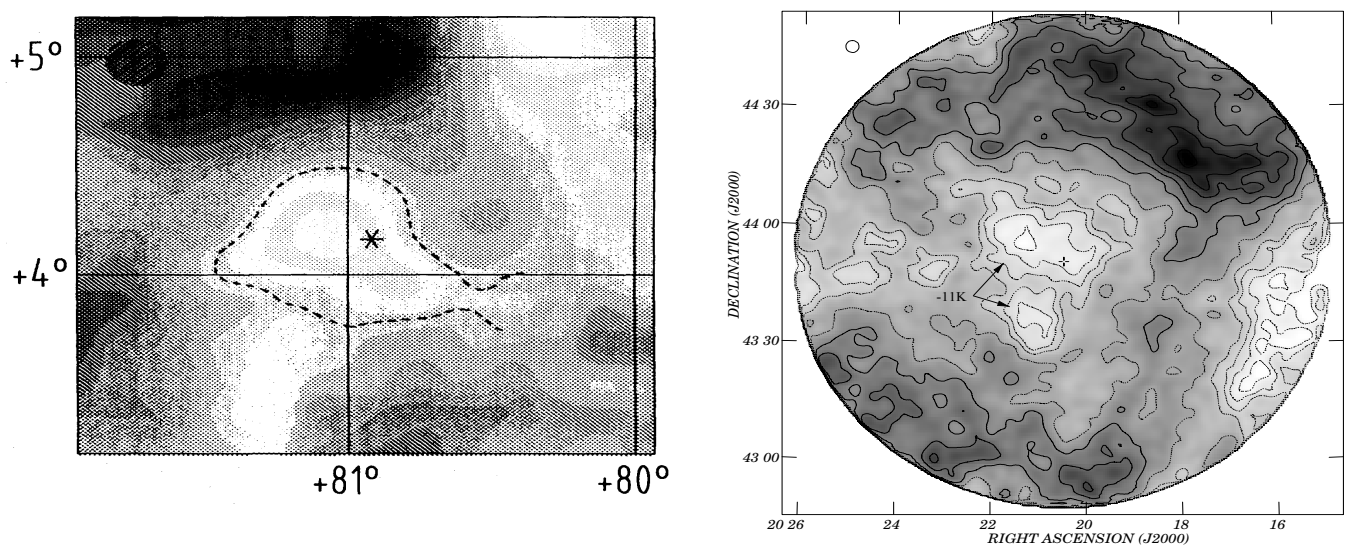

Figura 1.12: Panel izquierdo: Distribución de HI alrededor de WR 140. Datos obtenidos con HPBW=9' (Arnal, 1992). Panel derecho: Distribución de HI alrededor de WR 140. Datos obtenidos con HPBW $=2^{\prime} \times 3^{\prime}$ (Arnal, 2001)

Mediante observaciones en la línea de $21 \mathrm{~cm}$ del HI, se han detectado también cáscaras de gas atómico en expansión en las vecindades de varias estrellas de tipo espectral O. Cappa \& Benaglia (1998), realizaron un estudio del gas neutro en las vecindades de cuatro estrellas O del Hemisferio Sur: HD 112244, HD 175754, HD 175876 y HD 155913; en todos los casos se encontraron burbujas de HI asociadas a las estrellas. Las dimensiones de las mismas oscilan entre 90 y 70 pc y sus velocidades de expansión son relativamente bajas ( 10 $\mathrm{km} / \mathrm{seg}$ ). En este trabajo se sugirió también que HD 155913 pertenece a una asociación $\mathrm{OB}$, la cual en su conjunto podría ser la responsable de la creación de la burbuja. La presencia de cavidades formada por vientos de estrellas $\mathrm{O}$, parece dar sustento a la teoría de que las cavidades alrededor de estrellas WR se habrían empezado a formar en estadíos previos de su evolución.

Otro estudio completo del material interestelar (atómico e ionizado) fue realizado por Gervais \& St-Louis (1999), en los alrededores de WR 134. Estos autores estudiaron la línea de $21 \mathrm{~cm}$ del HI y el continuo de radio en 1420 y $408 \mathrm{MHz}$, usando el telescopio del DRAO. Encontraron una estructura anular de gas ionizado en $1420 \mathrm{MHz}$ cuya morfología coincide con la nebulosa óptica Anon (MR100). Según los autores, este gas podría provenir de una fase más temprana de la estrella (LVB), luego haber sido expulsado por la WR y finalmente ionizado por el intenso flujo UV de la misma. Las imágenes de HI revelaron la existencia de una cáscara de $\sim 21$ pc de radio casi elipsoidal rodeando a la estrella. La edad dinámica de la misma $\left(1,3 \times 10^{6}\right.$ años) sugiere la 
participación de alguna fase de secuencia principal de la estrella en su formación. El hecho de que la estructura anular de gas ionizado visible en el óptico y continuo de radio sea interior a la cavidad de HI, sugiere una evolución estelar en múltiples fases. La velocidad supersónica de la estrella respecto al MIE podría haber generado alguna compresión del mismo en la zona SO, volviendo más brillante la emisión $\mathrm{H} \alpha$ hacia esa zona.

La búsqueda de burbujas de HI alrededor de estrellas de gran masa ha sido muy fructífera, sobre todo en los últimos años (Arnal et al., 1999; Cazzolato \& Pineault, 2000; Cappa \& Herbstmeier, 2000; Cichowolski et al., 2001; Cichowolski et al., 2003; Cichowolski \& Arnal, 2004; Cappa, Niemela \& Mc Clure Griffits, 2005, Cichowolski et al., 2008) y los resultados obtenidos en estas investigaciones parecen ratificar los encontrados en trabajos anteriores.

En forma general puede decirse que desde el punto de vista observacional las burbujas interestelares:

- Están rodeadas en forma incompleta por una capa gruesa e inhomogénea de HI en emisión.

- Poseen dimensiones lineales que varían entre 20 y 100 pc.

- Poseen velocidades de expansión del orden de $10 \mathrm{~km} / \mathrm{seg}$.

- Presentan apartamientos de la simetría esférica.

Además, en general:

- La estrella responsable se encuentra en una posición excéntrica respecto del mínimo o centro de simetría de la cavidad.

- En algunos pocos casos, se puede observar la presencia de mínimos dobles en el interior de la BI.

\subsubsection{Observaciones en infrarrojo}

La emisión en IR alrededor de las estrellas, se debe fundamentalmente a la presencia de polvo que absorbe la radiación UV y la reemite en la banda del IR. Después de absorber el fotón UV, el grano de polvo alcanza un equilibrio cuando la energía absorbida es igual a la emitida y esto sucede a alguna temperatura del grano $\mathrm{T}_{d}$, la cual depende del tamaño del grano y de su composición; para esferas dieléctricas de tamaño $\sim 0,1 \mu \mathrm{m} \mathrm{T}_{d} \sim 10-20 \mathrm{~K}$ emitiendo en el IR lejano (FIR). La emisión en el IR medio es esperable de polvo con $\mathrm{T}_{d} \sim 100-500 \mathrm{~K}$ (van de Hulst, 1946). En el caso del IR cercano existen bandas de emisión centradas en $10 \mu \mathrm{m}$ provenientes de las emisiones vibracionales de moléculas complejas conocidas como PAHs (Polycyclic Aromatic Hydrocarbons); la emisión de estas moléculas es común en los bordes 
ionizados de las nubes moleculares conocidos como PDRs (Photo dissociation regions) (Hollembach \& Tielens, 1997)

Marston (1991), discutió los posibles orígenes de la capa de polvo que rodea a las estrellas de gran masa:

- En las capas atmosféricas extendidas de las supergigantes rojas, siendo luego dispersado por los vientos lentos característicos de esta fase formando una cáscara que posteriormente será barrida por los vientos rápidos de la fase WR.

- El polvo pertenece al MIE aledaño a la estrella y es barrido por el viento estelar que lo confina a una cáscara que se expande.

Marston (1996), llevó a cabo un análisis de los datos observados por el satélite IRAS en las bandas de 12, 25, 60 y $100 \mu \mathrm{m}$ en los alrededores de las 156 estrellas WR catalogadas hasta entonces (van der Hucht, 1981). Encontró que 49 de éstas tenían una estructura en forma de cáscara con diámetros $>20^{\prime}$ (los diámetros lineales van desde los 10 a los 338 pc). Para objetos con latitud galáctica por debajo de los $2^{\circ}$, la tasa de detección de cáscaras llega casi al $60 \%$. En 14 casos, se encontraron cáscaras coincidentes con estructuras de HI en expansión estudiadas previamente. En este trabajo, en que se discute también el origen de las cáscaras, especialmente de las más grandes, se propuso que las mismas se habrían formado como consecuencia de los vientos de la estrella $\mathrm{O}$ progenitora. También se analizó la posibilidad de que sean originadas en una explosión de supernova, o que se hayan creado por la eyección de masa de una estrella compañera compacta a través del Lóbulo de Roche. La no detección de cáscaras alrededor de estrellas WR con púlsar llevaron a descartar esta última posibilidad.

Como se mencionó anteriormente, muchos trabajos, especialmente los basados en la línea del HI, prestan especial atención a la posible existencia de cáscaras en el IR: Arnal et al. (1999), Marston et al. (1999), Cazzolato \& Pineault (2000), Cappa \& Herbstmeier (2000), Arnal (2001), Cappa et al. (2002), Cichowolski et al. (2001), Cichowolski et al. (2003), Cappa et al. (2005), Cichowolski et al. (2008). En muchos de los casos, la correspondencia entre las cáscaras en IR con las de gas atómico e incluso molecular en expansión, parece ser bastante buena.

\subsubsection{Observaciones en líneas moleculares}

Si la estrella se encuentra cerca de, o inmersa en una nube molecular, la cáscara de material en expansión podría generar una perturbación en la distribución espacial y en el campo de velocidades del material molecular propiamente dicho; es así que las cáscaras en expansión también podrían ser observadas en diversas líneas moleculares. 
A diferencia del hidrógeno atómico, el hidrógeno molecular $\left(\mathrm{H}_{2}\right)$ no ha sido muy estudiado en los alrededores de las estrellas de gran masa. Las líneas moleculares más estudiadas, son las transiciones rotacionales $J=1 \rightarrow 0$ y $J=2 \rightarrow 1$ de la molécula de $\mathrm{CO}$ que es una buena trazadora de la distribución del $\mathrm{H}_{2}$. Otras moléculas estudiadas, aunque en un número menor de objetos, son: $\mathrm{NH}_{3}, \mathrm{HCN}$ y $\mathrm{CN}$.

Marston et al. (1999a), analizaron la distribución de CO $(J=1 \rightarrow 0)$ en los alrededores de WR 16 y vieron que éste se correspondía notablemente con la nebulosa observada en $\mathrm{H} \alpha$ y con una cáscara de material difuso observada en $60 \mu m$ (ver Figura 1.13 ). La anormal abundancia de $\mathrm{N}$ en la cáscara y la masa deducida para la misma, llevaron a los autores a suponer para ésta un origen estelar. Similares características se observaron en el material molecular alrededor de WR 75 (Marston et al., 1999b). En ambos objetos, el CO parece estar concentrado en regiones donde las líneas de emisión en el óptico son débiles. Tanto para WR 16 como para WR 75, los autores concluyen que el material molecular circundante proviene de los vientos lentos emitidos en una fase intermedia (LBV/RSG) de la evolución estelar previa a la fase WR. En la vecindad de ambas estrellas existe una anticorrelación entre la línea de $\mathrm{H} \alpha$ y las imágenes IRAS de alta resolución con los datos de $\mathrm{CO}$, lo cual sugiere la presencia de una región de fotodisociación (PDR). Esta nebulosa será objeto de estudio en el Capítulo 4 de esta Tesis Doctoral.
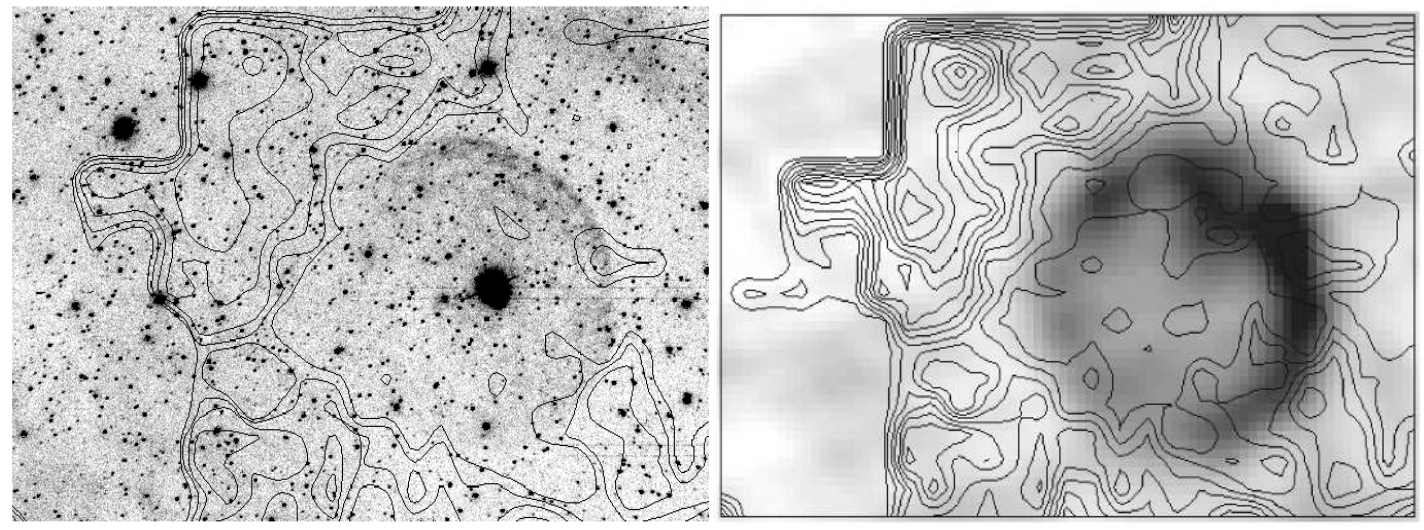

Figura 1.13: Panel izquierdo Superposición de la imagen de $\mathrm{CO}$ con $\mathrm{H} \alpha$. Panel derecho Superposición de la imagen de CO con la imagen IRAS de 60 $\mathrm{mm}$ para WR 16 (Marston, 1999)

Otro estudio del material molecular alrededor de una estrella WR, fue realizado en la nebulosa NGC 3199 (Marston 2001), en los alrededores de la estrella WR 18. Las líneas moleculares observadas fueron interpretadas como 
una cáscara en lenta expansión ( $\sim 4 \mathrm{~km} / \mathrm{seg})$. La morfología de la zona en emisión de $\mathrm{CO}(J=1 \rightarrow 0)$, no parece coincidir con el intenso borde de la nebulosa anillo (ver Figura 1.14), incluso presentan un mínimo en la región más brillante en $\mathrm{H} \alpha$ de la misma, por lo que, al igual que en el caso de WR 16 y WR 75, parece indicar la formación de una PDR. La masa del material molecular calculada por el autor serían unas decenas de masas solares, la cual sería una mezcla de material estelar e interestelar; en este trabajo se presentó la primera detección de las líneas moleculares $\mathrm{HCN}, \mathrm{CN}, \mathrm{HNC}$ y $\mathrm{HCO}^{+}$, hacia la posición central de WR 18 lo cual sugiere la existencia de altas densidades volumétricas $\left(n_{H_{2}}>10^{4} \mathrm{~cm}^{-3}\right)$. Esta nebulosa también será objeto de estudio en esta Tesis de Doctorado (Capítulo 5).
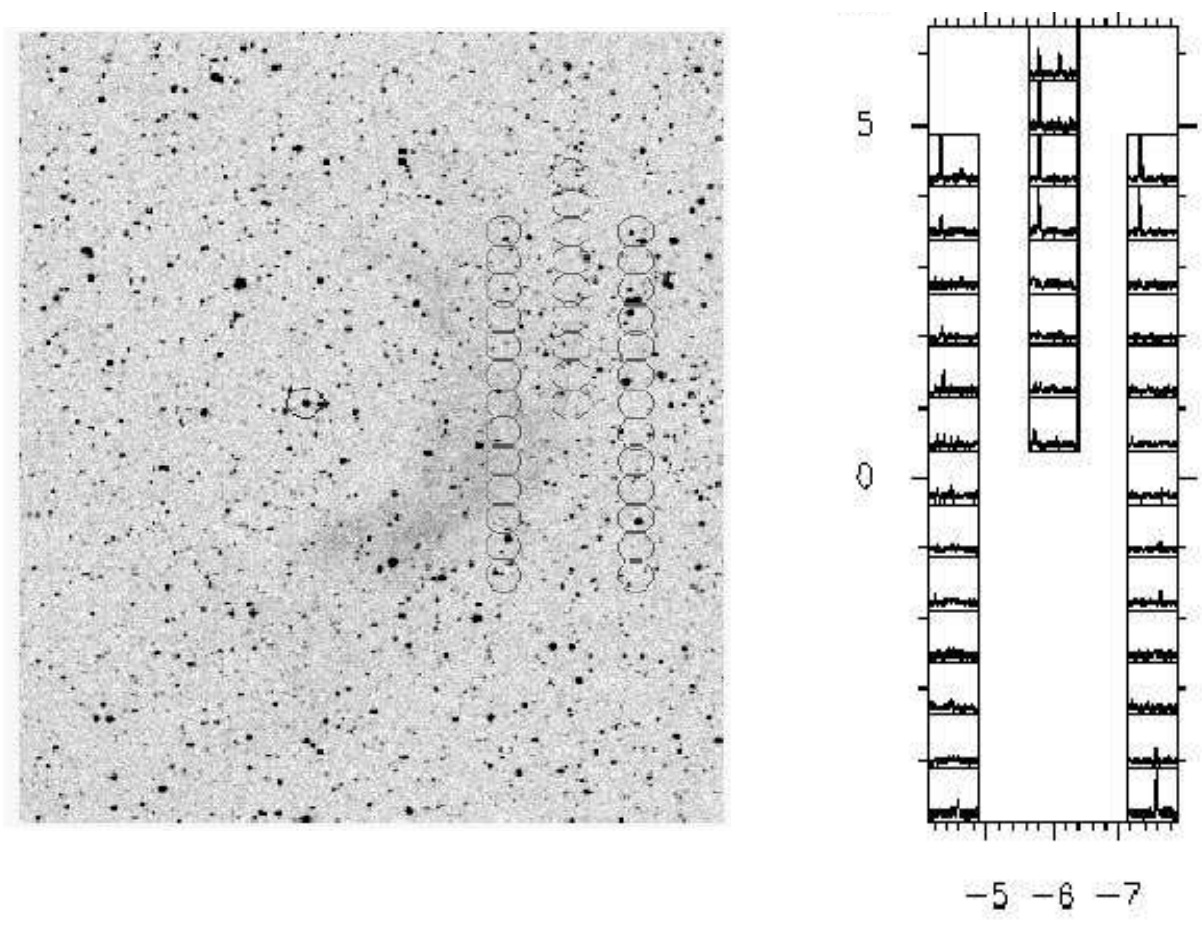

Figura 1.14: Panel izquierdo: Posición de las observaciones de CO en relación a la imagen de NGC 3199 obtenida del Digitalized Sky Survey (DSS). Panel derecho: Perfiles de las líneas en las posiciones señaladas (Marston 2001)

Un objeto muy estudiado en los últimos años en diversas clases de emisiones, es la nebulosa óptica NGC 2359. En efecto, esta región fue observada por Cappa et al. (1999), en la línea de $21 \mathrm{~cm}$ y en el continuo de radio en 1465 $\mathrm{MHz}$. Los datos muestran una excelente correlación, lo cual indica una clara interacción entre el material ionizado y atómico.

Cappa, Rubio \& Goss (2001), en una continuación del trabajo mencionado anteriormente, estudiaron el material molecular asociado a NGC 2359, mediante observaciones de $\mathrm{CO} J=1 \rightarrow 0$ y $J=2 \rightarrow 1$ de alta resolución angular. Se detectaron tres componentes a 37,54 y $67 \mathrm{~km} / \mathrm{seg}$, de las cuales, la segunda 
parecería estar relacionada con la nebulosa. La mayor parte de la estructura a $54 \mathrm{~km} / \mathrm{seg}$, se ubica en la zona sur de la nebulosa, mientras que otra pequeña parte se relaciona con la zona filamentosa de la burbuja, hacia la zona este (ver Figura 1.15). Las masas derivadas para la componente molecular de la nebulosa parecen indicar un origen interestelar para la misma. La comparación entre las distribuciones de gas ionizado, el filamento de HI detectado con el VLA a 54 $\mathrm{km} / \mathrm{seg}$ (Cappa et al., 1999) y el gas molecular a la misma velocidad, muestran que el filamento de HI se encuentra localizado en la interfase entre el material ionizado y molecular (ver Figura 1.15). Esto permitió concluir que el gas neutro de la nebulosa se originó muy probablemente por efecto de la fotodisociación del material molecular (PDR). Esta teoría parece corroborarse con los altos valores detectados para la relación entre las líneas $C O(2-1) / C O(1-0)$ y por la presencia de $\mathrm{H}_{2}$ excitado.

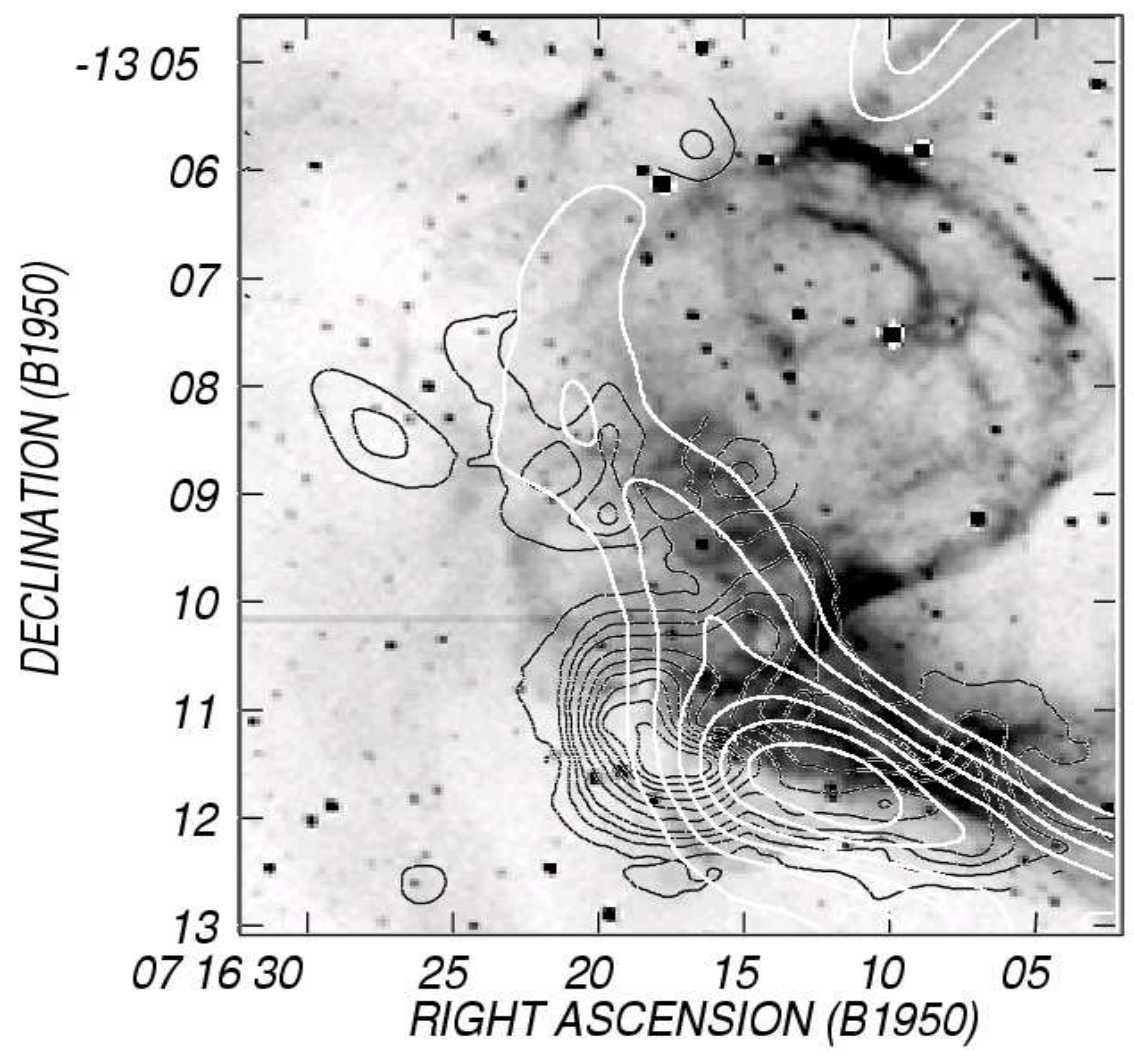

Figura 1.15: Superposición de la imagen integrada de HI entre 51,4-57,9 km/seg (contorno blanco) con la emisión integrada de $\mathrm{CO}(J=2 \rightarrow 1)$ de la componente molecular a $54 \mathrm{~km} / \mathrm{seg}$ (contorno negro) y la imagen $\mathrm{H} \alpha$ de la nebulosa (tonos de gris) de Cappa et al. (2001)

Siguiendo con el análisis de NGC 2359, Rizzo, Martín-Pintado \& Mangum (2001), analizaron la interacción entre la estrella central HD 56925 (WR7) y la nebulosa, estudiando la misma en las líneas $J=1 \rightarrow 0$ y $J=2 \rightarrow 1$ del $\mathrm{CO}$ y analizando la emisión a gran escala del HI. Al igual que en el trabajo 
anterior, encontraron que el gas molecular tiene tres componentes de velocidad; dos de estas (a 37 y $67 \mathrm{~km} / \mathrm{seg}$ ) poseen perfiles delgados, mientras que la tercera (a $54 \mathrm{~km} / \mathrm{seg}$ ) posee perfiles notablemente más anchos (la distribución espacial de estas componentes se muestra en la Figura 1.16. Debido a su morfología, ancho de sus líneas y temperaturas, los autores concluyen también que esta última sería la única componente relacionada con la nebulosa óptica. Las características antes mencionadas, parecen indicar que la componente a $67 \mathrm{~km} / \mathrm{seg}$ fue chocada y acelerada por una burbuja en expansión hasta llegar a la velocidad de la componente a $54 \mathrm{~km} / \mathrm{seg}$. El origen del frente de choque estaría relacionado con alguna fase previa a la WR (LBV o RSG). De las relaciones $\mathrm{C}^{12} \mathrm{O} / \mathrm{C}^{13} \mathrm{O}$ se deduce la presencia de una capa delgada y densa de gas que representaría el material chocado más recientemente en la zona sur de la nebulosa (entre las componentes a 54 y $67 \mathrm{~km} / \mathrm{seg}$ ).

La química molecular es una importante herramienta a la hora de detectar los frentes de choque como el mencionado anteriormente. Moléculas como el $\mathrm{NH}_{3}$, son fácilmente disociables por la radiación UV, pero también pueden ser liberadas de los granos de polvo fríos por el pasaje de ondas de choque de moderada velocidad. Por este motivo, Rizzo, Martín-Pintado \& Henkel (2001), realizaron un estudio de NGC 2359 en las líneas metaestables $(1,1)$ y $(2,2)$ de dicha molécula. El ancho de las líneas así como sus velocidades radiales indican que la emisión de las mismas proviene del gas que está interactuando con la WR. La presencia de frentes de choque en esta región, podría explicar las abundancias observadas de $\mathrm{NH}_{3}$. Si bien la presencia de esta molécula permite suponer una interacción entre el gas y la estrella WR a través de frentes de choque, observaciones de CO de alta resolución angular serían cruciales para detectar la presencia de las densas capas de gas molecular que se formarían por acción de los mismos. En una continuación de los trabajos anteriores, Rizzo, Martín-Pintado \& Desmurs (2003), realizaron observaciones de la nebulosa en las líneas de $\mathrm{C}^{12} \mathrm{O}$ y $\mathrm{C}^{13} \mathrm{O}$ con resolución angular $\sim 12^{\prime \prime}$ y encontraron que la masa, densidad y cinemática en la zona sur de la nebulosa (donde se cree que actuan los frentes de choque), se encontraba estratificada, debido tal vez a la presencia de múltiples capas de material chocado a lo largo de diversas etapas más tempranas de la evolución estelar (LBV o WR temprana).

Recientemente, Arnal (2008) utilizando observaciones de la línea $J=1 \rightarrow 0$ del $\mathrm{C}^{12} \mathrm{O}$, estudió la distribución del gas molecular en los alrededores de la estrella WR 102 la cual se encuentra asociada con la nebulosa anillo G2.4+1.4. Esta nebulosa había sido estudiada por Dopita \& Lozinskaya (1990) (DL 1990) quienes concluyeron que estaba asociada a dos componentes ionizadas, una de ellas era una cáscara expandiéndose a una velocidad de $48 \pm 3 \mathrm{kms}^{-1}$ mientras que la otra tenía una velocidad de $24,6 \pm 3,7 \mathrm{kms}^{-1}$ y no mostraba expansión. Basados en esto, los autores concluyeron que "el shell filamentario de G2.4+1.4 es aproximadamente hemisférico y es expulsado desde la superficie cercana de una nube molecular densa ubicada al sudeste" . DL 1990 ubicaron 


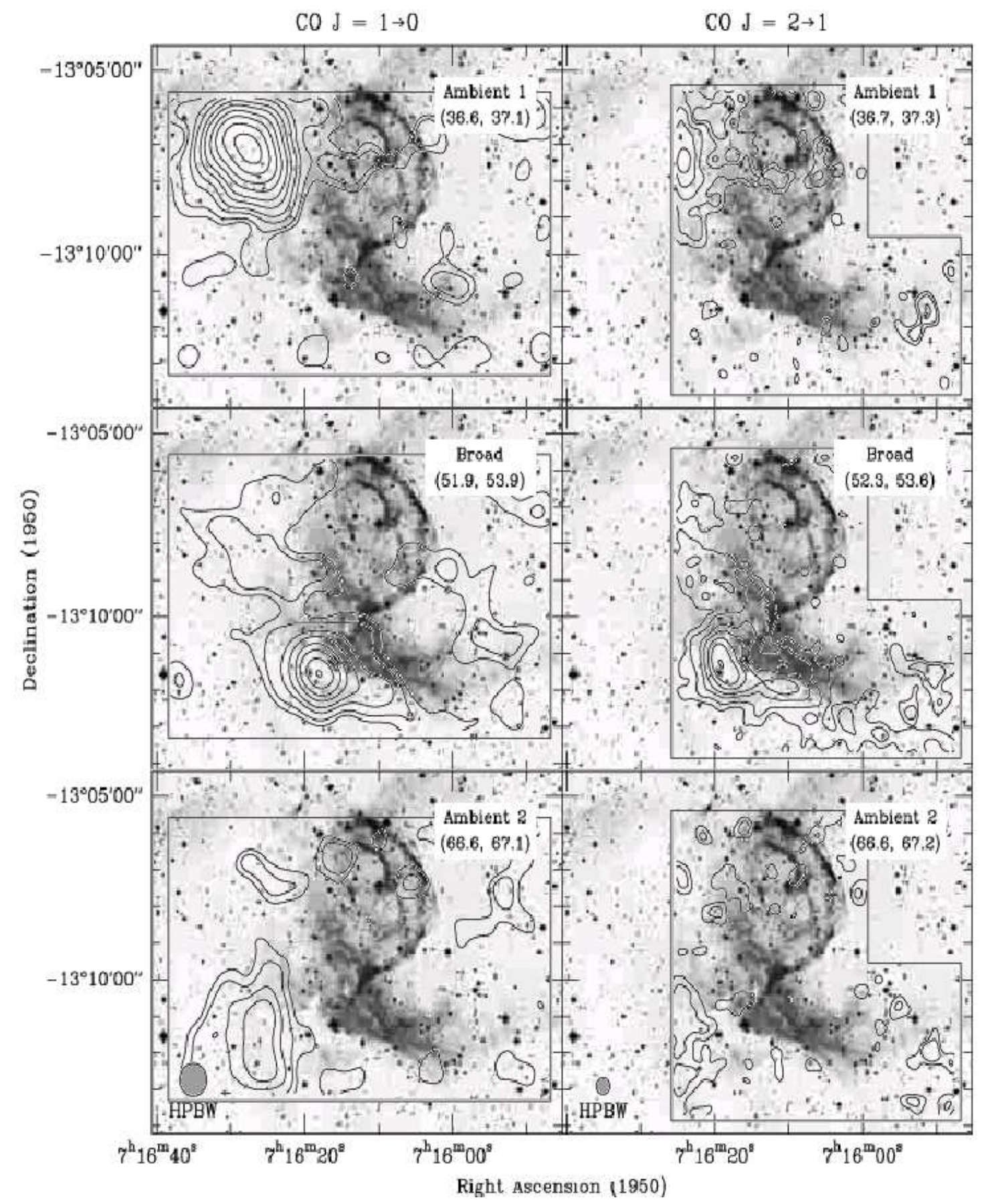

Figura 1.16: Emisión de CO en el campo de NGC 2359 obtenidas por Rizzo et al. (2001) superpuestas con la imagen del DSS. Los mapas de la izquierda corresponden a la transición $J=1 \rightarrow 0$ mientras que los de la derecha a la $J=2 \rightarrow 1$. Las componentes con perfiles delgados están indicados como "Ambient 1" y "Ambient 2", mientras que la de perfiles anchos como "Broad". 
esta nube molecular en el lado lejano de G2.4+1.4, impidiendo de esta forma que la componente en retroceso de la nebulosa anillo se expanda. Arnal (2008) encontró dos componentes moleculares en la dirección de G2.4+1.4. Una de ellas posee una gran correspondencia morfológica con el borde sur de la nebulosa, y está ubicada donde DL 1990 habían predicho la existencia de una nube densa. Esta componente posee una velocidad radial de $-24 \mathrm{kms}^{-1}$ y una masa de $450 \mathrm{M}_{\odot}$. La otra componente se encuentra a una velocidad de $13 \mathrm{kms}^{-1}$ y se encuentra ubicada en la dirección de la zona central de G2.4+1.4. Esta componente podría ser gas molecular expulsado a altas velocidades por el viento de WR 102.

\subsection{Nubes moleculares y formación estelar in- ducida}

Las estrellas de gran masa (y particularmente las estrellas WR), pueden estar asociadas a regiones HII que se forman como resultado de la ionización de nubes moleculares adyacentes. En estas nubes moleculares, los procesos de formación estelar son muy comunes y el entendimiento de los mismos es fundamental para comprender la interacción entre las estrellas de gran masa y el gas molecular circundante.

La formación estelar requiere para su desarrollo, una masa de gas densa y autogravitante, así como también un proceso de compresión que le dé origen.

La idea de que una alta presión interestelar pueda comprimir nubes preexistentes y causar un colapso, seguido de posible formación estelar, fue introducida por Ebert (1955) y Bonner (1956), y fue parte del escenario de "triggering" aplicado a los glóbulos oscuros por Dibai (1958). Actualmente se piensa que estos procesos tienen aplicación a los glóbulos cometarios, glóbulos en regiones HII y también nubes moleculares aisladas que sufran los efectos de las altas presiones producidas por supernovas, regiones HII, vientos estelares y otros disturbios producidos en el MIE debido a la deposición localizada de grandes cantidades de energía mecánica.

En un intento por organizar los mecanismos de formación estelar inducidos mencionados anteriormante, Elmegreen \& Lada (1977) y posteriormente Elmegreen (1998) propusieron la siguiente clasificación:

Formación estelar inducida a pequeña escala: compresión directa de nubes pre-existentes o glóbulos por efectos de una alta presión que rodea a la nube. Estas altas presiones podrían ser originadas por regiones HII jóvenes que al comenzar su expansión interactúan con nubes moleculares circundantes dando origen a bordes brillantes y pequeños glóbulos cometarios. En la Figura 1.17 se muestra un diagrama esquemático de este proceso (Elmegreen, 1992) 


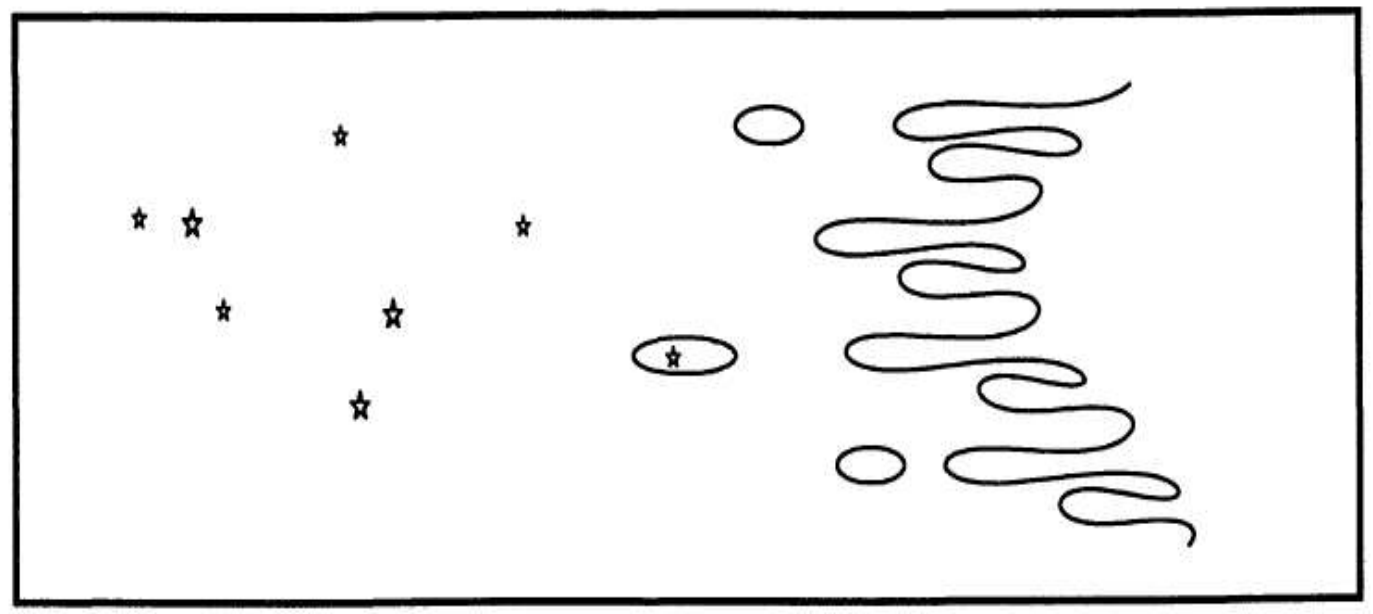

Figura 1.17: Diagrama esquemático de un cúmulo estelar (izquierda) interactuando con estructuras moleculares grumosas (derecha)en el borde de una nube molecular. Algunos de los grumos son comprimidos desencadenando la formación estelar (Elmegreen, 1992).

Los glóbulos pueden formarse independientemente de si existen estructuras grumosas en la nube molecular interactuante, al producirse inestabilidades dinámicas entre el frente de ionización y la nube molecular, como por ejemplo la inestabilidad Rayleigh-Taylor (Capriotti, 1996). Algunos ejemplos de formación estelar en "glóbulos cometarios" y "bordes brillantes" son: Nebulosa de Gum (Bhatt, 1993; Schoeller et al., 1996), Carina (Megeath et al., 1996).

Las altas presiones producidas por remanentes de supernovas o vientos estelares pueden "tragar" a los glóbulos en formación originando las estructuras de morfología cometaria mencionadas anteriormente, especialmente si la presión proviene de un solo lado.

La teoría de la formación estelar inducida en estos casos fue estudiada por varios autores: Bonner (1956), Chieze (1987), Tomisaka et al. (1989). Un importante elemento considerado en esta teoría es el campo magnético ya que la compresión en ausencia del mismo es muy diferente a la compresión cuando éste está presente, pudiendo el mismo evitar un proceso de colapso si la masa involucrada no es suficientemente grande. Los efectos del campo magnético son distintos dependiendo de si las líneas de campo son paralelas o perpendiculares a la compresión.

La formación espontánea y colapso de glóbulos dentro de filamentos es otra vía para la formación estelar. Los filamentos son muy comunes en el MIE, y pueden formarse por procesos magnéticos o colapso gravitacional producido por capas que impactan en el medio.

El análisis de la estabilidad de las nubes moleculares ante variaciones en la presión y la radiación, movimientos internos, rotación, turbulencia, calentamiento, enfriamiento, ondas magnéticas, etc. es más complicado que lo ex- 
puesto en las teorías mencionadas anteriormente y pueden alterar notablemente las condiciones en la formación estelar inducida.

Formación estelar inducida a escala intermedia: A medida que una región HII avanza en su expansión, va acumulando material de la nube molecular que la rodea hasta formar una densa capa que actúa como una interfase nube molecular/nebulosa. Esta capa de material molecular acumulado se vuelve inestable en corto tiempo, debido a procesos cinemáticos, magnéticos o gravitacionales (Elmegreen \& Elmegreen 1978b, Vishniac, 1983, García-Segura \& Franco, 1996); esta inestabilidad "rápida" puede ser oscilatoria o monótona, dependiendo de la desaceleración. De todas formas, debido a que la capa es delgada en su espesor, el colapso gravitacional se produce posteriormente a lo largo de su extensión. La gravedad siempre actúa para darle a la nube una geometría esférica si ésta está sotenida por la presión en dos dimensiones pero no en una tercera. La escala de tiempo gravitacional generalmente es mayor que la escala de tiempo cinemática, por lo tanto el colapso gravitacional ocurrirá luego, en una región que ha experimentado diversos tipos de inestabilidades a pequeña escala. Si las inestabilidades cinemáticas producen algún tipo de estructuras a pequeña escala, el colapso gravitacional empuja estas estructuras formando núcleos turbulentos (Figura 1.18).

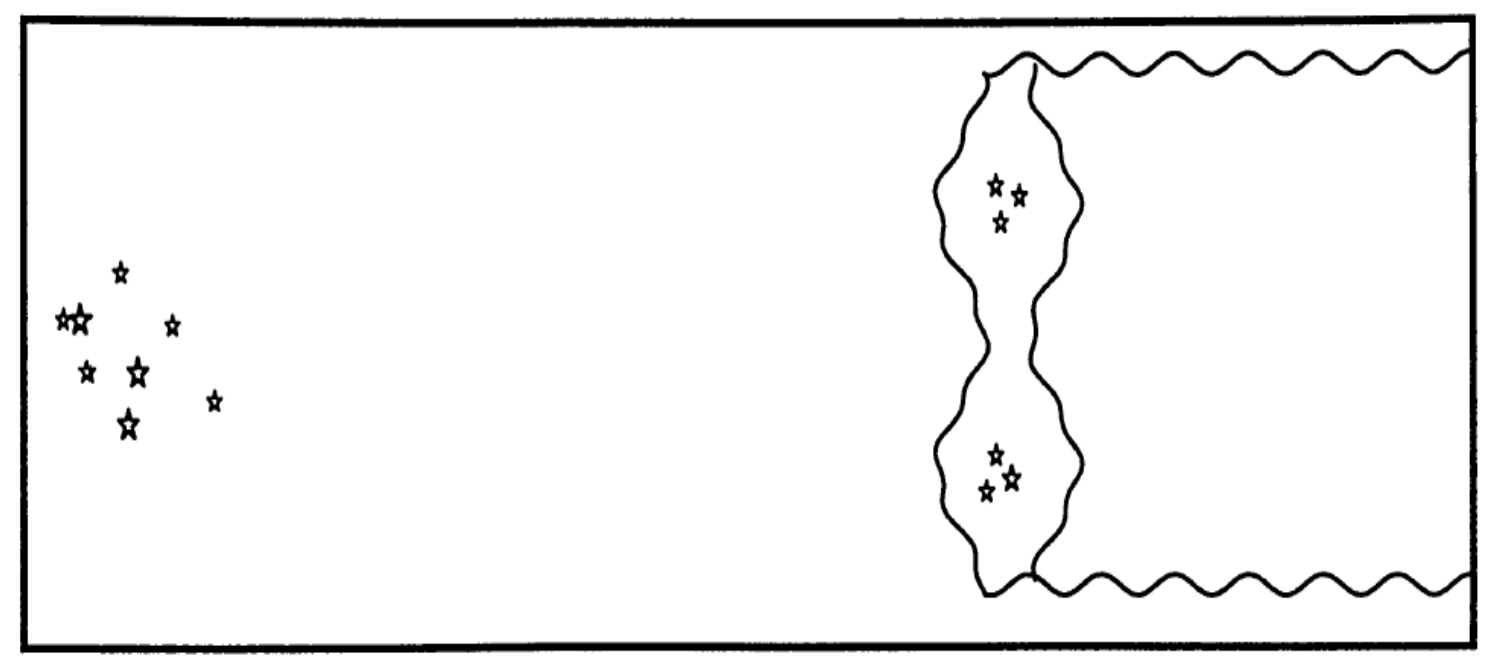

Figura 1.18: Diagrama esquemático del movimiento y compresión del gas molecular en el borde de una región HII en expansión. En el colapso se producen dos grandes grumos donde hay estrellas dentro (derecha)(Elmegreen, 1992).

La teoría de formación estelar inducida a esta escala fue estudiada por varios autores considerando distintas propiedades de la capa en expansión: Doroshkevich (1980) y Vishniac (1983) calcularon el tiempo de colapso para una capa en expansión plano-paralela a velocidad constante limitada en un lado por un frente de choque. Elmegreen (1989) y Nishi (1992), lo hicieron para 
una capa en desaceleración donde los núcleos nuevos en formación emigran más lentamente hacia el frente de choque provocando la curvatura de los mismos. Los campos magnéticos son también un importante factor en este escenario ya que la compresión inicial en dirección paralela a las líneas de campo origina núcleos de colapso más densos.

La idea más importante que parece desprenderse de los modelos en este escenario, es que existe un retraso entre la expansión de la región HII y el comienzo de la formación estelar inducida provocado por la estabilidad de la capa inicial en contra del colapso; como resultado de esto, todas las estrellas formadas por el choque de las capas en expansión en los bordes de una asociación $\mathrm{OB}$ deberían ser significativamente más jóvenes que las estrellas de dicha asociación sin una distribución progresiva de edades desde el centro hacia el borde, aspecto que parece concordar con las observaciones de algunas asociaciones OB. Algunos ejemplos observados son: Orion OB1 (Blaauw, 1991); Per OB2 y Ceph OB3 (Sargent, 1979); Rosseta (Phelps \& Lada, 1997). Este escenario parece ser contrario al de formación estelar inducida a "Pequeña escala" , en el cual la presión comprimía grumos ya existentes en forma rápida, dando origen a poblaciones estelares cuya edad no difería de las poblaciones progenitoras.

Formación estelar inducida a gran escala (cáscaras y anillos): La expansión alrededor de una fuente de presión centralizada, conlleva la formación de cáscaras o anillos que pueden volverse gravitacionalmente inestables y así formar una nueva generación de estrellas en la periferia. El tamaño de estos anillos puede ser pequeño (unos pocos parsecs) o grande (cientos de parsecs), dependiendo de la presión generada por la fuente interna y la densidad del MIE circundante. Existen varios ejemplos de cúmulos estelares ubicados a lo largo de cáscaras gigantes en nustra galaxia y galaxias vecinas: IC 443, W28, W44, S147, HB21 (Odenwald \& Shivanandan, 1985), W5 (Sato, 1990), AraOB1 (Arnal et al., 1987; Rizzo \& Bajaja, 1994). Tenorio-Tagle \& Bodenheimer (1988), hicieron un resumen de todas las cáscaras gigantes en expansión en nuestra galaxia y otras galaxias, focalizando especialmente en la relación de estas estructuras con la evolución del MIE y la formación estelar.

Los trabajos analíticos de inestabilidades gravitacionales en cáscaras en expansión comenzaron con Ostriker \& Cowie (1981) y Vishniac (1983), mientras que Mc Cray \& Kafatos (1987) trataron conjuntamente las teorías de expansión de cáscaras y formación estelar, usando como fuente de energía para la expansión los vientos estelares estacionarios o inyección de energía de supernovas en forma continua. Los criterios para la formación estelar en una cáscara en expansión o anillos, son similares a los vistos para la formación estelar inducida a "escala intermedia". Las cáscaras y anillos detrás del frente de choque conllevan una variedad de inestabilidades cinemáticas, magnéticas y gravitacionales. Algunas de éstas crean turbulencia y estructuras a pequeña escala 
que en un principio no están relacionadas con la formación estelar, pero que luego por medio de las inestabilidades gravitacionales darán origen a grandes condensaciones dentro del material barrido donde pueden formarse cúmulos estelares.

Otra condición importante para la formación estelar en la capa barrida, es que la misma sea ópticamente gruesa a la luz estelar, de forma tal que pueda enfriarse y volverse más densa. Esta condición fue tratada por Franco \& Cox (1986)

\subsection{Objetivos de esta Tesis}

La observación del material molecular alrededor de estrellas WR es importante para comprender la relación entre el MIE y las estrellas de gran masa. Es por esta razón, sumada a la relativa escasez de trabajos realizados en este tema, que se hace imprescindible incrementar la muestra de este tipo de observaciones.

En esta Tesis de Doctorado se propone:

- Estudiar la distribución del material molecular en los alrededores de diez estrellas WR galácticas usando la línea $(\mathrm{J}=1 \rightarrow 0)$ de la molécula de $\mathrm{C}^{12} \mathrm{O}$ como trazadora, los cuales fueron obtenidos con el radiotelescopio NANTEN. Se intentará comparar los resultados con los predichos por los modelos y teorías de la interacción de estrellas de gran masa con el MIE, anteriormente descriptos. En los casos en los que sea necesario, se desarrollarán modelos cinemáticos alternativos que permitan explicar los resultados obtenidos.

- En base a la posible relación existente entre los intensos vientos generados por las estrellas WR (tanto aisladas como pertenecientes a asociaciones estelares) con el proceso de formación estelar inducida, se estudiará el gas molecular que se encuentra asociado a regiones de formación estelar cercanas a los objetos estelares en cuestión por medio del análisis de sus propiedades físicas, morfológicas y cinemáticas. Se buscarán en las mismas, evidencias que indiquen que la formación estelar propiamente dicha se haya iniciado como causa de la interacción entre el material molecular preexistente y las estrellas cercanas.

- En todos los casos, las observaciones de $\mathrm{C}^{12} \mathrm{O}$ se complementarán con observaciones en otras frecuencias, obtenidas mediante el acceso a bases de datos disponibles mediante Internet, con el fin de encontrar las contrapartes de las estructuras halladas y realizar un estudio multifrecuencia 
completo del material interestelar en los alrededores de los objetos seleccionados para su estudio.

En esta Tesis se analizará la distribución de gas molecular en los alrededores de las estrellas WR 14, WR 16, WR 18, WR 55, WR 68, WR 75, WR 87, WR 89, WR 91, y WR 103. Estas estrellas fueron elegidas de acuerdo a diversos criterios:

- A los efectos de minimizar los posibles efectos de confusión por la emisión galáctica, la mayoría de las estrellas seleccionadas están ubicadas a una latitud galáctica $|b| \geq 1^{\circ}$.

- En el caso de WR 14,WR 16, WR 18, WR 55, WR 68, WR 75 y WR 103, las estrellas no forman parte de cúmulos o asociaciones y se encuentran relativamente aisladas de otras estrellas de gran masa. Esta situación es muy favorable a la hora de comparar los resultados con los modelos existentes. Además no existen observaciones moleculares ni trabajos previos referidos al MIE donde están los objetos WR 14, WR 68 y WR 103.

- Estrellas ubicadas en las proximidades de regiones de formación estelar previamente estudiadas, o regiones HII intensas donde podrían estar llevándose a cabo procesos de formación estelar. En el caso de WR 87 y WR 89 (posiblemente miembros del cúmulo abierto HM1) y WR 91, estas estrellas se encuentran próximas a RCW 122 y RCW 121, dos regiones HII muy intensas. No existen además en la bibliografía estudios a gran escala del material molecular en los alrededores de estas regiones.

- En la elección de WR 16 , WR 18, WR 55 y WR 75, influyó también la existencia de observaciones de mayor resolución que los datos de NANTEN pero en un campo muy reducido en la línea de CO. WR 16, WR 18 y WR 75 fueron observados con el instrumento SEST por Marston et al. (1999a) y Marston et al. (2001). Estos son buenos ejemplos que ilustran las posibles complicaciones a enfrentar cuando no se dispone de una adecuada cobertura espacial. En el caso de WR 55, este objeto fue estudiado por Cappa et al. (2009), también con observaciones obtenidas con el radiotelescopio SEST. 


\subsection{Bibliografía}

- Abbott, D., 1982a, ApJ, 259, 282

- Arnal, E.M., Cersosimo, J. C., May, J, \& Bronfman L., 1987, A\&A, 174, 78

- Arnal, E. M., \& Mirabel, I. F., 1991, AJ, 101,572

- Arnal, E. M., 1992, A\&A, 254, 305

- Arnal, E. M. \& Cappa, C. E., 1996, MNRAS, 279, 788

- Arnal, E. M. \& Roger, R. S., 1997, MNRAS, 285, 253

- Arnal, E. M., Cappa, C. E., Rizzo, J. R., Cichowolski, S., 1999, AJ, 118, 1798

- Arnal, E. M., 2001, AJ, 121, 413

- Arnal, E. M., 2008, 2008,RMxAC, 33, 140A

- Avedisova, V., 1972, Soviet Astronomy, 15, 708

- Avedisova,V., 1977, SaAL, 3, 217A

- Beals, 1938, Trans. IAU, 6, 248

- Blaaw A. 1991 "The Physics of Star Formation and Early Stellar Evolution", C.J Lada \& N.D. Kylafis, Kluwer, Dordrecht, 125

- Bhatt, H. C., 1993, MNRAS, 262, 812B

- Bonner W. B. 1956, MNRAS, 116, 351

- Cappa, C. E. \& Niemela, V. S., 1984, AJ, 89, 1398

- Cappa, C. E., Niemela V. S., Arnal, E. M., 1986, AJ, 92, 1414

- Cappa, C. E., Niemela V. S., Dubner G. M., Arnal, E. M., 1988, AJ, 96, 1671

- Cappa, C. E, Niemela, V. S., Herbstmeier, U., Koribalski, B., 1996, A\&A, 312,283

- Cappa, C. E \& Benaglia, P., 1998, AJ, 116, 1906

- Cappa, C. E, Goss, W. M., Niemela, V. S., Ostrov, P. G., AJ, 1999, 118, 948 
- Cappa, C. E \& Herbstmeier U., 2000, AJ, 120, 1963

- Cappa, C. E, Rubio M., Goss, W. M., 2001, AJ, 121, 2664

- Cappa, C. E, Goss, W. M., Pineault S., 2002, AJ, 123, 3348

- Cappa, C., Niemela, V. S., McClure-Griffiths, N., 2005, 2005 A\&A, 436, $155 \mathrm{C}$

- Capriotti, E. R., 1996, AAS, 188, 0714C

- Castor, J. I., Mc Cray, R. \& Weaver, R., 1975, ApJ, 200, L107

- Cazzolato, F. \& Pineault, F., 2000, AJ, 120, 3192

- Chevalier, R. A. \& Luo, D.,1994, ApJ, 469, L127

- Chièze J.P. 1987, A\&A, 171,225

- Cichowolski, S., Pineault, S., Arnal, E. M., Testori, J. C., Goss W. M., Cappa C. E., 2001, AJ, 122, 1938

- Cichowolski, S., Arnal, E. M., Cappa, C. E., Pineault S., St Louis, N., 2003, MNRAS, 343, 55

- Cichowolski, S. \& Arnal, E. M., 2004, A\&A, 414, 203

- Cichowolski, S.; Pineault, S.; Arnal, E. M.; Cappa, C. E., 2008, A\&A, 478, 443C

- Chiosi, C. \& Maeder, A., 1986, ARAA, 24, 329

- Chu, Y. -H., 1981, ApJ, 249, 195

- Chu, Y. -H., 1982a, ApJ, 254, 578

- Chu, Y. -H., 1982b, ApJ, 255, 79

- Chu Y. -H., Treffers, R. R., 1981a, ApJ, 249, 586

- Chu Y. -H., Treffers, R. R., 1981b, ApJ, 250, 615

- Chu, Y. -H., Troland, T. H., Gull, T. R., Treffers, R. R., Kwitter, K. B., 1982, ApJ, 254, 562

- Chu, Y. -H., Treffers, R. R., Kwitter, K. B., 1983, ApJS, 469, L127

- Dibai, E. A., 1958, SvA, 2, 429D

- Dopita, M \& Lozinskaya, T. A. 1990, ApJ, 539, 419 
- Doroshkecich A.G. 1980, Sov. Astron. , 24, 152

- Dubner, G., Niemela V. S., Purton C. R., 1990, AJ, 99, 857

- Dyson, J. E., 1973, A\&A, 23, 381

- Ebert, R 1955, Zs Ap., 37, 217

- Elmegreen B.G. \& Lada C.J, 1977, ApJ, 214, 725

- Elmegreen \& Elmegreen, 1978, apJ, 220, 1051

- Elmegreen B.G., 1989 ApJ, 340, 786

- Elmegreen B.G. 1992, "Star Formation in Stellar systems", III Canary Islands Winter School, ed. G Tenorio-Tagle, M. Prieto, and F. Sanchez, Cambridge University Press, p. 381

- Elmegreen ASP Conference Series, 1998, 148

- Falle, S. A. E. G., 1975, A\&A, 43, 323

- Franco J. \& Cox D.P. 1986, PASP, 98, 1076

- Freyer, Tim; Hensler, Gerhard; Yorke, Harold W., 2006, ApJ, 638, 262F

- García-Segura, G. \& Mac Low, M. M., 1995, ApJ, 455, 145

- García-Segura, G. \& Mac Low, M. M., 1995, ApJ, 455, 174

- García-Segura, G. \& Franco, J., 1996, ApJ, 469, 171

- Gervais, S. \& St-Louis, N., 1999, AJ,118, 2394

- Gomez, A., Lortet, M. -C., and Pitault, A., in Chiosi and R. Stalio (EDS) "Efects of mass loss on stellar evolution", proc. IAU coll. No. 59 (Dodrecht: Reidel), p. 291

- Heiles, C., 1979, ApJ, 229, 553

- Heiles, C., 1984, ApJS, 55, 855

- Heiles, C., 1987, ApJ, 315, 555

- Hidayat, B., Supelli, K., van der Hucht, K. A., 1982 IAUS, 99, 27

- Hidayat, B, Admiranto, G., van der Hucht, K. A., 1984, Ap\&SS, 99, 175

- Hiltner \& Schild, 1966, ApJ, 143, 770

- Hollembach, D. J. \& Tielens, A. G. G., 1997, ARAA, 35, 179 
- Johnson, H. M., Hogg, D. E., 1965, ApJ, 142, 1033

- Koo, B. C. \& McKee, C. F., 1992, ApJ, 338, 93K

- Koo, B. C. \& McKee, C. F., 1992, ApJ, 338, 103

- Kudritzki, R. P., Pauldrach, A., Puls, J., 1987, A\&A, 173, 293

- Lamers, H. J. G. L. M., Cassinelli, J. P., 1999, en "Introduction to stellar winds", Cambridge University

- Langer, N., 1989, A\&A, 220, 135

- Leitherer, C. \& Langer, N., 1991 In IAU Symp. 148

- Leitherer, C., Robert, C. \& Drissen, L., 1992, ApJ, 401, 596

- Livio, M. \& Soker, N,, 1988, ApJ, 329, 764

- Maeder, A., 1983, A\&A, 120, 113

- Maeder, A, Q.J1R. Astr. Soc. (1991) 32, 217

- Marston, A. P., 1991, ApJ, 366, 181

- Marston, A. P., Chu, Y. -H. \& Garcia-Segura, G., 1994, ApJS, 93, 229

- Marston, A. P., Yocum, D. R., Garcia-Segura, G., Chu, Y. -H., 1994, ApJS, 95, 151

- Marston, A. P., 1996, AJ, 112, 2828

- Marston, A. P., 1997, ApJ, 475, 188

- Marston, A. P., Wellzmiller, J. T., Black, J. H., Bransford, M. A., Berman P.,1999a, ApJ, 518, 769

- Marston, A. P., Welzmiller, J. T., Black, J. H. \& Berman, 1999b, IAU Symp. Proc 193

- Marston, A. P., 2001, ApJ, 563, 875

- McCray, R., 1983, HiA, 6, 565

- McCray, Richard; Kafatos, Minas, 1987, ApJ, 317, 190M

- McKee, C. F., van der Buren, D., Lazareff, B., 1984, ApJ, 278, L115

- Megeath et al. 1996, A\&A, 305, 296

- Moffat, A. F. J. \& Isserstedt, J., 1980, A\&AS, 42, 251 
- Nishi R. 1992, Prog. Theor. Phys. , 87, 347

- Noels, A. \& Gabriel, M., 1981, A\&A, 101, 215

- Odenwald, S. F.; Shivanandan, K., 1985, ApJ, 292, 4600

- Ostriker, J. P.; Cowie, L. L., 1981, ApJ, 243L., $127 \mathrm{O}$

- Owocki, S., Cranmer, S., Blondin, J., 1994, ApJ, 424,887

- Phelps, Randy L.; Lada, Elizabeth A., 1997, ApJ, 477, 176P

- Prantzos, N., Doom, C., Arnould, M. \& de Loore, C., 1986, ApJ, 304, 695

- Rizo J.R \& Bajaja E. 1994, A\&A, 289, 922

- Rizzo, J. R., Martin-Pintado, J., Mangum, J. G., 2001, A\&A, 366, 146

- Rizzo, J. R, Martin-Pintado, J., Henkel, C., 2001, ApJ, 553, L181

- Rizzo, J. R, Martin-Pintado, J., Desmurs, J. F., 2003, A\&A, 411, 465

- Roberts, M. S., 1962, AJ, 67, 79

- Rozyczca, M. \& Franco, J., 1996, ApJ, 469, L127

- Sargent A.I. 1979, ApJ, 233, 163

- Sato, Fumio, 1990, AJ, 99, 1897S

- Schoeller, M.; Brandner, W.; Lehmann, T.; Weigelt, G.; Zinnecker, H., 1996, A\&A, 315, 445S

- Smith, L., 1968, MNRAS, 138, 109

- Smith, L., 1968c, MNRAS, 141, 317

- Smith, L., 1973, IAUS, 49, 15S

- Smith, Lindsey F.; Shara, Michael M.; Moffat, Anthony F. J., 1996, MNRAS, 281, 163S

- Stone, J. M. \& Norman, M. L., 1992, ApJ, 389, 297

- Steigman, G. Strittmatter, P. A. \& Williams, R. E., 1975, ApJ, 198, 575

- Tenorio-Tagle \& Bodenheimer 1988, ARAA, 26, 146

- Tomisaka, Kohji; Ikeuchi, Satoru; Nakamura, Takashi, 1989, ApJ, 341, $220 \mathrm{~T}$ 
- Treffers, R. R. \& Chu, Y. -H., 1982a, ApJ, 254, 132

- Treffers, R. R. \& Chu, Y. -H., 1982b, ApJ, 254,569

- van de Hulst H. C., 1946, RAOU, 11, 2V

- van der Bij \& Arnal, 1986, ApL, 25, 119

- van der Hucht, K. A., Conti, P. S., Lundström, I. \& Stenholm, B., 1981, SSR, 28, 227

- van der Hucht, K. A., 2001, NAR, 45, 135

- van der Hucht, K. A. 2006, A\&A, 458, 453V

- van der Werf, P. P. \& Higgs, L. A., 1990, A\&A, 235, 407

- Vishniac E.T. 1983, ApJ, 274, 152

- Weaver, R., Mc Cray, R., Castor, J. Shapiro, P. \& Moore, R., 1977, ApJ, 218,377 


\section{Capítulo 2}

\section{Descripción del instrumento, observaciones y bases de datos utilizados}

\subsection{Radiotelescopio de disco simple}

Los radiotelescopios son instrumentos capaces de captar cantidades muy pequeñas de energía radiante y convertirla en potencia. Esto lo logra recolectando la mayor cantidad de energía posible, la que luego es amplificada y almacenada. Para lograr esto, un radiotelescopio cuenta fundamentalmente con un reflector principal que recolecta la energía que incide en él, y un receptor que la procesa y almacena.

\subsubsection{Principales parámetros de un radiotelescopio}

Existen numerosos parámetros y propiedades que caracterizan a un radiotelescopio. Aquí se presentan algunos de los más importantes (Kraus, 1966):

\section{Diagrama de antena}

Es una medida de la respuesta de la antena a la radiación, como función de los ángulos azimutal $(\phi)$ y cenital $(\theta)$. Se suele denominar $\mathrm{P}(\theta, \phi)$ al diagrama de recepción, el cual se normaliza:

$$
P_{n}(\theta, \phi)=\left(\frac{P(\theta, \phi)}{P_{\max }(\theta, \phi)}\right)
$$

El diagrama de antena describe el tamaño angular de la zona del cielo desde donde el radiotelescopio recibe energía. El radiotelescopio recibe mayor cantidad de energía de zonas del cielo que se encuentran alineadas con el eje mayor del lóbulo principal del diagrama de antena $\left(\mathrm{P}_{n}(0,0)=1\right)$. En la Figura 2.1 se muestra un diagrama de antena típico de un radiotelescopio. 


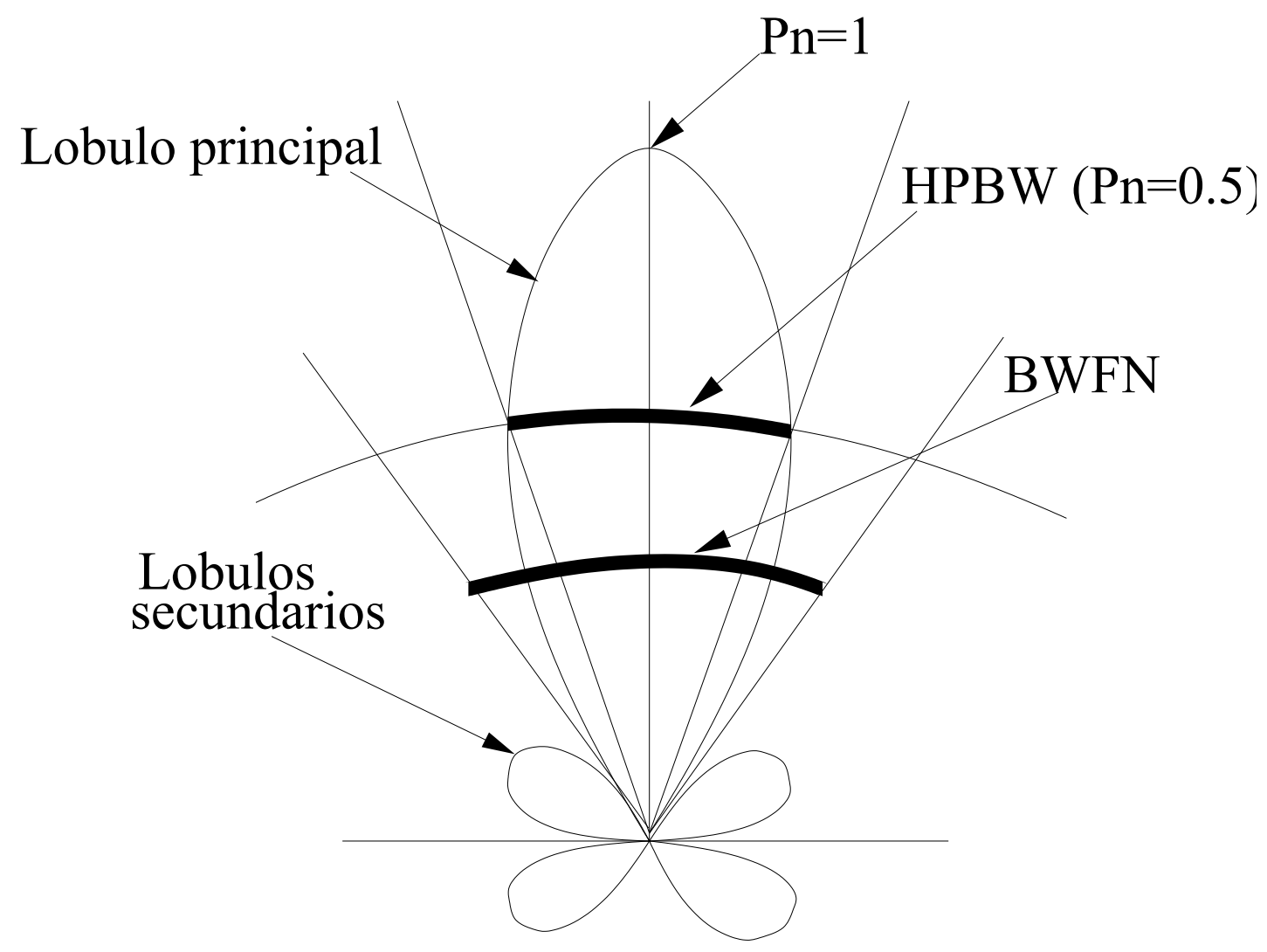

Figura 2.1: Diagrama de antena de un radiotelescopio

Cuanto más grande sea el ángulo entre la dirección a una fuente y el lóbulo principal, la energía detectada para dicha fuente será más pequeña. Los lóbulos secundarios al costado del lóbulo principal son fuente de ruido por lo que es deseable que sean lo más pequeños posible.

\section{Ancho del haz a mitad de potencia (HPBW)}

Ángulo entre dos puntos para los cuales la potencia recibida es la mitad $\left(\mathrm{P}_{n}=0,5\right)$ de lo que vale en dirección del eje principal $\left(\mathrm{P}_{n}=1\right)$ (ver Figura 2.1 ). Este valor representa la resolución angular del instrumento y su valor es aproximadamente la mitad del Ancho del Haz entre los Primeros Ceros (BWFN) por lo que: HPBW (radianes) $\approx 1,22 \times\left(\frac{\lambda}{D}\right)$, donde $\lambda$ es la longitud de onda y $\mathrm{D}$ el diámetro de la antena. Este parámetro está muy relacionado con otro parámetro conocido como Directividad

\section{Angulo sólido de antena $\left(\Omega_{A}\right)$}

Es aquél a través del cual la antena emitiría en forma isotrópica con una potencia igual al máximo y es igual a la integral: $\Omega_{A}=\int_{0}^{4 \pi} P_{n}(\theta, \phi) d \Omega$ (se integran lóbulos principal y secundarios) 


\section{Angulo sólido del haz principal $\left(\Omega_{M}\right)$}

Se integra sólo en el lóbulo principal. $\Omega_{M}=\int_{\text {lob.ppal }} P_{n}(\theta, \phi) d \Omega$

\section{Angulo sólido de los lóbulos secundarios $\left(\Omega_{m}\right)$}

Se integra sólo en los lóbulos secundarios. $\Omega_{m}=\int_{4 \pi-l o b . p p a l} P_{n}(\theta, \phi) d \Omega$.

Así puede definirse la Eficiencia del haz $\left(\eta_{b}=\Omega_{M} / \Omega_{A}\right)$, el cual indica qué tan importantes son los lóbulos secundarios y cuyo valor ideal es 1.

\section{Area efectiva $\left(\mathbf{A}_{e f f}\right)$}

Representa la porción del área del reflector principal usada para enviar los fotones recibidos al receptor. Este valor es menor al área física del receptor $\left(\mathrm{A}_{\text {geom }}\right)$, ya que las irregularidades de la superficie hacen que se pierdan muchos fotones. Así puede definirse la Eficiencia de apertura $\left(\eta_{a}=\mathrm{A}_{\text {eff }} / \mathrm{A}_{\text {geom }}\right)$, cuyo valor ideal es 1 .

\section{Sensibilidad}

Es la capacidad que tiene el instrumento de generar una respuesta detectable ante cantidades reducidas de energía que llegan hasta él. De acuerdo a la definición de la potencia espectral, se puede obtener una relación entre la temperatura de antena $\left(\mathrm{T}_{A}\right)$ (ver página 46) y el flujo observado:

$$
S_{o b s}=\frac{2 k T_{A}}{A_{e f f}} \quad[J y]
$$

siendo k la constante de Boltzman. Así, la sensibilidad se define como:

$$
\frac{S_{o b s}}{T_{A}}=\frac{2 k T_{A}}{A_{\text {eff }}} \quad[J y / K]
$$

La sensibilidad se incrementa cuando $\mathrm{A}_{e f f} \rightarrow \mathrm{A}_{\text {geom }}$ y es máxima cuando $\mathrm{A}_{\text {eff }}=\mathrm{A}_{\text {geom }}\left(\eta_{a}=1\right)$.

\subsubsection{Interpretación de las señales recibidas por un ra- diotelescopio}

La cantidad de energía recibida por unidad de tiempo por un radiotelescopio (potencia) W, se puede expresar en funcion del brillo espectral B, el cual es función de los ángulos azimutal y cenital. Así, se puede demostrar que:

$$
W=1 / 2 A_{\text {eff }} \int_{\Omega} B(\theta, \phi) P_{n}(\theta, \phi) d \Omega
$$

siendo $\Omega$ el ángulo sólido de la fuente, $\mathrm{P}_{n}(\theta, \phi)$ el diagrama de antena y el $1 / 2$ es debido a que el instrumento sólo recoge una componenete de polarización (en el caso de radiación no polarizada y con un dipolo como alimentador). 
En la práctica, no se pueden ver los objetos tales como son ya que el instrumento distorsiona la imagen, por lo tanto lo que se ve es la convolución entre la realidad y el diagrama de antena del instrumento. Para una fuente puntual, se define densidad de flujo a la integral:

$$
S_{\text {verdadero }}=\int_{\Omega_{\text {fuente }}} B(\theta, \phi) d \Omega
$$

cuya unidad de flujo es el Jansky (Jy) ( $1 \mathrm{Jy}=10^{-26}$ Watts $\left.\mathrm{m}^{-2} \mathrm{~Hz}^{-1}\right)$. $\mathrm{Al}$ observar una fuente con una antena con un diagrama $\mathrm{P}_{n}(\theta, \phi)$, el flujo observado está ahora dado por:

$$
S_{\text {observado }}=\int_{\Omega_{\text {fuente }}} B(\theta, \phi) P_{n}(\theta, \phi) d \Omega
$$

de donde puede verse que $S_{\text {verdadero }}>S_{\text {observado, }}$ excepto en el caso de una fuente puntual, donde $\mathrm{P}_{n}(\theta, \phi)=1$ entonces $S_{\text {verdadero }}=S_{\text {observado }}$. En forma más general:

$$
S\left(\theta_{0}, \phi_{0}\right)=\int_{\Omega_{\text {fuente }}} B(\theta, \phi) P_{n}\left(\theta-\theta_{0}, \phi-\phi_{0}\right) d \Omega
$$

con $\left(\theta_{0}, \phi_{0}\right)$ la dirección de la fuente discreta y considerando que $\mathrm{P}_{n}(\theta, \phi)$ es simétrico. Por lo tanto:

$$
S\left(\theta_{0}, \phi_{0}\right)=B(\theta, \phi) * P_{n}\left(\theta_{0}-\theta, \phi_{0}-\phi\right)
$$

de la misma manera para la potencia espectral:

$$
W\left(\theta_{0}, \phi_{0}\right)=1 / 2 A_{e f f} B(\theta, \phi) * P_{n}\left(\theta_{0}-\theta, \phi_{0}-\phi\right)
$$

El efecto producido por la convolución en la imagen, es el de "suavizar" los detalles en la distribución de brillo $\mathrm{B}(\theta, \phi)$, pero el área debajo de la misma se conserva. El $B(\theta, \phi)$ convolucionado será igual al original sólo si la antena es perfecta, es decir, si $\mathrm{P}_{n}(\theta, \phi)$ puede representarse por una función Delta de Dirac o bien si la fuente es puntual, en cuyo caso la Delta de Dirac representaría ahora al perfil de brillo $\mathrm{B}(\theta, \phi)$

\section{Temperatura de Antena y Temperatura de Brillo :}

La Temperatura de Antena $\left(T_{A}\right)$ es una medida de la potencia total recibida por la antena y depende del instrumental utilizado. Se la puede considerar como la temperatura que debería tener un resistor que reemplaza a una antena para generar la misma potencia que se genera cuando se observa el objeto celeste. La Temperatura de Antena no es una característica física del objeto. Como se indicó anteriormente, se puede obtener una relación entre $T_{A}$ y el flujo observado:

$$
S_{o b s}=\frac{2 k T_{A}}{A_{e f f}}
$$


La Temperatura de Brillo $\left(T_{B}\right)$ a diferencia de $T_{A}$, puede representar una temperatura real del objeto observado. Considerando la Ley de Planck y la aproximación de Rayleigh-Jeans para bajas frecuencias:

$$
B(\theta, \phi, \lambda)=\frac{2 k T_{B}(\theta, \phi)}{\lambda^{2}}
$$

Si el objeto celeste se comporta como un cuerpo negro, entonces $T_{B}$ representa la temperatura real del mismo, de lo contrario $T_{B}$ es simplemente una medida de la intensidad de la radiación del cuerpo que emite la señal. Utilizando algunos conceptos definidos anteriormente, es posible obtener una relación entre $T_{B}$ y $T_{A}$ para una fuente puntual, de la forma

$$
T_{B}=\frac{T_{A}}{\eta_{b}}
$$

donde $\eta_{b}$ se define como Eficiencia del haz.

\subsubsection{Señal y ruido}

Cuando un radiotelescopio realiza un barrido a lo largo de una fuente, se obtiene una señal similar a la mostrada en la Figura 2.2

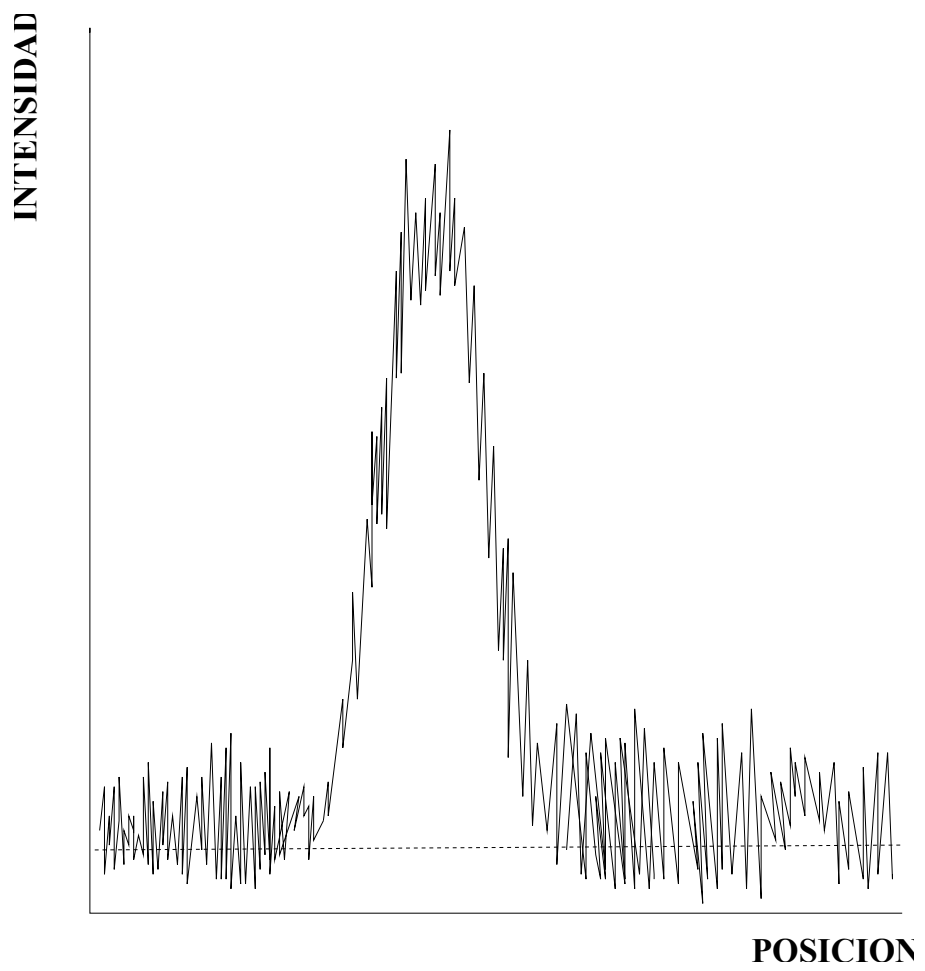

Figura 2.2: Señal típica detectada por un radiotelescopio 
En esta señal se ve claramente la presencia de una radiofuente, caracterizada por un incremento en la intensidad detectada, así como también pequeñas fluctuaciones de intensidad, tanto sobre la radiofuente como sobre la línea de base. Estas fluctuaciones se denominan "ruido de señal", y están presentes todo el tiempo. Debido a que la presencia de este ruido disminuye la calidad de los datos obtenidos, es muy importante mantener el valor del mismo lo más bajo posible, o lo que es lo mismo, mantener la relación señal-ruido $(\mathrm{S} / \mathrm{N})$ lo más alta posible (esta problemática es similar no sólo en radioastronomía sino también en las otras bandas de observación). Por este motivo es necesario identificar las fuentes del ruido. El ruido de un sistema radioastronómico $\left(\Delta T_{r m s}\right.$ o también llamado $\sigma$ ) está dado por:

$$
\Delta T_{r m s}=\frac{C T_{s y s}}{\sqrt{\Delta B t}}
$$

donde $C$ es una constante que depende del modo de observación, $T_{\text {sys }}$ es la temperatura del sistema (en $\mathrm{K}$ ), $\Delta B$ es el ancho de banda de detección (en $\mathrm{Hz}$ ), y $t$ el tiempo de integración (en segundos). El término $T_{\text {sys }}$ tiene varias contribuciones: $T_{\text {sys }}=T_{A}+T_{R}+T_{a t m}+T_{f}+\ldots$, dode $T_{A}$ es la temperatura de antena (explicada anteriormente), $T_{R}$ es la temperatura del receptor, $T_{a t m}$ la producida por la atmósfera (es muy importante en la banda milimétrica) y $T_{f}$ la proveniente de una zona del cielo no vinculada al objeto de interés. Estadísticamente, una fuente requiere para su detección que su relación $\mathrm{S} / \mathrm{N}$ sea mayor o igual que 3 ( $\left.\mathrm{T}>3 \Delta T_{r m s}\right)$. De la fórmula anterior se puede ver que la relación $\mathrm{S} / \mathrm{N}$ se incrementa aumentando el tiempo de observación, aumentando el ancho de banda utilizado o disminuyendo $T_{\text {sys }}$.

El receptor radioastronómico está conformado por un conjunto de amplificadores conectados en serie. Cada uno de estos posee una ganancia de amplificación y es también generador de ruido de lectura. Puede demostrarse que:

$$
T_{R}=T_{1}+\frac{T_{2}}{G_{1}}+\frac{T_{3}}{G_{1} G_{2}}+\frac{T_{4}}{G_{1} G_{2} G_{3}}+\ldots
$$

donde $T_{i}$ y $G_{i}$ representan la temperatura y ganancia del amplificador $i$. Como el receptor radioastronómico es una de las principales fuentes de ruido, es necesario reducir éste al mínimo. De la expresión anterior se ve que el primer amplificador es el más importante, por lo tanto llevando éste a muy bajas temperaturas, se reduce significativamente el ruido de lectura mejorando sensiblemente la relación $\mathrm{S} / \mathrm{N}$.

\subsection{Instrumento utilizado y observaciones re- alizadas}

Las observaciones utilizadas en esta Tesis de Doctorado fueron obtenidas con el radiotelescopio japonés NANTEN de $4 \mathrm{~m}$ de diámetro, que la Univer- 
sidad de Nagoya (Japón) tenía instalado en el Observatorio de Las Campanas (Chile) (ver Figura 2.3). Las observaciones fueron realizadas por el Dr. Marcelo Arnal y el Sr. Federico Bareilles en mayo de 2001. Para una descripción detallada del instrumento ver Ogawa et al. (1990).

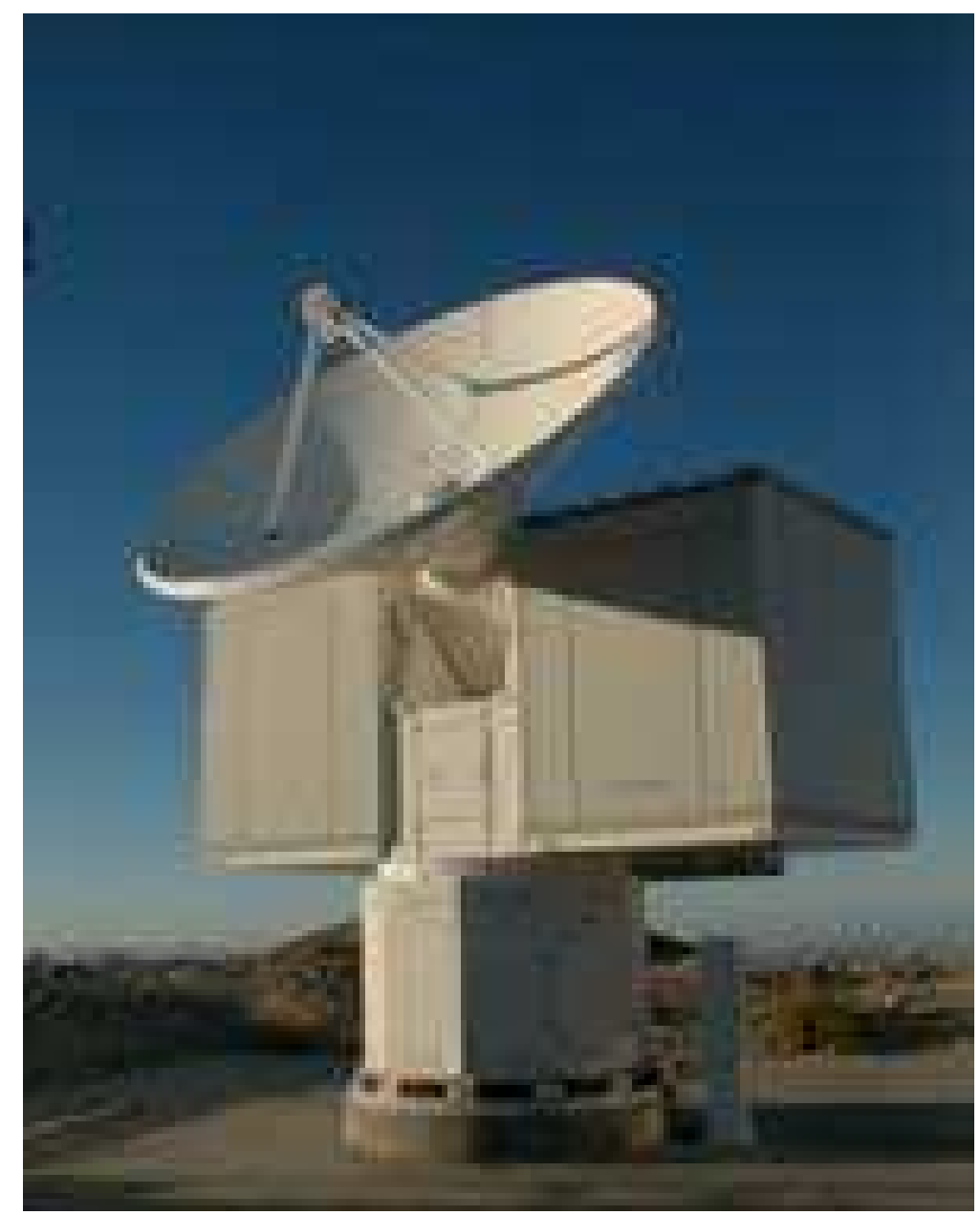

Figura 2.3: Imagen del radiotelescopio NANTEN

Los espectros fueron tomados en la transición rotacional $\mathrm{J}=1 \rightarrow 0(\lambda \sim 2,6$ $\mathrm{mm}, \nu=115 \mathrm{GHz})$ del ${ }^{12} \mathrm{CO}$. El analizador espectral es un espectrómetro acusto-óptico de 2048 canales, con una resolución en velocidad de $0,055 \mathrm{~km} / \mathrm{seg}$ el que otorga una cobertura en velocidad de $113 \mathrm{~km} / \mathrm{seg}$; el mismo fue centrado en una velocidad radial de $-20 \mathrm{~km} / \mathrm{seg}$. A la frecuencia observada la resolución angular del instrumento (HPBW) es de $2^{\prime}, 7$. Para la calibración en intensidad se usó el método denominado "Chopper - Wheel" (Kutner \& Ulich, 1981). La calibración de la escala de temperatura de los perfiles fue llevada a cabo mediante la observación frecuente de las fuentes Orion A (calibradora principal) y $\rho$ Oph-East (calibradora secundaria). Con el fin de pasar de temperatura de 
antena $\left(T_{A}\right)$ a temperatura de brillo $\left(T_{B}\right)$ los perfiles fueron multiplicados por un valor constante de 0,7 , que se obtuvo a partir de las observaciones de los puntos de calibración.

Para cada uno de los objetos estudiados en esta Tesis, se observó una zona cuadrada de $86^{\prime}, 40$ de lado centrada en la estrella con un espaciado de 5', 4 entre los puntos observados. A los efectos de obtener una mejor cobertura espacial, una zona cuadrada interna (también centrada en la estrella a ser estudiada) que tiene $32^{\prime}, 4$ de lado fue observada cada haz $\left(2^{\prime}, 7\right)$. Estas observaciones permitieron obtener para cada objeto dos cubos de datos: el primero de ellos puso en evidencia la estructura molecular a "gran escala", mientras que el segundo permitió estudiar con mayor definición angular las estructuras más cercanas a la estrella. En dos casos, las zonas centrales donde el espaciamiento fue de $2^{\prime}, 7$, las observaciones se complementaron con otra grilla para lograr un espaciamiento en la zona central de $1^{\prime}, 35$ (muestreo completo)

\subsection{Bases de datos utilizadas}

Además de las observaciones de CO ya descriptas, se utilizaron diferentes relevamientos a distintas $\lambda$, de acceso público en la red, como son:

- Continuo de radio a $2400 \mathrm{MHz}$, llevado a cabo con el radiotelescopio de Parkes (Australia). Resolución angular: 10',23 × 10',62. Disponibles en: http : //www.uq.edu.au/ roy

- Continuo de radio en 4,85 GHz, del relevamiento Parkes -MIT-NRAO (PMN) Southern Radio Survey. Resolución angular: 4',2. Disponibles en: http : //www.parkes.atnf.csiro.au/observing/databases/pmn/pmn.html.

- Continuo de radio en $5 \mathrm{GHz}$, llevado a cabo con el radiotelescopio Parkes (Australia). Resolución angular: 4',1. Disponibles en:

http : //www.mpifr - bonn.mpg.de/survey.html

- Continuo de radio en 8,35 y 14,35 GHz, Galactic Plane Survey (GPA) (NRAO/NASA Green Bank Earth Station). Resolución angular (FWHM): $9^{\prime}, 7 \pm 0^{\prime}, 1$ en $8,35 \mathrm{GHz}$ y $6^{\prime}, 6 \pm 0^{\prime}, 2$ en $14,35 \mathrm{GHz}$. Disponibles en:

http : //www.gb.nrao.edu/ glangsto/GPA/ 
- Línea de $\lambda=21 \mathrm{~cm}$ del HI del Southern Galactic Plane Survey (SGPS I) obtenido con Australian Telescope Compact Array (ATCA) + Parkes. Resolución angular: 2'. Disponibles en:

http : //www.atnf.csiro.au/research/HI/sgps/queryForm.html

- Óptico, $H \alpha$ obtenido del relevamineto SuperCOSMOS. Resolución angular: $1^{\prime \prime}$. Disponibles en:

http : //www - wfau.roe.ac.uk/sss/halpha/

- Óptico $H \alpha$ obtenido del relevamiento Southern H-Alpha Sky Survey Atlas (SHASSA). Resolución angular: $\sim 6^{\prime}$. Disponibles en:

http;//www.skyview.gsfc.nasa.gov

- Óptico, obtenido del Digitalized Sky Survey (DSS). Resolución angular: $1^{\prime \prime}, 7$. Disponibles en:

http;//www.skyview.gsfc.nasa.gov

- Infrarrojo (IRAS Sky Survey Atlas) para $\lambda=12$, 25, 60 y $100 \mu \mathrm{m}$. Resolución angular: $\sim 2^{\prime}$. Pertenecientes al archivo de datos infrarrojos de la NASA (IRSA). Disponibles en:

http : //irsa.ipac.caltech.edu

- Infrarrojo del Midcourse Space Experiment (MSX) para $\lambda=8,28,12,13$, 14,65 , y $21,3 \mu \mathrm{m}$. Pertenecientes al archivo de datos infrarrojos de la NASA (IRSA). Resolución angular: 18",3. Disponibles en:

http : //irsa.ipac.caltech.edu/Missions/msx.html

- Biblioteca digital del Sistema de Datos Astrofísicos de la NASA (ADS).

Disponibles en:

http : //adsabs.harvard.edu

- Centro de datos de Estrasburgo (CDS). Disponibles en:

http : //cdsweb.u-strasbg.fr 


\subsection{Bibliografía}

- Kraus J.D., 1966, Radio Astronomy, Eds. McGraw-Hill, New York.

- Kutner, M. L. \& Ulich, B. L., 1981, ApJ, 250, 341

- Ogawa H. S., Mizuno, A., Hoko, H., Ishikawa, H., Fukui, Y., 1990 Int.J. Infrared millimeter Waves, 11, 717 


\section{Capítulo 3}

\section{Tratamiento de los datos y parámetros derivables de las observaciones}

\subsection{Observaciones de ${ }^{12} \mathrm{CO}$}

\subsubsection{Las moléculas de $\mathrm{H}_{2}$ y $\mathrm{CO}$}

Es sabido con certeza que el elemento más abundante en el Universo es el HI (aproximadamente un 90 \% del mismo). La estabilidad del hidrógeno (al igual que la de cualquier otro elemento), depende de las condiciones a las que se encuentra expuesto; es así que éste puede encontrarse en forma ionizada, atómica o molecular, de acuerdo a las condiciones de temperatura y radiación dominantes. Como se mencionó anteriormente, el hidrógeno ionizado puede ser detectado por su emisión de energía en el continuo (radiación free-free o de Brehmsstralung), mientras que el hidrógeno atómico, por su emisión en la línea de $21 \mathrm{~cm}$, ambas en la banda de las radiofrecuencias.

La energía de una molécula (absorbida o emitida), se debe a tres procesos:

- Transiciones electrónicas: involucran energías de unos pocos electrón-volts $(\mathrm{eV})$ y se observan principalmente en la banda óptica y ultravioleta del espectro electromagnético.

- Transiciones vibracionales:se originan por oscilaciones de la molécula respecto de la posición de equilibrio; involucran energías de $\sim 0,01 \mathrm{eV}, \mathrm{y}$ se observan principalmente en la banda IR del espectro electromagnético.

- Transiciones rotacionales: se originan por la rotación de la molécula; involucran energías de $\sim 0,001 \mathrm{eV}$, y se observan en la banda de radio. 
Considerando una molécula diatómica con una configuración electrónica determinada, existe una expresión empírica que reproduce aproximadamente la energía potencial de un estado ligado en dicha molécula. Esta aproximación es conocida como Potencial de Morse, y su expresión matemática es:

$$
V(r)=D\left(1-e^{-a\left(r-r_{e}\right)}\right)^{2}
$$

donde $r_{e}$ representa la separación de equilibrio de los átomos constituyentes de la molécula diatómica y $D$ es la energía de disociación cuyo valor depende de la molécula.

A potenciales vibracionales bajos, el Potencial de Morse se puede aproximar por una parábola, y así las soluciones a la ecuación de Schrödinger conforman un conjunto de niveles de energía vibracional cuantificados, dados por:

$$
E_{v}=(v+1 / 2) \hbar w_{0} \quad \text { con } v=0,1,2,3, \ldots .
$$

siendo $v$ el número cuántico vibracional con $\Delta v= \pm 1 \mathrm{y} w_{0}$ la frecuencia de la transición (ver Figura 3.1).

Para el análisis de los niveles de energía rotacionales, la molécula diatómica es considerada como un 'rotador rígido', es decir como un sistema constituido por dos masas puntuales unidas por una barra rígida. Para este modelo de molécula, la energía de rotación es:

$$
E_{\text {rot }}=1 / 2 I w^{2} \quad \text { con } I=1 / 2 \mu r_{0}^{2}
$$

siendo $I$ el momento de inercia respecto del centro de masas, $r_{0}$ la distancia media entre los átomos, $\mu$ la masa reducida del sistema y $w$ la velocidad angular.

Considerando que el momento angular $L$ tiene la dirección de $w$, la energía de rotación puede ser expresada como

$$
E_{\text {rot }}=L^{2} / 2 I
$$

Resolviendo la ecuación de Schrödinger, se obtiene que la energía rotacional de esta molécula está discretamente cuantificada a valores

$$
E_{J}=\hbar 2 \pi B J(J+1) \quad \operatorname{con} B=\hbar / 4 \pi I \quad \text { y } \mathrm{J}=0,1,2, \ldots
$$

siendo $J$ el número cuántico rotacional con $\Delta J= \pm 1$.

A medida que la energía rotacional aumenta, la molécula se estira, por lo que a la ecuación anterior se le debe agregar un término adicional

$$
E_{J}=\hbar 2 \pi B J(J+1)-\hbar D(J(J+1))^{2}
$$




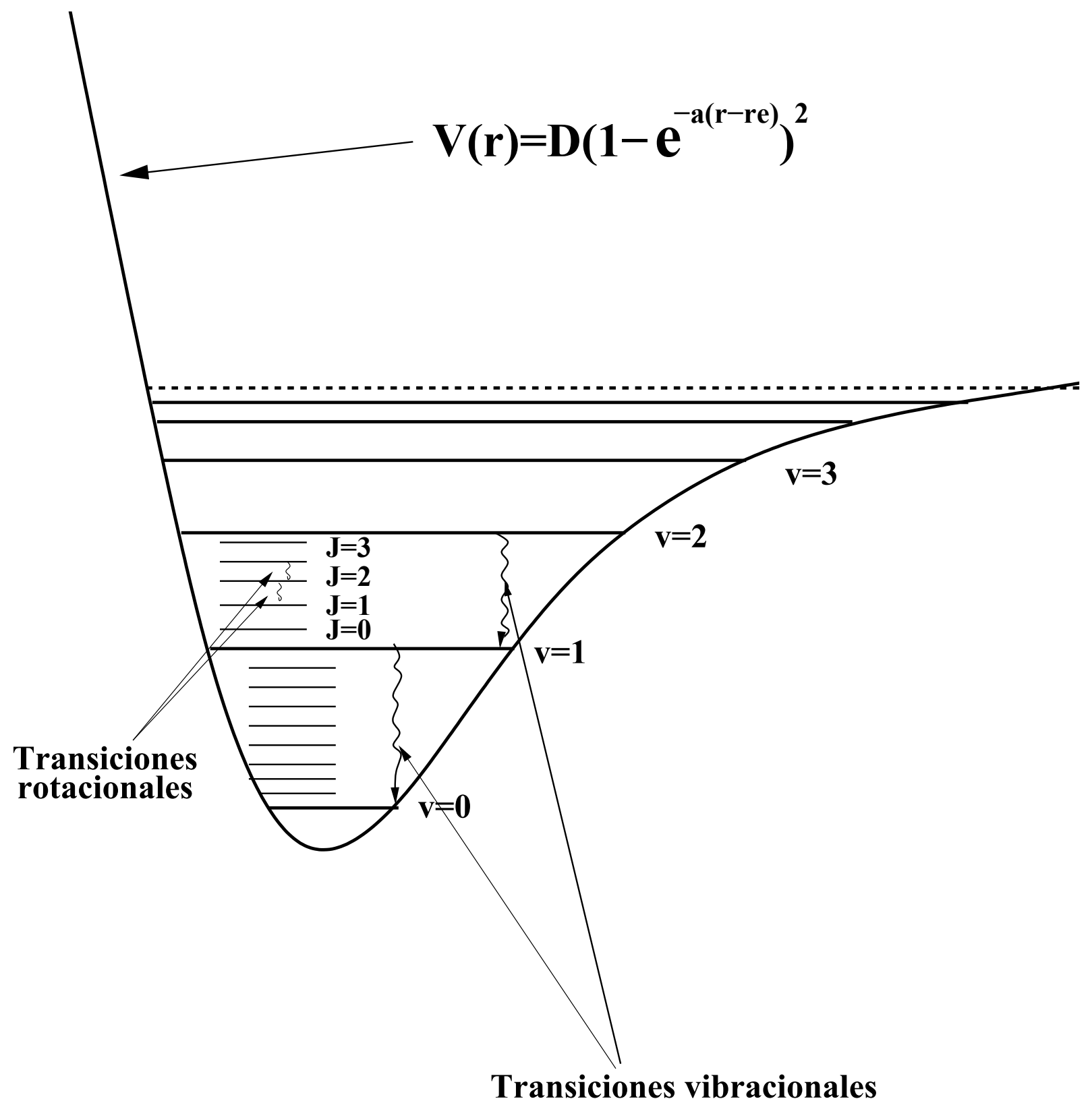

Figura 3.1: Representación esquemática de los niveles vibracionales y rotacionales en una molécula diatómica

En la Figura 3.1 se representan esquemáticamente algunas transiciones rotacionales y vibracionales para una molécula diatómica.

En una nube molecular las temperaturas promedio son muy bajas (típicamente $\sim 10 \mathrm{~K})$ y es así que dentro de éstas predominan las transiciones rotacionales. Cabe destacar que para que las mismas se produzcan, la molécula tiene que tener un "momento dipolar eléctrico permanente", es decir desplazamiento entre el centro de cargas y el centro de masas, condición que el $\mathrm{H}_{2}$ 
claramente no cumple. Es por este motivo que la molécula $\mathrm{H}_{2}$ no se observa directamente a través de transiciones rotacionales, sino en forma indirecta a través de su acción sobre otras moléculas, como el CO. El $\mathrm{H}_{2}$ emite líneas vibracionales claramente detectables, pero éstas se producen por la acción del campo de radiación de estrellas de gran masa cercanas al borde de la nube molecular en las zonas conocidas como PDRs (ver Hollembach \& Tielens, 1997).

La colisión entre las moléculas $\mathrm{H}_{2}$ y $\mathrm{CO}$, provoca un cambio en los estados rotacionales de esta última permitiendo la detección de sus líneas. De esta manera, la molécula de $\mathrm{CO}$ se convierte en una excelente trazadora de la distribución de $\mathrm{H}_{2}$. Es por este motivo que la distribución de gas molecular en el MIE suele estudiarse mediante las líneas de $\mathrm{CO}$ en las transiciones rotacionales $J=1 \rightarrow 0(\nu \sim 115 G H z)$ y $J=2 \rightarrow 1(\nu \sim 230 G H z)$.

\subsubsection{Reducción de los espectros y confección de los cubos de datos}

Los espectros calibrados (ver Capítulo 2) fueron procesados utilizando el paquete de procesamiento de datos CLASS (Continuum and Line Analysis Single-dish Software). Es usual que a cada perfil se le substraiga la línea de base, la cual representa la respuesta en frecuencia del radiómetro. Con este proceso se eliminan de las observaciones los efectos instrumentales. Este proceso debió hacerse individualmente en cada espectro. Luego, las observaciones de $5^{\prime}, 4$ y $2^{\prime}, 7$ de espaciado fueron separadas para obtener sendos cubos de datos con la tarea CUBE. Estos cubos de datos debieron ser convertidos y pasados a extensión FITS (Flexible Image Transport Sistem) por medio del paquete GILDAS

El cubo de datos consiste en un archivo de datos, que contiene el arreglo de perfiles observados dispuestos de acuerdo a un conjunto de tres ejes coordenados. En un cubo de datos estándar, dos de los ejes corresponden a algún sistema de coordenadas astronómicas y el tercero a frecuencia o velocidad radial. En estas condiciones, el cubo es especificado como $(l, b, v)$ donde $l$ y $b$ son latitud y longitud galácticas respectivamente y $v$ es velocidad radial respecto del LSR. Este cubo puede ser rotado, dando lugar a cubos de la forma $(v, l, b)$ o $(v, b, l)$. En la Figura 3.2 se muestra un esquema de un cubo de de datos $(1, b, v)$ y una imagen "posición-posición" que puede extraerse de éste. Las imágenes extraídas de un cubo $(v, l, b)$ o $(v, b, l)$ son llamadas "posición-velocidad", ya que la velocidad estará necesariamente en uno de sus ejes.

Con la tarea CUBE se crearon cubos de datos de $17 p x \times 17 p x \times 2048$ canales (para los datos con $5^{\prime}, 4$ de espaciado), de $13 p x \times 13 p x \times 2048$ canales (para los datos de $2^{\prime}, 7$ de espaciado) y $12 p x \times 12 p x \times 2048$ canales (para los datos tomados con muestreo completo). 


\section{Latitud Galactica}

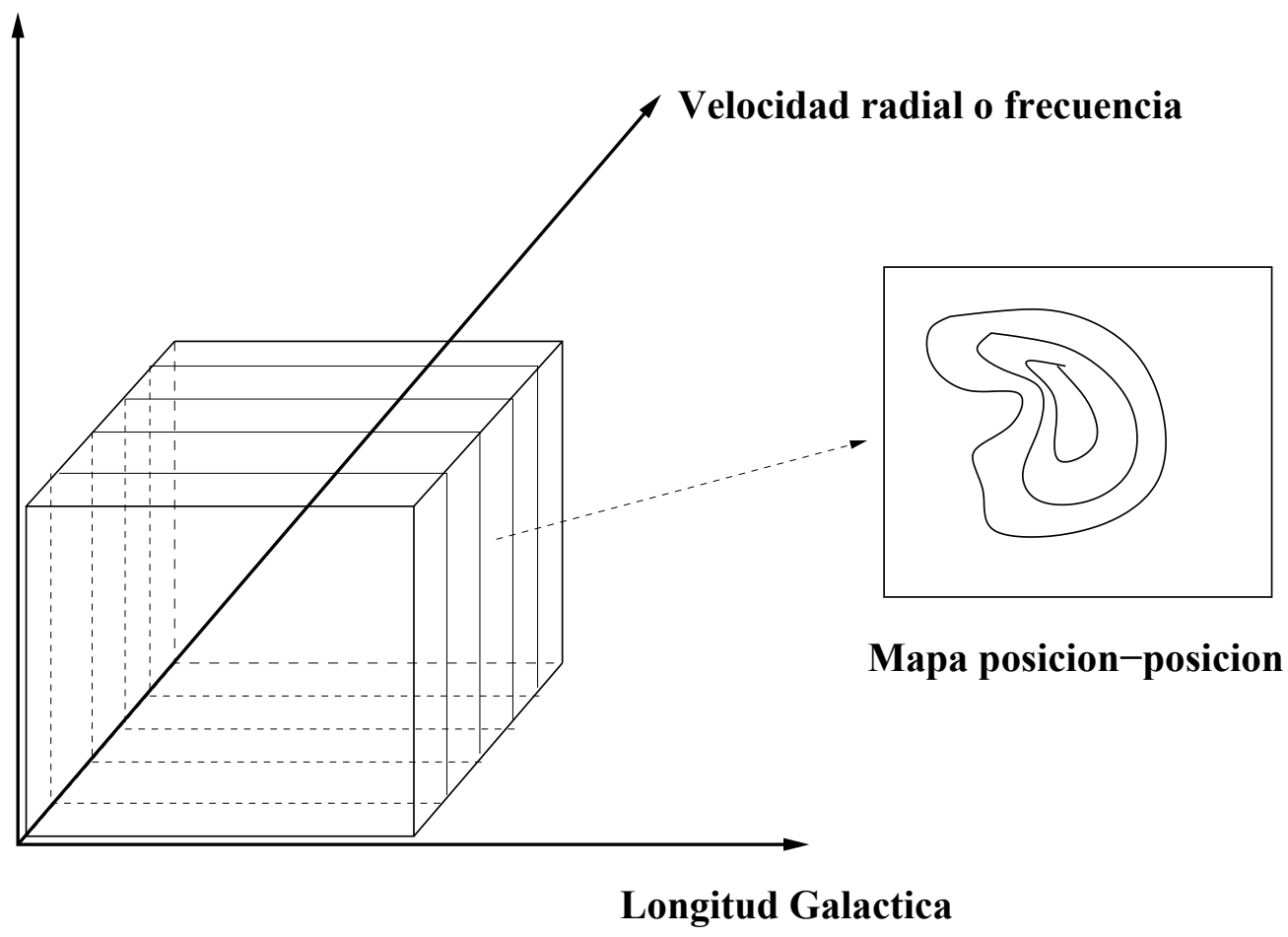

Figura 3.2: Esquema de un cubo de datos $(1, \mathrm{~b}, \mathrm{v})$ y de uno de los planos del mismo.

\subsubsection{Análisis del cubo de datos y detección preliminar de las estructuras moleculares relacionadas con las estrellas WR}

El análisis del cubo de datos, se realizó con el paquete de procesamiento de imágenes AIPS (Astronomical Imaging Processing System). A los efectos de reducir el volumen de datos a ser procesados, se buscó trabajar sólo con los rangos de velocidad del cubo de datos que mostraban la presencia de señal de $\mathrm{CO}\left(\delta_{\text {canal }}\right)$. Para identificar esas imágenes se utilizó la tarea ISPEC, con el fin de obtener en forma general la distribución del CO y un rango preliminar de velocidades entre los que se encuentra la misma. Luego se usó la tarea SUBIM para extraer del cubo de datos dichas imágenes y poder así más tarde trabajar con éstas. La tarea TVSTAT fue utilizada para calcular el ruido cuadrático medio individual $\left(R M S_{\text {ind }}\right)$ en aquellas imágenes que se encontraban libres de señal. Luego se utilizó la tarea LGEOM, con el fin de incrementar el número de pixels en las imágenes pero respetando la información original de las mismas; así pasamos a tener dos cubos de $170 \times 170 \times \delta_{\text {canal }}$ y $130 \times 130 \times \delta_{\text {canal }}$, que son los datos con los que finalmente se trabajó.

Para la identificación de las estructuras moleculares asociadas a las estrellas se utilizó como primer herramienta la tarea GREYS; con esta tarea, la 
distribución de emisión de $\mathrm{CO}$ se despliega como una graduación cromática en tonos de grises o líneas de contornos para algún nivel de intensidad, las cuales facilitan la detección de las estructuras buscadas; esta graduación de grises o líneas de contorno pueden representar temperaturas o bien densidades de columna, las cuales pueden considerarse directamente proporcionales y que son fácilmente transformables entre sí mediante la tarea COMB.

Como se mencionó con anterioridad, las BI podrían detectarse como un mínimo (en la distribución de gas ionizado, atómico o molecular), rodeado por una capa en emisión y eventualmente en expansión. Con estas consideraciones, se analizaron las imágenes de CO con el programa AIPS, buscando dichos mínimos de acuerdo a los siguientes criterios:

1. El mínimo mencionado anteriormente, así como cualquier estructura que lo rodee (en forma total o parcial), debe ser detectado en un número significativo de imágenes consecutivas, es decir, en un rango mínimo de velocidades.

2. La estrella debe estar ubicada dentro o cerca del mínimo de la distribucion de CO.

3. En el caso de existir alguna contrapartida de gas atómico, ionizado o emisión IR, la estructura molecular debe ser exterior a éstas.

4. Haciendo uso de la relación velocidad-distancia obtenida a partir del modelo de rotación galáctica (Brand \& Blitz, 1993), es posible determinar la distancia de una estructura molecular. Esta distancia (llamada distancia cinemática), debería coincidir dentro de los errores, con alguna de las distancias catalogadas para la estrella WR.

En referencia al modelo de rotación galáctica mencionado anteriormente, es importante destacar las limitaciones del mismo. Los errores involucrados en la determinación de la distancia cinemática pueden ser grandes (1 kpc o más). Otro inconveniente es la "ambigüedad en la distancia", por la cual en el primer $\left(0^{\circ} \leq l \leq 90^{\circ}\right)$ y cuarto cuadrante $\left(270^{\circ} \leq l \leq 360^{\circ}\right)$, para cada velocidad, existen dos distancias posibles. Otra fuente de error es el bajo gradiente de velocidades en determinadas direcciones $\left(75^{\circ} \leq l \leq 90^{\circ}\right)$ y $\left(270^{\circ} \leq l\right.$ $\leq 295^{\circ}$ ). Esto ocasiona que un pequeño error en la velocidad implique un gran error en la distancia.

La búsqueda de Burbujas Interestelares y/o cáscaras de material molecular en expansión, fue derivando en la gran mayoría de los casos en el hallazgo de estructuras moleculares cinemáticamente más complejas que requirieron de un análisis diferente al expuesto y en algunos casos muy 
distintos entre sí y que serán discutidos caso por caso, por lo que los métodos y criterios expuestos anteriormente pueden considerarse como un primer criterio de búsqueda

Para la identificación de las estructuras moleculares posiblemente asociadas a las estrellas (o a las regiones HII cercana a ellas), se procedió a hacer una integración de las imágenes en distintos intervalos de velocidad. Las mismas debieron extraerse previamente con la tarea SUBIM. La integración propiamente dicha, se realizó con la tarea SUMIM. Como consecuencia de este promedio se mejora la relación señal/ruido $(\mathrm{S} / \mathrm{N})$, a cambio de perder resolución en velocidad; de esta manera se acentuó la presencia de determinadas componentes que aparecen en un rango amplio de velocidades y por otro lado, pierden intensidad aquellas que lo hacen en un rango más pequeño (fluctuaciones del MIE). En primer lugar, se realizaron imágenes integradas en intervalos de $1 \mathrm{~km} / \mathrm{seg}$ (18 imágenes aproximadamente); el ruido cuadrático medio de estas imágenes integradas, según la teoría de errores está dado por:

$$
R M S_{\text {integrado }}=\frac{R M S_{\text {ind }}}{\sqrt{18}}
$$

Esta teoría indica también, que un valor de temperatura "confiable", es aquel en el cual la relación $(\mathrm{S} / \mathrm{N}) \geq 3$, es así que los valores de temperatura del contorno más bajo, tomado sobre las imágenes integradas, fueron de 3 RMS $(3 \sigma)$ o mayores.

Luego de analizar estas imágenes, y con el fin de mejorar la resolución en velocidad y visualizar mejor dónde empiezan y terminan las estructuras posiblemente vinculadas con las estrellas, se hicieron imágenes integradas cada $0,5 \mathrm{~km} / \mathrm{seg}$ (9 canales aprox.). Finalmente se confeccionó una última imagen, integrando en el rango de velocidad total en el que de acuerdo a nuestros criterios se encontraba la estructura molecular posiblemente vinculada a la estrella o a la región HII asociada a ella.

Como se verá más adelante, estas estructuras fueron estudiadas y comparadas con imágenes de la región a otras longitudes de onda.

\subsubsection{Cálculo de los principales parámetros asociados a las nubes moleculares}

\section{Determinación de densidades de columna}

Se define la densidad de columna de una especie como el número de moléculas o átomos de dicha especie que están contenidos a lo largo de la línea de la visual dentro de un cilindro de área $1 \mathrm{~cm}^{2}$. Matemáticamente, para una especie A: 


$$
N_{A}=\int_{s_{1}}^{s_{2}} n_{A} d s \quad\left[\text { moléculas } \mathrm{cm}^{-2}\right]
$$

donde $n_{A}$ es la densidad numérica de la especie A y $s_{1}$ y $s_{2}$ son las distancias lineales entre las que se encuentra la misma.

Usualmente, la determinación de la densidad de columna de hidrógeno molecular $\left(N_{H_{2}}\right)$ requiere el uso de dos líneas del CO: la línea $J=1 \rightarrow 0$ del ${ }^{12} \mathrm{CO}$ (ópticamente gruesa) y la línea $J=1 \rightarrow 0$ del ${ }^{13} \mathrm{CO}$ (ópticamente delgada); haciendo luego uso de la suposición de que la temperatura de excitación del ${ }^{12} \mathrm{CO}$ es igual a la del ${ }^{13} \mathrm{CO}$ puede inferirse el valor de la densidad de columna del ${ }^{12} \mathrm{CO}\left(\mathrm{N}_{{ }^{12} \mathrm{CO}}\right)$, que mediante relaciones de abundancia entre éste y el $\mathrm{H}_{2}$ permite obtener $N_{H_{2}}$.

Para esta Tesis de Doctorado, sólo se contó con observaciones de la línea $J=1 \rightarrow 0$ del ${ }^{12} \mathrm{CO}$, por lo que el método brevemente descripto anteriormente no pudo ser empleado. En su lugar se hizo uso de la relación existente entre la densidad de columna del $\mathrm{H}_{2}$ y la intensidad integrada (área debajo del perfil) de la línea de $\mathrm{CO}\left(I_{C O}\right), N_{H_{2}} / I_{C O}$, que es frecuentemente usada para determinar la distribución de $\mathrm{H}_{2}$ en la galaxia. Probablemente esta relación no sea la misma para todas las nubes moleculares individuales, pero aun así, resulta muy útil para la determinación de la masa de $\mathrm{H}_{2}$. Este valor fue determinado por varios autores: Gordon \& Burton (1976); Solomon \& Sanders (1980); Black \& Wilner (1984); Sanders et al. (1984); Bloemen et al. (1986). En este trabajo se utilizará el valor obtenido por Diegel et al (1996). Utilizando observaciones de rayos $\gamma(>70 \mathrm{eV})$ hacia las nubes moleculares en Cepheus Flare, estos autores encontraron que:

$$
\left.N_{\mathrm{H}_{2}} / I_{C O}=(1,9 \pm 0,3) \times 10^{20} \quad \text { [moléculas } \mathrm{cm}^{-2} \mathrm{~K}^{-1} \mathrm{~km}^{-1} \mathrm{seg}\right]
$$

Este valor se tomará como un promedio global en toda la galaxia y no está afectado por las distintas condiciones de excitación, abundancias y profundidades ópticas locales. Cabe considerar que los valores de $N_{H_{2}} / W_{C O}$ obtenidos en esta clase de estudios conforman un límite superior, debido a la posible existencia de fuentes puntuales de rayos $\gamma$ que no han sido tenidos en cuenta para los cálculos.

De esta manera:

$$
\left.N_{H_{2}}=1,9 \times 10^{20} \int_{v_{1}}^{v_{2}} T_{C O}(v) d v \quad \text { [moléculas } \mathrm{cm}^{-2}\right]
$$

donde la integral del segundo miembro, representa el área debajo del perfil entre los valores de velocidad $v_{1}$ y $v_{2}$ entre los que se encuentra la estructura. Para calcularlo numéricamente la integral se reemplaza por: 


$$
N_{\mathrm{H}_{2}}=1,9 \times 10^{20} \bar{T}_{C O} \Delta v \quad \text { [moléculas } \mathrm{cm}^{-2} \text { ] }
$$

donde $\bar{T}_{C O}$ es el valor promedio de temperatura de la región y $\Delta v$ la extensión en velocidad de la estructura. El valor $\bar{T}_{C O}$ es calculado sobre la imagen promediada en el rango total de velocidad utilizando la tarea TVSTAT de AIPS y considerando como material perteneciente a la estructura molecular a aquél que se encuentra comprendido dentro del primer nivel de temperatura que circunscribe a la estructura, adoptando este nivel como el correspondiente a $3 \sigma$ (o superior). Como se verá en los próximos capítulos, la determinación del primer nivel de temperatura en regiones que son cinemáticamente complejas (reg HII y/o regiones de formación estelar) requiere un análisis más exhaustivo.

\section{Determinación de la masa}

Obtenida la densidad de columna del $\mathrm{H}_{2}$, la masa de $\mathrm{H}_{2}$ puede calcularse directamente por medio de la siguiente relación:

$$
M=\mu m_{H} N_{H_{2}} A_{C O} \times\left(2 \times 10^{33} g r\right)^{-1} \quad\left[M_{\odot}\right]
$$

siendo $\mu=2,76$ el peso molecular medio suponiendo una abundancia de Helio del $25 \%, A_{C O}=\Omega_{C O} \times d^{2}, d$ la distancia y $\Omega_{C O}$ el ángulo sólido de la estructura de CO, el cual se calcula a partir de la cantidad de pixels ocupados por ésta (TVSTAT) y el tamaño angular de los mismos. Para el cálculo de la densidad volumétrica debe suponerse alguna forma geométrica para la nube.

Es importante tener en cuenta los errores en el cálculo de la masa. Estos se producen debido a la incertidumbre en algunos de los parámetros utilizados. En este caso las principales fuentes de error son:

- La relación entre $N_{H_{2}}$ y $W_{C O}$, cuyo error fue cuantificado por Diegel et al. (1996) (ver arriba).

- La incerteza en las distancias espectrofotométricas estelares utilizadas, algunas de las cuales pueden llegar al 40 \% (van der Hucht, 2001).

Como puede verse en la Ecuación 3.5, la dependencia de $M$ con la distancia es $d^{2}$ por lo que, si el error en la distancia es grande, el error en $N_{H_{2}}$ se hace despreciable. Haciendo una simple propagación de errores, puede verse que un error del $50 \%$ en la distancia introduce un error del $100 \%$ en el cálculo de las masas, por lo que las masas calculadas pueden diferir notablemente del valor medio. Estas diferencias se trasladan también a las densidades volumétricas. 


\section{Determinación de las velocidades de expansión y sistémica}

A lo largo de esta Tesis, se encontrarán diversos tipos estructuras moleculares, algunas de ellas comprendidas en un amplio rango de velocidades.

Siendo $v_{1}$ y $v_{2}$ las velocidades máximas y mínimas respecto del LSR entre las que se encuentra la estructura de $\mathrm{CO}$, la extensión en velocidad $\Delta v=v_{2}-v_{1}$, corresponde al rango de velocidad en el que dicha estructura está definida; en el caso de una cáscara o estructura expandiéndose, la velocidad de expansión se calculó simplemente como $\Delta v / 2$.

La velocidad sistémica está aproximadamente definida por $v_{1}+\Delta v / 2$, y representa la velocidad con la que la estructura se acerca o aleja del observador. En el caso de una BI o cáscara en expansión corresponde a aquella en la que la cavidad se nota más claramente y existe un mayor gradiente de temperatura.

\section{Determinación de las dimensiones}

Dada la morfología irregular de algunas de las estructuras anulares o semianulares encontradas, en los parámetros geométricos calculados interviene un cierto factor de subjetividad; para obtener el radio de las mismas se utilizó la tarea IRING del paquete AIPS. Esta tarea realiza integraciones en anillos concéntricos alrededor de un centro a elección (en este caso es el centro geométrico que se determina con anterioridad), de esta manera se obtiene un gráfico de $\bar{T}$ (temperatura promedio) vs. distancia angular, lo que permite (suponiendo una distribución gaussiana de temperaturas) el cálculo del radio de las estructuras, proyectado en el plano del cielo. Luego, adoptando las distancias a las estructuras se calcularon los radios lineales de las mismas.

\subsection{Observaciones de $\mathrm{HI}$}

La línea de $\lambda=21 \mathrm{~cm}(\nu=1420,40576 \mathrm{MHz})$ se origina debido a una transición entre dos estados de la estructura hiperfina del átomo de HI. Por ser una línea espectral, al igual que en el caso del $\mathrm{CO}$, la base de datos con la que se cuenta consiste generalmente en un cubo de datos.

La detección de estructuras de HI posiblemente asociadas a las estrellas en estudio así como a las regiones HII relacionadas con ellas, es relativamente más complicada que en el caso del CO, ya que el átomo de HI es mucho más abundante y se encuentra distribuído más uniformemente en la galaxia.

Los criterios utilizados para identificar BI alrededor de estrellas WR, son similares a los explicados para el caso de $\mathrm{CO}$, es decir, se espera que exista un mínimo en la distribución de HI alrededor de la estrella, rodeado por una capa en emisión y eventualmente en expansión. 


\section{Determinación de la densidad de columna y la masa}

Como ya se vio anteriormente, la densidad de columna de HI es

$$
N_{H I}=\int_{0}^{\infty} n_{H I} d s
$$

Resolviendo la ecuación de Boltzman para los niveles 0 y 1 de la estructura hiperfina del HI y considerando el coeficiente de absorción del HI, puede obtenerse

$$
\int_{-\infty}^{\infty} \tau(\nu) d \nu=5,4873 \times 10^{-19} \quad\left(T_{S}\right)^{-1} \quad \int_{0}^{\infty} n_{H I} d s
$$

donde $\tau(\nu)$ es la profundidad óptica de la línea y $T_{S}$ es la temperatura de excitación de la línea (temperatura de spin). Reemplazando esta ecuación en la primera

$$
N_{H I}\left(\mathrm{~cm}^{-2}\right)=1,823 \times 10^{18} T_{S}(K) \int_{-\infty}^{\infty} \tau(\nu) d \nu
$$

Suponiendo una nube de HI con $T_{S}, \tau(\nu)$ y que no tiene una radiofuente de continuo por detrás, la resolución de la ecuación de transporte resulta

$$
T_{b}=T_{S}\left(1-e^{-\tau}\right)
$$

siendo $T_{b}$ la temperatura de brillo. En el caso de que la nube de HI sea transparente (ópticamente delgada), entonces $\tau<<1$ y así la expresión de la $T_{b}$ puede aproximarse por

$$
T_{b}=T_{S} \quad \tau
$$

así volviendo a la densidad de columna

$$
N_{H I}\left(\mathrm{~cm}^{-2}\right)=1,823 \times 10^{18} \quad \int_{-\infty}^{\infty} T_{b}(\nu) d \nu
$$

La integral del segundo término representa al área debajo de la línea de HI y puede calcularse en forma geométrica o gráfica (AIPS).

El cálculo de la masa se realiza a partir de $N_{H I}$ y es similar al caso del CO, es decir, multiplicando la densidad de columna por el área subtendida por la estructura de HI y por la masa del átomo de H. De igual manera que en el caso del CO, esta masa depende del cuadrado de la distancia, por lo que los errores introducidos en el cálculo pueden llegar a ser altos. 


\subsection{Observaciones infrarrojas}

A partir de las densidades de flujo medidas en 12, 25, 60 y $100 \mu \mathrm{m}$ del relevamiento IRAS es posible derivar varios parámetros de interés astrofísico:

Flujo y luminosidad infrarroja total

Midiendo los flujos en las cuatro bandas IRIS, es posible determinar los flujos y luminosidades totales en el IR (Tokunaga 2000)

$$
F_{I R}\left(W m^{-2}\right)=1,0 \times 10^{-14}\left(20,653 F_{12}+7,538 F_{25}+4,578 F_{60}+1,762 F_{100}\right)(3.7)
$$

donde $F_{12}, F_{25}, F_{60}$ y $F_{100}$ corresponden a las densidades de flujo en 12, 25, 60 y $100 \mu \mathrm{m}$, respectivamente, en unidades de Jansky. Así, la luminosidad IR total será

$$
L_{I R}\left(L_{\odot}\right)=3,112 \times 10^{7} d^{2} F_{I R}
$$

siendo $d$ la distancia en pc.

A diferencia de las líneas espectrales, la emisión en el continuo (IR o continuo de radio) puede estar contaminada con emisión de fondo galáctico la cual puede originar un error por exceso en las mediciones del flujo. Es por este motivo que la emisión de fondo debe removerse con anterioridad. Con este fin se utiliza la tarea IMFLT del paquete AIPS. Esta tarea 'ajusta' un fondo de acuerdo a mediciones en pequeños sectores del cielo que luego son interpolados y este cielo es luego sustraído de la imagen.

\section{Temperatura y masa de polvo}

Como fuera mencionado anteriormente, la radiación UV emitida por las estrellas es absorbida por los granos de polvo inmersos en las nubes moleculares aledañas y reemitido en el IR, fundamentalmente en el IR lejano (FIR). Esta emisión puede ser descripta por una distribución Planckiana multiplicada por un factor de 'emisividad' proporcional a $\nu^{m}$ donde $m$ se denomina índice de emisividad y su valor está comprendido entre 1 y 2 , dependiendo del material que conforma el grano de polvo y de la morfología del mismo (Scoville \& Kwan, 1976). Así la emisión de un grano de polvo está dada por

$$
B\left(T_{d}\right)=\nu^{m} \times 2 h \frac{\nu^{3}}{c^{2}} \frac{1}{e^{h \nu / k T_{d}}-1}
$$

con $T_{d}$ la temperatura del polvo.Puede verse que si se cuenta con los valores de densidad de flujo a dos frecuencias, $T_{d}$ puede ser obtenida ya que haciendo el cociente de flujos 


$$
\frac{S_{\nu_{1}}}{S_{\nu_{2}}}=\left(\frac{\nu_{1}}{\nu_{2}}\right)^{m+3} \frac{e^{h \nu_{2} / k T_{d}}-1}{e^{h \nu_{1} / k T_{d}}-1}
$$

Por lo general para el cálculo de $T_{d}$ en una nebulosa suele usarse $\nu_{1}=5000$ $\mathrm{GHz}(\lambda=60 \mu \mathrm{m})$ y $\nu_{2}=3000 \mathrm{GHz}(\lambda=100 \mu \mathrm{m})$ ya que a estas frecuencias las densidades de flujo tienen poca contaminación de líneas nebulares.

Teniendo el valor de $T_{d}$ es posible calcular la masa del polvo

$$
M_{d}\left(M_{\odot}\right)=4,81 \times 10^{-12} F_{100} d^{2}\left(e^{143,88 / T_{d}}-1\right)
$$

donde $F_{100}$ es la densidad de flujo en $100 \mu \mathrm{m}$.

\subsection{Observaciones en continuo de radio}

Como se mencionó en el Capítulo 1, las regiones HII ionizadas por el campo radiativo de las estrellas cercanas, emiten radiación originada por procesos libre-libre y que es detactada en el continuo de radio.

Considerando una región HII con una profundidad óptica para la emisión de contiuno $\tau_{c}$, con una extensión en la línea de la visual $l$, usando la aproximación de Rayleigh-Jeans (bajas frecuencias), y no habiendo una fuente de continuo de fondo, de la solución de la ecuación de transporte para esta región HII se puede obtener la expresión del flujo observado para la misma

$$
S_{\text {obs }}=S_{\text {fuente }}\left(1-e^{-\tau_{c}}\right)
$$

siendo $S_{\text {obs }}=\left(2 \mathrm{kT}_{B} / \lambda^{2}\right) \Omega_{\text {fuente }}$ y $S_{\text {fuente }}=\left(2 \mathrm{kT} T_{e} / \lambda^{2}\right) \Omega_{\text {fuente }}$, con $T_{B}$ y $T_{e}$ las temperaturas de brillo y electrónicas de la región HII respectivamente y $\Omega_{\text {fuente }}$ el ángulo sólido subtendido por la fuente. Considerando:

- $\tau_{c}>>1$ (proceso ópticamente grueso)

$\rightarrow S_{\text {obs }}=S_{\text {fuente }}=2 \mathrm{k} \mathrm{T}_{e}(\nu / c)^{2} \Omega_{\text {fuente }}$

- $\tau_{c}<<1$ (proceso ópticamente delgado)

$\rightarrow S_{\text {obs }}=S_{\text {fuente }} \tau_{c}=2 \mathrm{k} \mathrm{T}(\nu / c)^{2} \Omega_{\text {fuente }} \tau_{c}$

Utilizando para $\tau_{c}$ la aproximación de Altenhoff et al. (1960)

$$
\tau_{c}=8,235 \times 10^{-2} T_{e}^{-1,35} \nu^{-2,1} E M
$$


siendo EM la medida de emisión dada por

$E M=\int_{0}^{l} n^{2}{ }_{e} d l$ con $\mathrm{n}_{e}$ la densidad electrónica de la región HII (con puro $\mathrm{H}$ )

el flujo observado queda expresado por

$$
S_{o b s}=C t e \quad T_{e}^{-0,35} \nu^{-0,1}
$$

es decir que el flujo observado en el contiuno de radio para una región HII es de la forma $S_{o b s} \propto \nu^{\alpha}$, donde $\alpha$ es el índice espectral, que toma el valor $\sim 2$ para $\tau_{c}>>1$ (bajas frecuencias) y $\sim-0,1$ para $\tau_{c}<<1$ (altas frecuencias). Emisiones de este tipo son conocidas como térmicas y son típicas en regiones HII. La frecuencia para la cual el flujo es el mayor es conocida como frecuencia de turn-over $\left(\nu_{T O}\right)$ y es la frecuencia en la que la curva cambia la pendiente. Las emisiones no térmicas poseen un $\alpha \sim-0,5 /-0,7$ y son espectros típicos en remanentes de supernovas. En la Figura 3.3 se puede ver un espectro típico de una región térmica y una no térmica.

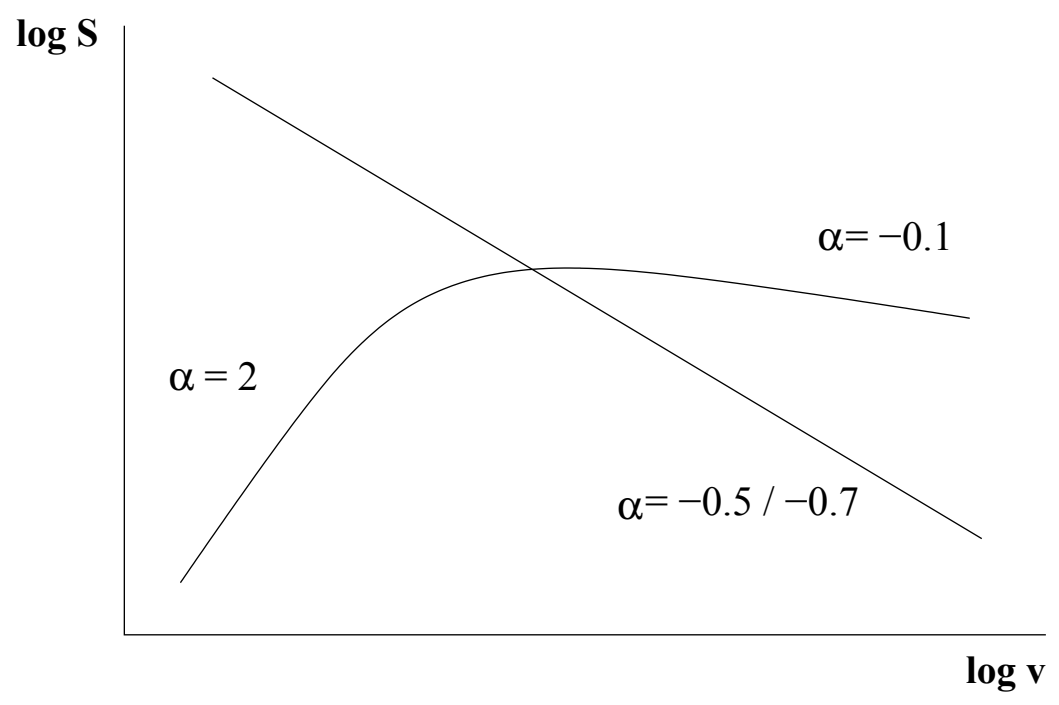

Figura 3.3: Espectros típicos de una fuente térmica y una no térmica.

Por lo tanto, la obtención del valor de $\alpha$ es muy importante para entender la naturaleza del proceso de emisión que se observa. La obtención de $\alpha$ puede hacerse midiendo el flujo en el continuo en dos frecuencias distintas por encima de $\nu_{T O} S_{1}$ y $S_{2}$ así:

$$
\alpha=\frac{\log \left(S_{1} / S_{2}\right)}{\log \left(\nu_{1} / \nu_{2}\right)}
$$


Teniendo mediciones de flujos en más de dos frecuencias es posible una determinación más exacta de $\alpha$ a partir del gráfico $\log (\mathrm{S})$ vs. $\log (\nu)$ ya que la recta determinada por tres puntos o más posee una menor incerteza que una determinada con sólo dos puntos.

Para la determinación de otros parámetros físicos de una región HII tales como la masa de gas ionizado $\left(M_{i o n}\right)$, la densidad electrónica $\left(n_{e}\right)$ y la medida de emisión máxima $\left(E M_{\max }\right)$, es necesario usar algunos modelos geométricos sencillos para la misma (para más detalles de este procedimiento ver Mezger \& Henderson, 1967). Los modelos considerados son:

- Modelo I: Densidad electrónica constante $\mathrm{n}_{e}$ dentro de una esfera de diámetro aparente $\theta_{\text {esf }}$ y 0 fuera de ésta.

- Modelo II: Densidad electrónica constante $\mathrm{n}_{e}$ dentro de un cilindro de diámetro aparente $\theta_{c i l}$ cuyo eje de simetría es paralelo al eje de la visual y con largo igual al diámetro, y 0 fuera de éste.

- Modelo III: Distribución exponencial decreciente con densidad máxima $\mathrm{N}_{0}$ y ancho a potencia mitad $\theta_{G}$

Con estos modelos pueden obtenerse:

$$
\begin{gathered}
\left(\frac{n_{e}}{c m^{-3}}\right)=u_{1} 6,884 \times 10^{2}\left(\frac{T_{e}}{10^{4} K}\right)^{0,175}\left(\frac{S_{5 G H z}}{J y}\right)^{0,5}\left(\frac{D}{k p c}\right)^{-0,5}\left(\frac{\theta_{G}}{\text { minarc }}\right)^{-1,5}( \\
\left(\frac{M_{\text {ion }}}{M_{\odot}}\right)=u_{2} 0,419\left(\frac{T_{e}}{10^{4} K}\right)^{0,175}\left(\frac{S_{5 G H z}}{J y}\right)^{0,5}\left(\frac{D}{k p c}\right)^{2,5}\left(\frac{\theta_{G}}{\text { min arc }}\right)^{1,5} \\
E M_{\max }=u_{3} 0,291\left(\frac{D}{k p c}\right)\left(\frac{\theta_{G}}{\min \text { arc }}\right)\left(\frac{n_{e}}{c m^{-3}}\right)^{2}
\end{gathered}
$$

siendo $S_{5 G H z}$ la densidad de flujo en $5 \mathrm{GHz}$, D la distancia, y $\theta_{G}$ el ancho a potencia mitad aparente de la fuente. Los valores $u_{1}, u_{2}$ y $u_{3}$ fueron tabulados por Mezger \& Henderson (1967) y están dados en la Tabla 3.1

En una región HII pueden existir diferencias en la densidad que pueden afectar el cálculo de las cantidades mencionadas anteriormente. Una vez elegido el modelo, es necesario estimar qué fracción del volumen está ocupado en realidad por el gas ionizado. Esta fracción puede ser estimada con el factor de llenado $f$, el cual se define como la fracción del volumen total ocupado por el plasma referido al volumen total en el que éste se distribuye. A modo de ejemplo, si se está estudiando una nebulosa que presenta una morfología 
Tabla 3.1:

\begin{tabular}{c|c|c|c}
\hline & $u_{1}$ & $u_{2}$ & $u_{3}$ \\
\hline \hline Modelo I & 0.775 & 1.291 & 1.471 \\
\hline Modelo II & 0.857 & 1.167 & 1.201 \\
\hline Modelo III & 0.911 & 3.106 & 1.065 \\
\hline
\end{tabular}

anular, y para el cálculo de su masa ionizada se utilizó el Modelo I (esfera de densidad constante), entonces $f$ puede calcularse como:

$$
f=\frac{4 / 3 \pi\left(R_{e x t}^{3}-R_{i n t}^{3}\right)}{4 / 3 \pi R_{e x t}{ }^{3}}
$$

siendo $R_{\text {ext }}$ y $R_{\text {int }}$ los radios exteriores e interiores de la nebulosa anillo, respectivamente. El valor de $f$ puede ser calculado también multiplicando por un factor que represente el porcentaje de ocupación del anillo por el plasma. De esta manera, $M_{i o n}, n_{e}$ y $E M_{\text {max }}$ se ven modificados de la siguiente forma :

$$
M_{\text {ion }}^{\prime}=f^{1 / 2} M_{i o n} \quad n_{e}^{\prime}=f^{-1 / 2} n_{e} \quad E M_{\max }^{\prime}=f^{1 / 3} E M_{\max }
$$

$M_{i o n}^{\prime}, n_{e}^{\prime}$ y $E M_{\text {max }}^{\prime}$ son los nuevos valores, obtenidos al considerar una morfología más aproximada a la real. Como puede observarse $n_{e}^{\prime}>n_{e}$. Los valores de densidades electrónicas en nebulosas anillo y regiones HII obtenidos por medio de la utilización de cociente de líneas en el espectro óptico, son notablemente más altos que los obtenidos por medio del método explicado anteriormente. Esta diferencia puede ser entendida en término de incrementos localizados de densidad dentro de la nebulosa. Por lo tanto la determinación de $n_{e}$ por medio de la utilización de líneas ópticas ofrece una alternativa al cálculo de $f$ como:

$$
f=\left(\frac{n_{e}}{n_{e}^{\prime}}\right)^{0,5}
$$

siendo $n_{e}$ el valor de la densidad electrónica calculado utilizando la Ecuación 3.13 y $n_{e}^{\prime}$ es el valor obtenido por cociente de líneas ópticas. Esto significa que $f$ podría encontarse entre un rango de valores dados por las Ecuaciones 3.13 y 3.17

Otra cantidad que es posible medir en una región HII es el número de fotones ionizantes en el continuo de Lyman requeridos para mantener la ionización $\left(N_{L y c}\right)$. Este parámetro puede ser calculado utilizando la ecuación obtenida por Simpson \& Rubin (1990):

$$
N_{\text {Lyc }}=5,25 \times 10^{48} T_{e}^{-0,45} S_{5 G H z} d^{2}
$$

La obtención de este valor permite estimar (suponiendo un tipo espectral) la cantidad de estrellas que pueden estar ionizando la región HII. 


\subsection{Bibliografía}

1. Altenhoff W, Mezger, P.G., Wender H. , Westerhout G. 1960, Veröff. Sternwarte, Bonn, No 59, 48

2. Black, J. H., Willner, S. P., 1984, ApJ, 279, 673

3. Bloemen, J. B. G. M.; Strong, A. W.; Mayer-Hasselwander, H. A.; Blitz, L.; Cohen, R. S.; Dame, T. M.; Grabelsky, D. A.; Thaddeus, P.; Hermsen, W.; Lebrun, F. 1986, A\&A, 154, 25

4. Brand, J. \& Blitz, L., 1993, A\&A, 275, 67

5. Digel, Seth W.; Lyder, David A.; Philbrick, Amy J.; Puche, Daniel; Thaddeus, Patrick, 1996, ApJ, 458, 561D

6. Gordon, M. A. \& Burton, W. B., 1976, ApJ, 208, 346

7. Hollembach, D. J. \& Tielens, A. G. G., 1997, ARAA, 35, 179

8. Mezger, P. G.; Henderson, A. P., 1967, ApJ, 147, 471M

9. Sanders, D. B., Solomon, P. M. \& scoville, N. Z., 1984, ApJ, 276, 182(SSS)

10. Scoville, N. Z.; Kwan, J., 1976, ApJ, 206, 718S

11. Simpson, J. P.; Rubin, R. H., 1990, ApJ, 354, 165S

12. Solomon, P. M. \& Sanders, D. B., 1980, gmcg.work, 41S

13. Tokunaga, A.T., en Allen's Astrophysical Quantities", Cuarta Edición.

14. van der Hucht, K. A., 2001, NAR, 45, 135 


\section{Capítulo 4}

\section{El gas molecular asociado a WR 16}

\subsection{Descripción de la zona y antecedentes}

Las nebulosas anillo ópticas múltiples, son objetos que se han encontrado alrededor de algunas estrellas WR. Estas nebulosas son anillos concéntricos de distintos tamaños que pueden ser vistos en una misma línea espectral o en líneas distintas; comunmente las líneas espectrales usadas para estos estudios son las líneas de $\mathrm{H} \alpha(\lambda=6563 \AA)$ y de OiII $(\lambda=5007 \AA)$. La existencia de tales objetos puede ser explicada en el marco del modelo denominado The three wind model (García Segura \& Mac Low, 1995; ver Capítulo 1, Sección 3). En este modelo la evolución de una estrella $\mathrm{O}$ origina una cavidad en el MIE que es llenada por el viento denso y lento que tiene lugar durante la fase de gigante roja (RSG), material que es luego alcanzado por el viento rápido y menos denso de la fase WR. Una de las primeras búsquedas sistemáticas de nebulosas anillos múltiples en la banda óptica fue hecha por Marston (1995). En dicho trabajo se detectó la presencia de anillos múltiples alrededor de las estrellas WR 16, WR 30, WR 40 y WR 85. En la Figura 4.1 se muestra la emisión en la línea $\mathrm{H} \alpha$ observada en los alrededores de la estrella WR 16 (HD 86161) obtenida del relevamiento SuperCOSMOS. En dicha imagen puede apreciarse la estructura de múltiples anillos encontrada por Marston (1995). El anillo más interno bordea casi completamente a la estrella a una distancia angular de $\sim 4^{\prime}$, siendo más intenso en la región norte y noroeste y menos notable en la región sureste. La emisión de este anillo se torna más difusa a medida que se acerca a la estrella. Existe un segundo anillo, con un radio de $\sim 8^{\prime}$ y que posee un filamento muy intenso que se extiende desde $(l, b)=\left(281^{\circ},-02^{\circ} 22^{\prime}\right)$ hasta $(l, b)=\left(280^{\circ} 57^{\prime},-02^{\circ} 36^{\prime}\right)$. La emisión de este anillo también se debilita a medida que disminuye la distancia angular a la estrella. Existe otro filamento que se extiende desde $(l, b)=\left(280^{\circ} 55^{\prime},-02^{\circ} 22^{\prime}\right)$ hasta $(l, b)=\left(280^{\circ} 50^{\prime},-02^{\circ} 35^{\prime}\right.$ y que podría ser parte de un tercer anillo que rodea a la estrella WR 16. 


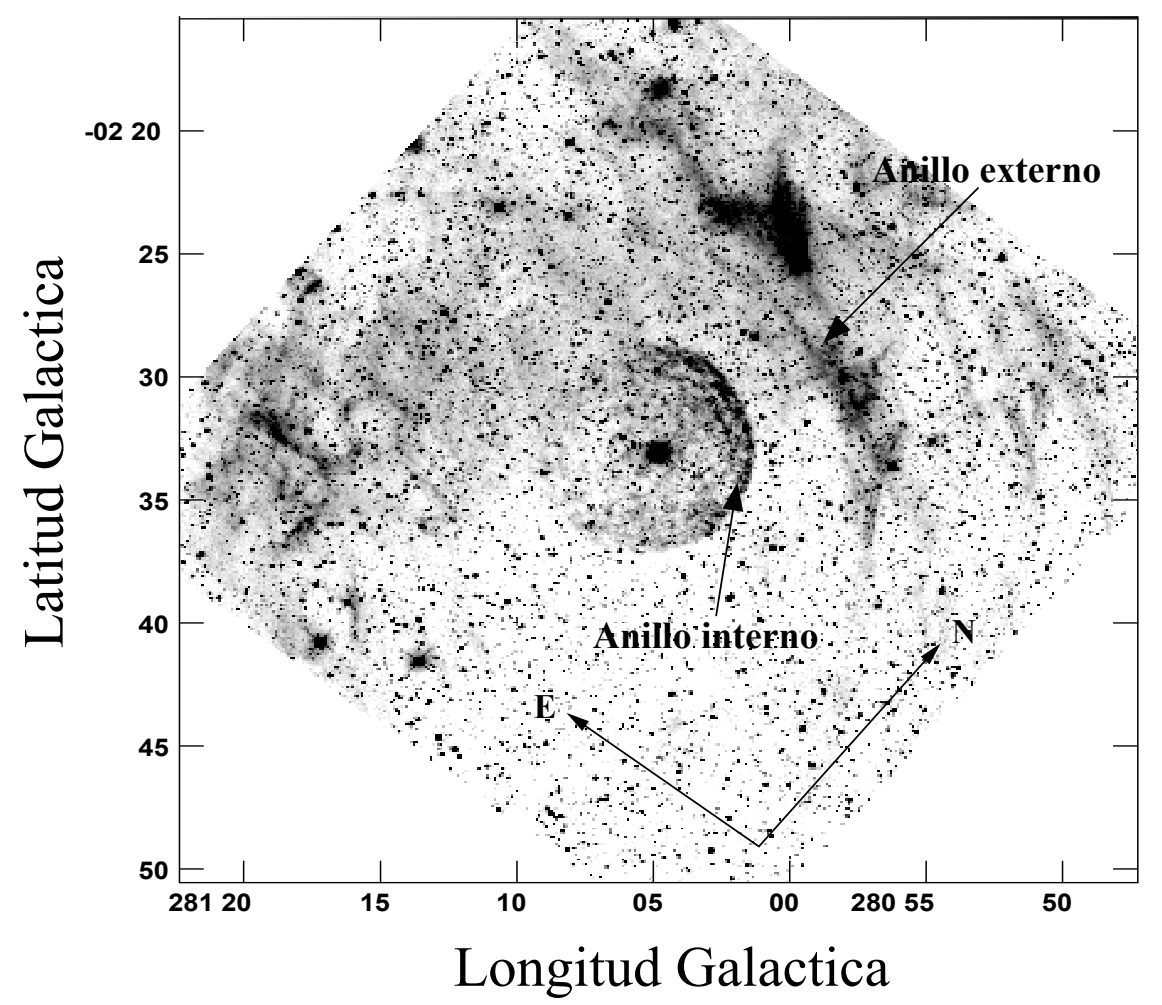

Figura 4.1: Imagen $\mathrm{H} \alpha$ obtenida del relevamiento SuperCOSMOS. La estrella WR 16 se encuentra en el centro del campo.

Como se mencionó en el Capítulo 1, el material molecular alrededor de WR 16 fue estudiado por Marston et al. (1999) utilizando observaciones de la línea $\mathrm{J}=1 \rightarrow 0$ del ${ }^{12} \mathrm{CO}$ obtenidas con el radiotelescopio SEST, con una resolución angular de 45 ". Los autores encontraron un "capullo" de material molecular que rodea al anillo $\mathrm{H} \alpha$ interno, a una velocidad de $\sim-5 \mathrm{~km} / \mathrm{seg}$. La masa calculada por los autores para el mismo está entre 5 y $78 \mathrm{M}_{\odot}$ (dependiendo de la distancia adoptada y la metalicidad) por lo que atribuyeron a éste un origen estelar. La región observada no parece cubrir toda la extensión del material molecular detectado, siendo tal vez éste uno de los motivos para la determinación de una masa tan pequeña. En las próximas secciones de este capítulo, nos proponemos investigar la componente molecular encontrada por Marston et al. (1999) utilizando las observaciones de la línea $\mathrm{J}=1 \rightarrow 0$ del ${ }^{12} \mathrm{CO}$ obtenidas con el radiotelescopio NANTEN en un campo de mayor extensión a fin de establecer con aún mayor certeza si esta componente está asociada a WR 16 así como también el origen del material molecular que la conforma. Se buscarán también otras componentes moleculares que puedan estar asociadas a WR 16 o que tengan alguna vinculación con algunos de los anillos anteriormente descriptos. 


\subsection{Búsqueda y análisis de las componentes moleculares asociadas a WR 16}

En la Figura 4.2 se muestran los perfiles de emisión obtenidos con NANTEN en la dirección de seis puntos de la nebulosa anillo alrededor de WR 16, cada uno de ellos identificados con una letra minúscula en el borde superior izquierdo. Los perfiles $a, b, c \mathrm{y} d$ fueron tomados en posiciones correspondientes al anillo externo, mientras que los perfiles $e$ y $f$ en posiciones correspondientes al anillo interno.

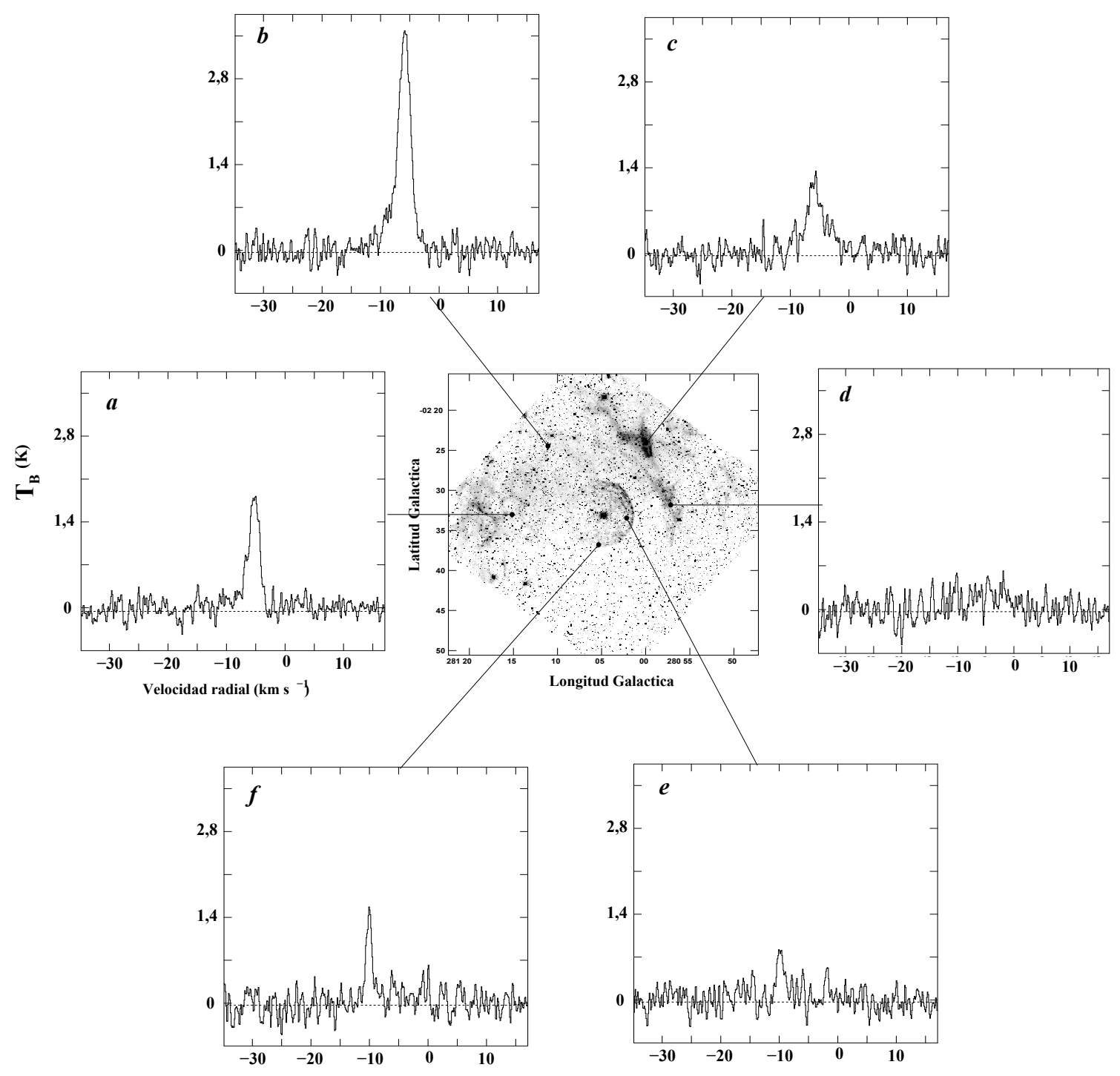

Figura 4.2: Perfiles de emisión obtenidos en seis posiciones de la nebulosa anillo alrededor de WR16. Los perfiles fueron tomados en áreas circulares de $\sim 3^{\prime}$ de diámetro centradas en las posiciones indicadas por los círculos negros. 
Como puede observarse de la Figura 4.2, la presencia de CO es detectada a lo largo de dos intervalos de velocidades: i) $\sim-8 \mathrm{a}-4 \mathrm{~km} / \mathrm{seg}$ (perfiles $a, b$ y c) y ii) -11 a $-9 \mathrm{~km} / \mathrm{seg}$ (perfiles $f$ y posiblemente $e$ ).

En la Figura 4.3 se muestra la emisión promedio de CO en la región comprendida en la Figura 4.1. Puede apreciarse la existencia de una única componente molecular intensa $\left(\mathrm{T}_{B} \sim 0,9 \mathrm{~K}\right)$ en el rango de velocidades $\sim-12 \mathrm{a}-1$ $\mathrm{km} / \mathrm{seg}$. Esta única componente observada podría ser el resultado de la suma de las dos componentes detectadas anteriormente. Como puede observarse no se aprecian componentes moleculares a velocidades mayores que 0 ni menores que $-12 \mathrm{~km} / \mathrm{seg}$.

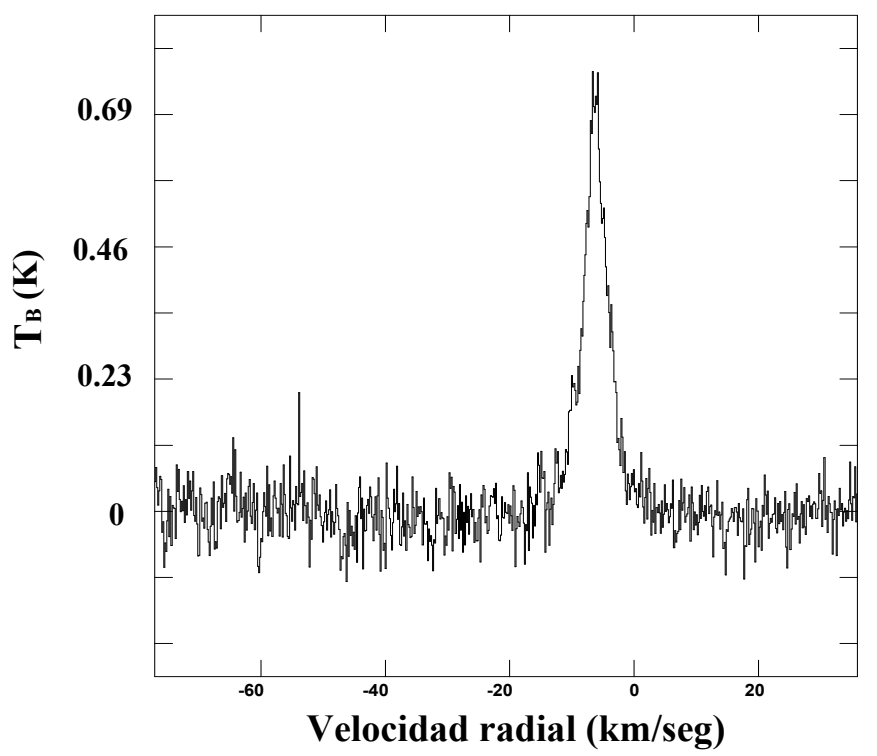

Figura 4.3: Perfil de emisión del CO en una región de 32',4 de lado alrededor de WR 16.

En la Figura 4.4 se muestra la distribución de la emisión del ${ }^{12} \mathrm{CO}$ obtenida del cubo de datos realizado con un muestreo de $2^{\prime}, 7$ de espaciado. Las imágenes abarcan un rango de velocidad que va desde $-11,5$ a $-2,5 \mathrm{~km} / \mathrm{seg}$ y el intervalo de velocidad de cada imagen es de $1 \mathrm{~km} / \mathrm{seg}$. El campo de las mismas es similar al de la Figura 4.1.

A lo largo de todo el intervalo de velocidad se pueden apreciar distintas componentes moleculares las cuales son identificadas en la Figura 4.4 con letras mayúsculas y en orden creciente de velocidad radial. En el intervalo -10,5 a $-9,5 \mathrm{~km} / \mathrm{seg}$ se observa una estructura intensa $\left(\mathrm{T}_{B}(\mathrm{pico}) \sim 2,4 \mathrm{~K}\right)$ que será denominada componente A, ubicada al suroeste de WR 16 y cuya extensión en velocidad es $\sim 1 \mathrm{~km} / \mathrm{seg}$.

En el rango de velocidades $-7,5$ a $-3,5 \mathrm{~km} / \mathrm{seg}$ puede apreciarse que la estrella WR se encuentra en una zona con muy baja emisión molecular. La misma se encuentra circundada por una estructura molecular que la rodea 
parcialmente hacia altas longitudes galácticas y que está formada por varias componentes que denomminaremos B, C y D.

La componente $\mathrm{B}$ comienza a hacerse distinguible en el intervalo de velocidades $-7,5 \mathrm{a}-6,5 \mathrm{~km} / \mathrm{seg}$ y alcanza su máxima intensidad $\left(\mathrm{T}_{B} \sim 3,7 \mathrm{~K}\right)$ en el intervalo $-6,5 \mathrm{a}-5,5 \mathrm{~km} / \mathrm{seg}$ en la posición $(l, b)=\left(281^{\circ} 08^{\prime},-2^{\circ} 25^{\prime}\right)$.

La componente $\mathrm{C}$ aparece en el intervalo de velocidades $-6,5 \mathrm{a}-5,5 \mathrm{~km} / \mathrm{seg}$ y alcanza su máxima intensidad $\left(\mathrm{T}_{B} \sim 2 \mathrm{~K}\right)$ en la posición $(l, b)=\left(281^{\circ} 08^{\prime}\right.$, $\left.-2^{\circ} 40^{\prime}\right)$, en el intervalo de velocidad $-5,5$ a $-4,5 \mathrm{~km} / \mathrm{seg}$.

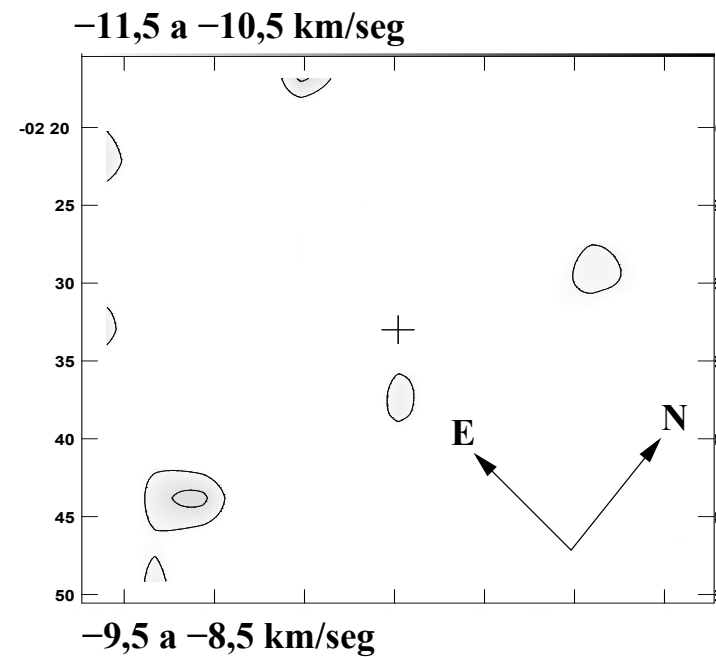
$-10,5$ a $-9,5 \mathrm{~km} / \mathrm{seg}$

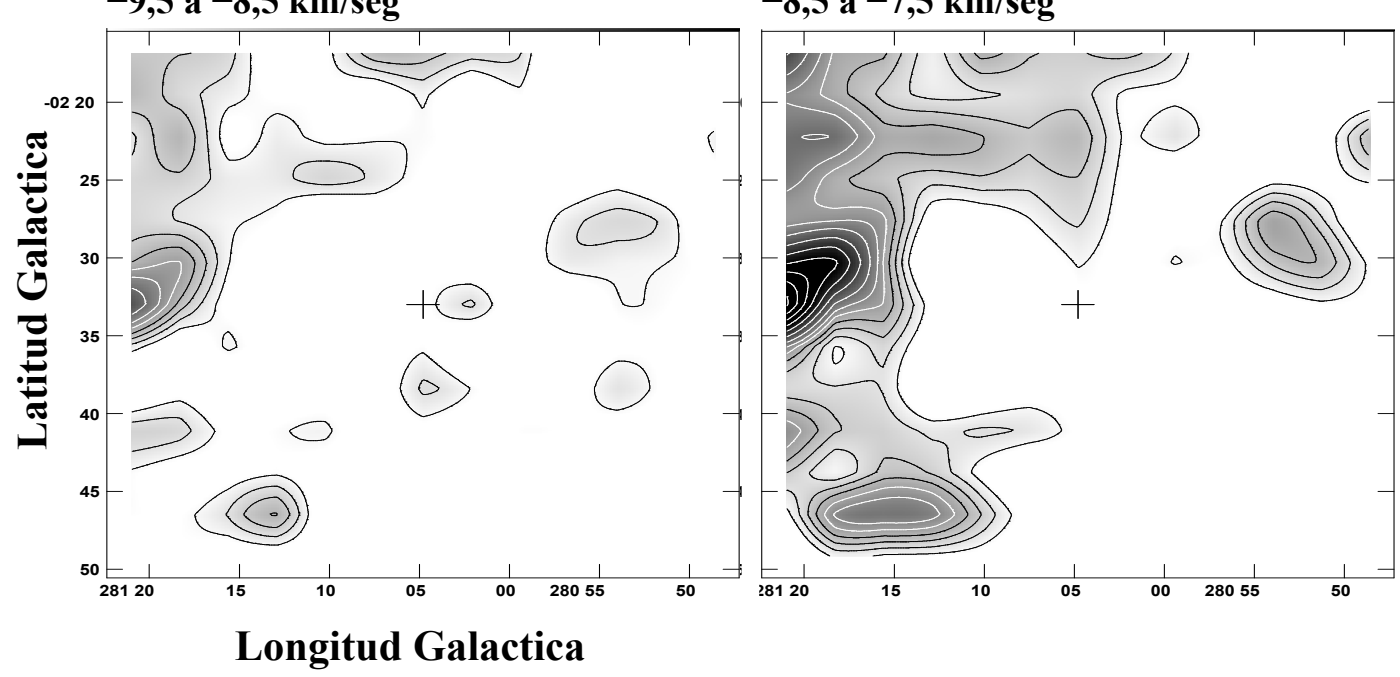

Figura 4.4: Imágenes de la distribución de ${ }^{12} \mathrm{CO}$ integradas en intervalos de $1 \mathrm{~km} / \mathrm{seg}$. La posición de WR 16 está indicada por la cruz en el centro del campo. Los niveles de contorno van de $0,4 \mathrm{~K}(\sim 5 \sigma)$ a $1,75 \mathrm{~K}$ en intervalos de $0,2 \mathrm{~K}$, y desde $1,75 \mathrm{~K}$ en intervalos de 0,35 $\mathrm{K}$. El intervalo de velocidades abarcado por cada mapa está indicado arriba a la izquierda.

En el intervalo de velocidades de $-5,5$ a $-4,5 \mathrm{~km} / \mathrm{seg}$ puede apreciarse también una pequeña componente ubicada en $(l, b)=\left(281^{\circ} 11^{\prime},-2^{\circ} 33^{\prime}\right)$ que podría estar físicamente asociada a las componentes $\mathrm{C}$ y $\mathrm{B}$. 


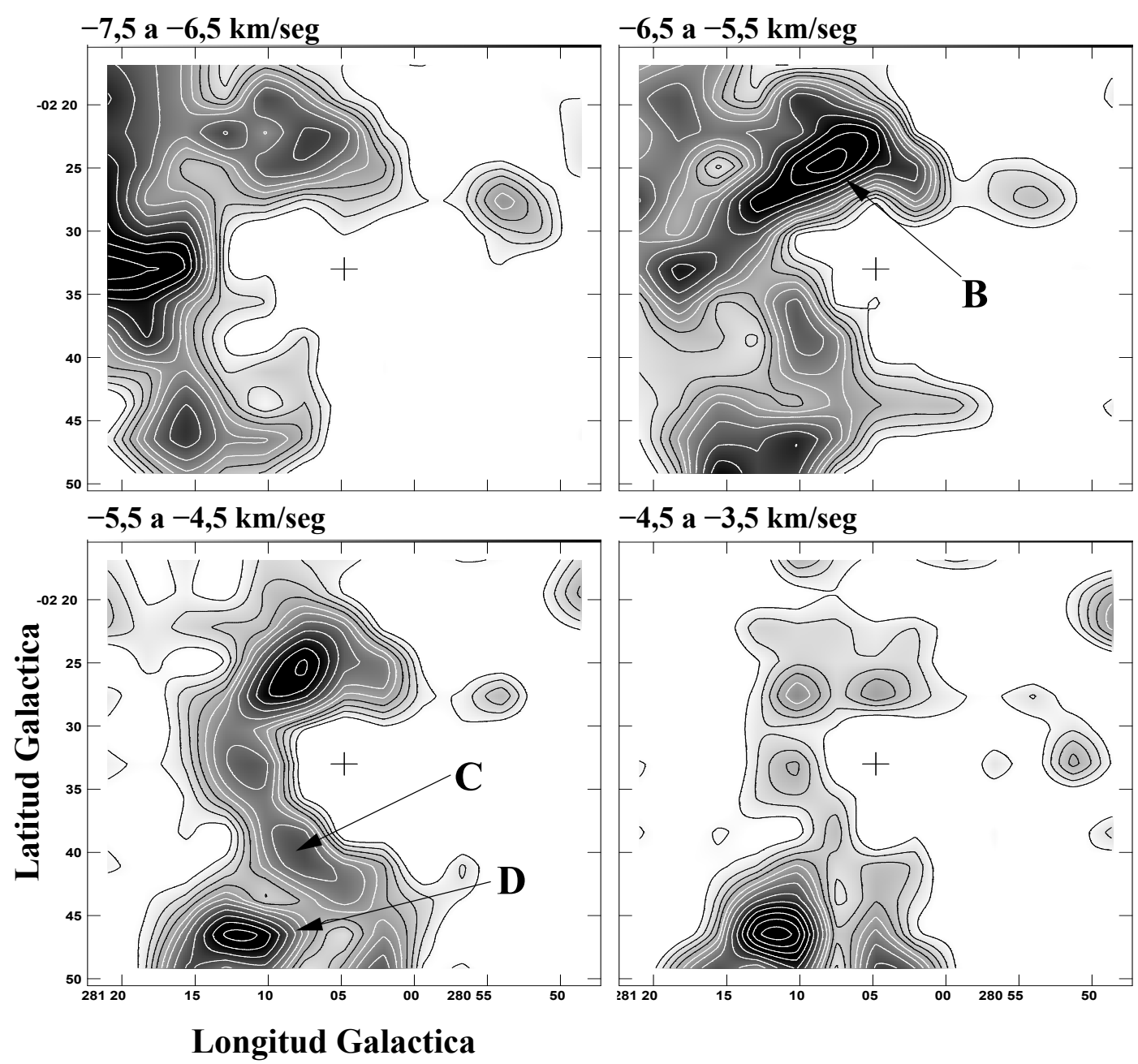

Figura 4.4: (continuación)

La cuarta componente molecular (componente D) comienza a ser detectada en el intervalo de velocidades de $-6,5$ a $-5,5 \mathrm{~km} / \mathrm{seg}$ y alcanza su máxima intensidad $\left(\mathrm{T}_{B} \sim 4 \mathrm{~K}\right)$ en el intervalo $-5,5 \mathrm{a}-4,5 \mathrm{~km} / \mathrm{seg}$ en la posición $(l, b)=\left(281^{\circ} 12^{\prime},-2^{\circ} 47^{\prime}\right)$. Esta componente continúa detectable a velocidades mayores a $-3,5 \mathrm{~km} / \mathrm{seg}$ cuando las componentes $\mathrm{B}$ y $\mathrm{C}$ han desaparecido.

En la Figura 4.5 se presenta una imagen integrada de la distribución de CO en el intervalo de velocidades $-6,5$ a $-3,5 \mathrm{~km} / \mathrm{seg}$ superpuesta con la emisión $\mathrm{H} \alpha$. Como puede apreciarse, el gas molecular en este intervalo de velocidades muestra una notable correspondencia morfológica con el anillo interno visible en la emisión $\mathrm{H} \alpha$ hacia el borde menos brillante del mismo. Esta estructura, que de aquí en adelante será denominada Anillo Molecular Externo (AME), es la estructura molecular encontrada por Marston et al. (1999) y que fue 
denominada "capullo molecular" en dicho trabajo (ver Figura 1.13 de esta Tesis Doctoral). En la Figura 4.5 está indicada la zona observada por Marston et al. (1999). Como puede apreciarse, el AME no fue observado en su totalidad por dichos autores.

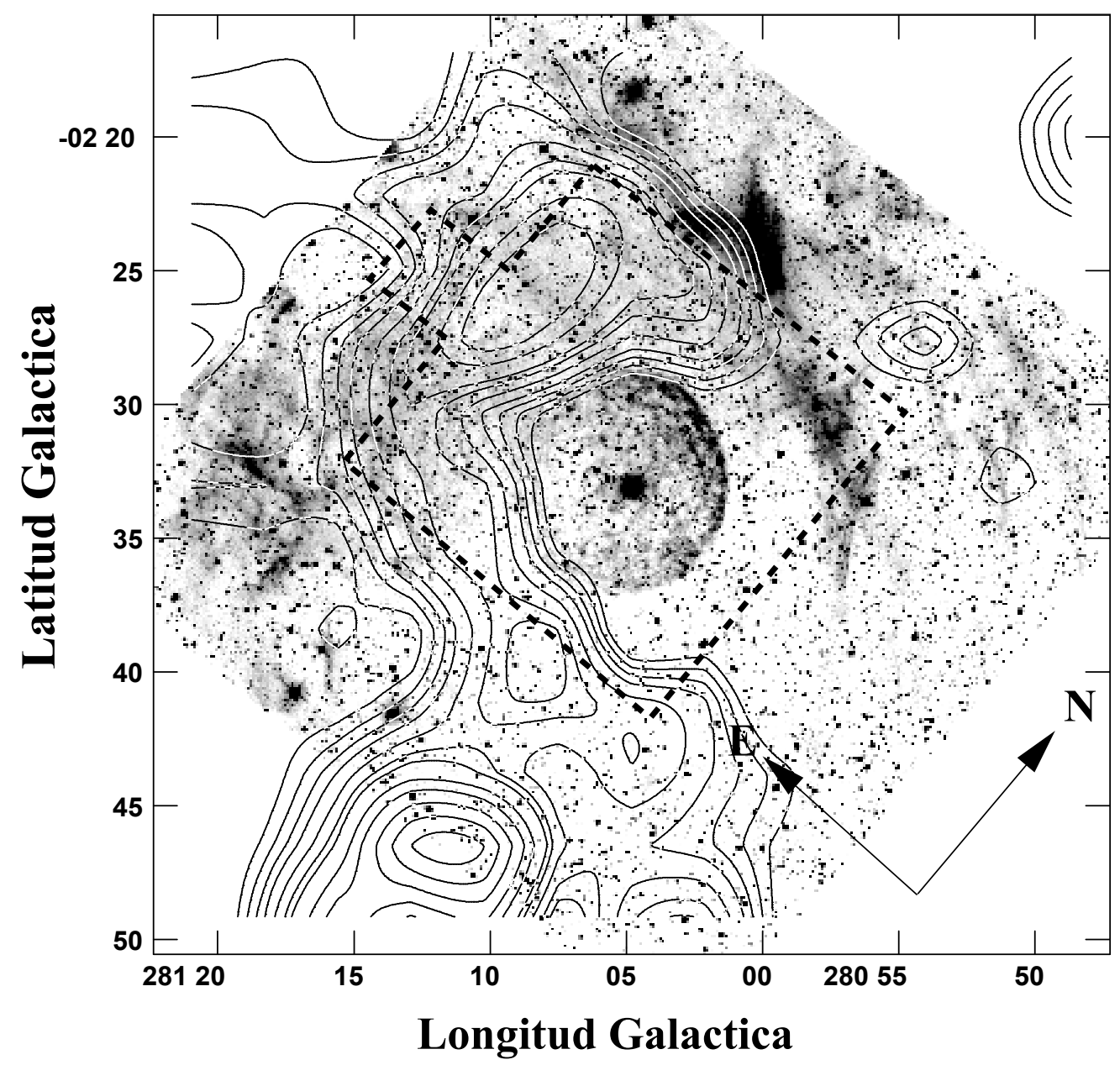

Figura 4.5: Emisión del ${ }^{12} \mathrm{CO}$ (contornos) integrada en el rango de velocidad $-6,5$ a $-3,5$ $\mathrm{km} / \mathrm{seg}$ superpuesta con la emisión $\mathrm{H} \alpha$ (grisado). Los niveles de contorno van de 0,5 ( 6,3 $\sigma)$ a $1,5 \mathrm{~K}$ en intervalos de $0,15 \mathrm{~K}$, y de $1,5 \mathrm{~K}$ a $6,3 \mathrm{~K}$ en intervalos de $0,35 \mathrm{~K}$. La línea de trazos delimita la zona observada por Marston et al. (1999)

Una inspección visual de la Figura 4.5 permite individualizar a la componentes $\mathrm{B}, \mathrm{C}$ y $\mathrm{D}$ anteriormente mencionadas. Como puede observarse las componentes B y C conforman claramente la estructura del AME, mientras que la componente D se encuentra espacialmente separada del mismo. Para una mejor visualización de la extensión espacial de estas estructuras, en la 
Figura 4.6 se muestra la emisión del ${ }^{12} \mathrm{CO}$ integrada en el mismo rango de velocidades de la Figura 4.5 pero construida con el cubo de datos realizado con un muestreo de $5^{\prime}, 4$ de espaciado que permite abarcar un campo de $\sim 86^{\prime}$ de lado. En dicha figura se pueden observar las componentes B y C notoriamente separadas de la componente D. El AME está indicado por la línea de puntos.

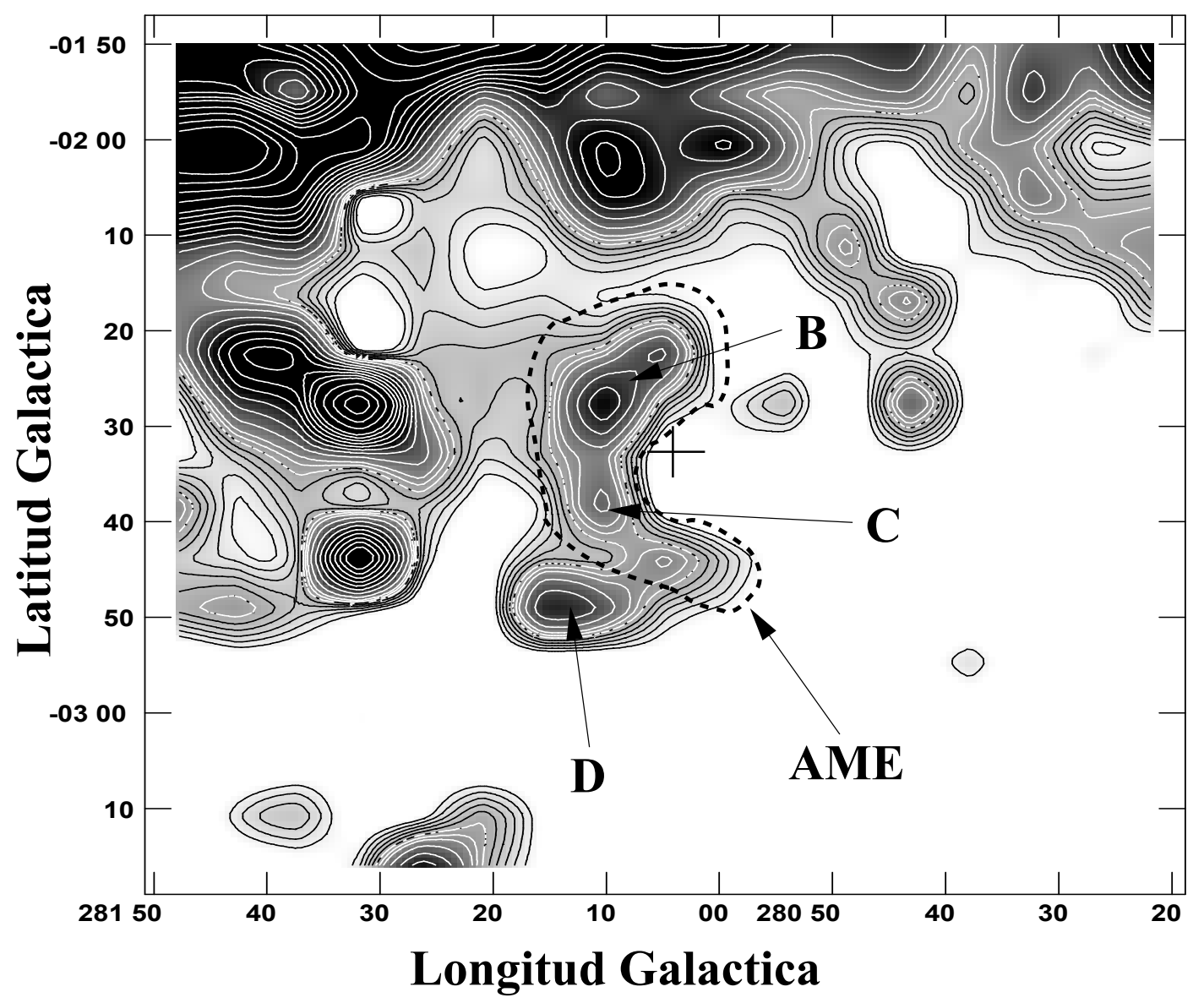

Figura 4.6: Emisión de ${ }^{12} \mathrm{CO}$ integrada en el rango de velocidad $-6,5$ a $-3,5 \mathrm{~km} / \mathrm{seg}$ en un campo de $\sim 86^{\prime}$ de lado. La posición de WR 16 está indicada por la cruz en el centro. Los niveles de contornos son similares a los de la figura anterior.

Para observar en mayor detalle los rangos de velocidad abarcados por cada estructura, se confeccionaron las imágenes posición-velocidad. En la Figura 4.7 se muestra una imagen velocidad-latitud galáctica promediada en un intervalo de longitud galáctica que va de $281^{\circ}$ a $281^{\circ} 20^{\prime}$. Puede apreciarse que la componente $\mathrm{B}$ abarca el rango de velocidad que se extiende desde $\sim-9$ hasta $-4 \mathrm{~km} / \mathrm{seg}$, mientras que la componente $\mathrm{D}$ abarca un rango de velocidades distinto, que se extiende de $\sim-7,5$ a $-2,5 \mathrm{~km} / \mathrm{seg}$. La posición aproximada de la componente $\mathrm{C}$ está indicada aunque ésta no puede identificarse claramente. 


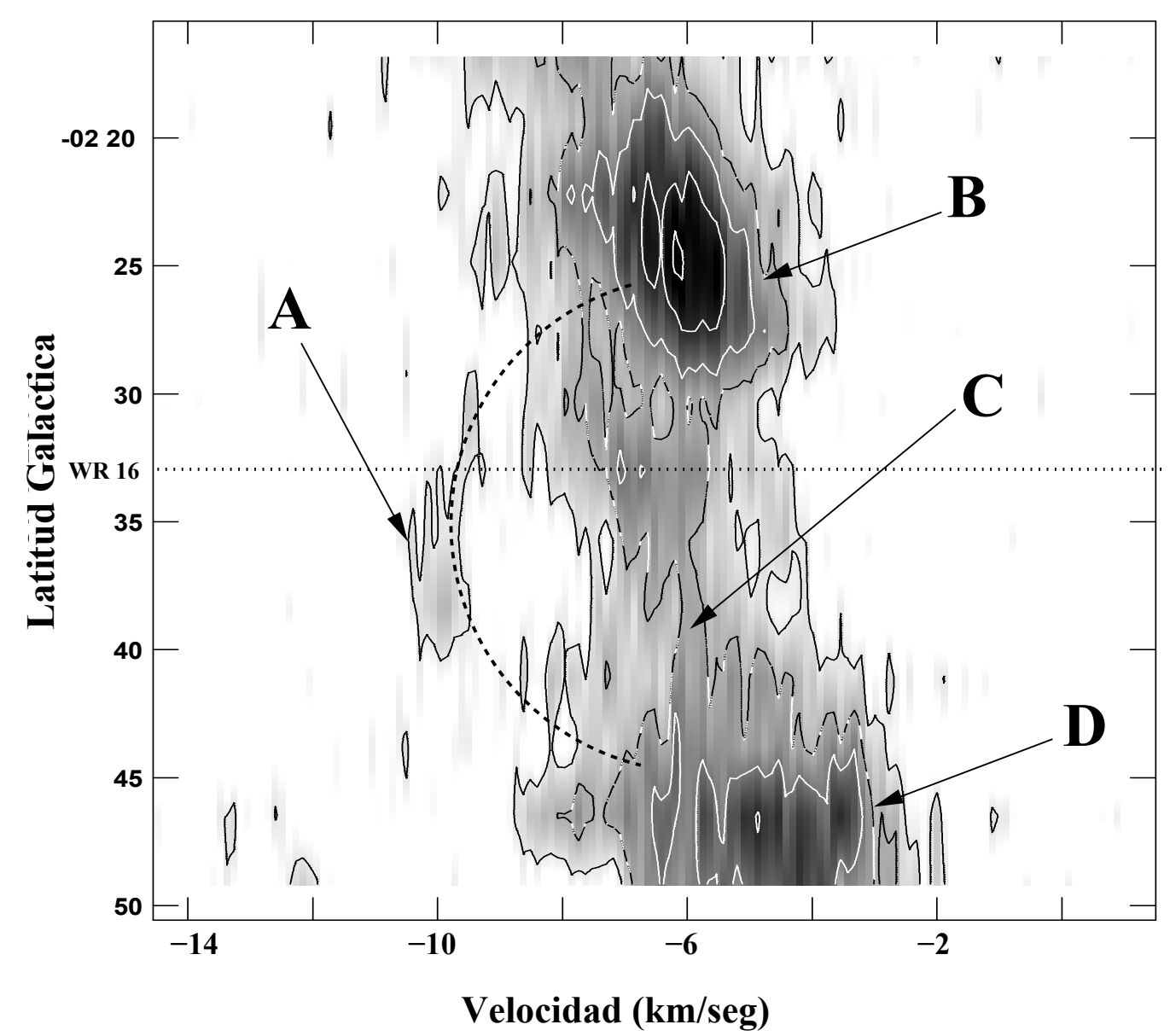

Figura 4.7: Imagen Velocidad-Latitud Galáctica integrada en $281^{\circ} \leq l \leq 281^{\circ} 20^{\prime}$. El nivel de contorno inferior es de $0,4 \mathrm{~K}(\sim 3 \sigma)$ y el espaciado entre los mismos es de $0,3 \mathrm{~K}$. La latitud galática de WR 16 está indicada por la línea punteada en el centro del campo.

Al observar la imagen posición-velocidad de la Figura 4.7 en el rango de velocidad -6 a $-11 \mathrm{~km} / \mathrm{seg}$, el AME (conformado por las componentes B y C) junto con la componente A adoptan una morfología semianular (indicada en la Figura 4.7 por una semicircunferencia a trazos) a modo de cáscara en expansión, con el casquete de la misma (componente A) moviéndose hacia el observador. La posición de WR 16 (indicada en la Figura 4.7 por una línea punteada) está cerca del centro de la semicircunferencia.

En la Figura 4.4, puede apreciarse que la emisión extendida $\left(\mathrm{T}_{B}<1,2 \mathrm{~K}\right)$ asociada a la componente A se encuentra proyectada sobre el borde noroeste del anillo interno observado en $\mathrm{H} \alpha$. Con el fin de investigar una posible relación entre estas dos estructuras se realizó un estudio más detallado de esta componente molecular. En la Figura 4.8 se muestra una serie de imágenes de la distribución de emisión del CO integradas en un rango de velocidad de $0,11 \mathrm{~km} / \mathrm{seg}$ dentro del rango de velocidad que va desde $-9,83$ hasta $-9,39$ 
$\mathrm{km} / \mathrm{seg}$, superpuestos con la emisión $\mathrm{H} \alpha$ del anillo interno. El rango de velocidad mostrado en la Figura 4.8 abarca sólo $0,44 \mathrm{~km} / \mathrm{seg}$. Este intervalo de velocidad es más pequeño que el intervalo en el que la componente A es observable $(\sim 1 \mathrm{~km} / \mathrm{seg})$.
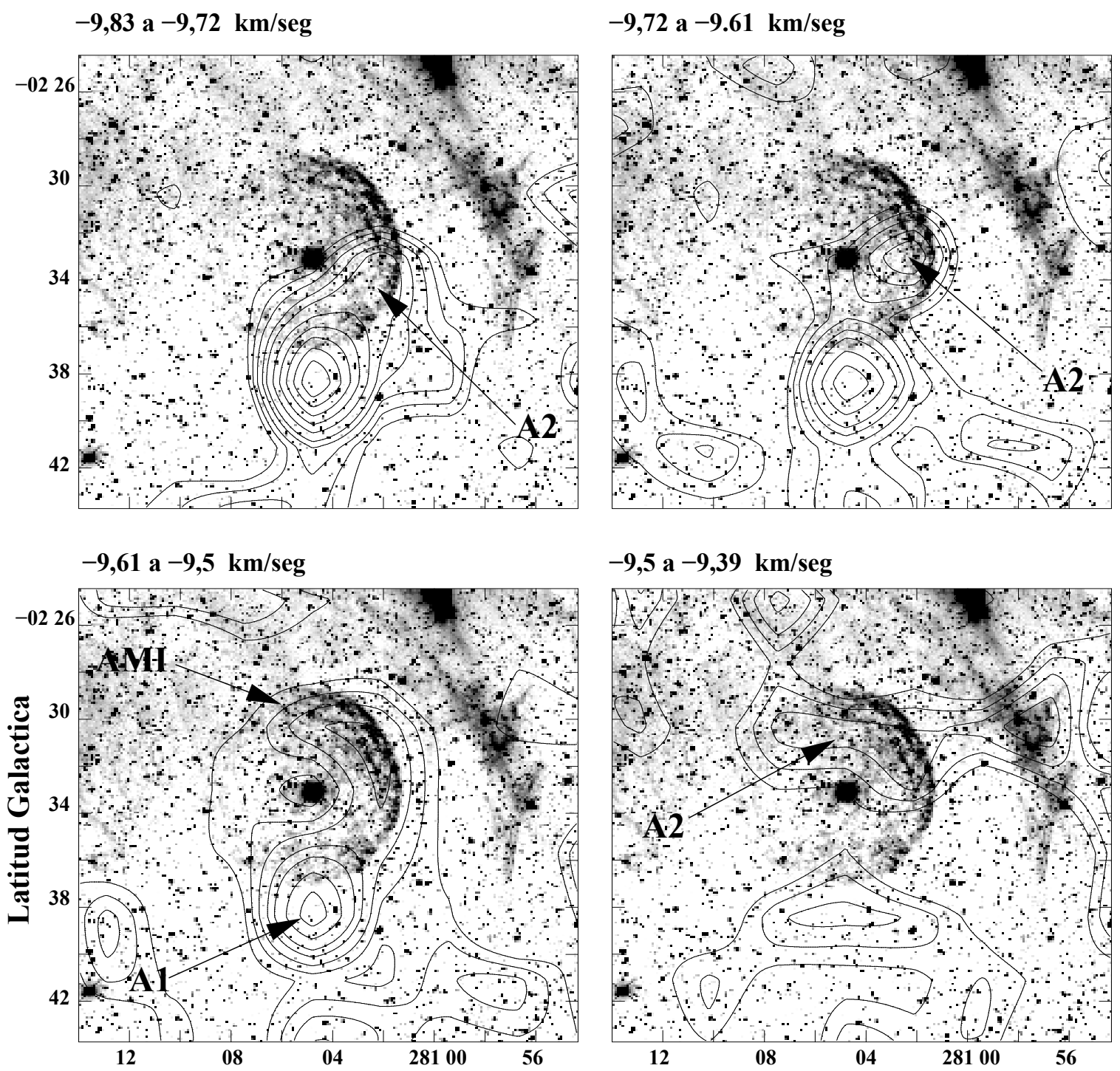

\section{Longitud Galactica}

Figura 4.8: Imágenes de la distribución de ${ }^{12} \mathrm{CO}$ integradas en intervalos de velocidad de $0,11 \mathrm{~km} / \mathrm{seg}$ (contornos) dentro del rango de velocidad de $-9,83$ hasta $-9,39 \mathrm{~km} / \mathrm{seg}$ superpuestos con la emisión $\mathrm{H} \alpha$ del anillo interno (grisado). Los niveles de contorno van de $0,45 \mathrm{~K}(\sim 2,5 \sigma)$ hasta $1,12 \mathrm{~K}$ en intervalos de $0,17 \mathrm{~K}$ y a partir de $1,12 \mathrm{~K}$ en intervalos de $0,35 \mathrm{~K}$. El intervalo de velocidades de cada imagen está indicado en el borde superior izquierdo de cada panel. 
En la Figura 4.8 se observa que la componente A está formada por dos subcomponentes claramente distinguibles. Una muy intensa ubicada en $(l, b)=$ $\left(281^{\circ} 05^{\prime},-02^{\circ} 38^{\prime}\right)(\mathrm{A} 1)$ y otra menos intensa y más difusa que se extiende irregularmente desde una latitud galáctica $b=-02^{\circ} 28^{\prime}$ hasta $b=-02^{\circ} 36^{\prime}$ abarcando la posición del anillo H $\alpha$ interno (A2), y cuya morfología cambia notablemente de un intervalo de velocidad al siguiente. En el intervalo de velocidades $-9,61$ a $-9,5 \mathrm{~km} / \mathrm{seg}$, la subcomponente A2 adopta una morfología semianular en muy buena correspondencia morfológica con el anillo $\mathrm{H} \alpha$ interno y con un mínimo coincidente con la posición de WR 16. Esta estructura será denominada Anillo Molecular Interno (AMI). En la Figura 4.9 se muestra éste con más detalle.
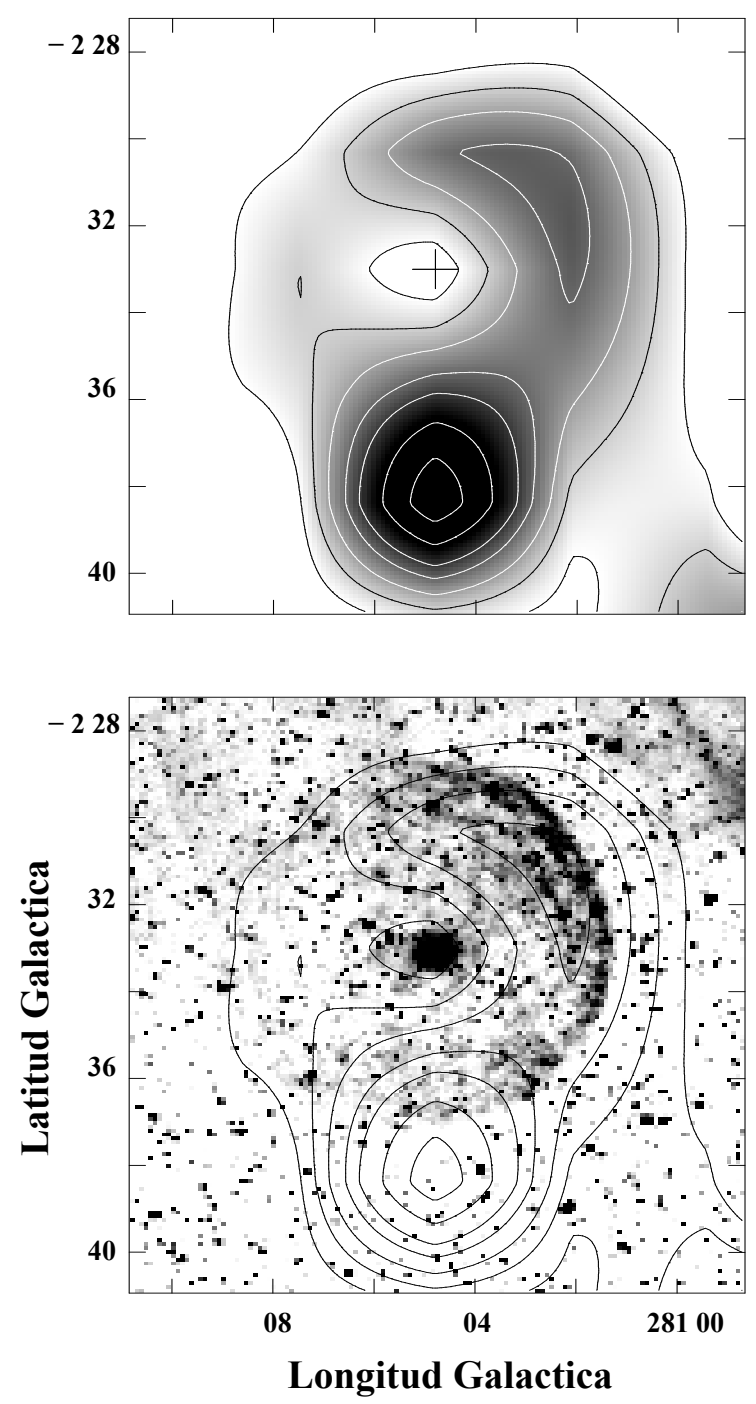

Figura 4.9: Panel superior: Emisión de ${ }^{12} \mathrm{CO}$ en el intervalo de velocidad $-9,61$ a $-9,5$ $\mathrm{km} / \mathrm{seg}$ (AMI). El rango de grises va desde $0,385 \mathrm{~K}$ hasta 1,33 K. La posición de WR 16 está indicada por la cruz en el centro. Panel inferior: Superposición del AMI con la imagen $\mathrm{H} \alpha$. 
La determinación del intervalo de velocidad del AMI se basó exclusivamente en la coincidencia morfológica entre la distribución de $\mathrm{CO}$ y la emisión correspondiente a $\mathrm{H} \alpha$, por lo que dicho intervalo podría extenderse hacia velocidades ligeramente superiores y/o inferiores. Es decir que el rango de velocidad de $0,11 \mathrm{~km} / \mathrm{seg}$ debe considerarse como un límite inferior. En la Figura 4.10 se muestra la integración realizada sobre cinco canales $(0,275 \mathrm{~km} / \mathrm{seg})$ anteriores y posteriores al intervalo de velocidad en el que se identifica al AMI. Como puede apreciarse, en estos intervalos de velocidad se ha perdido completamente la morfología anular y no parece haber correspondencia morfológica con la emisión $\mathrm{H} \alpha$. Por lo tanto, el intervalo $-9,61$ a $-9,5 \mathrm{~km} / \mathrm{seg}$ parece ser una elección adecuada para identificar al material molecular que mayoritariamente podría encontrarse vinculado con el AMI.
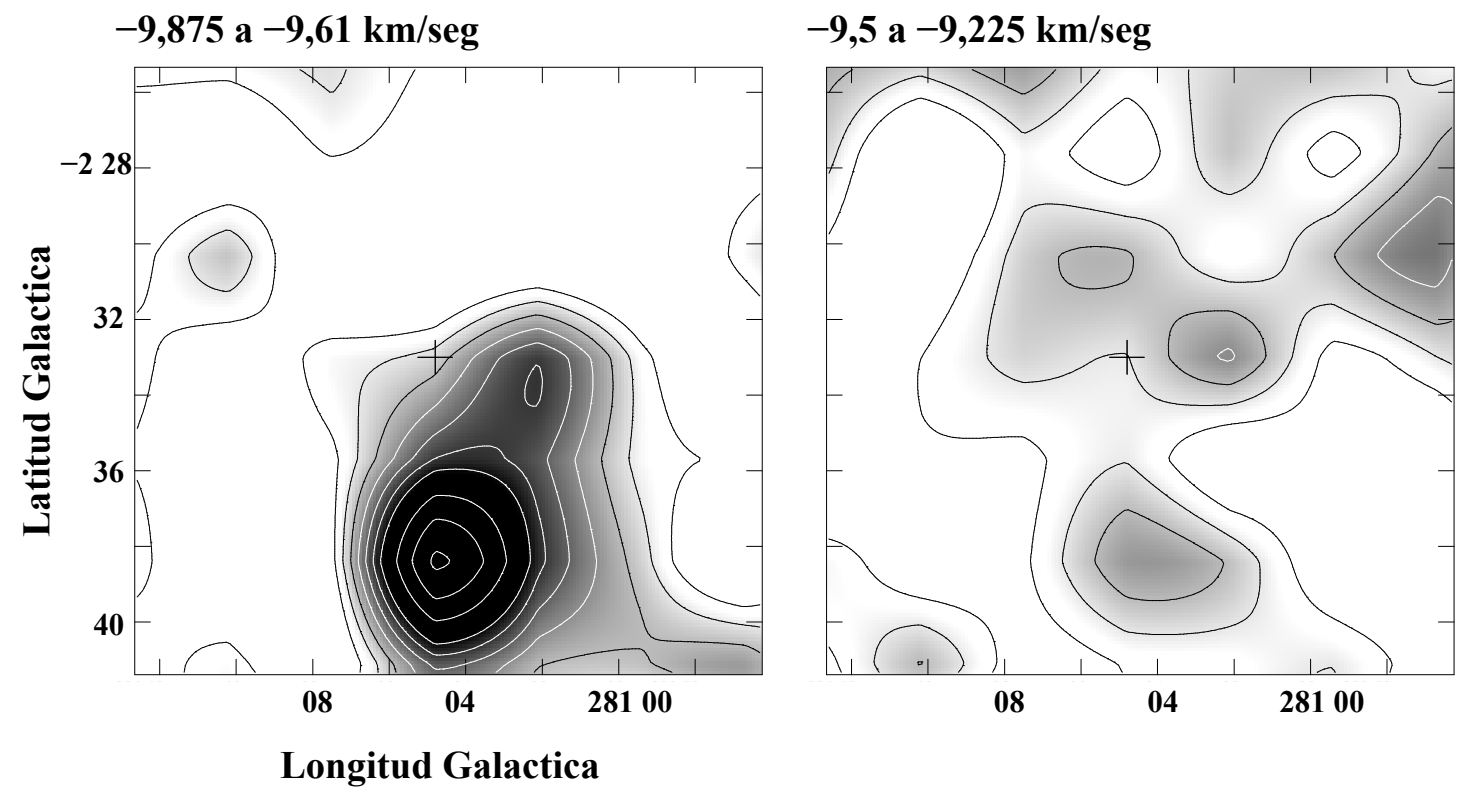

Figura 4.10: Emisión de ${ }^{12} \mathrm{CO}$ en los intervalos de velocidad anterior y posterior al del AMI. Los niveles de contorno van de $0,19(\sim 2,5 \sigma)$ a $1,35 \mathrm{~K}$ en intervalos de $0,19 \mathrm{~K}$, y a partir de 1,35 K en intervalos de 0,35 K. Los intervalos de velocidad se encuentran en la esquina superior izquierda de cada imagen. La posición de WR 16 está representada por la cruz en el centro del campo.

Al observar la Figura 4.10, puede notarse que la subcomponente A1 es visible en un rango de velocidades mayor respecto al del AMI. Para mayor detalle, en la Figura 4.11 se muestran las imágenes Velocidad-Longitud Galáctica obtenidas integrando en los rangos de latitudes galácticas correspondientes al AMI $\left(-2^{\circ} 34^{\prime}<b<-2^{\circ} 28^{\prime}\right)$ y a la sucomponente A1 $\left(-2^{\circ} 42^{\prime}<b<-2^{\circ} 34^{\prime}\right)$. Ambas imágenes fueron obtenidas de un cubo de datos que fue previamente alisado en velocidad (filtro tipo hanning) con el fin de individualizar en forma más clara las componentes moleculares mencionadas anteriormente. 

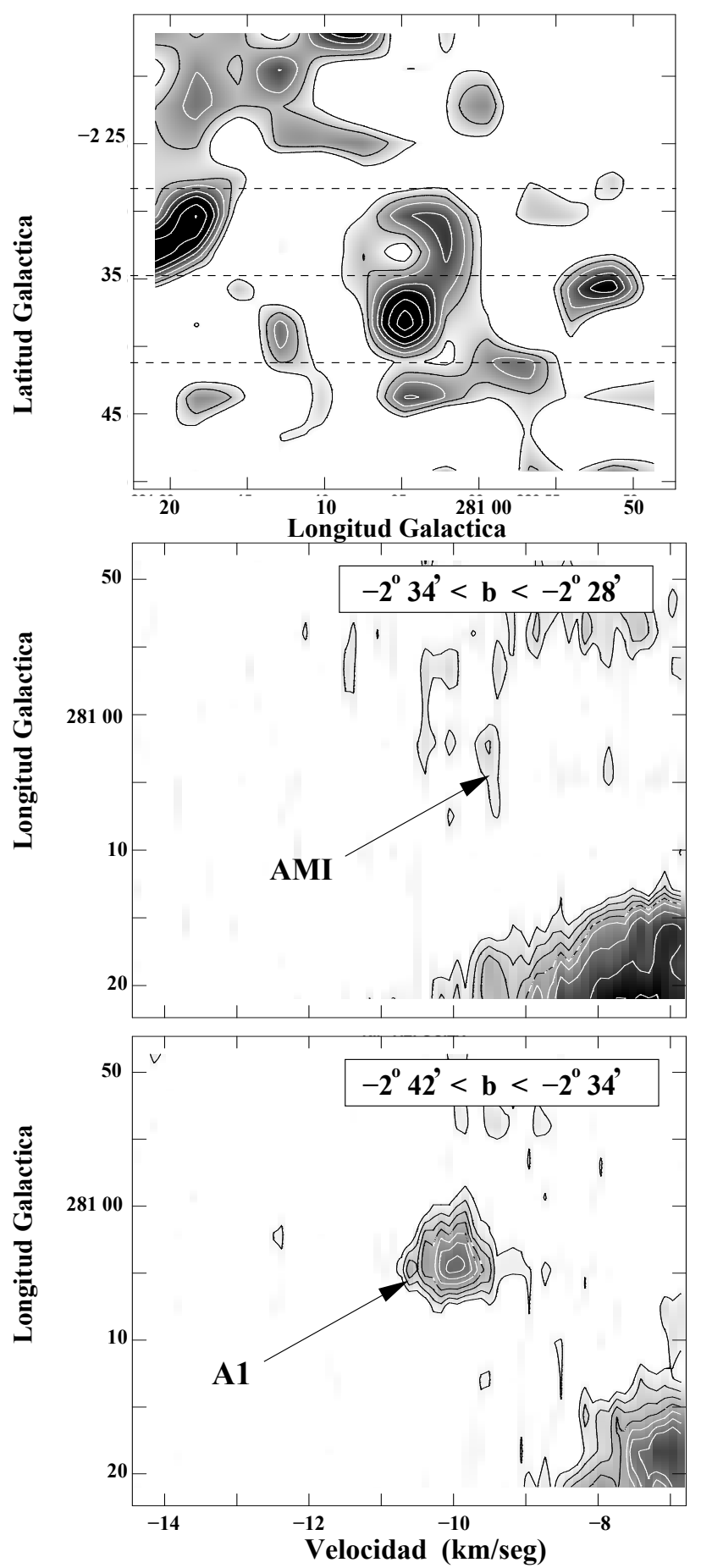

Figura 4.11: Panel superior: distribución de ${ }^{12} \mathrm{CO}$ entre $-9,61$ y $-9,5 \mathrm{~km} / \mathrm{seg}$. Panel intermedio: Imagen longitud galáctica-velocidad obtenida promediando la emisión entre $-2^{\circ} 34^{\prime}<b<-2^{\circ} 28^{\prime}$. Panel inferior: Imagen longitud galáctica-velocidad obtenida promediando la emisión entre $-2^{\circ} 42^{\prime}<b<-2^{\circ} 34^{\prime}$ 
En la Figura 4.11 claramente se puede apreciar que la subcomponente A1 está presente en un intervalo de velocidades que va aproximadamente desde $-10,5$ a $-9,5 \mathrm{~km} / \mathrm{seg}$, mientras que el material asociado al AMI sólo está presente desde $\sim-9,6$ hasta $-9,5 \mathrm{~km} / \mathrm{seg}$. No parece existir una superposición en velocidad entre ambas estructuras. Además de las diferencias en la velocidad antes señaladas, existe también una diferencia notoria en la intensidad de la emisión de la línea molecular. La estructura molecular correspondiente al AMI alcanza sólo una intensidad de emisión de 0,7 K $(\sim 5 \sigma)$ mientras que la correspondiente a la subcomponente A1 supera los 2,3 K $(\sim 14 \sigma)$.

En las próximas secciones analizaremos las posibles relaciones entre el AME, la subcomponente A1 y el AMI con las nebulosas anillo $\mathrm{H} \alpha$ y la estrella WR 16. Se intentará explicar también el corto intervalo de velocidad en el que el AMI es detectado.

\subsection{La nebulosa infrarroja}

La Figura 4.12 muestra la emisión correspondiente a las bandas de 60 y $100 \mu \mathrm{m}$ del relevamiento IRAS de alta resolución (HIRES) a la que se le ha sustraído la emisión de fondo. La emisión en $60 \mu \mathrm{m}$ revela la existencia de un conspicuo anillo cuya posición y tamaño coinciden con el anillo $\mathrm{H} \alpha$ interno y con el AMI. La estrella WR 16 se ubica aproximadamente en el centro del mismo.

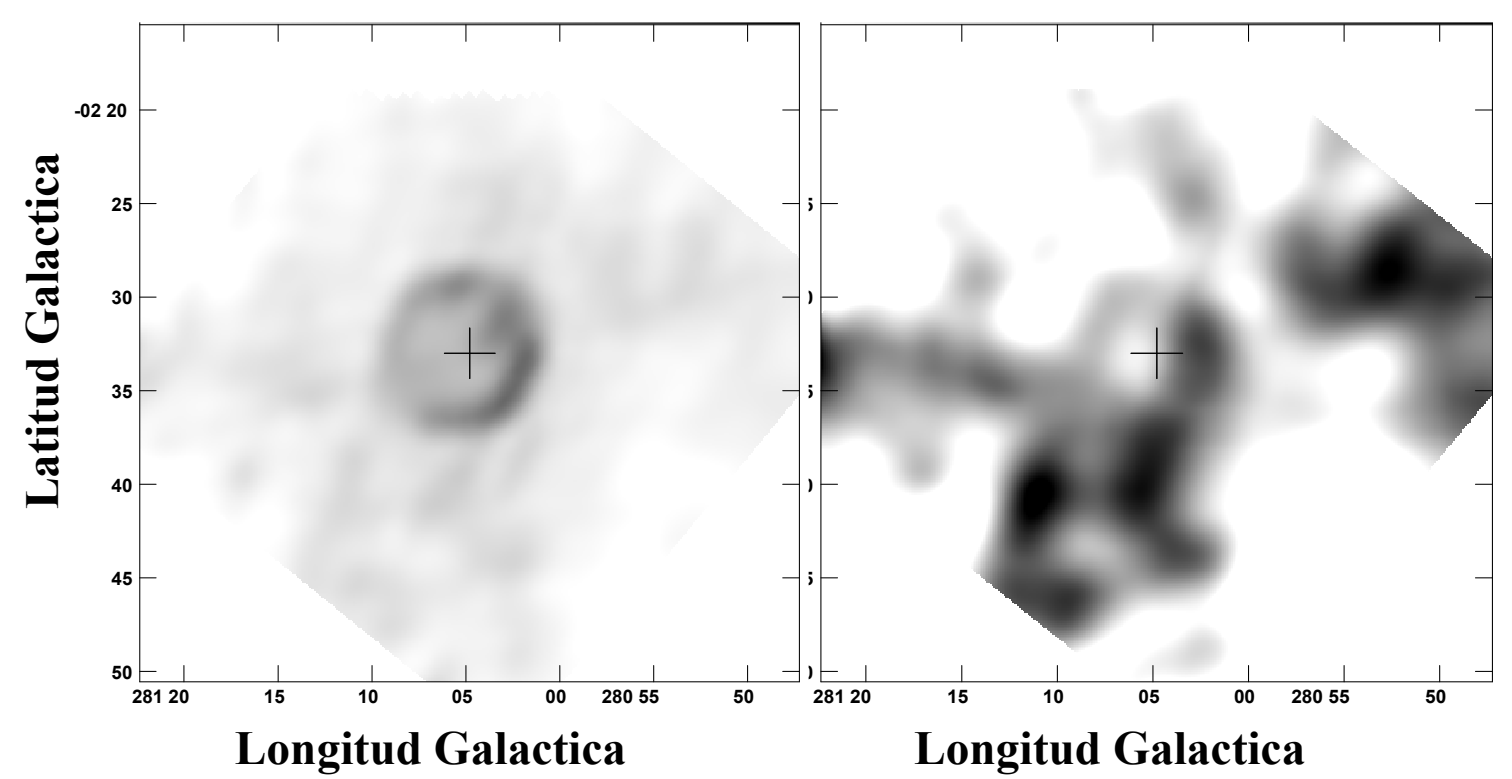

Figura 4.12: Panel izquierdo: Emisión en $60 \mu \mathrm{m}$ de gran resolución (HIRES) obtenida por el satélite IRAS. Panel derecho: Emisión en $100 \mu \mathrm{m}$. La posición de WR 16 está indicada por la cruz en el centro de ambas figuras. 
La emisión en $100 \mu \mathrm{m}$ es más irregular, detectándose varias estructuras que no están presentes en la emisión en $60 \mu \mathrm{m}$. En la emisión en $100 \mu \mathrm{m}$ también se observa una emisión anular ubicada alrededor de WR 16, aunque la morfología de ésta no es tan simétrica como la observada en $60 \mu \mathrm{m}$.

\subsection{Análisis y discusión}

Como ya se mencionó anteriormente, Marston et al. (1999) concluyeron que el AME (o "capullo molecular" en dicho trabajo) encontrado a velocidades entre $-7,5$ y $-3,5 \mathrm{~km} / \mathrm{seg}$, tenía un origen estelar debido principalmente al bajo valor de la masa determinada para esta estructura. Sin embargo, esta conclusión presenta algunos puntos controversiales, a saber:

- El método utilizado para calcular la masa de la estructura y las suposiciones posiblemente hechas para tal fin (sobre esto se volverá más adelante)

- La extensión espacial de la estructura, la cual no fue observada en su totalidad por Marston et al. (1999) debido a una cobertura espacial insuficiente.

- La morfología de la estructura. De haber sido ésta originada en la atmósfera de WR 16 durante la fase RSG, como proponen Marston et al. (1999), debería esperarse una distribución más esférica y no rodear sólo una parte del anillo interno.

- La no existencia de ionización en la cara interna de la estructura molecular. Ésta sería esperable siendo material molecular tan próximo a la estrella.

En la Sección 4.2 se analizó la componente molecular denominada AMI presente en el intervalo de velocidades $\sim-9,6$ a $-9,5 \mathrm{~km} / \mathrm{seg}$. Esta componente adopta una morfología circular que está en muy buena coincidencia morfológica con la emisión de la línea $\mathrm{H} \alpha$ y la emisión en IR en $60 \mu \mathrm{m}$. Esta componente se encuentra en una posición interior al AME. Por lo mencionado, es dable pensar que la estructura más externa (AME) represente material molecular interestelar barrido por los vientos estelares en una etapa más temprana de la evolución estelar (posiblemente en la Secuencia Principal), y que la más interna (AMI) se formó en una etapa posterior (¿LBV ó RSG?) en la cual la 
atmósfera de la estrella es más fría, lo que facilitaría la formación de moléculas y granos de polvo. Además la existencia de material molecular ubicado muy próximo a WR 16 hace suponer que tanto la energía radiante como la mecánica producidas en la actual fase WR no han llegado a actuar en forma apreciable sobre el AMI y mucho menos sobre el AME.

A continuación se analizarán en cierto detalle las características del AME y AMI, se calcularán algunos de sus parámetros físicos y se intentará corroborar el origen propuesto para dichas estructuras.

\subsubsection{Características del AME y la subcomponente A1}

\section{Densidad columnar y origen del AME}

En el Capítulo 1, se mencionó que Marston et al. (1999) encontraron una masa para el AME de $5 \mathrm{M}_{\odot}$, valor que podría llegar a $78 \mathrm{M}_{\odot}$ dependiendo de la distancia a la estrella WR 16 y del grado de metalicidad del material molecular. El bajo valor de la masa encontrado para esta componente molecular fue uno de los argumentos más fuertes de los autores para atribuirle a la misma un origen estelar. Cabe mencionar que para derivar este valor de masa los autores utilizaron una densidad de columna de CO calculada mediante

$$
N_{C O} \sim 1,24 \times 10^{15} I_{C O}^{1,175} \quad\left[\mathrm{~cm}^{-2}\right]
$$

donde $I_{C O}$ representa la intensidad integrada (área debajo del perfil) de la transición $\mathrm{J}=1 \rightarrow 0$ del ${ }^{12} \mathrm{CO}$ en unidades de $\mathrm{K} \mathrm{km} / \mathrm{seg}$. Luego la masa fue calculada haciendo uso de

$$
M=N_{C O} B A_{\text {beam }} \mu f_{C O}^{-1} \quad\left[M_{\odot}\right]
$$

siendo $f_{C O}=N_{C O} / N_{H_{2}}$ la relación de abundancias entre el CO y el $\mathrm{H}_{2}, A_{\text {beam }}$ el área del haz, $B$ el número de haces abarcado por la estructura molecular y $\mu$ el peso atómico de la molécula $\mathrm{H}_{2}$. Para $f_{C O}$ los autores adoptaron el valor $9 \times 10^{-4}$, que fuera el calculado para la envoltura circumestelar de la supergigante roja IRC +10420 . Los autores explican que esta relación entre $N_{C O}$ e $I_{C O}$ es aplicable en un rango limitado de valores de $I_{C O}(1-10 \mathrm{~K}$ $\mathrm{km} / \mathrm{seg})$ y temperaturas de excitación $(5-25 \mathrm{~K})$ pero no detallan el origen de la fórmula ni las suposiciones utilizadas para llegar a ella. Una relación directa entre estas cantidades, en principio sólo podría encontrarse bajo la suposición de que la línea $\mathrm{J}=1 \rightarrow 0$ de la molécula de ${ }^{12} \mathrm{CO}$ es ópticamente delgada $\left(\tau_{12} C O<<1\right)$.

Para una línea $(u \rightarrow l)$ ópticamente delgada, suponiendo equilibrio termodinámico local (LTE) y que la temperatura de excitación es muy superior a la temperatura de fondo cósmico $\left(\mathrm{T}_{e x c}>>\mathrm{T}_{c b}\right)$ puede encontrarse que:

$$
I_{C O}=3 \times 10^{-15} \mu_{D} \nu\left(e^{-\frac{h B J_{u}\left(J_{u}+1\right)}{k T_{x}}}\right)\left(e^{\frac{h \nu_{u l}}{k T_{x}}-1}-1\right) N_{C O} \quad[\mathrm{Kkm} / \mathrm{seg}]
$$


siendo $J_{u}$ el número cuántico rotacional del nivel superior de la transición, $\nu_{u l}$ la frecuencia de la transición (en unidades de $\mathrm{GHz}$ ), $T_{x}$ la temperatura de excitación (en unidades de $\mathrm{K}$ ), $B$ la constante molecular rotacional (en unidades de $\mathrm{Hz}$ ) y $\mu_{D}$ el momento dipolar molecular (en unidades de Debye). Introduciendo los valores de las constantes correspondientes a la línea $\mathrm{J}=1 \rightarrow 0$ de la molécula de ${ }^{12} \mathrm{CO}\left(J_{u}=1, \nu=115 \mathrm{GHz}, B=5,76 \times 10^{10} \mathrm{seg}^{-1}, \mu=\right.$ 0,112 Debye) en la ecuación anterior, se obtiene:

$$
N_{12} C O=\frac{2,31 \times 10^{14}}{1-e^{\frac{-5,521}{T_{x}}}} I_{C O} \quad\left[\mathrm{~cm}^{-2}\right]
$$

Considerando temperaturas de excitación $T_{x} \sim 5-25 \mathrm{~K}$

$$
N_{12 C O} \approx\left(1,16 \times 10^{15}-3,45 \times 10^{14}\right) I_{C O} \quad\left[\mathrm{~cm}^{-2}\right]
$$

La ecuación 4.5 es muy similar a la ecuación 4.1 empleada por Marston et al. (1999), a excepción del exponente 1,175 el cual representa una parametrización ligada al rango de $\mathrm{T}_{e x c}$ e $I_{C O}$ mencionados anteriormente. La ecuación 4.5 representa también un límite inferior en la densidad de columna del ${ }^{12} \mathrm{CO}$, ya que la línea rotacional $\mathrm{J}=1 \rightarrow 0$ de esta molécula generalmente se comporta como ópticamente gruesa.

El cálculo de la masa del AME requiere ciertas suposiciones acerca del origen del mismo. Según lo visto en la Ecuación 4.5, Marston et al.(1999) probablemente supusieron que el material molecular de esta estructura es ópticamente delgado, lo que implica que el valor de $\mathrm{N}_{H_{2}}$ obtenido de esa manera es muy inferior al que se obtendría suponiendo que el material molecular es de origen interestelar (ver Ecuación 3.3). Si se pudiese obtener $\mathrm{N}_{H_{2}}$ mediante un método que no impliquara efectuar alguna suposición acerca del origen del mismo, o bien de la física de emisión de las líneas moleculares, podría compararse este valor con los valores obtenidos con los métodos mencionados anteriormente (Ecuación 3.3 y Ecuación 4.5) y verificar cuál de ellos es más aproximado.

Cuando se observa en la dirección de una estrella, la radiación emitida por la misma sufre a lo largo de la línea de la visual un proceso de absorción y extinción producido por el $\mathrm{H}$ y los granos de polvo del MIE entre la misma y el observador. Existe una relación entre la absorción producida en la luz visual de la estrella con la densidad de columna del $\mathrm{H}$ dada por

$$
A_{V}=R_{V} \times 1,72 \times 10^{-22} \times N_{H}
$$

donde $\mathrm{N}_{H}$ representa la densidad de columna total de $\mathrm{H}\left(\mathrm{N}_{\left(H+2 H_{2}\right)}\right)$. Además

$$
R_{V}= \begin{cases}3,1 & \text { (MIE difuso) } \\ 4-5 & \text { (en algunas nubes densas) }\end{cases}
$$


Consideremos dos estrellas 1 y 2 cuyas posiciones aparentes son muy cercanas entre sí, pero en la dirección de la estrella 2 existe una única nube molecular que no está presente en la dirección de la estrella 1 (ver Figura 4.13)

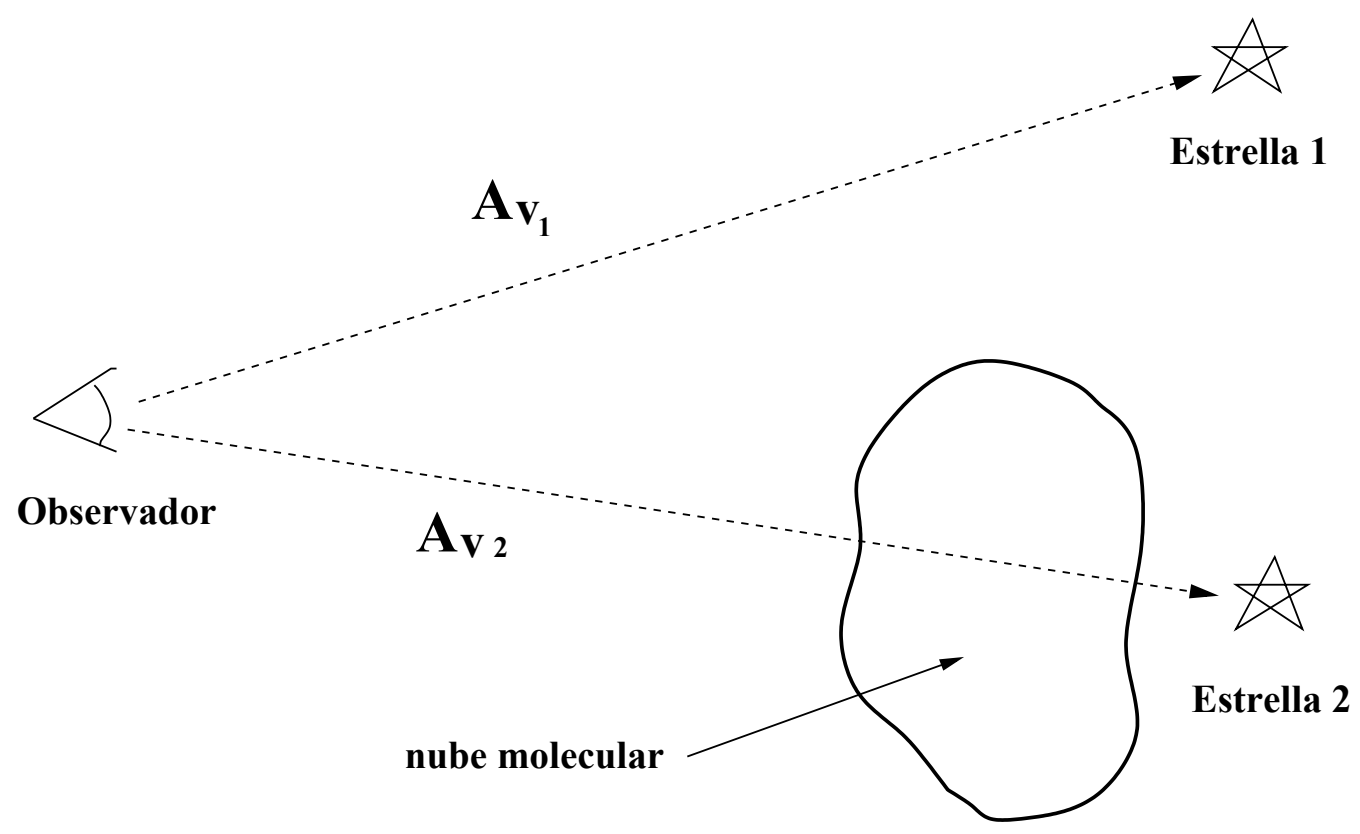

Figura 4.13:

De acuerdo a este escenario la estrella 1 sufrirá una absorción visual $\mathrm{A}_{V_{1}}=\mathrm{R}_{V} \times$

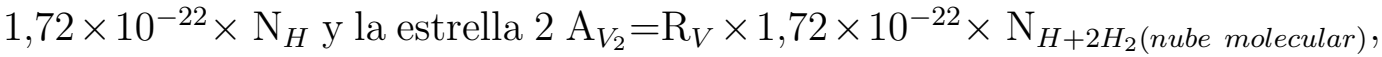
o sea que la diferencia en magnitudes de absorción entre la estrella 1 y la 2 se debe exclusivamente a la nube molecular, o sea que:

$$
\Delta A_{V}=A_{V_{1}}-A_{V_{2}}=R_{V} \times 1,72 \times 10^{-22} \times N_{H_{2}(\text { nube molecular })}
$$

Determinando de alguna manera $\Delta A_{V}$ es posible obtener una estimación de la densidad de columna de una nube molecular sin hacer ningún tipo de especulaciones acerca de la física de emisión de sus líneas. Una estimación de $\mathrm{A}_{V_{1}}$ y $\mathrm{A}_{V_{2}}$ puede derivarse a partir de la relación entre la extinción (o enrojecimiento) con la absorción visual. Ésta es apreciable en los diagramas color-color en el IR cercano (bandas J,H y K). En la Figura 4.14 está representado un esquema simple del diagrama $(\mathrm{J}-\mathrm{H})$ vs $(\mathrm{H}-\mathrm{K})$ en el que se muestra la ubicación en el mismo de las estrellas 1 y 2 de la Figura 4.13. Se puede observar que la estrella 2 está más alejada de la curva que representa las estrellas enanas sin enrojecer que la estrella 1 ; es decir que $A_{V_{1}}<A_{V_{2}}$. Por lo tanto, observando en la dirección de la estrella 1 y de la estrella 2 pero obteniendo los colores 
de un grupo de estrellas (y no sólo de una), es posible inferir una absorción representativa en cada una de estas direcciones. Luego restándolas entre sí, es posible obtener una estimación de $\Delta \mathrm{A}_{V}$.

$(\mathbf{J}-\mathbf{H})$

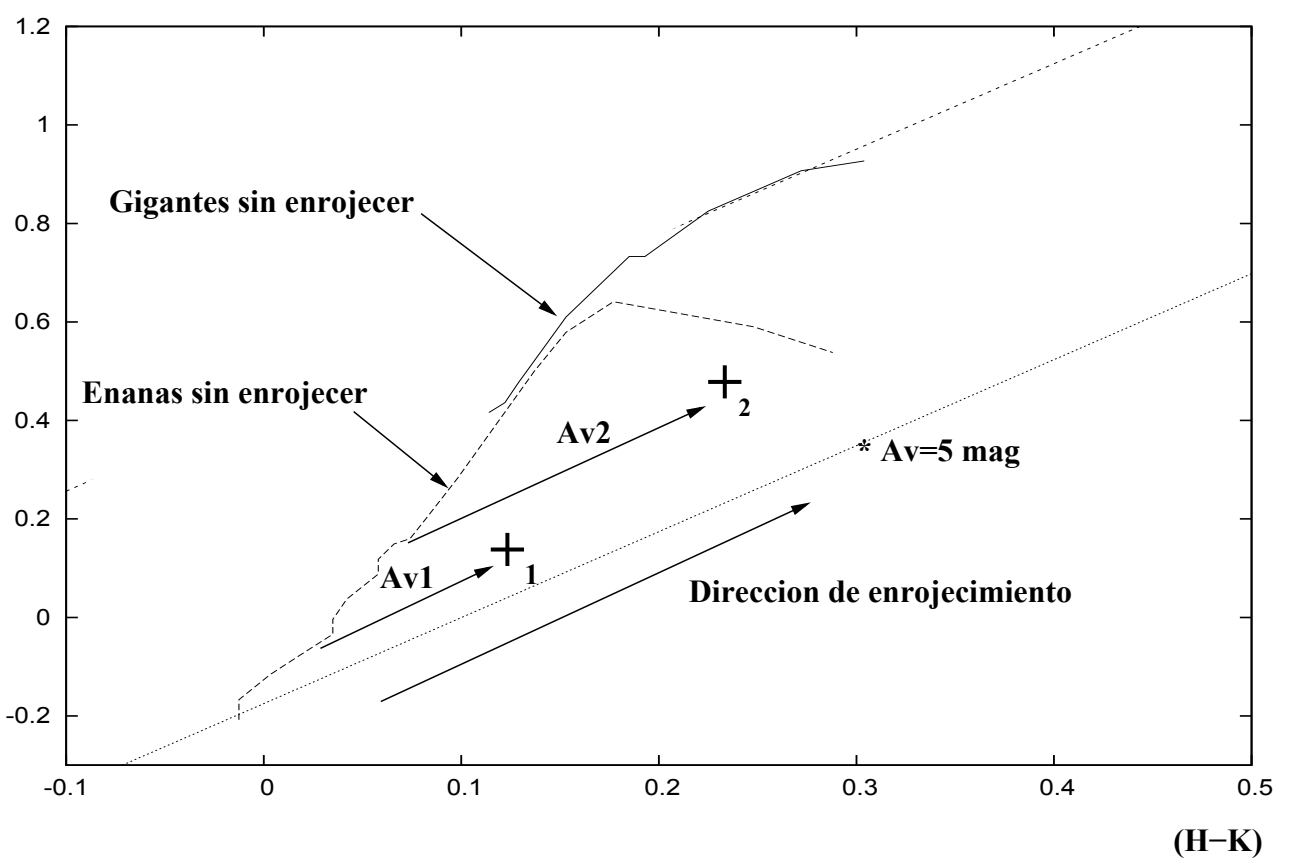

Figura 4.14: Esquema de un diagrama color-color en el IR cercano en el que se encuentran las estrellas 1 (no enrojecida por la nube molecular) y la estrella 2 (enrojecida por la nube molecular).

Utilizando la información de las magnitudes J,H y K del catálogo 2MASS para algunos puntos en la dirección del AME así como también de zonas fuera del mismo, donde no hay detección de la línea ${ }^{12} \mathrm{CO}(1-0)$, es posible graficar los diagramas color-color para dichas posiciones. Sólo se tomaron aquellas fuentes con relación señal/ruido $>10$ (calidad AAA). En la Figura 4.15 se muestran los diagramas $(\mathrm{J}-\mathrm{H})$ vs. $(\mathrm{H}-\mathrm{K})$ para estrellas ubicadas en la dirección del AME (panel inferior) y estrellas ubicadas fuera de éste (panel superior). La búsqueda de las fuentes se realizó en áreas circulares de $3^{\prime}$ de radio indicadas por las circunferencias punteadas en las figuras de la derecha. Puede apreciarse cualitativamente el comportamiento esperado, es decir que en la dirección del AME, hay una mayor cantidad de estrellas enrojecidas (mayor $\mathrm{A}_{V}$ ).

En la Figura 4.16 se muestran histogramas en los que se representan el número de estrellas que tienen una $\mathrm{A}_{V}$ dada. Las líneas de trazos corresponden a las estrellas observadas hacia el AME, mientras que las líneas sólidas identifican las estrellas de la zona de comparación. A fin de reducir la confusión originada por las estrellas gigantes, las estrellas utilizadas para confeccionar 

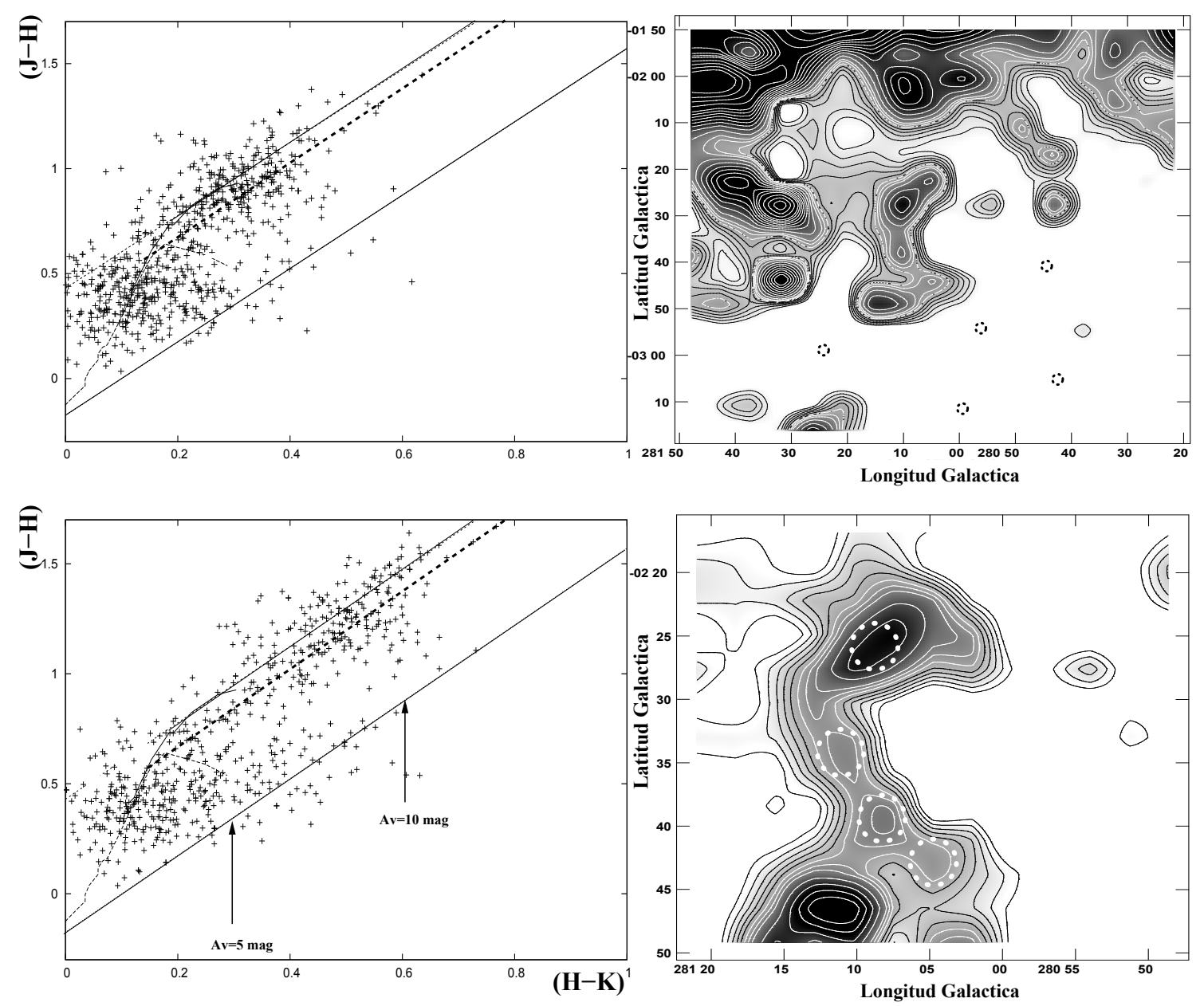

Figura 4.15: Panel superior izquierdo: Diagrama color-color para estrellas ubicadas fuera de la extensión del AME. Panel superior derecho: Emisión de CO en el rango de velocidad $-6,5$ a $-3,5 \mathrm{~km} / \mathrm{seg}$. Las posiciones donde se obtuvieron las fuentes 2MASS están indicadas por las circunferencias punteadas. Paneles inferiores. Idem panel superior pero en la dirección del AME. Las líneas punteadas en los diagramas color-color representan los límites en el diagrama de las estrellas usadas para confeccionar los histogramas (ver texto)

los histogramas se ubican por debajo de la recta de enrojecimiento superior de las enanas (ver Figura 4.15). Los anchos de las barras $\left(\sim 1 \mathrm{~A}_{V}\right)$ fueron adoptados en base a los errores de las magnitudes fotométricas del relevamiento 2MASS. Los histogramas reflejan el comportamiento explicado anteriormente, es decir que existe una mayor cantidad de estrellas enrojecidas en la dirección del AME.

La resta directa de estos histogramas permitiría, en teoría, eliminar a todas las estrellas que han sufrido los mismos procesos de absorción en ambas direcciones; en otras palabras el histograma resultante podría interpretarse como el histograma representativo de las absorciones producidas exclusivamente por el AME. En la Figura 4.17 se muestra el histograma resultante de la resta 


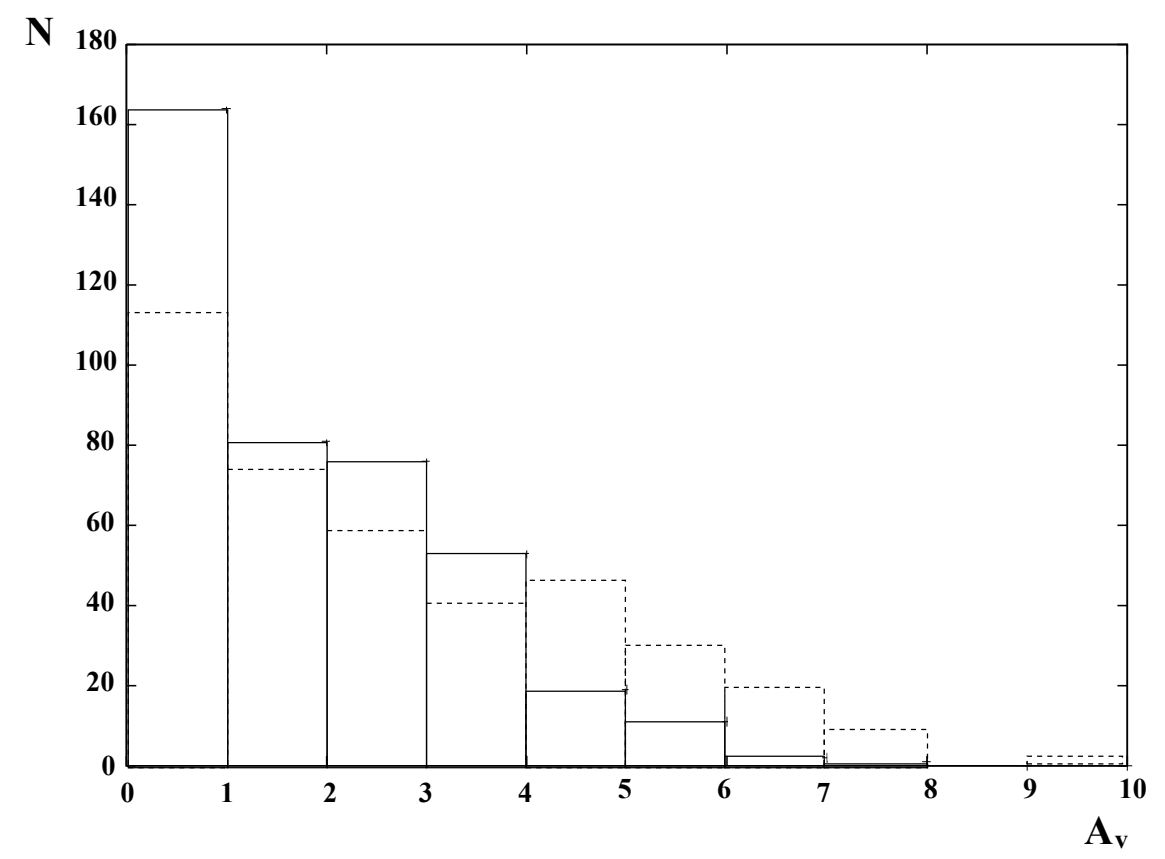

Figura 4.16: Histogramas en el que se representan las absorciones visuales de las estrellas. El histograma de trazos discontinuos representa a las estrellas observadas en la dirección del AME, y el de trazos continuos a las estrellas fuera de éste.

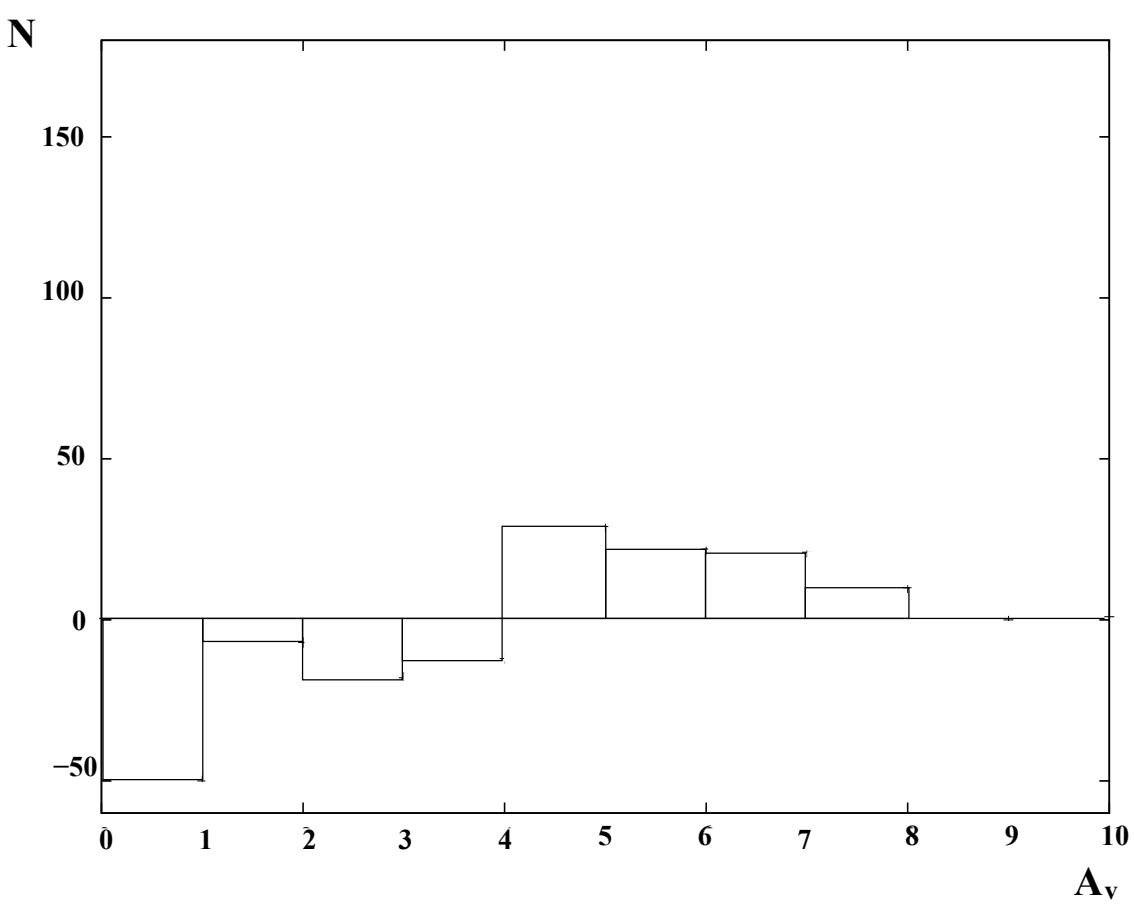

Figura 4.17: Histograma resultante de la resta entre los histogramas correspondientes a objetos en la dirección del AME y en la direcciones fuera de éste. 
mencionada anteriormente. Los barras con valores negativos corresponderían a estrellas que no han sufrido la absorción de esta nube molecular, es decir a aquellas estrellas que no están en la dirección del AME y aquellas que sí lo están pero se encuentran delante del mismo. Por otra parte, las barras con valores positivos representarían a las estrellas que han sufrido absorción del AME, es decir aquellas estrellas que se encuentran por detrás del mismo. Entre los valores positivos, puede observarse que las absorciones visuales entre 4 y 7 , son las más frecuentemente producidas para estrellas ubicadas por detrás del AME, por lo tanto estos valores serían los más indicados para representar la absorción visual producida por el mismo.

De esta manera considerando un valor intermedio de $A_{V} \approx 6$, a partir de la Ecuación 4.6 obtenemos un valor de $N_{H_{2}} \approx 8 \times 10^{21}$ moléculas $/ \mathrm{cm}^{2}$. Si comparamos este valor de densidad de columna con el obtenido por Marston et al. (1999) $\left(N_{H_{2}}=7 \times 10^{18}\right.$ moléculas $\left./ \mathrm{cm}^{2}\right)$ y el que se obtiene de usar la Ecuación $3.3\left(N_{H_{2}} \approx 1 \times 10^{21}\right.$ moléculas $\left./ \mathrm{cm}^{2}\right)$, puede apreciarse que esta última está en mejor acuerdo. Es decir que la emisión del material molecular del AME se asemeja más a la emisión del material molecular promedio en la Vía Láctea. Este hecho reafirma aún más la suposición de que el AME es de origen interestelar.

Cabe destacar que el método desarrollado anteriormente posee grandes fuentes de error y no es recomendado para determinar en forma exacta el valor de $N_{H_{2}}$; sin embargo aquí se lo ha empleado tan sólo para tener una idea de los órdenes de magnitud de dicho valor, a fin de compararlo con los valores obtenidos por otros métodos.

\section{Distancia al AME}

Uno de los principales parámetros a determinar para el AME es su distancia. Utilizando el modelo de rotación circular galáctico (Brand \& Blitz, 1993) es posible obtener la distancia cinemática. En base a la distribución en velocidad observada para el $\mathrm{CO}$ en la Figura 4.7, la velocidad sistémica que fue adoptada para el AME es $\sim-6 \mathrm{~km} / \mathrm{seg}$. En la Figura 4.18 se muestra la relación velocidad radial vs. distancia obtenida de la curva de rotación galáctica para una longitud galáctica $l=281^{\circ}$. En esta figura se encuentra señalada la velocidad radial sistémica adoptada para el AME.

Debido a la ambigüedad en la distancia para este cuadrante, a la velocidad radial $-6 \mathrm{~km} / \mathrm{seg}$, le corresponden los valores de distancia cercano y lejano de 0,7 y 2,6 kpc respectivamente. La distancia cinemática lejana 2,6 kpc coincide con la distancia (dentro de los errores) de 2,37 $\pm 0,9 \mathrm{kpc}$ encontrada para WR 16 (van der Hucht et al., 2001). 


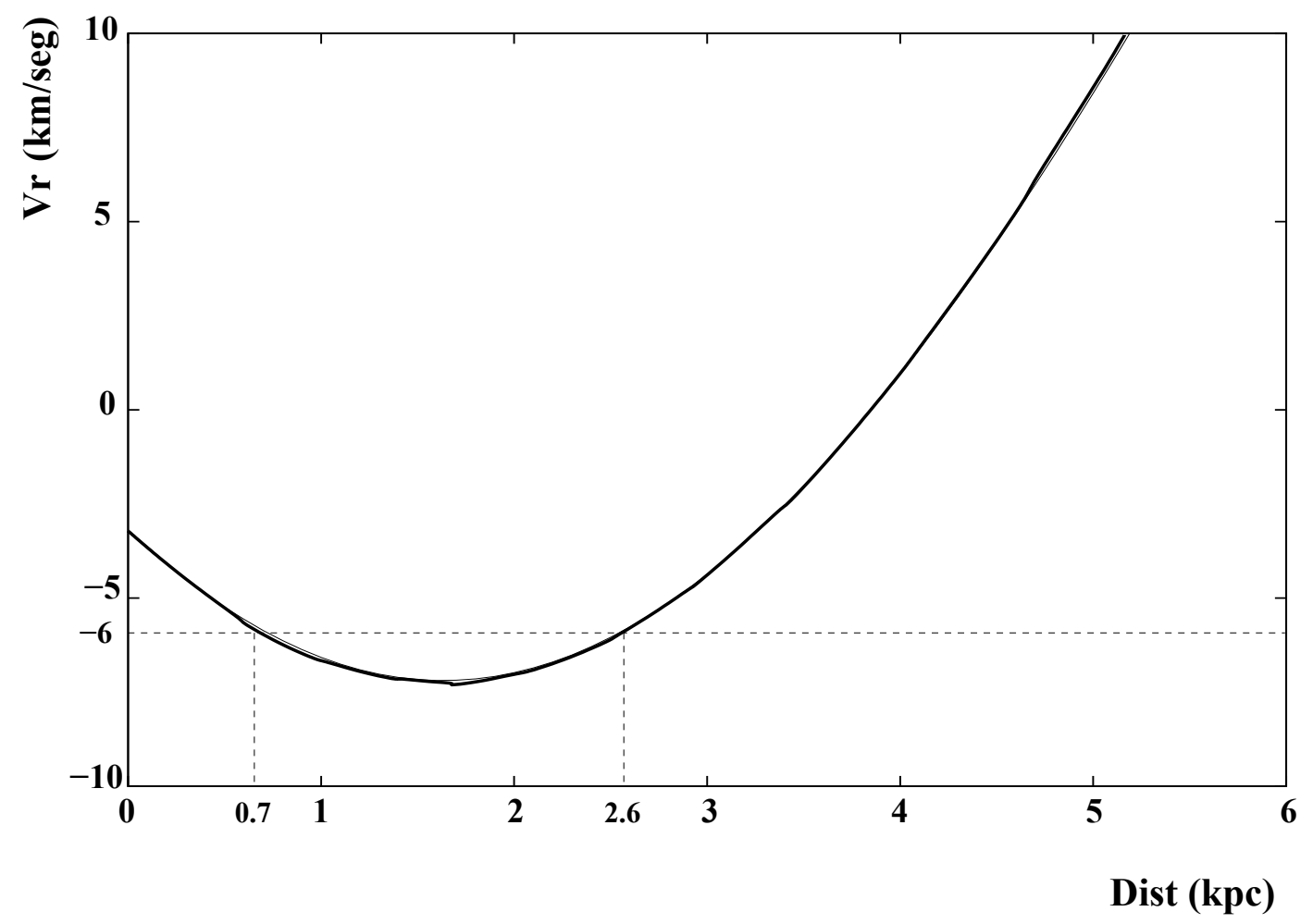

Figura 4.18: Curva de rotación galáctica obtenida para $l=281^{\circ}$

\section{Subcomponente A1: Son los vientos de WR 16 responsables de $\underline{\text { su velocidad? }}$}

En la Sección 4.2 se mostró que la componente A estaba conformada por dos subcomponentes denominadas A1 y A2, las cuales se encuentran muy próximas entre sí, tanto angularmente como en velocidad. La subcomponente A2 es visible en un rango más pequeño de velocidad, y a velocidades entre $-9,6$ a $-9,5 \mathrm{~km} / \mathrm{seg}$ su morfología se asemeja a la emisión en $\mathrm{H} \alpha$ e IR en $60 \mu \mathrm{m}$. A esta estructura se la denominó AMI y muy probablemente esté formada por material molecular de origen estelar (esta estructura se analizará en detalle en la próxima sección). Por otro lado, la subcomponente A1 es más intensa y se encuentra presente en un intervalo de velocidad más extenso (ver Figura 4.11). Esta diferencia en las intensidades y velocidades radiales entre la subcomponente A1 y el AMI muy probablemente las convierta en dos estructuras moleculares completamente distintas entre sí que se encuentran proyectadas en casi la misma dirección de la visual.

En la Sección 4.2 se mencionó también la posibilidad de que la subcomponente A constituya algun tipo de "casquete" molecular que se dirige hacia el observador, expandiéndose junto con el AME debido posiblemente a los efectos 
producidos por los vientos de WR 16 (ver Figura 4.7). De acuerdo al escenario planteado en el párrafo anterior, este posible "casquete" asociado al AME estaría conformado sólo por la subcomponente A1. En la Figura 4.19 se muestra la distribución de CO asociada al AME y a la subcomponente A1 (integrada en el intervalo $-10,6$ a $-9,7 \mathrm{~km} / \mathrm{seg}$ ) superpuestas.

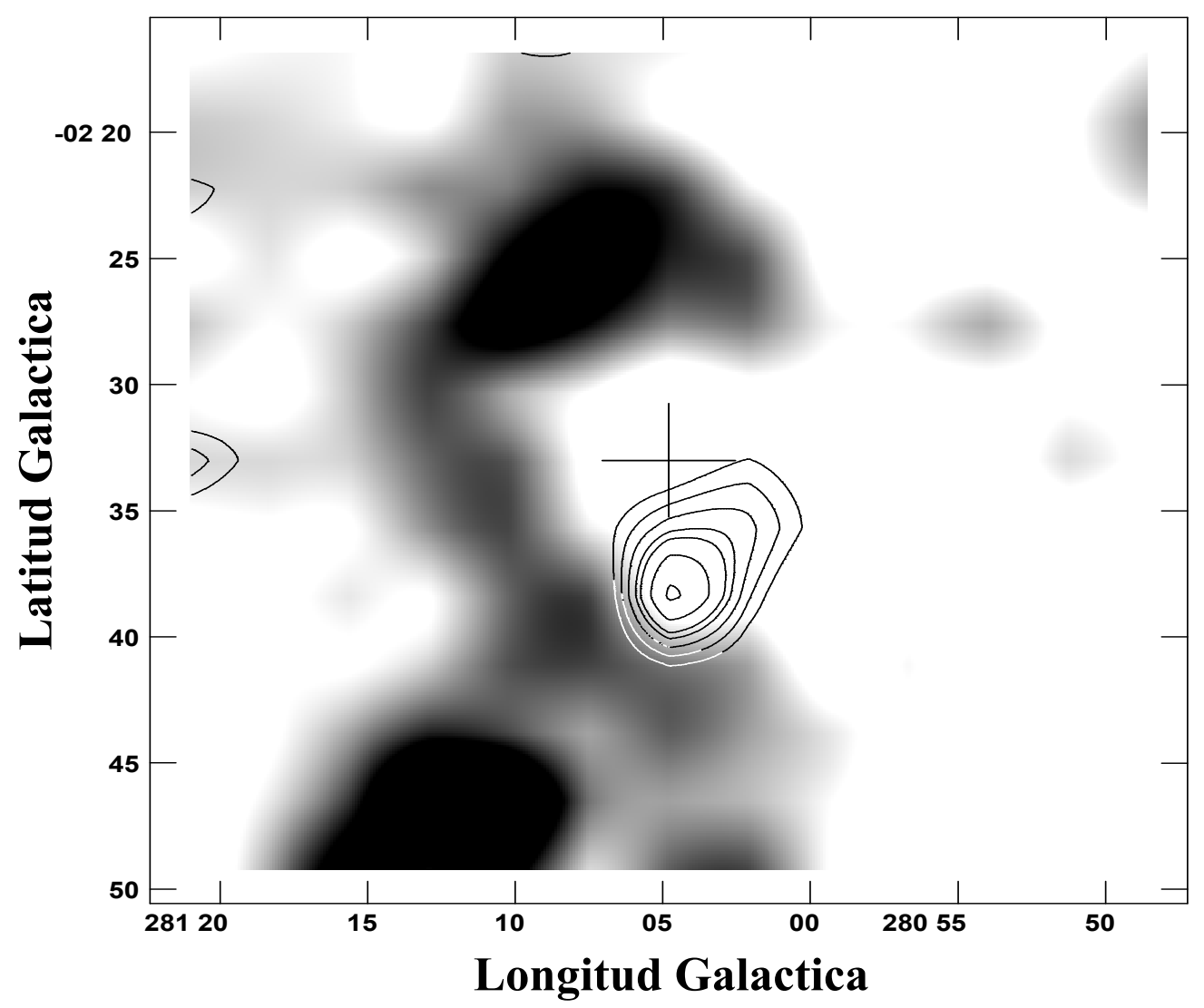

Figura 4.19: Superposición de la distribución de emisión del CO correspondiente al AME (tono de grises) con la subcomponente A1 (líneas de contorno). La posición de WR 16 está representada por la cruz en el centro.

¿Es posible que la velocidad de la subcomponente A1 se deba a la interacción de la misma con los vientos de la estrella WR 16? En el siguiente análisis nos proponemos investigar esta posibilidad. En la Figura 4.20 se presenta el esquema utilizado para este fin.

En la Figura 4.20 están representadas la posición del observador, separado de la estrella WR 16 por una distancia $d$, y separado de la subcomponente A1 por una distancia $d_{1}$. El ángulo sólido subtendido por la subcomponente A1 desde el observador está representado por $\Omega$ y el ángulo de separación entre el observador y el centro de la subcompomente A1 (visto desde la estrella WR 16) 


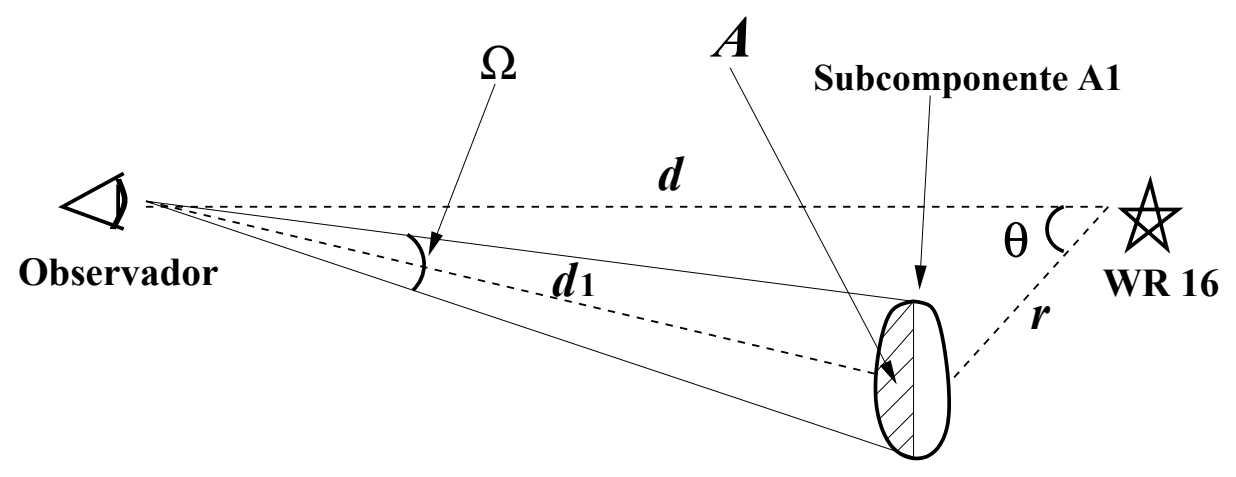

Figura 4.20: Esquema utilizado el el cálculo de la posible distancia entre la subcomponente A1 y la estrella WR 16.

está representado por $\theta$. La distancia entre la estrella y A1 está representada por $r$. El área de A1 (indicada con $A$ ) está dada por:

$$
A=\Omega \times d_{1}^{2} \quad \text { con } \quad d_{1}^{2}=(d-r \times \cos (\theta))^{2}+(r \times \operatorname{sen}(\theta))^{2}
$$

Desarrollando los cuadrados y reorganizando,

$$
d_{1}^{2}=d^{2} \times\left(1+(r / d)^{2}-2(r / d) \times \cos (\theta)\right)
$$

De esta manera, considerando $\mathrm{r} / \mathrm{d}<<1$

$$
A \approx d^{2} \times \Omega
$$

Por el motivo explicado a comienzos de la Sección 4.4, se considerará que la subcomponente A1 sólo fue afectada por los vientos producidos en la Secuencia Principal. Si consideramos una masa inicial para WR 16 en la Secuencia Principal del orden de $50 \mathrm{M}_{\odot}(\mathrm{O} 5 \mathrm{~V})$, la tasa de pérdida de masa para este tipo espectral (suponiendo abundancias metálicas sola es) $\log (\dot{M})=-6,24$ y su velocidad terminal es $\mathrm{v}_{\infty}=2870 \mathrm{~km} / \mathrm{seg}$ (Smith et al., 2002), por lo tanto la liminosidad del viento será $\mathrm{L}_{w}=1,4 \times 10^{36} \mathrm{erg} / \mathrm{seg}$; el tiempo de vida en esta fase es del orden de $\mathrm{t}_{S P} \sim 4,3 \times 10^{6}$ años (Schaller et al., 1992). Por lo tanto la energía mecánica inyectada al MIE durante la Secuencia Principal es $\mathrm{E}_{w} \sim$ $1,9 \times 10^{50} \mathrm{erg}$. Se considerará una eficiencia de conversión de energía mecánica del viento en energía cinética de la nube molecular $\left(\epsilon=\mathrm{E}_{\text {cin gas molec }} / \mathrm{E}_{\text {mec WR16 }}\right)$ de $\sim 0,03$ (valor encontrado empíricamente para las BI a partir de las observaciones). De esta manera la cantidad de energía mecánica inyectada por la estrella O progenitora de WR 16 que puede ser "usada" para incrementar la energía cinética de las nubes moleculares adyacentes es $\sim 6 \times 10^{48}$. La energía mecánica (convertible en energía cinética) que atravesó una unidad de área a una distancia $r$ de la estrella es $6 \times 10^{48} \mathrm{erg} / 4 \pi \mathrm{r}^{2}$. La subcomponente A1, con una masa $\mathrm{M} \sim 400 \mathrm{M}_{\odot}$ (ver Tabla 4.1) y una velocidad de expansión $\mathrm{v}_{\text {exp }} \sim$ $4 \mathrm{~km} / \mathrm{seg}$ (respecto de una velocidad sistémica $\mathrm{v}_{\text {sist }} \sim-6 \mathrm{~km} / \mathrm{seg}$ ) posee una 
energía cinética $\mathrm{E}_{c}(A 1) \sim 6,4 \times 10^{46}$ erg. Si se supone una emisión isotrópica del viento, la cantidad de energía cinética por unidad de área es la misma para cualquier punto de la esfera de radio $r$, entonces

$$
\frac{6 \times 10^{48} \mathrm{erg}}{4 \pi r^{2}}=\frac{6,4 \times 10^{46} \mathrm{erg}}{A} \text { o también } \frac{6 \times 10^{48} \mathrm{erg}}{4 \pi r^{2}}=\frac{6,4 \times 10^{46} \mathrm{erg}}{d^{2} \times \Omega}
$$

por lo tanto

$$
r=\sqrt{\frac{6 \times 10^{48} \mathrm{erg} \times d^{2} \times \Omega}{4 \pi \times 6,4 \times 10^{46} \mathrm{erg}}}=2,73 \times d \times \sqrt{\Omega}
$$

Siendo $\Omega=2,69 \times 10^{-6}$ ster y $d=2,37 \pm 0,9 \mathrm{kpc}$, obtenemos $r=10,6 \pm$ 4,1 pc (el error en $r$ fue calculado principalmente en base a la incertidumbre en la distancia de la estrella). El tiempo necesario para que la subcomponente A1 recorra esta distancia a una velocidad $\mathrm{v}_{\exp } \sim 4 \mathrm{~km} / \mathrm{seg}$ es aproximadamente $3 \times 10^{6}$ años, el cual es muy similar al tiempo de vida de una estrella con la masa inicial considerada para WR 16 en la fase de Secuencia Principal.

Es decir que de acuerdo a su distancia a la estrella WR 16, la subcomponente A1 podría estar siendo impulsada a una velocidad $\sim 4 \mathrm{~km} / \mathrm{seg}$ por el viento de la estrella. Por este motivo, la subcomponente A1 se considerará desde ahora asociada cinemáticamente al AME.

\section{Parámetros físicos asociados al AME y a la subcomponente A1}

Por lo visto hasta aquí, el AME y la subcomponente A1 pueden considerarse como distintas componentes de una estructura molecular en expansión. Por un lado, se observa una expansión lateral, o perpendicular a la línea de la visual, evidenciada por la casi perfecta coincidencia espacial entre el borde interior del AME y la nebulosa $\mathrm{H} \alpha$ más interna que rodea a WR 16 (ver Figura 4.5). Por otro lado, lo que podría interpretarse como una expansión radial, evidenciada por la ubicación, velocidad y posible distancia a la estrella WR 16 de la subcomponente A1. Esta última podría ser interpretada como un casquete acercándose hacia el observador (ver Figura 4.7).

En la Tabla 4.1 se listan los parámetros físicos calculados para el AME y la subcomponente A1. La distancia considerada para el AME y la subcomponente A1 es de 2,37 $\pm 0,9 \mathrm{kpc}$. La densidad de columna fue calculada utilizando la Ecuación 3.3. El valor de la extinción visual $\left(\mathrm{A}_{V}\right)$ fue obtenido de la relación $\mathrm{N}_{H_{2}} / \mathrm{A}_{V}=0,94 \times 10^{21} \mathrm{~cm}^{-2} \mathrm{mag}^{-1}$ (Bohlin et al., 1978)

Considerando una masa de $\sim 3000 \mathrm{M}_{\odot}$ para el AME y de $\sim 400 \mathrm{M}_{\odot}$ para la subcomponente A1, la energía cinética total del sistema $\mathrm{AME}+\mathrm{A} 1$ es $\mathrm{E}_{\text {cin }} \sim$ $5,5 \times 10^{47} \mathrm{erg}$, la cual es inferior a la energía mecánica inyectada al MIE por la fase O previa a la fase WR. Esta diferencia puede explicarse tal vez debido a una pobre eficiencia en la conversión de energía mecánica en energía cinética 
de las nubes moleculares. Además el sistema AME + A1 no rodea en forma total a WR 16, por lo tanto sólo una parte de la energía mecánica radiada por la estrella es utilizada para poner en movimiento el material molecular.

Tabla 4.1: Principales parámetros físicos determinados para el AME y la subcomponente A1. La posición del centro del AME corresponde a la posición de WR 16.

\begin{tabular}{|c|c|c|}
\hline Parámetro & $\mathrm{AME}$ & A1 \\
\hline Centro $\left(l^{\circ}, b^{\circ}\right)$ & $281,08-2,55$ & $281,083-2,64$ \\
\hline Radio angular $\left({ }^{\prime}\right)$ & 7,9 & 1,8 \\
\hline Radio lineal (pc) & 5,37 & 1,24 \\
\hline Extensión en velocidad (km/seg) & $\sim 4,5$ & $\sim 1,4$ \\
\hline Velocidad sistémica (km/seg) & $\sim-6$ & $\sim-6$ \\
\hline Velocidad de expansión (km/seg) & $\sim 4$ & $\sim 4$ \\
\hline Angulo sólido (ster) & $2,43 \times 10^{-5}$ & $2,69 \times 10^{-6}$ \\
\hline Densidad de columna $\left(\mathrm{cm}^{-2}\right)$ & $1,0 \times 10^{21}$ & $1,1 \times 10^{21}$ \\
\hline Masa de $H_{2}\left(M_{\odot}\right)$ & $3000 \pm 2000$ & $400 \pm 300$ \\
\hline Energía cinética (erg) & $4,8 \times 10^{47}$ & $6,4 \times 10^{46}$ \\
\hline $\mathrm{A}_{V}(\mathrm{mag})$ & $\sim 1$ & $\sim 1,2$ \\
\hline
\end{tabular}

\subsubsection{El Anillo Molecular Interno}

\section{Análisis morfológico:}

La morfología del AMI hace pensar inmediatamente en una componente molecular que está claramente asociada a la zona más interna de la nebulosa anillo múltiple asociada a la estrella WR 16. Sin embargo una estructura que 
es tan claramente identificable con las observaciones de resolución angular intermedia de NANTEN (HPBW $=2^{\prime}, 7$ ), sería esperable que fuera identificable también con observaciones de elevada resolución angular. Esta estructura no fue encontrada por Marston et al. (1999), quienes utilizaron observaciones de alta resolución angular $\left(\mathrm{HPBW}=45^{\prime \prime}\right)$. ¿Es posible que el AMI sea el resultado de un efecto fortuito debido a un espaciado insuficiente al cubrir la zona central de la nebulosa?

En la Figura 4.21 se muestran los apuntamientos llevados a cabo con el telescopio NANTEN en la zona de WR 16. En esta figura se puede apreciar la óptima cobertura en la zona interna de la nebulosa anillo que rodea a WR 16. Puede observarse también que las zonas más brillantes y notorias de la nebulosa anillo interna visible en $\mathrm{H} \alpha$ han sido cubiertas completamente.

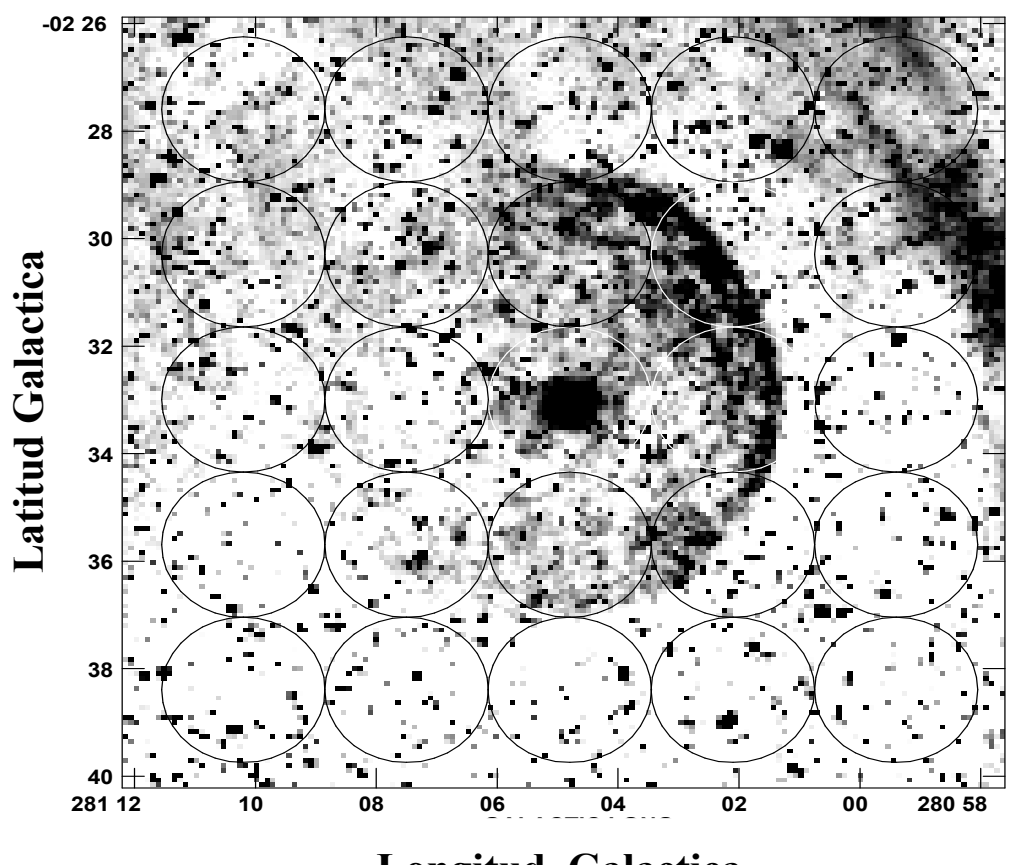

Longitud Galactica

Figura 4.21: Esquema de los apuntamientos realizados en la región de WR 16, superpuesto con la imagen $\mathrm{H} \alpha$ de la nebulosa.

En la Figura 4.22 se muestra la emisión en $60 \mu \mathrm{m}$ de alta resolución (HIRES) de la nebulosa anillo interna alrededor de WR 16 superpuesta con la emisión de ${ }^{12} \mathrm{CO}$ en el rango de velocidades de $-9,61$ a $-9,5 \mathrm{~km} / \mathrm{seg}$ en la cual se observa al AMI. Al igual que en el caso de la emisión en $\mathrm{H} \alpha$ (ver Figura 4.9), la distribución de ${ }^{12} \mathrm{CO}$ delinea casi perfectamente la emisión del polvo en el infrarrojo cercano. En esta figura puede observarse una emisión intensa hacia el oeste, tanto en la banda IR como en ${ }^{12} \mathrm{CO}$. A esta emisión se la denominará Brazo O. En la misma figura se muestra el perfil de emisión del Brazo $O$ para la línea de CO y para la emisión de $60 \mu \mathrm{m}$. La dirección en la 
que fue tomado el perfil (ver panel superior) es aquella en la cual el Brazo O presenta su emisión más conspicua e intensa. En dicha figura puede apreciarse la perfecta coincidencia en la posición de los máximos de emisión para las dos frecuencias en las que fueron realizados los perfiles.
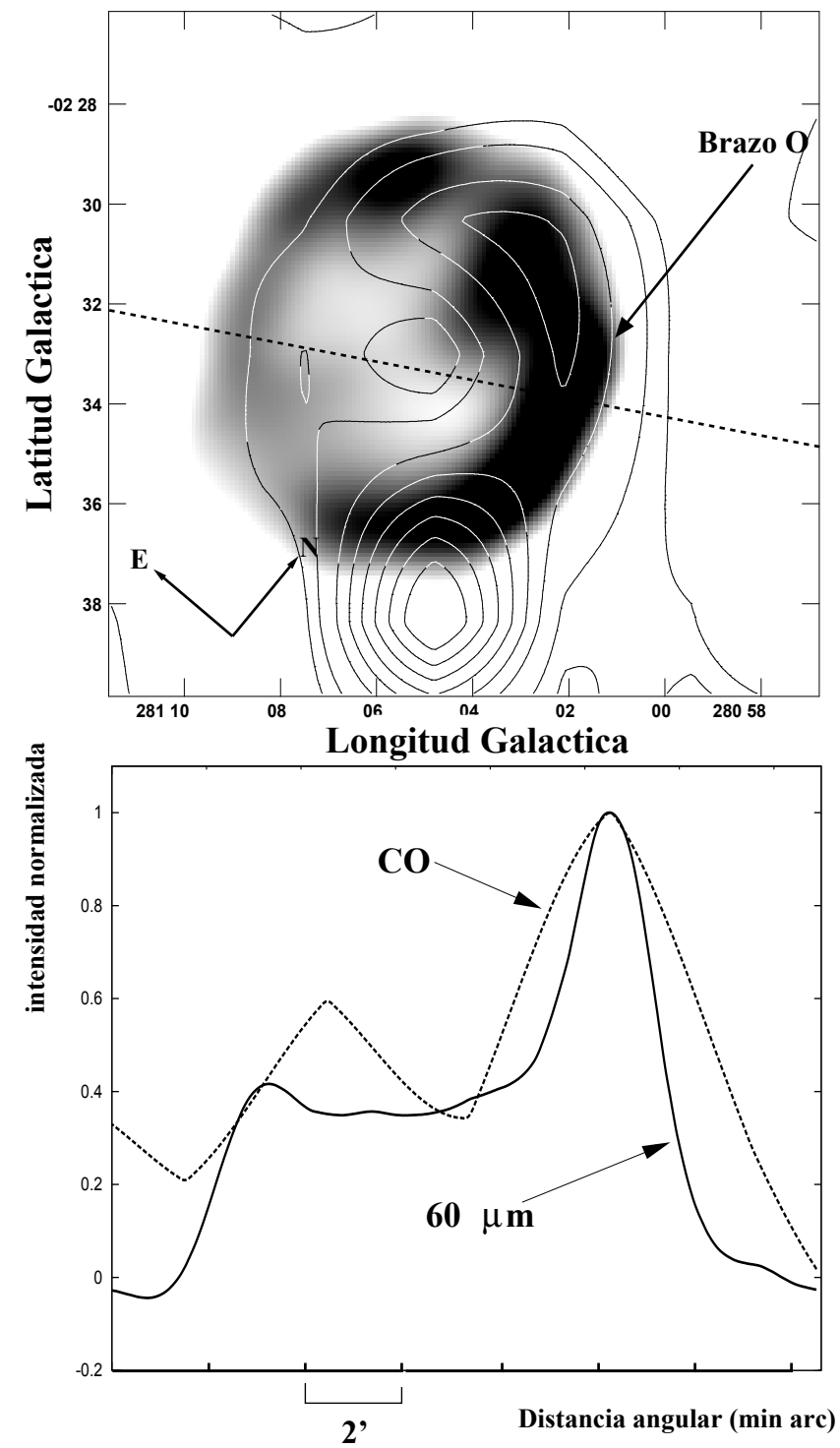

Figura 4.22: Panel superior Superposición de la imagen de $60 \mu \mathrm{m}$ (tono de grises) con la emisión de CO correspondiente al AMI (contornos). La línea de puntos representa la dirección en la que se obtuvieron los perfiles de emisión en $60 \mu \mathrm{m}$ y CO. Panel inferior perfiles de emisión obtenidos en $60 \mu \mathrm{m}$ y en $\mathrm{CO}$.

En la Figura 4.23 (panel superior) se muestra la emisión en $60 \mu \mathrm{m}$ de la nebulosa anillo interna convolucionada a una haz común de $2^{\prime}, 7$ y superpuesta con la emisión de ${ }^{12} \mathrm{CO}$ en el rango de velocidades que corresponde al AMI $(-9,61 \mathrm{a}-9,5 \mathrm{~km} / \mathrm{seg})$. Sobre estas imágenes se realizaron integraciones en 
anillos concéntricos de 15 segundos de arco de ancho, los cuales estaban centrados en la posición de la estrella WR 16. El ángulo de integración fue elegido de manera tal de no incluir la emisión de A1. De esta manera se obtuvieron los perfiles de emisión promedio para ambas frecuencias (panel inferior).
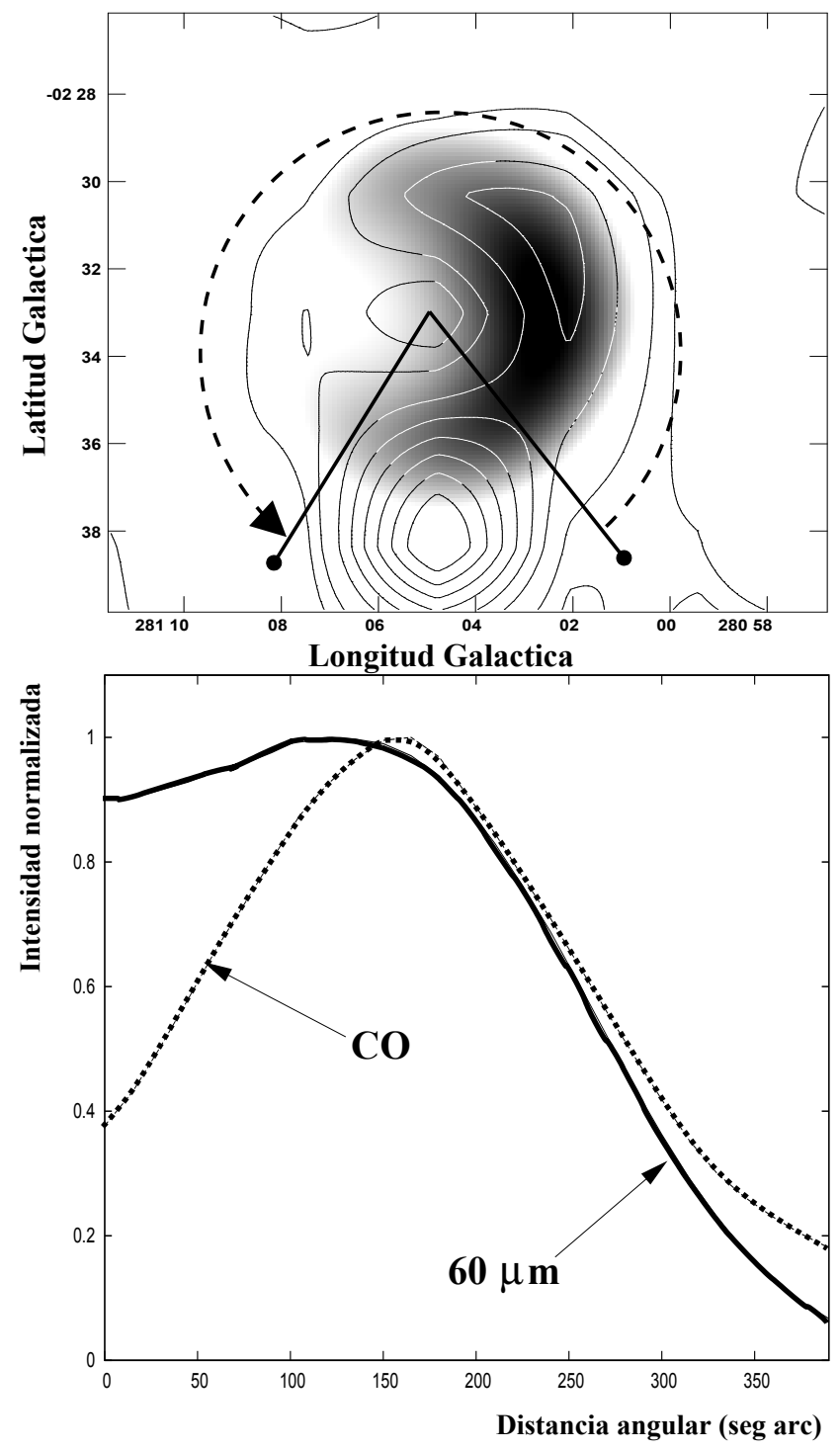

Figura 4.23: Panel superior Superposición de la imagen de $60 \mu \mathrm{m}$ convolucionada a un haz de $2^{\prime}, 7$ (tono de grises) con la emisión de CO correspondiente al AMI (contornos). La flecha en línea de puntos representa la dirección en la que se realizó la integración en anillos concéntricos en la emisión en $60 \mu \mathrm{m}$ y CO. Panel inferior perfiles de emisión obtenidos en $60 \mu \mathrm{m}$ (línea continua) y en CO (línea de trazos).

Como puede observarse, la emisión promedio en ambas frecuencias es muy similar hacia la zona externa de la estructura. El máximo de emisión se encuentra en ambos casos a una distancia angular de la estrella de $\sim 150$ se- 
gundos de arco. Por otro lado, la emisión correspondiente a la zona interna de la estructura presenta alguna diferencia entre ambas emisiones. El perfil que corresponde a la emisión en $60 \mu \mathrm{m}$ posee una pendiente menos pronunciada que la correspondiente a la emisión de $\mathrm{CO}$, aunque este exceso de emisión es originado por la presencia de una pequeña estructura perteneciente al anillo, ubicada a $2^{\prime}$ de la estrella en la dirección norte.

¿Es posible que esta coincidencia morfológica sea debida a efectos de proyección de estructuras no vinculadas físicamente entre sí? Para investigar la posibilidad de que esta coincidencia se deba al azar se generó, mediante un programa FORTRAN, una serie de tres números aleatorios: los dos primeros representan la posición del centro de una estructura anular con las mismas dimensiones que el AMI y el tercero representa el ángulo de posición de la misma. El ángulo de posición se midió desde un eje cuyo origen es la estrella y cuya dirección está dada por la dirección de eje de latitud galáctica. La tolerancia en la posición del centro (primeros dos valores) está dada por la posibilidad de que cualquier punto caiga en un área equivalente al haz, mientras que la tolerancia en el ángulo de inclinación (tercer valor) esta dada por el ángulo subtendido por el semihaz desde la posición central (ver Figura 4.24)

(tolerancia en el angulo de inclinacion)

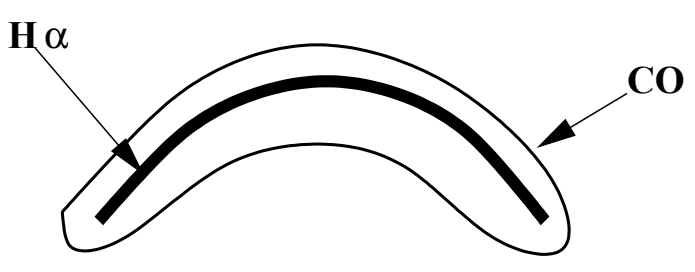

CO

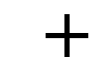

CENTRO

(WR 16)
HAZ DEL TELESCOPIO

(tolerancia en la posicion del centro)

Figura 4.24: Esquema en el que se explican las variables aleatorias consideradas para evaluar la posibilidad de coincidencia morfológica al azar entre las estructuras observadas.

Contando la cantidad de puntos que caen en la posición del centro (dentro de la tolerancia en posición) y con un ángulo de inclinación similar al del máximo del anillo $\mathrm{H} \alpha$ (dentro de la tolerancia en el ángulo de inclinación), es posible calcular la probabilidad de que la correlación morfológica observada entre los objetos observados en CO, H $\alpha$ e IR sea fortuita. Se hicieron 100 corridas y en cada una de ellas se generaron $10^{8}$ valores al azar para cada uno de los parámetros. Cada una de las corridas se inició con números semilla aleatorios. 
La probabilidad obtenida es del orden de $\sim 0.3 \%$. En otras palabras, la posibilidad de que una estructura como la del AMI coincida en forma casual con la nebulosa vista en $\mathrm{H} \alpha$ y en $60 \mu \mathrm{m}$ en posición e inclinación es extremadamente baja. Por lo expresado hasta aquí, se considerará que el AMI es efectivamente la contraparte molecular de la nebulosa interna $\mathrm{H} \alpha$ y del anillo visible en 60 $\mu \mathrm{m}$ que rodean a WR 16.

\section{Análisis cinemático:}

La morfología del AMI así como también la de sus contrapartes en $\mathrm{H} \alpha$ y 60 $\mu \mathrm{m}$ hacen suponer que el mismo consiste en alguna clase de cáscara esférica o envoltura circumestelar alrededor de WR 16. En la Figura 4.25 (panel superior) se muestra el perfil de emisión de CO a lo largo de la línea punteada que se muestra en el panel inferior; se pueden observar dos componentes ubicadas a ambos lados del mínimo, el cual posee un valor de intensidad no nulo.

En la Sección 4.3, se hizo mención al intervalo de velocidades angosto en el que es visible el AMI $(\sim 0,1 \mathrm{~km} / \mathrm{seg})$. Claramente un intervalo de velocidades de este orden implicaría una velocidad de expansión para la cáscara muy baja para una estructura de este tipo, incluso para fases en las que el viento es más lento (RSG). Una posible explicación a este intervalo de velocidades tan angosto implica la existencia de una estructura que no posea material molecular moviéndose en la dirección de la visual. Es decir que pueda estar tal vez expandiéndose en dirección tangencial a la visual pero no radial. En la Figura 4.26 se muestra un diagrama esquemático de un modelo simple para explicar la emisión observada en la Figura 4.25 así como también el corto intervalo de velocidades observado en el AMI.

El modelo consiste en una sección de una cáscara esférica determinada por un ángulo de corte $(\Theta)$ medido desde la posición de WR 16, con simetría radial a lo largo de la línea de la visual y expandiéndose radialmente desde la estrella. En este modelo se supone también que la emisividad por unidad de volumen es constante y que el material molecular emisor es ópticamente delgado, por lo que la emisión a lo largo de una línea de la visual dada es directamente proporcional a la extensión de la misma dentro del material emisor. En este esquema, los perfiles de emisión constan de tres partes, cada una de ellas originadas por tres zonas en las que la longitud del material emisor varía geométricamente en forma distinta (ver Figura 4.26)

Este modelo nos permite cambiar parámetros como el ángulo de corte $\Theta$ y el radio interno, con lo cual se obtienen distintos perfiles de emisión. Los perfiles obtenidos del modelo deben ser convolucionados con un haz de $2^{\prime} .7$ para poder efectuar una comparación con el perfil de emisión observado en la Figura 4.25. La determinación del ángulo de corte puede ser realizada en base a las velocidades observadas. Al observar una estructura en expansión, las velocidades radiales observadas pueden deberse a movimientos en la dirección de la visual o bien a las proyecciones de los mismos en esta dirección. En la 

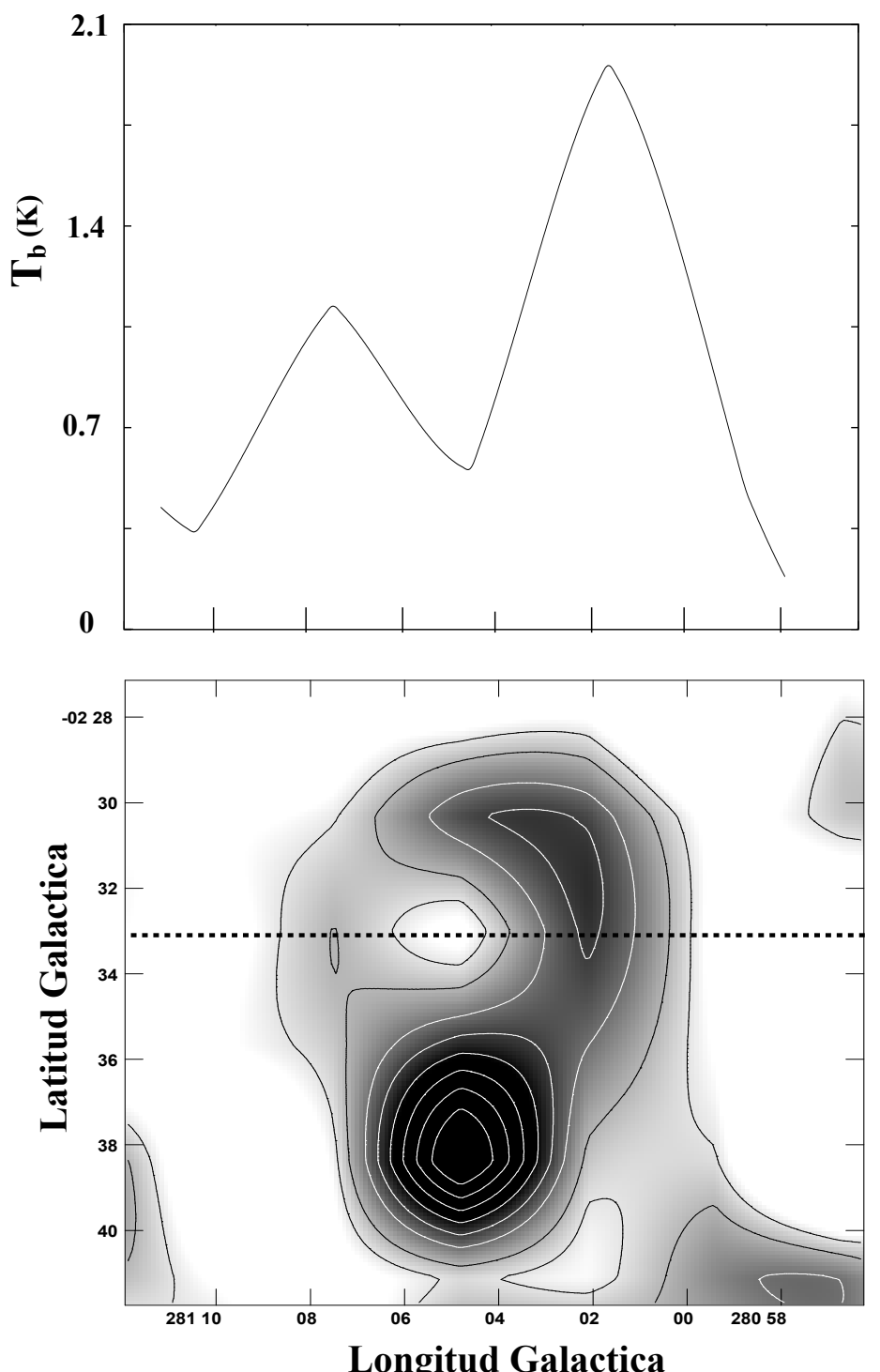

Figura 4.25: Panel superior: Perfil de emisión a lo largo de la longitud del AMI. Panel inferior: Dirección en la que fue obtenido el perfil.

Figura 4.27 se muestran esquemáticamente, las componentes de las velocidades de nuestro modelo.

Si consideramos que la estructura se expande radialmente con una velocidad $\mathrm{V}_{\text {exp }}$, entonces las componentes de esa velocidad en la dirección de la visual serán $\pm \mathrm{V}_{\text {exp }} \operatorname{sen}(\Theta / 2)$. Si la estructura se mueve con una velocidad sistémica $V_{0}$, entonces el observador la verá en un rango de velocidades que va desde $V_{0}$ $+\mathrm{V}_{\text {exp }} \operatorname{sen}(\Theta / 2)$ hasta $\mathrm{V}_{0}-\mathrm{V}_{\text {exp }} \operatorname{sen}(\Theta / 2)$. Por lo tanto el máximo intervalo de velocidad en el que sería visible la estructura será $\Delta \mathrm{V}_{\max }=\left(\mathrm{V}_{0}+\mathrm{V}_{\text {exp }}\right.$ $\operatorname{sen}(\Theta / 2)-\left(\mathrm{V}_{0}-\mathrm{V}_{\text {exp }} \operatorname{sen}(\Theta / 2)=2 \mathrm{~V}_{\text {exp }} \operatorname{sen}(\Theta / 2)\right.$. En secciones anteriores se mencionó la posibilidad de que el AMI haya sido formado en alguna etapa 

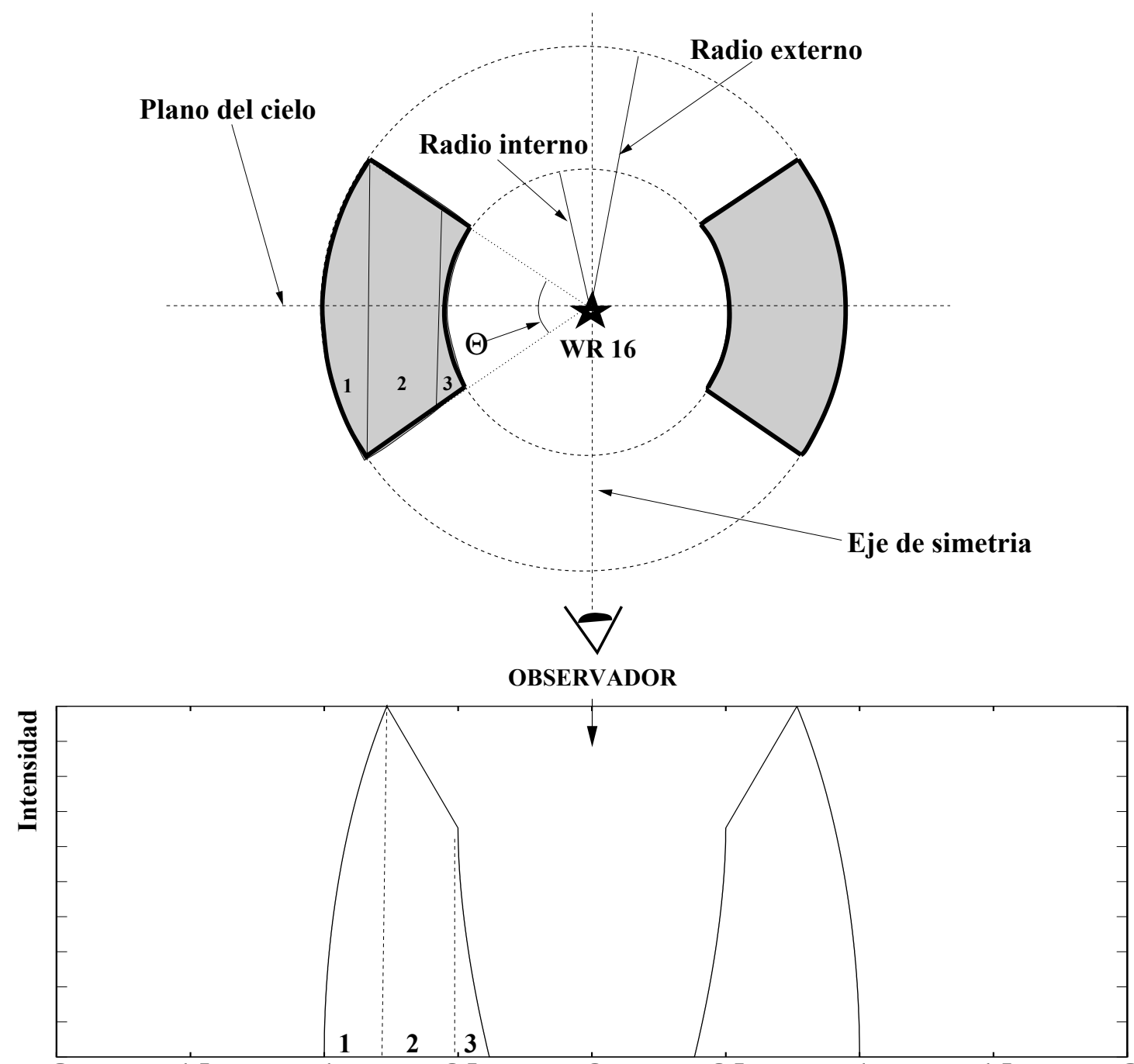

Distancia angular

Figura 4.26: Diagrama esquemático del modelo propuesto para explicar el AMI

intermedia entre la Secuencia Principal y la fase WR, en la que también la atmósfera fuera lo suficientemente fría como para que puedan formarse las moléculas sin ser destruídas. Esta fase, posiblemente, sea la RSG. Para esta fase las velocidades terminales del viento estelar son muy bajas y tienen valores entre 10 y $25 \mathrm{~km} / \mathrm{seg}$ (Leitherer, Robert \& Drissen, 1992). Considerando estos valores para las velocidades terminales y distintos valores del ángulo de corte $(\Theta)$, es posible encontrar distintos valores de $\Delta V_{\max }$ y así compararlos con el intervalo de velocidades observado para el AMI. En la Tabla 4.2 se muestran algunos de estos valores.

Como puede observarse de la Tabla 4.2, el ángulo de corte cuyo valor aproxima al intervalo de velocidades observado para el AMI $(0,1 \mathrm{~km} / \mathrm{seg})$ es $\Theta \sim 1^{\circ}$. 

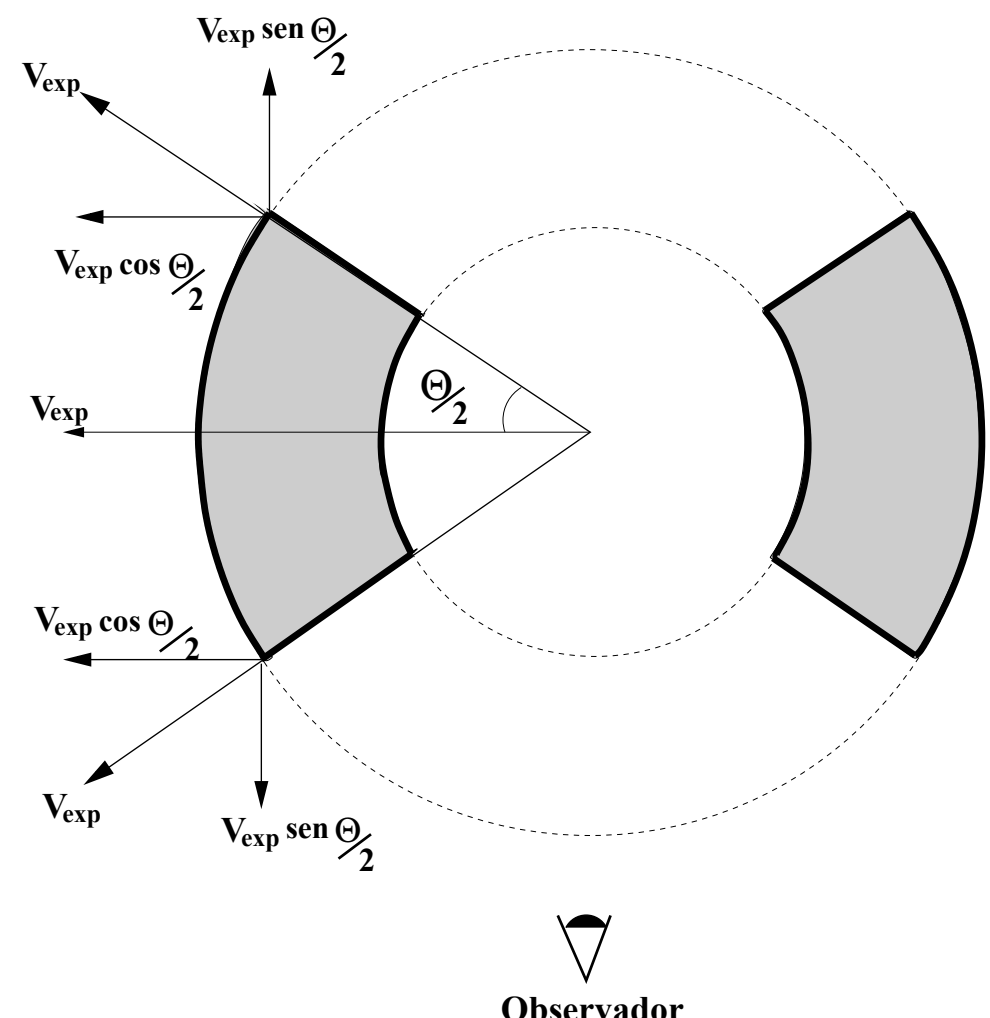

Figura 4.27: Diagrama en el que se muestran las componentes de las velocidades del modelo propuesto para el AMI

Tabla 4.2: Relación Angulo de corte - $\Delta \mathrm{V}_{\max }$

\begin{tabular}{l|r}
\hline \hline$\Theta\left(^{\circ}\right)$ & $\Delta V_{\max }(\mathrm{km} / \mathrm{seg})$ \\
\hline 5 & $\sim 1-2$ \\
3 & $\sim 0,5-1,5$ \\
2 & $\sim 0,35-0,85$ \\
1 & $\sim 0,15-0,4$ \\
\hline
\end{tabular}

Es decir que para explicar este intervalo tan pequeño de velocidades, el ángulo de corte debe ser también muy pequeño, lo que le confiere a la estructura una morfología similar a la de un disco. 
La determinación del radio interno de la estructura puede hacerse en base a un análisis del perfil de emisión de la Figura 4.28. En esta figura se muestran los perfiles de emisión teóricos obtenidos del modelo descripto anteriormente para distintos valores del radio interno (en veces de $\mathrm{R}_{\text {ext }}$ ) y un ángulo de corte $\Theta=1^{\circ}$. Los perfiles fueron convolucionados a un haz equivalente de $2^{\prime}, 7$.

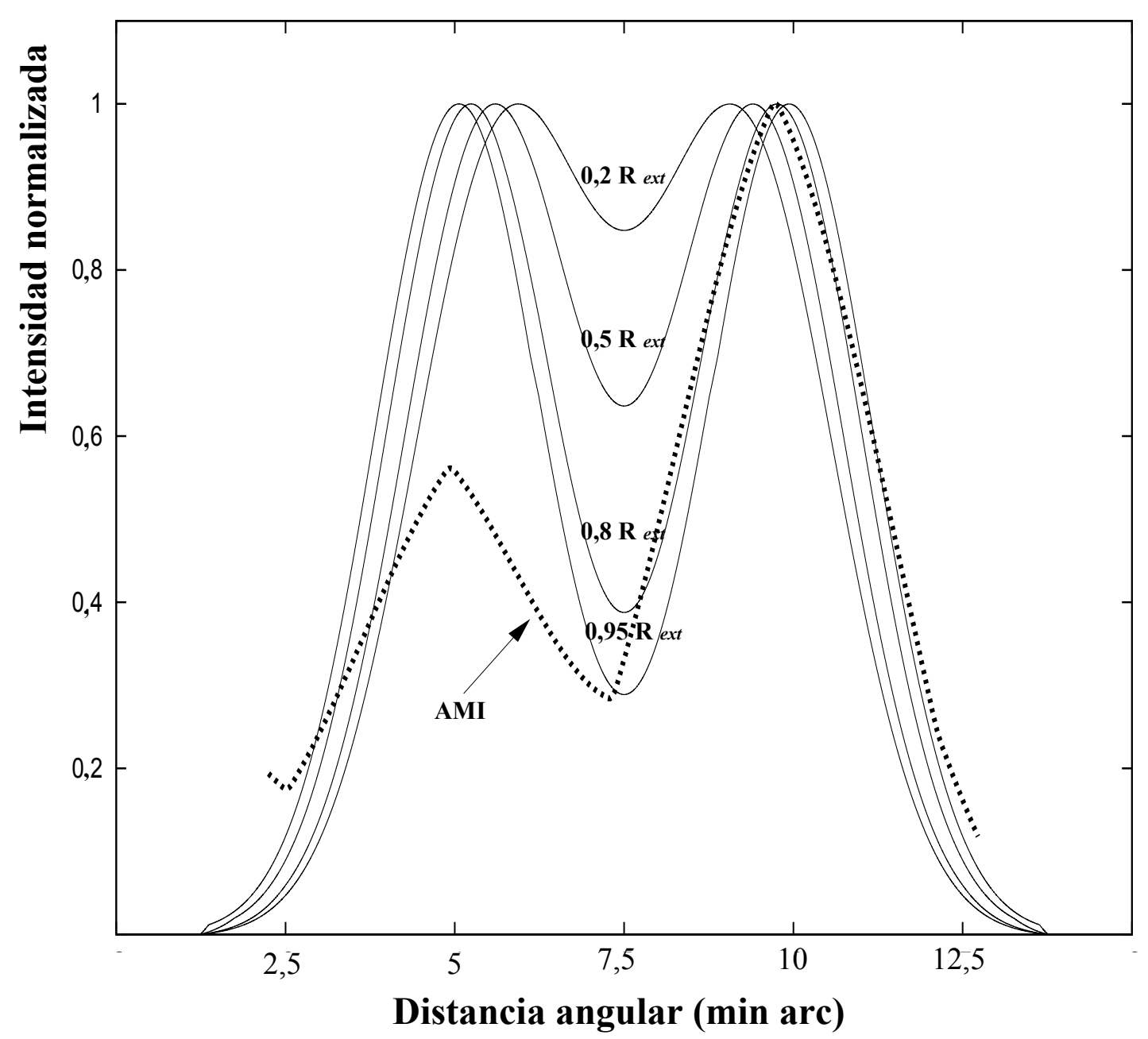

Figura 4.28: Perfiles de emisión teóricos obtenidos del modelo para $\Theta=1^{\circ}$ y diferentes valores del $\mathrm{R}_{\text {int }}$ (líneas continuas) convolucionados a un haz equivalente de $2^{\prime}, 7$. El perfil de emisión observado del AMI está representado por la línea de trazos.

En la Figura 4.28 puede observarse que el perfil teórico que mejor ajusta con el observado es aquel construido con un $\mathrm{R}_{\text {int }}=0,95 \mathrm{R}_{\text {ext }}$. Existe una clara diferencia en la intensidad de la componente izquierda entre el perfil observado y los teóricos, que podría ser resultado de alguna asimetría en la distribución del material molecular. Este efecto, no está considerado en nuestro modelo.

Por lo tanto, de acuerdo al modelo propuesto, el AMI podría explicarse como un disco/anillo circumestelar ubicado casi en el plano del cielo, con un radio 
interno que es aproximadamente igual al radio externo. Los discos circumestelares han sido considerados en numerosos trabajos. Los mismos parecen haber sido detectados alrededor de numerosas estrellas gigantes, especialmente de tipo B[e] (Mc Gregor, Hillier \& Hyland, 1988, Kraus \& Lamers, 2003) y Variables Luminosas Azules (LBV) (Nota et al., 2002); también han sido modelados como resultado de una elevada rotación estelar (Bjorkman \& Casinelli, 1993). Los discos circumestelares parecen ser según los modelos, las estructuras más indicadas para explicar la presencia tanto de material molecular como de granos de polvo, en las cercanías de estrellas cuyo campo radiativo es muy intenso. Los discos circumestelares (especialmente los formados por una elevada rotación estelar) podrían acumular en la región ecuatorial el suficiente material molecular con la densidad requerida tanto para la emisión de las líneas moleculares como también para "autoapantallar" al material molecular (y a los granos de polvo) de la intensa radiación estelar.

\section{Propiedades físicas del AMI:}

Como ya fue expresado anteriormente, el AMI parecería tener un origen estelar. La interrogante que se plantea es similar a la planteada para el caso del AME: ¿Cómo calcular la masa? Muy probablemente el método utlizado para calcular la masa del AME a partir de su densidad de columna, con la Ecuación 3.3, no sea el indicado. Como ya se explicó en el Capítulo 3, esta ecuación refleja un comportamiento general del material molecular en el medio interestelar de la galaxia. Por lo tanto, sólo puede ser aplicada al material molecular del medio intertestelar. No es ilógico suponer que el material molecular que se origine en las atmósferas estelares no tenga un comportamiento similar al material molecular galáctico, por lo que el cálculo de la masa requiera un enfoque diferente.

Como ya se describió en la sección anterior, la suposición de que el material molecular pueda ser ópticamente delgado, ofrece una alternativa para el cálculo de la masa. Si el material molecular cumple con esta condición, la emisión de la línea molecular proveniente de todas las moléculas a lo largo del material emisor es capaz de llegar al observador. Por lo tanto, bajo la suposición de que el ${ }^{12} \mathrm{CO}$ es ópticamente delgado, la masa calculada es en realidad un límite inferior, ya que de no serlo sólo estaríamos observando la emisión de las líneas provenientes de las moléculas exteriores y así la masa calculada tendría un error por defecto.

Existen indicios de presencia de material molecular ópticamente delgado en los alrededores de estrellas gigantes. Olofsson, Eriksson, Gustafsson \& Carlström (1993) estudiaron la emisión de CO alrededor de sesenta y ocho estrellas de Carbón galácticas, y encontraron que muchas de ellas podían explicarse en base a una envoltura de material molecular ópticamente delgado.

Utilizando la Ecuación 4.4, usando una distancia de 2,37 $\pm 0,9$ kpc, una 
temperatura de excitación $T_{x} \sim 15 \mathrm{~K}$, y una $I_{C O}=0,07 \mathrm{~K} \mathrm{~km} / \mathrm{seg}$, el valor obtenido para la densidad de columna de ${ }^{12} \mathrm{CO}$ del AMI es $N_{C O} \geq 5,2 \times$ $10^{14}$ moléculas $/ \mathrm{cm}^{2}$. Usando arbitrariamente el valor $f=N_{C O} / N_{H_{2}}=4 \times 10^{-4}$ (Oudmaijer et al. 1996), la densidad de columna de $\mathrm{H}_{2}$ es $N_{H_{2}} \geq 1,3 \times 10^{18}$ moléculas $/ \mathrm{cm}^{2}$. Así la masa total de $\mathrm{H}_{2}$ es $\mathrm{M} \geq 0,07 \mathrm{M}_{\odot}$.

En la Tabla 4.3 se listan algunos parámetros físicos asociados al AMI, calculados a partir de su emisión en CO e IR.

Tabla 4.3: Principales parámetros físicos determinados para el AMI

\begin{tabular}{|c|c|}
\hline $\mathrm{CO}$ & \\
\hline $\begin{array}{l}\text { Centro }\left(l^{\circ}, b^{\circ}\right) \\
\text { Radio angular }\left({ }^{\prime}\right) \\
\text { Radio lineal }(\mathrm{pc}) \\
\text { Extensión en velocidad }(\mathrm{km} / \mathrm{seg}) \\
\text { Angulo sólido }(\mathrm{sr}) \\
\mathrm{N}_{\mathrm{H}_{2}}\left(\mathrm{~cm}^{-2}\right) \\
\text { Masa de } H_{2}\left(M_{\odot}\right) \\
\text { Energía cinética }(\mathrm{erg}) \\
\mathrm{A}_{V}\left({ }^{(}\right)\end{array}$ & $\begin{array}{r}281,08-2,55 \\
2,7 \\
1,9 \\
\sim 0,1 \\
4,35 \times 10^{-6} \\
\geq 1,3 \times 10^{18} \\
\geq 0,07 \\
\sim 1,5 \times 10^{44} \\
\geq 1,4 \times 10^{-4}\end{array}$ \\
\hline IR & \\
\hline $\begin{array}{l}\text { Radio angular }\left(^{\prime}\right) \\
\text { Radio lineal }(\mathrm{pc}) \\
\mathrm{F}_{60 \mu m}(\mathrm{Jy}) \\
\mathrm{F}_{100 \mu m}(\mathrm{Jy}) \\
\mathrm{T}_{\text {polvo }}(\mathrm{K})(m=1,5)^{(\dagger \dagger)} \\
\left.\mathrm{M}_{\text {polvo }}{ }^{(\dagger \dagger}\right)\left(M_{\odot}\right)\end{array}$ & $\begin{array}{r}2,2 \\
1,4 \\
80 \pm 6 \\
26 \pm 2 \\
85 \pm 12 \\
\sim 3 \times 10^{-3}\end{array}$ \\
\hline
\end{tabular}

(†) Valor calculado en base a una velocidad de expansión de entre 10 y $25 \mathrm{~km} / \mathrm{seg}$

(††) Índice de emisividad utilizado (ver Capítulo 3)

(††) Este valor posee un error de $\sim 100 \%$ debido al error del $\sim 40 \%$ en la distancia.

El elevado valor obtenido para la temperatura del polvo $\left(\mathrm{T}_{\text {polvo }}\right)$ podría ser consecuencia de la cercanía del AMI a WR 16. La relación gas-polvo obtenida para el AMI es $\sim 20$, valor que es aproximadamante un orden de magnitud menor al encontrado por Oloffsson et al. (1987) (350 \pm 100$)$ para las envolturas circumestelares alrededor de estrellas de $\mathrm{C}$ ricas en $\mathrm{N}$. 


\subsection{Resumen y conclusiones}

El análisis de la emisión de la línea rotacional $(\mathrm{J}=1 \rightarrow 0)$ de la molécula de ${ }^{12} \mathrm{CO}$ en los alrededores de la estrella WR 16 reveló la presencia de tres estructuras moleculares que evidencian una clara asociación morfológica y física entre ellas y con la nebulosa anillo alrededor de la estrella.

1. El AME: esta estructura corresponde a la estructura molecular encontrada por Marston et al. (1999) y que fuera denominada "capullo molecular" en dicho trabajo.

2. La subcomponente A1: se encuentra casi en la dirección de la visual de la estrella WR 16.

3. El AMI: se encuentra íntimamente asociado a la nebulosa anillo alrededor de WR 16 y su ubicación es en una posición interior al AME.

Después de un análisis realizado a estas componentes se pudo concluir que:

- El AME está formado por material molecular interestelar, y su morfología puede explicarse como el resultado de una interacción con los vientos de WR 16 en un estadío evolutivo más temprano, posiblemente durante la Secuencia Principal.

- La subcomponente A1 es una estructura molecular cuya velocidad radial pudo también ser el resultado de una interacción de la misma con los vientos de la estrella WR 16. Posiblemente estos vientos han sido originados en el mismo estadío evolutivo que el que interaccionó con el AME.

- El AME y la subcomponente A1 estarían físicamente asociadas conformando un complejo molecular que se mueve a una velocidad sistémica de $\sim-6 \mathrm{~km} / \mathrm{seg}$. El mismo se está expandiendo respecto de la posición de la estrella WR 16 a una velocidad $\sim 4 \mathrm{~km} / \mathrm{seg}$.

- El AMI consiste en material molecular eyectado por la estrella WR 16 en un estadío evolutivo en el cual su atmósfera era más fría, posiblemente en la etapa RSG. Por las características morfológicas y cinemáticas de esta componente, podemos concluir que el AMI consiste en alguna estructura 
de tipo disco/anillo dispuesta en forma casi paralela al plano del cielo (face-on). Este tipo de estructura permite explicar no sólo la morfología observada sino también la ausencia de material molecular moviéndose en la dirección del observador. Una estructura de este tipo podría asegurar la densidad suficiente para autoapantallar al material molecular que se encuentra por detrás del frente de ionización del AMI.

- Los vientos y la radiación de WR 16 no han llegado a actuar en forma apreciable sobre el AMI (y aún menos sobre el AME), de otra manera no podría explicarse la presencia de material molecular tan cercano a la estrella, a pesar del probable autoapantallamiento. Esto podría significar que la estrella WR 16 (tipo espectral WN8) ha comenzado la fase WR recientemente, lo cual corrobora la secuencia evolutiva $W N \mapsto W C \mapsto$ WO. 


\subsection{Bibliografía}

- Bjorkman, J. E.; Cassinelli, J. P., 1993, ApJ, 409, 429B

- Bohlin, R.C., Savage B.D., \& Drake J.F., 1978, ApJ, 224, 132

- Brand, J. \& Blitz, L., 1993, A\&A, 275, 67

- García-Segura, G. \& Mac Low, M. M., 1995, ApJ, 455, 145

- Kraus, M.; Lamers, H. J. G. L. M., 2003, A\&A, 405, 165K

- Leitherer, C., Robert, C. \& Drissen, L., 1992, ApJ, 401, 596

- Marston, A. P., 1995, AJ, 109, 1839M

- Marston, A. P., Wellzmiller, J. T., Black, J. H., Bransford, M. A., Berman P.,1999a, ApJ, 518, 769

- McGregor, Peter J.; Hyland, A. R.; Hillier, D. J., 1988, ApJ, 334, 639M

- Nota, A.; Pasquali, A.; Marston, A. P.; Lamers, H. J. G. L. M.; Clampin, M.; Schulte-Ladbeck, R. E., 2002, AJ, 124, 2920N

- Olofsson, H.; Eriksson, K.; Gustafsson, B., 1987, A\&A, 183L, 130

- Olofsson, H.; Eriksson, K.; Gustafsson, B.; Carlstroem, U., 1993, ApJS, 87,3050

- Oudmaijer, Rene D.; Groenewegen, M. A. T.; Matthews, H. E.; Blommaert, J. A. D. L.; Sahu, K. C., 1996, MNRAS, 280, 1062 O

- Schaller, G.; Schaerer, D.; Meynet, G.; Maeder, A., 1992, A\&AS, 96, 269S

- Smith, Linda J.; Norris, Richard P. F.; Crowther, Paul A., 2002, MNRAS, 337, 1309S

- van der Hucht, K. A., 2001, NewAR, 45, 135V 


\section{Capítulo 5}

\section{El complejo MIE en los alrededores de WR 18}

\subsection{La nebulosa NGC 3199}

La region HII NGC 3199 (RCW 48) es una nebulosa óptica de forma irregular, que rodea a la estrella WR 18 (HD 89358) (Chu, 1981). Esta nebulosa está formada por una estructura intensa ubicada $5^{\prime}$ al oeste de la estrella (que desde ahora se llamará "borde brillante oeste" (BBO), y otra hacia el este que es apenas visible y está constituida por dos filamentos (ver Figura 5.1). Esto le confiere a la nebulosa una morfología de "doble cáscara". Una de las mismas, que llamaremos cáscara interna, está conformada por el BBO y el filamento que se ubica a lo largo de $l \sim 283^{\circ} 40^{\prime}$, y la otra, que denominaremos cáscara externa también constituida por el BBO y el filamento ubicado a $l \sim 283^{\circ} 47^{\prime}$. La cáscara interna posee una forma ovoide, mientras que la cáscara externa es casi circular (ver Figura 5.1).

NGC 3199 fue estudiada en continuo de radio a $408 \mathrm{MHz}$ (Shaver \& Goss, 1970) y a $2650 \mathrm{MHz}$ (Smith \& Batchelor, 1970). Deharveng \& Maucherat (1974) realizaron un estudio espectroscópico basado en las líneas H $\alpha$ y NII tomadas en 282 posiciones dentro de la nebulosa y concluyeron que la misma se está expandiendo con una velocidad de $30 \mathrm{~km} / \mathrm{seg}$. Chu (1982) realizó un estudio cinemático utilizando observaciones en las líneas $\mathrm{H} \alpha$ y OIII, y encontró dentro del BBO un gradiente de velocidades con velocidades más negativas en la dirección de WR 18. Además encontró desdoblamientos en las líneas (splitting) en la dirección de la estrella y de los filamentos débiles hacia el este. Estas características fueron interpretadas por la autora como evidencias de una expansión irregular, respecto de la velocidad radial deducida para WR 18. Whitehead, Meaburn, and Goudis (1988) realizaron observaciones espectroscópicas en las líneas H $\alpha$, Niı6548+6584 A y Sir6716+6731 A en tres posiciones dentro del $\mathrm{BBO}$ a $2^{\prime}$ al oeste y al noroeste de WR 18; las velocidades 
encontradas por los autores parecerían coincidir con las encontradas por Chu (1982), destacando la ausencia de nudos (knots) de alta velocidad en la nebulosa lo que llevó a los autores a concluir que la misma tiene un origen interestelar y que fue ionizada radiativamente por WR 18; esta conclusión parece coincidir con el trabajo de Kwitter (1984) quien calculó una masa para la nebulosa de $252 \mathrm{M}_{\odot}$.

Dyson \& Ghambari (1989) intentaron explicar la morfología de NGC 3199 en base a un modelo de BI deformada, producida por una estrella en movimiento en un medio estático y uniforme y concluyeron que WR 18 se estaría moviendo a una velocidad de $60 \mathrm{~km} / \mathrm{seg}$ en un medio con densidad $10 \mathrm{~cm}^{-3}$, la masa de gas ionizado sería de $110 \mathrm{M}_{\odot}$ y la masa de gas neutro de $230 \mathrm{M}_{\odot}$ (adoptando una distancia de $3,6 \mathrm{kpc}$ )

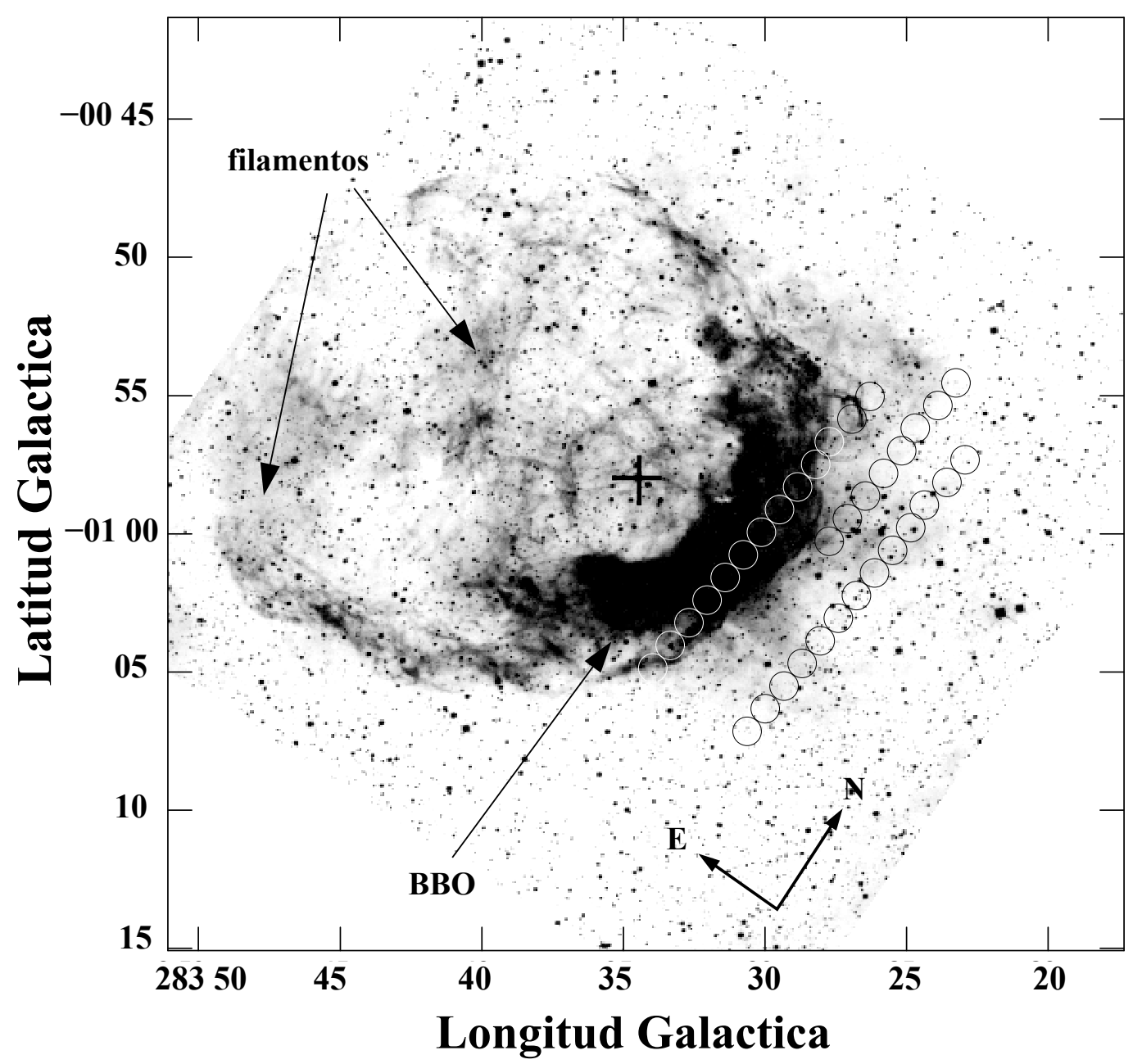

Figura 5.1: Imagen $\mathrm{H} \alpha$ de la nebulosa NGC 3199 obtenida del relevamiento SuperCOSMOS. Los círculos representan las posiciones de observación realizadas por Marston (2001). La posición de WR 18 está indicada por la cruz en el centro de la imagen. 
Como se mencionó en el Capítulo 1, Marston (2001) realizó un estudio de esta región utilizando diversas líneas moleculares en tres franjas en la dirección del BBO (ver Figuras 5.1 y 1.14). Se detectó la línea $J=1 \rightarrow 0$ del ${ }^{12} \mathrm{CO}$ en las posiciones hacia el norte de las franjas interna y central a velocidades de $\sim-16$ $\mathrm{km} / \mathrm{seg}$ y al sur de la franja externa a velocidades de $\sim 7 \mathrm{~km} / \mathrm{seg}$. A pesar de la limitada extensión angular de la zona observada, Marston (2001) interpretó que las líneas moleculares eran producidas por una cáscara de material molecular expandiéndose $\mathrm{a} \sim 4 \mathrm{~km} / \mathrm{seg}$ con una PDR en su borde interno. La detección de líneas moleculares tales como $\mathrm{HCN}, \mathrm{CN}, \mathrm{HNC}_{\text {y }} \mathrm{HCO}^{+}$en la posición de WR 18 llevó al autor a sugerir la existencia de densas aglomeraciones de material molecular eyectado por la estrella en una fase previa a la WR, las cuales sobrevivieron a la posterior ionización.

Numerosas estimaciones de la distancia se han realizado: Smith (1968) obtuvo una distancia espectrofotométrica para WR 18 de 3,63 kpc; Shaver \& Goss (1970) basados en la velocidad radial medida para la línea H109 $\alpha$ en NGC 3199, calculó una distancia de 3,8 kpc; Chu (1982), usando datos fotométricos de van der Hucht (1981) calculó una distancia para WR 18 de 3,6 kpc; Kwitter (1984) determinó una distancia espectrofotométrica para WR 18 de 3,7 kpc usando la calibración de Lundstrom \& Stenholm (1982). Para el desarrollo de esta Tesis Doctoral, se adoptará para WR 18 una distancia de 2,2 $\pm 1,1 \mathrm{kpc}$. Este valor corresponde a la determinación de distancia más reciente y fue realizado por van der Hucht (2001).

\subsection{Resultados observacionales}

\subsubsection{Emisión general de $\mathrm{CO}$}

En la Figura 5.2 se muestran los perfiles de emisión de la línea $J=1 \rightarrow 0$ del ${ }^{12} \mathrm{CO}$, en siete posiciones de la nebulosa NGC 3199, la cual se muestra en el centro y que fue obtenida del relevamiento DSSR (Digitalized Sky Survey Red). Los perfiles se han identificado con letras minúsculas en el borde superior izquierdo de cada perfil. En una primera inspección visual puede observarse que la emisión del material molecular posee numerosas componentes en distintos intervalos de velocidad.

Los perfiles $a$ y $b$ fueron tomados en posiciones entre los filamentos que conforman la cáscara extena y la cáscara interna. En ambos perfiles se observa una componente molecular intensa $\left(\mathrm{T}_{B} \sim 4,2 \mathrm{~K}\right)$ que se encuentra en el intervalo de velocidad de $\sim 0$ a $17 \mathrm{~km} / \mathrm{seg}$ para el perfil $a$ y de 0 a $20 \mathrm{~km} / \mathrm{seg}$ para el perfil $b$. En el caso del perfil $a$ existen tres componentes de menor intensidad $\left(\mathrm{T}_{B} \sim 1,8 \mathrm{~K}\right)$ a velocidades $\sim-5 \mathrm{~km} / \mathrm{seg}, \sim-12 \mathrm{~km} / \mathrm{seg} \mathrm{y} \sim-18 \mathrm{~km} / \mathrm{seg}$. Esta última también aparece en los perfiles $b$ y $c$.

El perfil $c$ fue obtenido aproximadamente $5^{\prime}$ al norte de la posición de WR 18 y es una zona cuya emisión en el óptico es algo menos intensa que el BBO. 


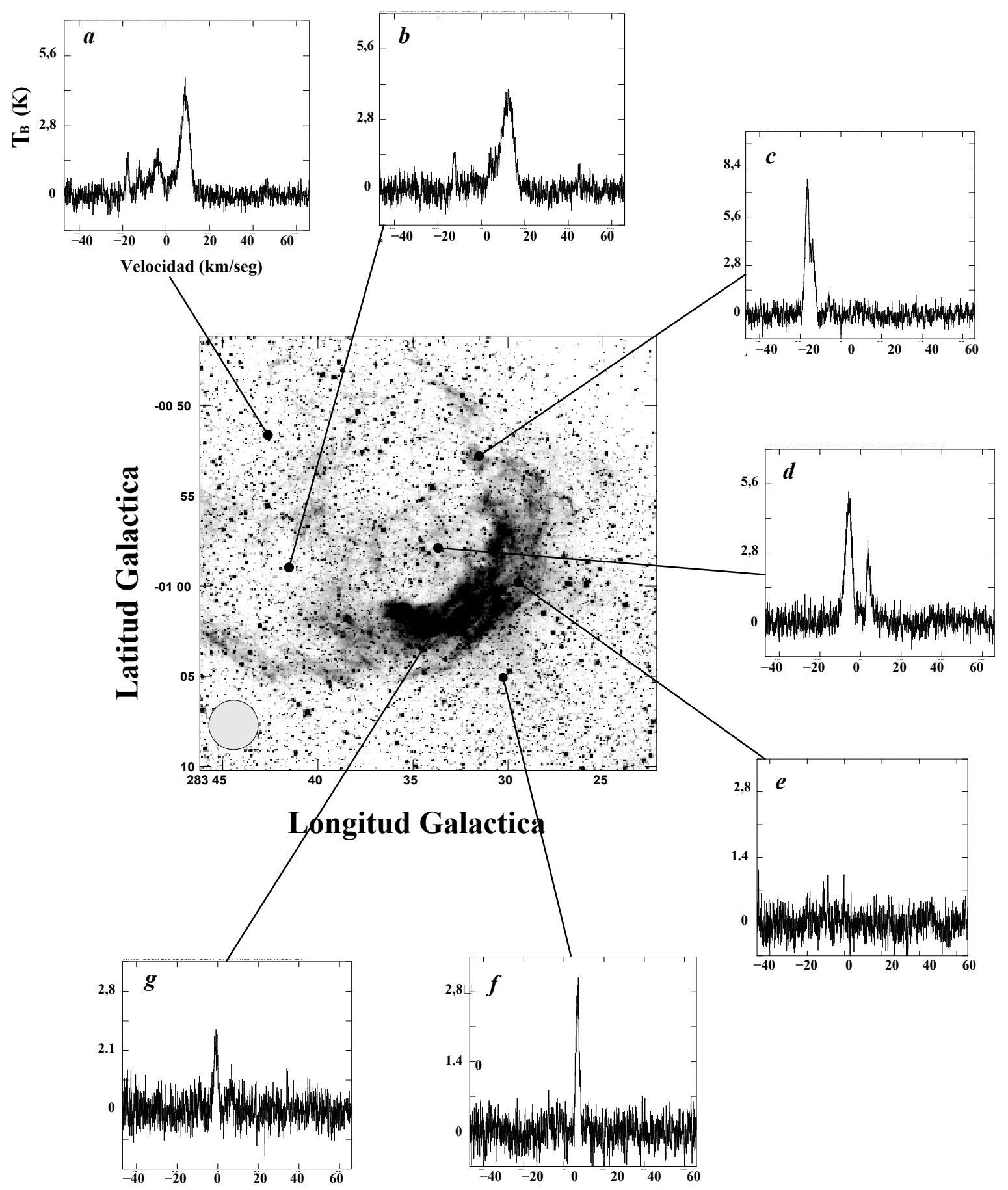

Figura 5.2: Perfiles de la distribución de la emisión del CO en NGC 3199 en temperatura de brillo $\left(\mathrm{T}_{B}\right)$ vs velocidad radial. En el centro se muestra la imagen de la nebulosa NGC 3199 obtenida del relevamiento Digitalized Sky Survey en la banda R (DSSR). El haz correspondiente a las observaciones de CO se encuentra en la figura central, abajo a la izquierda 
Se puede identificar una componente muy intensa $\left(\mathrm{T}_{B} \sim 8,4 \mathrm{~K}\right)$ centrada en una velocidad $\sim-17 /-16 \mathrm{~km} / \mathrm{seg}$.

El perfil $d$ se obtuvo en la posición correspondiente a la ubicación de WR 18. Pueden distinguirse dos componentes muy intensas cuyas temperaturas pico son del orden de $\mathrm{T}_{B} \sim 5,6$ y $4 \mathrm{~K}$, siendo sus velocidades $\sim-6$ y $4 \mathrm{~km} / \mathrm{seg}$ respectivamente.

Las posiciones de los perfiles $e$ y $g$ corresponden a zonas inmersas en el BBO. El perfil $g$ presenta una débil emisión $\left(\mathrm{T}_{B} \sim 1,9 \mathrm{~K}\right)$ a una velocidad $\mathrm{v}$ $\sim-3 \mathrm{~km} / \mathrm{seg}$.

El perfil $f$ fue tomado en una zona cercana al BBO. Se puede observar una componente intensa $\left(\mathrm{T}_{B} \sim 2,8 \mathrm{~K}\right)$ a una velocidad $\mathrm{v} \sim 5 \mathrm{~km} / \mathrm{seg}$.

\subsubsection{Distribución espacial del CO}

Debido a la variedad y diversidad de componentes moleculares detectadas en los perfiles de la Figura 5.2, no fue posible determinar a priori todas las estructuras de CO presentes en el campo de la nebulosa NGC 3199. Por este motivo, la búsqueda de estructuras moleculares en la zona de NGC 3199 se basó fundamentalmente en la inspección visual de los cubos de datos obtenidos en dicha región.

Haciendo uso de las observaciones de CO, se analizó la distribución espacial del material molecular en la zona de NGC 3199. La meta de este análisis fue identificar las estructuras de $\mathrm{CO}$ que pudiesen encontrarse físicamente vinculadas (asociadas) con NGC 3199. La distribución del material molecular fue comparada con la correspondiente a la emisión en $\mathrm{H} \alpha$. Esta última caracteriza la distribución del gas ionizado. Según se lo requiera, la distribución de la emisión del gas molecular que se presentará a continuación en las siguientes imágenes, corresponderán a las obtenidas con el cubo de datos realizado con un muestreo espacial completo (si se requiere la inspección de una región pequeña pero con un mejor cubrimiento) o con un muestreo de una observación por haz (si se requiere un mayor campo de observación). Las integraciones en rangos pequeños de velocidad, permiten encontrar correspondencias morfológicas a "pequeña escala", que de trabajar con rangos de integración en velocidad más extensos se perderían. Las integraciones en todo el rango de velocidad observado se realizaron para evidenciar las estructuras mencionadas anteriormente en forma general (a gran escala).

En la Figura 5.3 se muestra la distribución espacial de ${ }^{12} \mathrm{CO}$ en el rango de velocidades de $-20,7 \mathrm{a}-14,2 \mathrm{~km} / \mathrm{seg}$ obtenida del cubo de datos que posee muestreo espacial completo. 

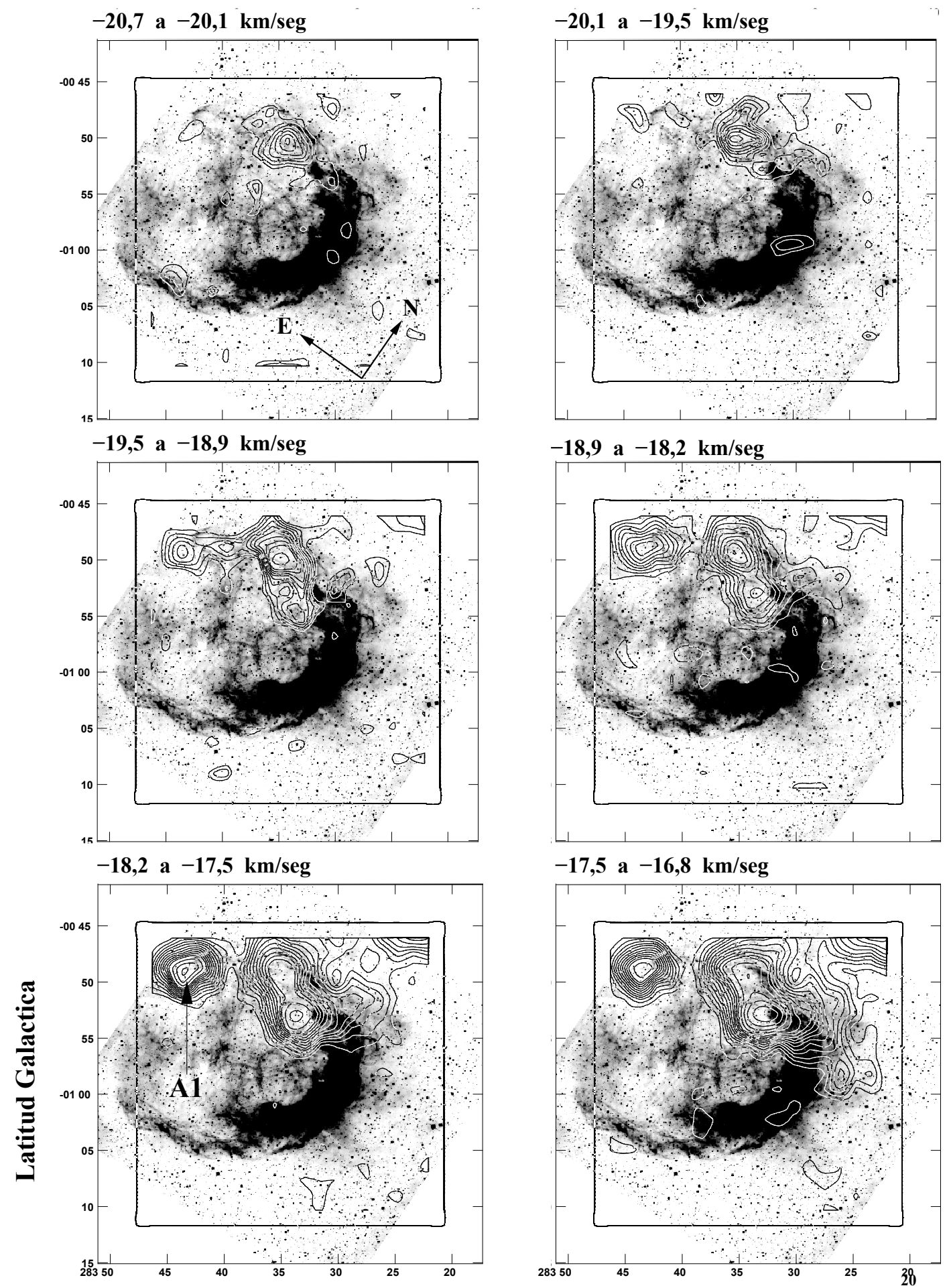

\section{Longitud Galactica}

Figura 5.3: Distribución del ${ }^{12} \mathrm{CO}$ en la nebulosa NGC 3199 (contornos) superpuesto con la emisión $\mathrm{H} \alpha$ (tonos de grises). Las imágenes abarcan un intervalo de velocidad de 0,6 km/seg. El rango de velocidad cubierto se indica en el borde superior izquierdo de cada imagen. Los niveles de contorno van desde $0,3 \mathrm{~K}(\sim 3 \sigma)$ hasta $3,5 \mathrm{~K}$ en intervalos de $0,3 \mathrm{~K}$, y de $3,5 \mathrm{~K}$ en intervalos de $0,7 \mathrm{~K}$. 

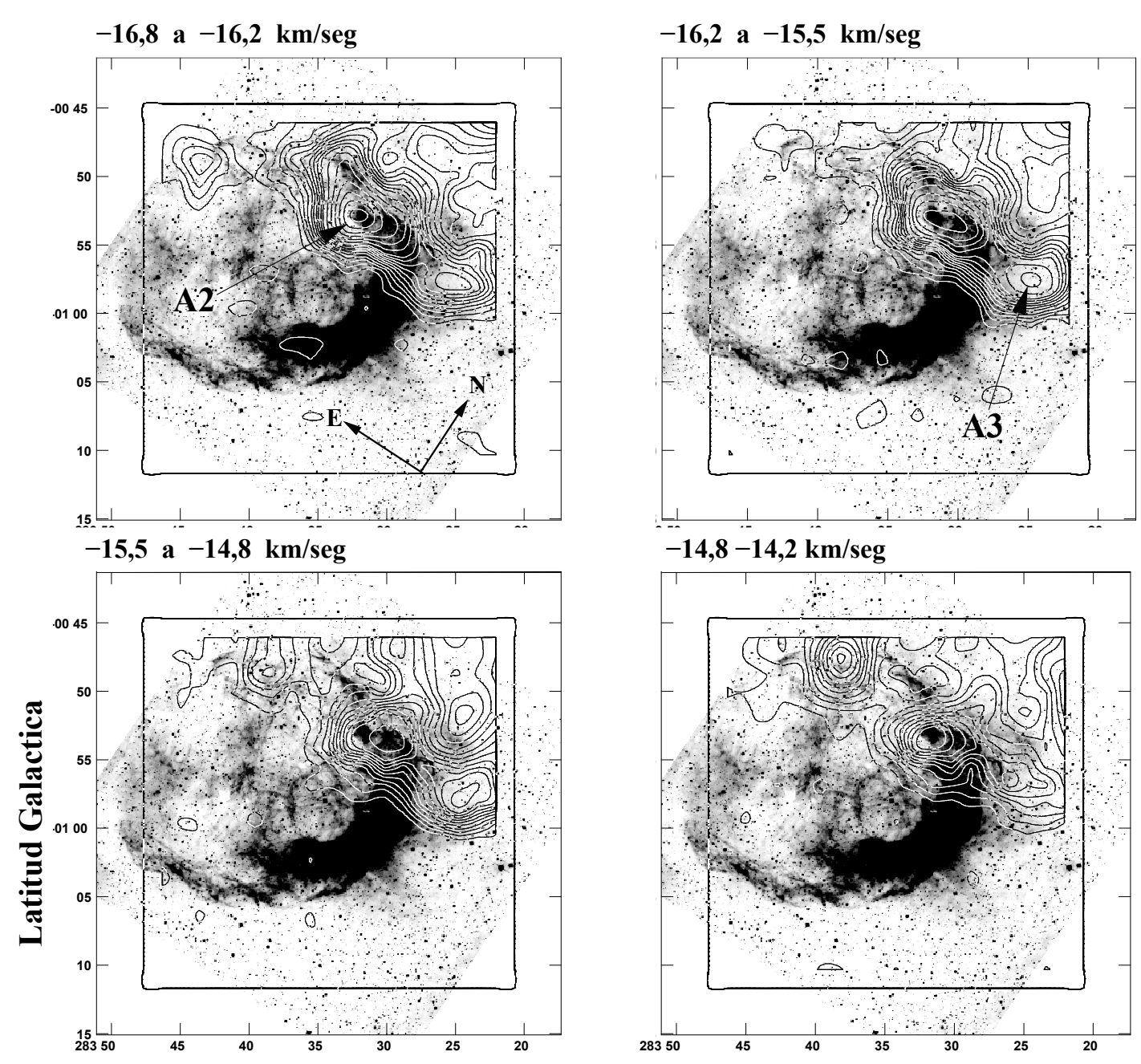

\section{Longitud Galactica}

Figura 5.3: continuación

La componente molecular visible en este rango de velocidades (que denominaremos componente A) parece tener una buena correspondencia morfológica con los bordes norte y noreste de NGC 3199. Dicha componente estaría formada a su vez por tres subcomponentes. La primera de ellas (que denominaremos A1 alcanza su máximo $\left(\mathrm{T}_{B} \sim 5,6 \mathrm{~K}\right)$ en $(l, b) \simeq\left(283^{\circ} 43^{\prime},-00^{\circ} 49^{\prime}\right)$ en el intervalo de velocidades de $-18,2$ a $-17,5 \mathrm{~km} / \mathrm{seg}$. Esta estructura es visible en el rango de velocidades que va de $-19,5$ a $-16,2 \mathrm{~km} / \mathrm{seg}$. La otra componente (denominada A2) puede observarse en todo el rango de velocidades $-20,7 \mathrm{a}-14,2 \mathrm{~km} / \mathrm{seg}$ y se extiende desde $(l, b)=\left(283^{\circ} 33^{\prime},-00^{\circ} 49^{\prime}\right)$ hasta $(l, b)$ $=\left(283^{\circ} 25^{\prime},-01^{\circ} 00^{\prime}\right)$ recorriendo el borde norte de la nebulosa, y alcanzando 
su máximo $\left(\mathrm{T}_{B} \sim 8 \mathrm{~K}\right)$ en el intervalo de velocidad $-16,8 \mathrm{a}-16,2 \mathrm{~km} / \mathrm{seg}$ en la posición $(l, b)=\left(283^{\circ} 32^{\prime},-00^{\circ} 52^{\prime}\right)$.

En el rango de velocidades desde $-16,8$ a $-14,8 \mathrm{~km} / \mathrm{seg}$, se ve una extensión de esta estructura cuyo máximo $\left(\mathrm{T}_{B} \sim 5,1 \mathrm{~K}\right)$ se encuentra en la posición $(l, b)=\left(283^{\circ} 25^{\prime},-00^{\circ} 57^{\prime}\right)$ en el intervalo de velocidades de $-16,2$ a $-15,5 \mathrm{~km} / \mathrm{seg}$. Esta estructura se denominará A3. Las componentes A1, A2 y A3 se encuentran indicadas en la Figura 5.3.

En la Figura 5.4, se muestra la emisión promedio de la componente A integrada en el rango total de velocidades, desde - 20,7 a -14,2 km/seg (líneas de contornos) superpuesta con la emisión $\mathrm{H} \alpha$ (en tonos de grises).

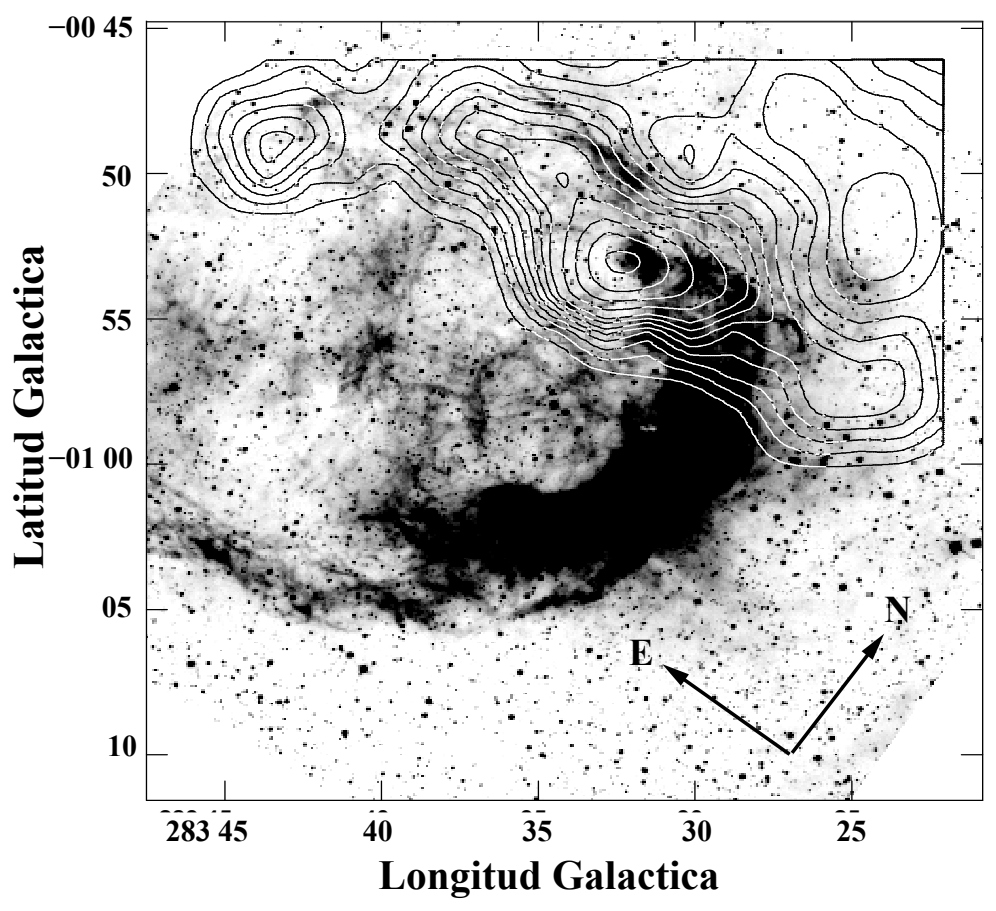

Figura 5.4: Imagen promedio de la distribución del CO integrada en el intervalo de velocidades $-20,7$ a $-14,2 \mathrm{~km} / \mathrm{seg}$ (contornos), superpuesta con la emisión H $\alpha$ de NGC 3199 (tonos de grises). Los niveles de contorno del $\mathrm{CO}$ van desde $0,4 \mathrm{~K}$ hasta $1,5 \mathrm{~K}$ en pasos de 0,3 , y desde 1,8 hasta 7,7 en pasos de $0,4 \mathrm{~K}$.

Continuando con el análisis, cabe destacar que el perfil $d$ de emisión de CO (ver Figura 5.2) muestra dos componentes intensas a velocidades $\sim-6$ y 4 $\mathrm{km} / \mathrm{seg}$. La primera componente será denominada B y la segunda C.

En la Figura 5.5 se muestra la distribución espacial del CO en el rango de velocidades total en el que la componente B está presente. Las imágenes están integradas en intervalos de velocidad de $1,3 \mathrm{~km} / \mathrm{seg}$ y están superpuestas con la emisión $\mathrm{H} \alpha$ de NGC 3199. La disposición espacial del gas molecular de la componente B coincide con la región central de la nebulosa NGC 3199. 

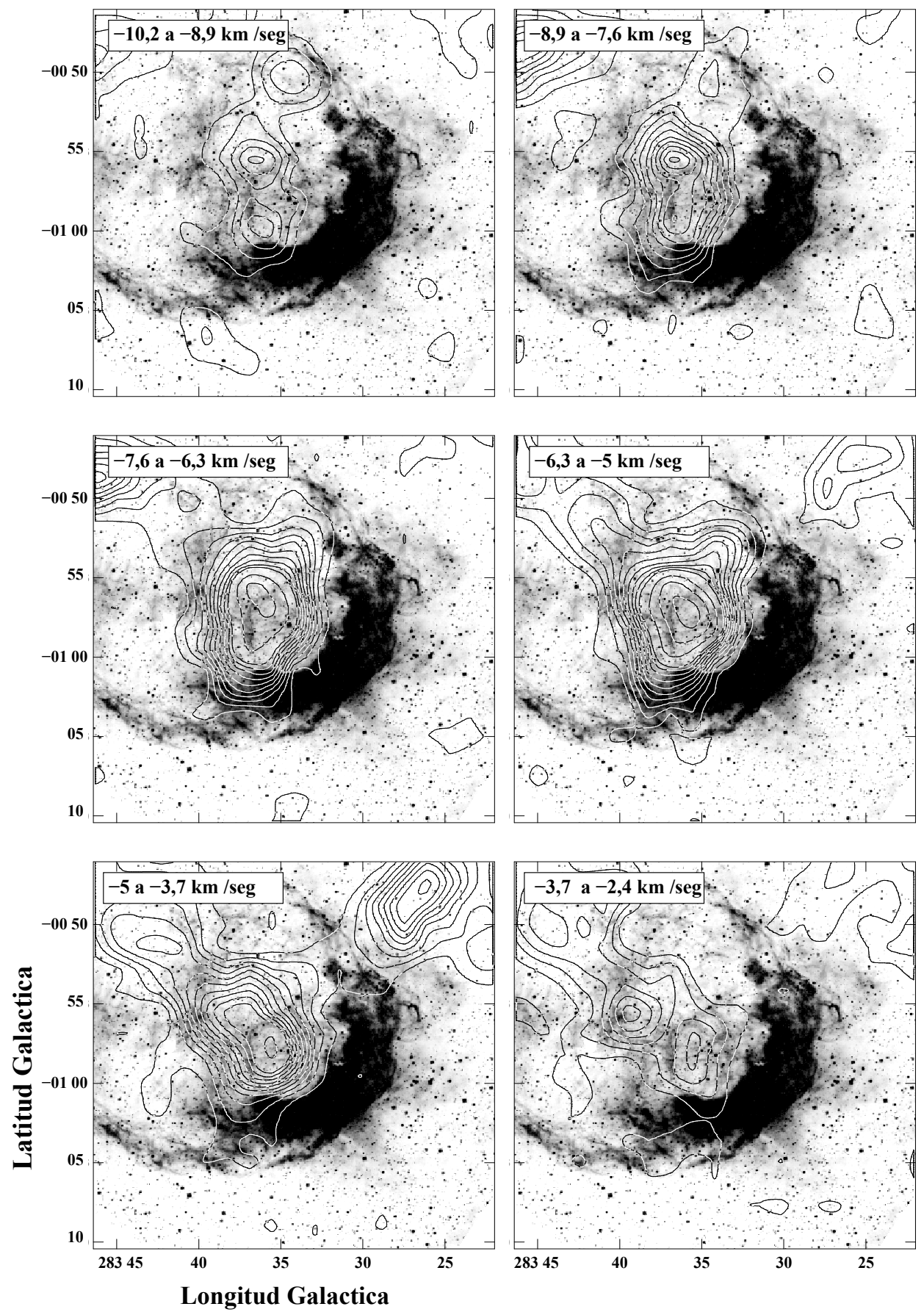

Figura 5.5: Distribución del ${ }^{12} \mathrm{CO}$ en la nebulosa NGC 3199 (contornos) en el intervalo de velocidades de $-10,2 \mathrm{a}-2,4 \mathrm{~km} / \mathrm{seg}$ (componente $\mathrm{B}$ ), superpuesto con la emisión $\mathrm{H} \alpha$ (tonos de grises). Las imágenes abarcan un intervalo de velocidad de 1,3 km/seg. El rango de velocidad de cada imagen está indicado en el borde superior izquierdo. Los niveles de contorno van desde $0,7 \mathrm{~K}(\sim 8 \sigma)$ hasta $7 \mathrm{~K}$ en intervalos de $0,7 \mathrm{~K}$, y desde $7 \mathrm{~K}$ en intervalos de $2,1 \mathrm{~K}$. 
La intensidad de emisión máxima $\left(\mathrm{T}_{B} \sim 14,2 \mathrm{~K}\right)$ se observa en el intervalo de velocidades de $-6,3 \mathrm{a}-5 \mathrm{~km} / \mathrm{seg}$ en la posición $(l, b)=\left(283^{\circ} 36^{\prime},-00^{\circ} 57^{\prime}\right)$. Es importante destacar la muy buena concordancia existente entre los primeros niveles de contorno de la componente $\mathrm{B}$ con el contorno interno del $\mathrm{BBO}$ de NGC 3199.
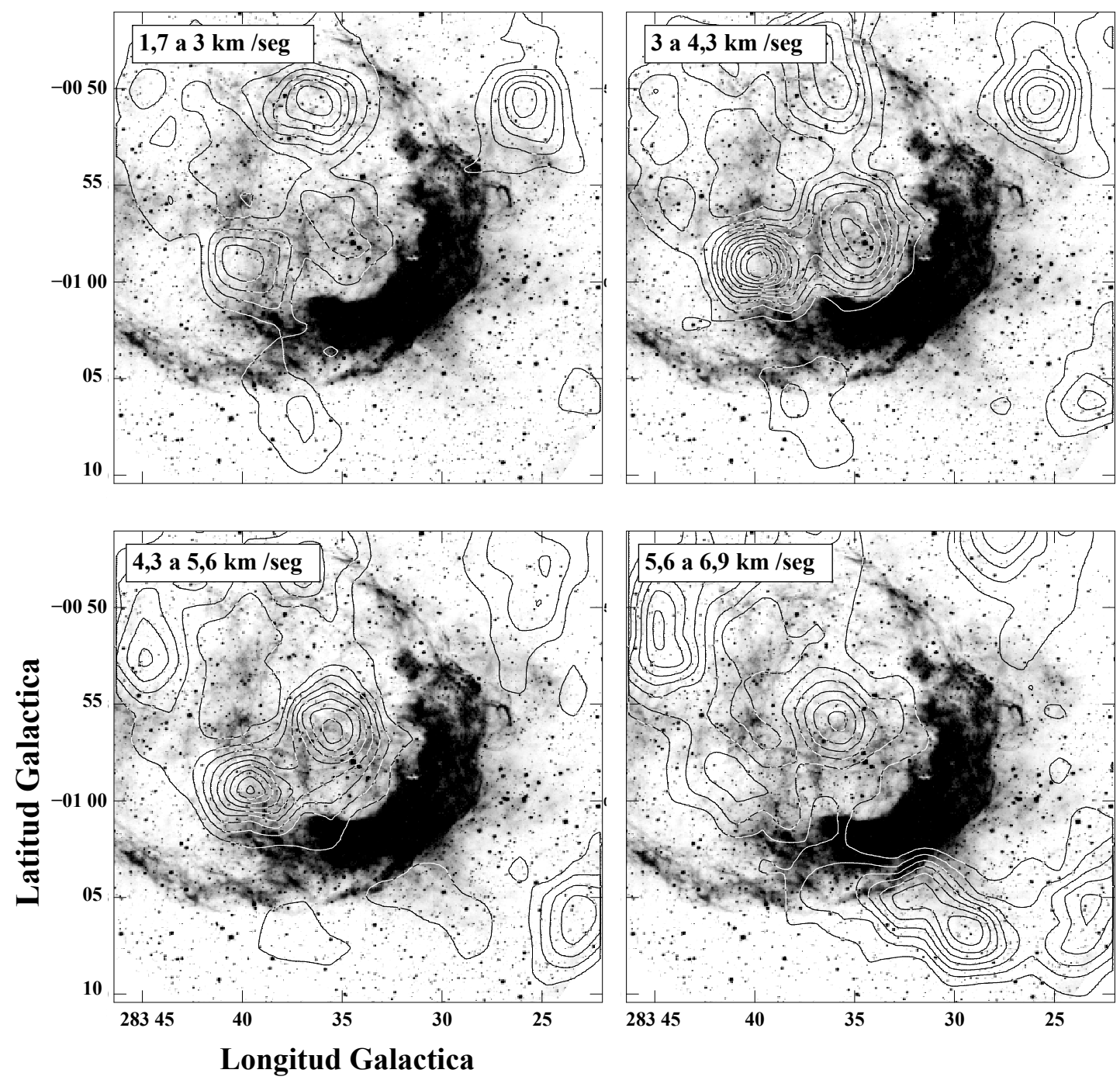

Figura 5.6: Distribución del ${ }^{12} \mathrm{CO}$ en la nebulosa NGC 3199 (contornos) en el intervalo de velocidades de 1,7 a $6,9 \mathrm{~km} / \mathrm{seg}$ (componente C), superpuesto con la emisión $\mathrm{H} \alpha$ (tonos de grises). Los mapas abarcan un intervalo de velocidad de $1,3 \mathrm{~km} / \mathrm{seg}$. El rango de velocidad de cada imagen está indicado en el borde superior izquierdo. Los niveles de contorno van desde $0,7 \mathrm{~K}(\sim 8 \sigma)$ hasta $7 \mathrm{~K}$ en intervalos de $0,7 \mathrm{~K}$, y desde $7 \mathrm{~K}$ en intervalos de 2,1 K.

La distribución de emisión del $\mathrm{CO}$ en el intervalo de velocidades de 1,7 a 6,9 $\mathrm{km} / \mathrm{seg}$, superpuesta con la emisión $\mathrm{H} \alpha$ está mostrada en la Figura 5.6. Esta componente molecular fue previamente denominada componente C. La misma 
está constituida por dos estructuras intensas cuyos máximos se encuentran en $(l, b)=\left(283^{\circ} 35^{\prime},-00^{\circ} 57^{\prime}\right)$ y $(l, b)=\left(283^{\circ} 40^{\prime},-00^{\circ} 59^{\prime}\right)$. Las temperatura de emisión en estos máximos son de $\mathrm{T}_{B} \sim 5,3 \mathrm{~K}$ y $\mathrm{T}_{B} \sim 7,8 \mathrm{~K}$, respectivamente. En la Figura 5.6 pueden observarse también otras dos componentes menos intensas ubicadas en $(l, b)=\left(283^{\circ} 26^{\prime},-00^{\circ} 51^{\prime}\right)$ y $(l, b)=\left(283^{\circ} 36^{\prime},-00^{\circ} 50^{\prime}\right)$. Al igual que en el caso de la componente $\mathrm{B}$, las dos estructuras más intensas de la componente C parecen delimitar la región interior del BBO de NGC 3199, especialmente hacia el borde sur.

A continuación analizaremos la distribución espacial del CO en el rango de velocidades de $\sim 6$ a $13 \mathrm{~km} / \mathrm{seg}$. A esta componente molecular se la denominará D. En la Figura 5.7, se muestra la distribución espacial de CO en imágenes integradas en rangos de velocidad de $0,6 \mathrm{~km} / \mathrm{seg}$, superpuestos con la imagen en $\mathrm{H} \alpha$ de NGC 3199. En este rango de velocidades puede apreciarse la existencia de varias estructuras moleculares, a saber:

- Una componente cuyo centro se encuentra en $(l, b)=\left(283^{\circ} 44^{\prime},-00^{\circ} 50^{\prime}\right)$ (a la que se denominará subcomponente D1), que es visible en el rango de velocidades 5,7 a 11,7 km/seg alcanzando su máximo $\left(\mathrm{T}_{B} \sim 5,8 \mathrm{~K}\right)$ a velocidades entre 7,7 a $8,3 \mathrm{~km} / \mathrm{seg}$. El extremo oeste de esta estructura parece delinear perfectamente el filamento interno de NGC 3199 para $l$ $>-00^{\circ} 55^{\prime \prime}$. Esta componente se observa en el perfil $a$ de la Figura 5.2

- Otra componente cuyo centro se encuentra en $(l, b)=\left(283^{\circ} 40^{\prime},-00^{\circ} 58^{\prime}\right)$ (la que se denominará subcomponente D2), que se extiende en un rango de velocidades de 6,4 a $13,6 \mathrm{~km} / \mathrm{seg}$, alcanzando su máximo $\left(\mathrm{T}_{B} \sim 4 \mathrm{~K}\right)$ a velocidades entre 11 y $11,7 \mathrm{~km} / \mathrm{seg}$. Al igual que en el caso anterior, esta subcomponente tiene una excelente correspondencia morfológica con los filamentos interno y externo de NGC 3199 en $-01^{\circ} 05^{\prime}<b<-00^{\circ} 55^{\prime}$; el borde norte de esta subcomponente parece delinear el filamento interno, mientras que el borde sur el filamento externo (ver Figura 5.7 en el intervalo de velocidad de 11 a $12,3 \mathrm{~km} / \mathrm{seg}$. El perfil de línea de esta componente es el correpondiente al panel $b$ de la Figura 5.2.

- Una última estructura (subcomponente D3), que se extiende desde $(l, b)=$ $\left(283^{\circ} 37^{\prime},-01^{\circ} 05^{\prime}\right)$ hasta $(l, b)=\left(283^{\circ} 25^{\prime},-01^{\circ} 07^{\prime}\right)$ en el rango de velocidades 5,7 a $8,3 \mathrm{~km} / \mathrm{seg}$ y que corresponde a la componente detectada en el panel $f$ de la Figura 5.2. Esta estructura alcanza su máximo de emisión $\left(\mathrm{T}_{B} \sim 3,2 \mathrm{~K}\right)$ en $(l, b)=\left(283^{\circ} 30^{\prime},-01^{\circ} 07^{\prime}\right)$. A velocidades entre 8,3 a $12,3 \mathrm{~km} / \mathrm{seg}$, se observa una estructura muy intensa cuyo centro está en $(l, b)=\left(283^{\circ} 26^{\prime},-01^{\circ} 07^{\prime}\right)$ que parece desprenderse de la subcomponente D3. 

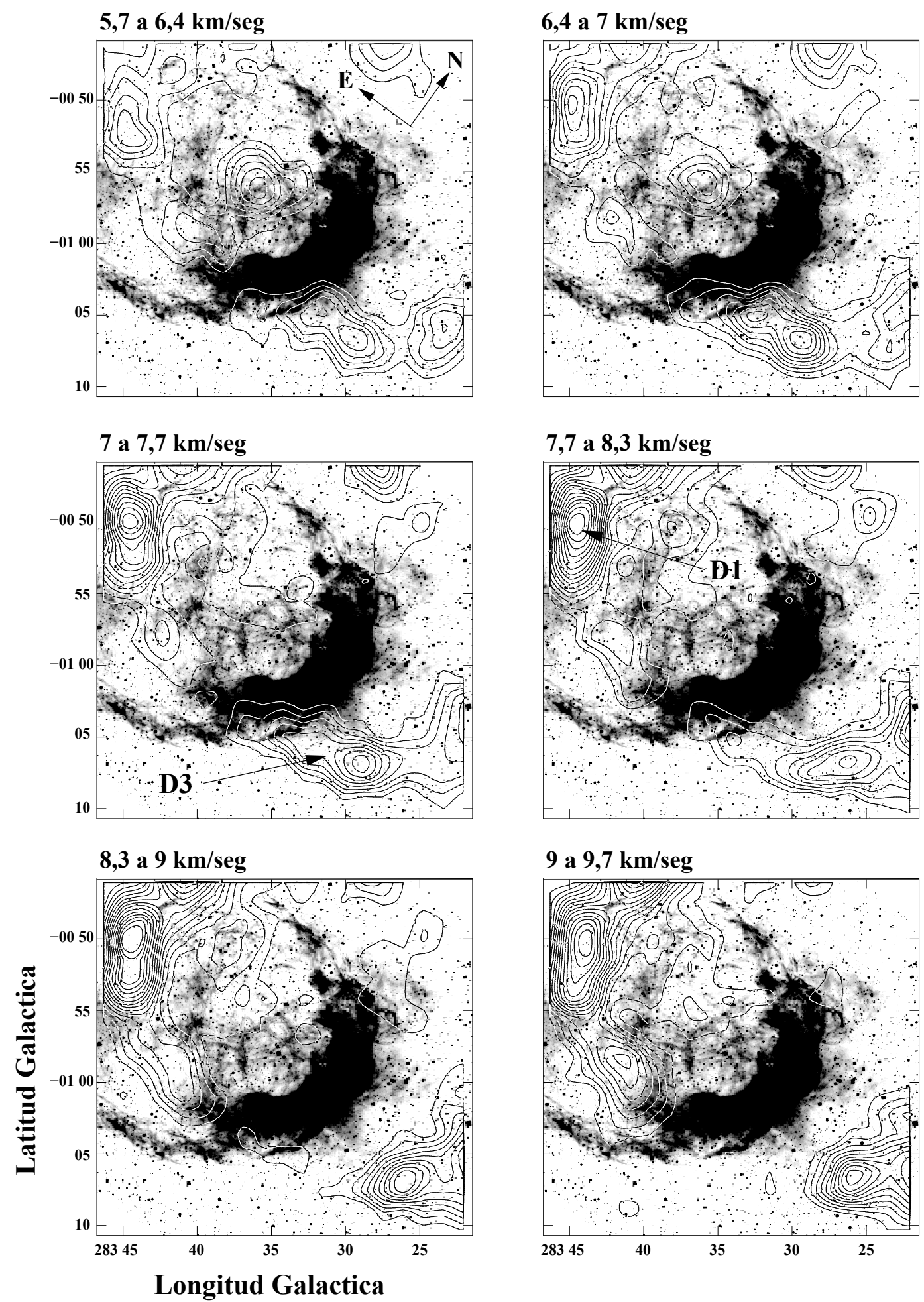

Figura 5.7: Distribución del CO en la nebulosa NGC 3199 (contornos) superpuesto con la emisión $\mathrm{H} \alpha$ (tonos de grises). El rango de velocidad cubierto se indica en el borde superior izquierdo de cada imagen. Los niveles de contorno van desde $0,6 \mathrm{~K}(6,6 \sigma)$ hasta $5,6 \mathrm{~K}$ en intervalos de $0,5 \mathrm{~K}$. 

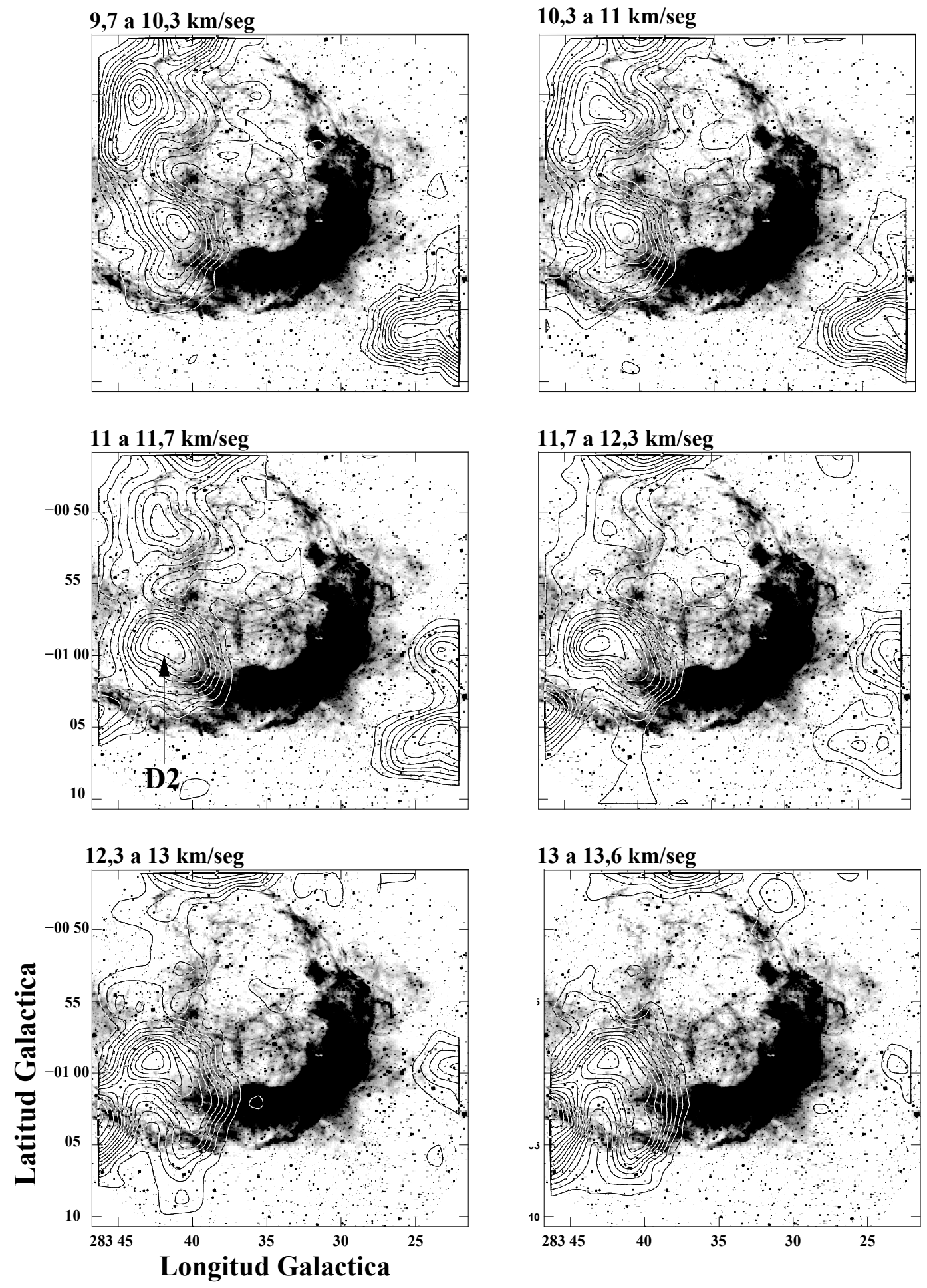

Figura 5.7: continuación 
En la Figura 5.8 se muestra la distribución integrada de la emisión de CO en el rango de velocidad comprendido entre 5 y $12,5 \mathrm{~km} / \mathrm{seg}$. Para producir esta imagen se usó la base de datos en la que los puntos observados se encuentran espaciados en un haz $\left(\equiv 2^{\prime}, 7\right)$
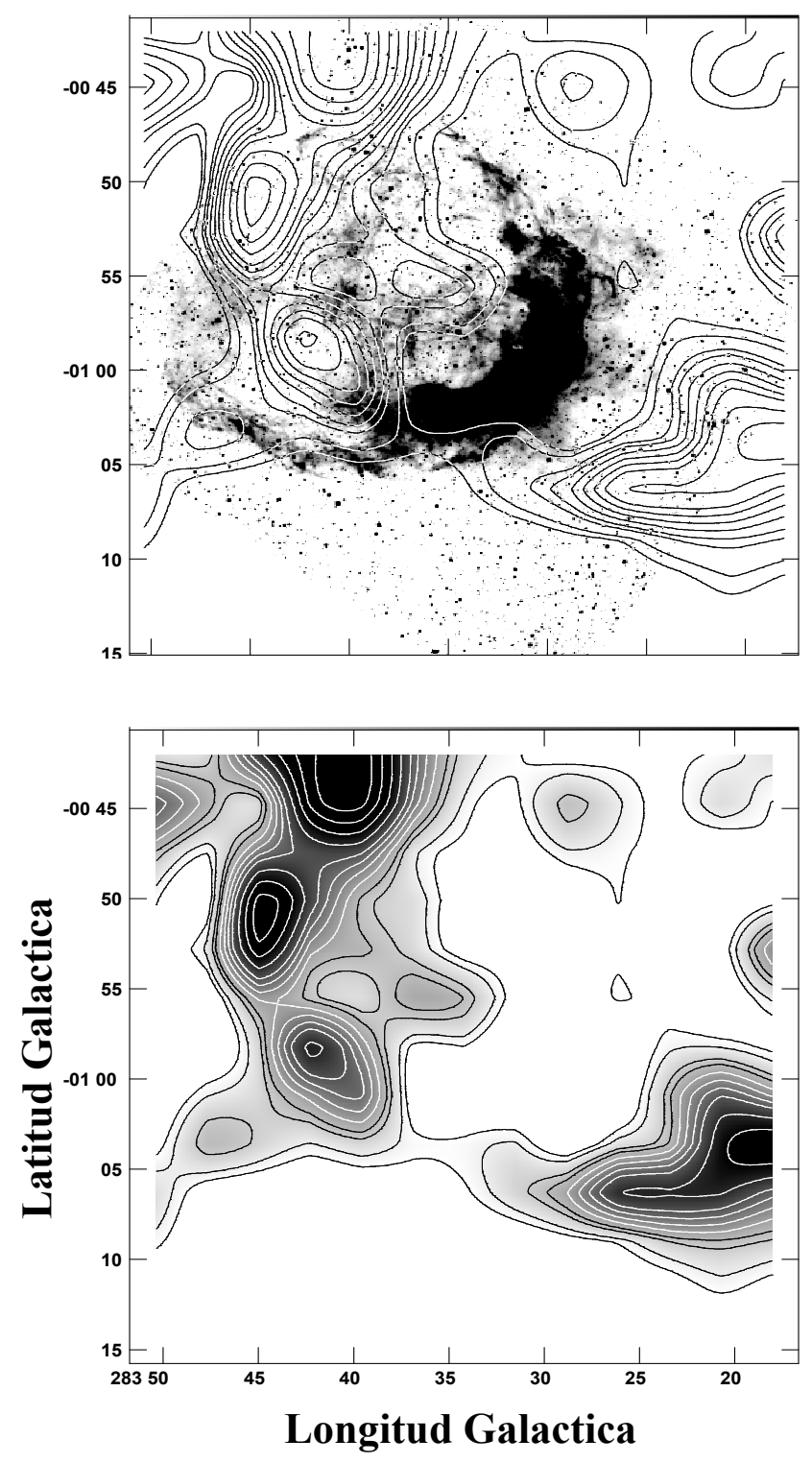

Figura 5.8: Arriba: Distribución espacial del ${ }^{12} \mathrm{CO}$ integrada en el rango de velocidades de 5 a $12,5 \mathrm{~km} / \mathrm{seg}$ (contornos) superpuesta con la imagen $\mathrm{H} \alpha$ (tono de grises). Los niveles de contorno van de $0,35 \mathrm{~K}$ a $1,75 \mathrm{~K}$ en intervalos de $0,15 \mathrm{~K}$ y desde $2,5 \mathrm{~K}$ en intervalos de 0,35 K. Abajo: Emisión de ${ }^{12} \mathrm{CO}$ en escala de grises. 


\subsection{Emisión de HI}

Al igual que para el material molecular, se buscó evidencia en la línea de $21 \mathrm{~cm}$ del HI de alguna estructura que pudiese vincularse a la nebulosa óptica NGC 3199. Se encontró una estructura cuya correspondencia morfológica con el BBO es notable. En la Figura 5.9 se presentan las imágenes que muestran la distribución espacial de la línea de HI, obtenidas del relevamiento Southern Galactic Plane Survey (SGPS I) (HPBW $\left.=2^{\prime}\right)$, integradas en intervalos de velocidad $0,8 \mathrm{~km} / \mathrm{seg}$ en el rango de velocidades de 8,2 a $13,2 \mathrm{~km} / \mathrm{seg}$.
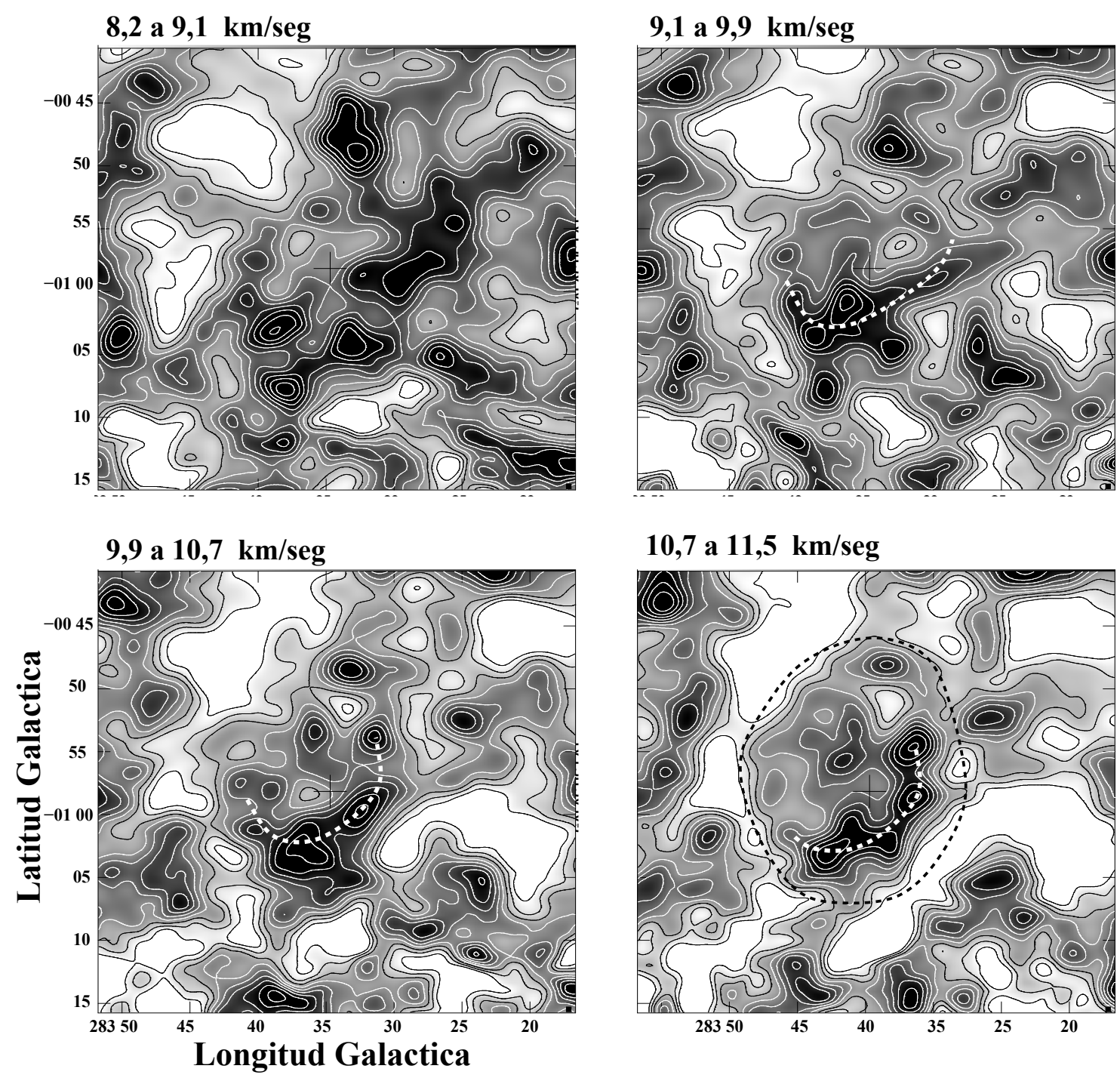

Figura 5.9: Emisión de HI en la zona de NGC 3199. Las imágenes correponden a intervalos de velocidad de $0,8 \mathrm{~km} / \mathrm{seg}$. Los niveles de contorno van de $90(\sim 30 \sigma)$ a $150 \mathrm{~K}$ en intervalos de $5 \mathrm{~K}$. La cruz en el centro indica la posición de WR 18. 


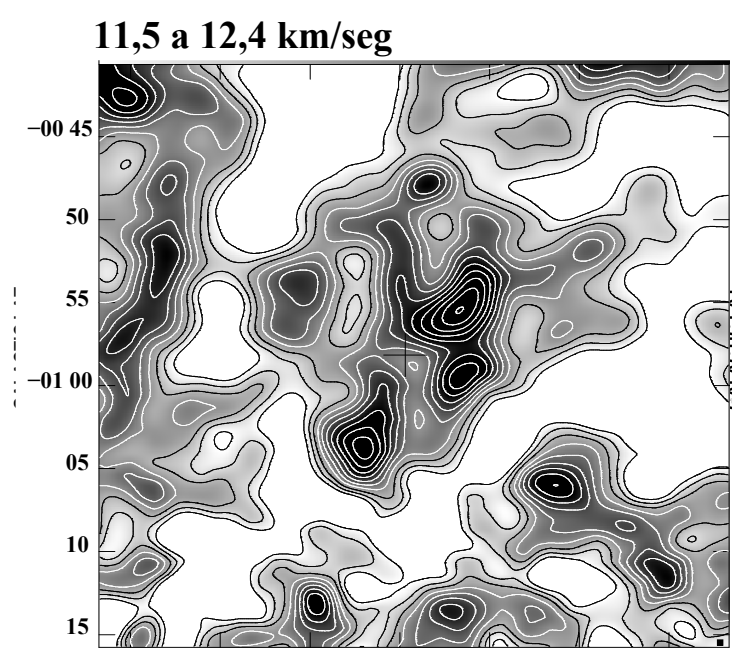

\section{2,4 a $13,2 \mathrm{~km} / \mathrm{seg}$}
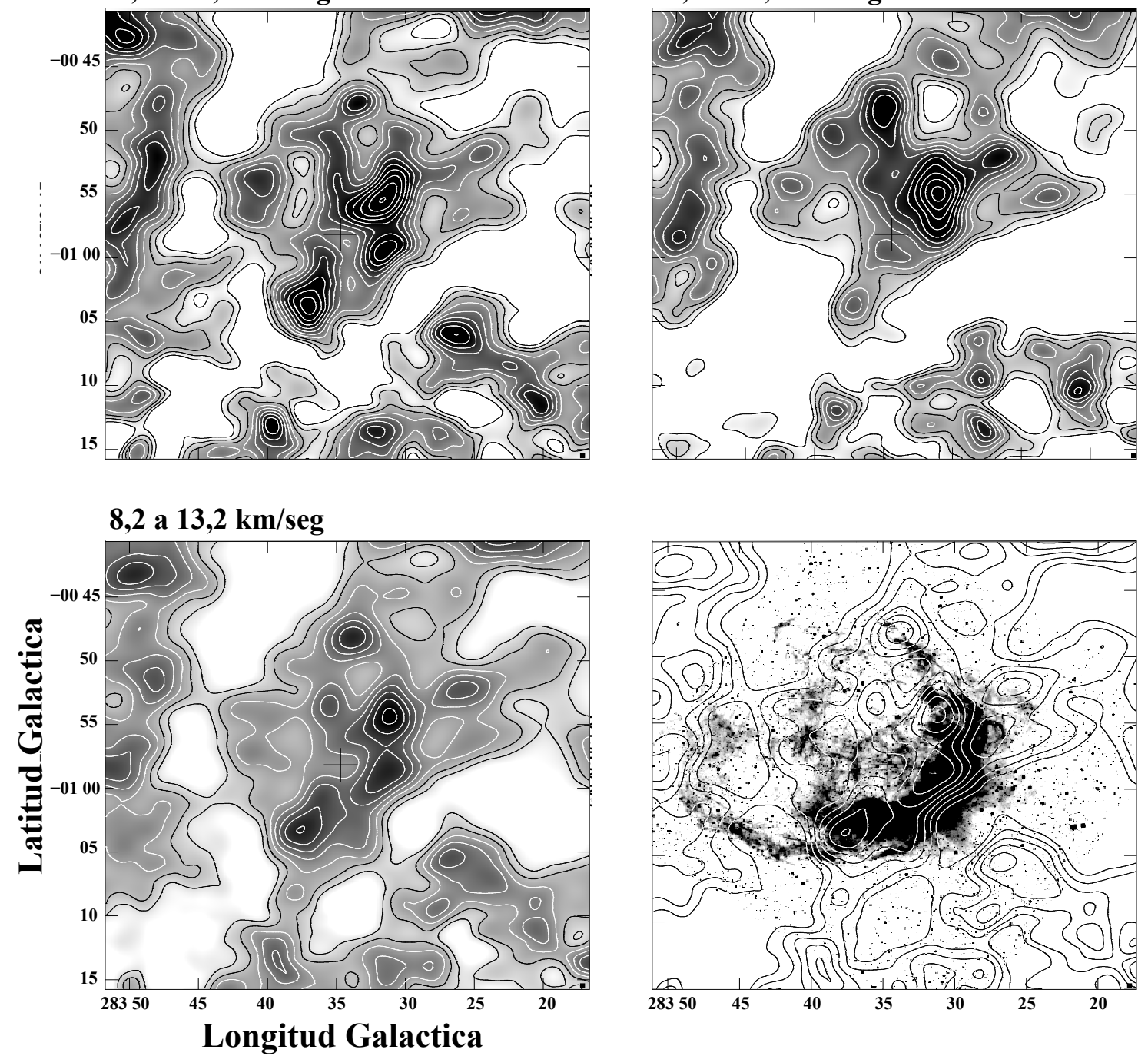

Figura 5.9: (continuación). En los últimos dos paneles se muestra la distribución del HI integrado en el rango total de velocidades. En el panel inferior derecho se muestra la superposición del HI en el rango total de velocidades con la imagen $\mathrm{H} \alpha$ de NGC 3199

En el intervalo de velocidades de 9,1 a $9,9 \mathrm{~km} / \mathrm{seg}$ se aprecia una estructura en forma de arco (indicada por la línea de trazos blanca) ubicada por debajo de la posición de WR 18. En el intervalo de 9,9 a 10,7 km/seg, esta estructura persiste, pero ahora la posición de WR 18 aparece rodeada por la emisión del HI ubicándose ésta en un mínimo. En el intervalo 10,7 a 11,5 km/seg la morfología del arco de HI alcanza su mejor correspondencia morfológica con el $\mathrm{BBO}$ visible en $\mathrm{H} \alpha$, y con la posición de WR 18 todavía en un mínimo de emisión. La emisión del HI en este intervalo alrededor de la estrella comienza a formar una estructura en forma de óvalo (indicada por la línea de trazos 
negra) que ocupa la misma área delimitado por la cáscara interna vista en $\mathrm{H} \alpha$ (descripta en la Sección 4.1). A partir de $\mathrm{v}=12,4 \mathrm{~km} / \mathrm{seg}$ el arco de HI comienza a desintegrarse pero la estructura de óvalo todavía persiste. En el último panel de la Figura 5.9 se puede ver la emisión de HI integrada en el rango de velocidad 8,2 a 13,2 km/seg superpuesta con la imagen $\mathrm{H} \alpha$ de NGC 3199, donde puede verse una clara correspondencia morfológica entre las estructuras de HI anteriormente descriptas y la imagen óptica de la nebulosa.

\subsection{NGC 3199 en IR}

En la Figura 5.10 se muestran las distribuciones de la emisión en $60 \mu \mathrm{m}$ obtenida del relevamiento IRAS de alta resolución (HIRES) y de 8,28 $\mu \mathrm{m}$ (MSX banda A) superpuestas con el contorno que representa la emisión en $\mathrm{H} \alpha$ a un nivel de 9000 Rayleighs. Puede apreciarse que la distribución del polvo guarda buena correspondencia morfológica con la distribución del hidrógeno ionizado del BBO. Para $l>283^{\circ} 40^{\prime}$ la emisión en IR es muy irregular y notablemente intensa en la banda A de MSX. Lo mismo parece suceder en $60 \mu \mathrm{m}$ aunque la cobertura del relevamiento IRAS en esta banda no permite apreciarla por completo.
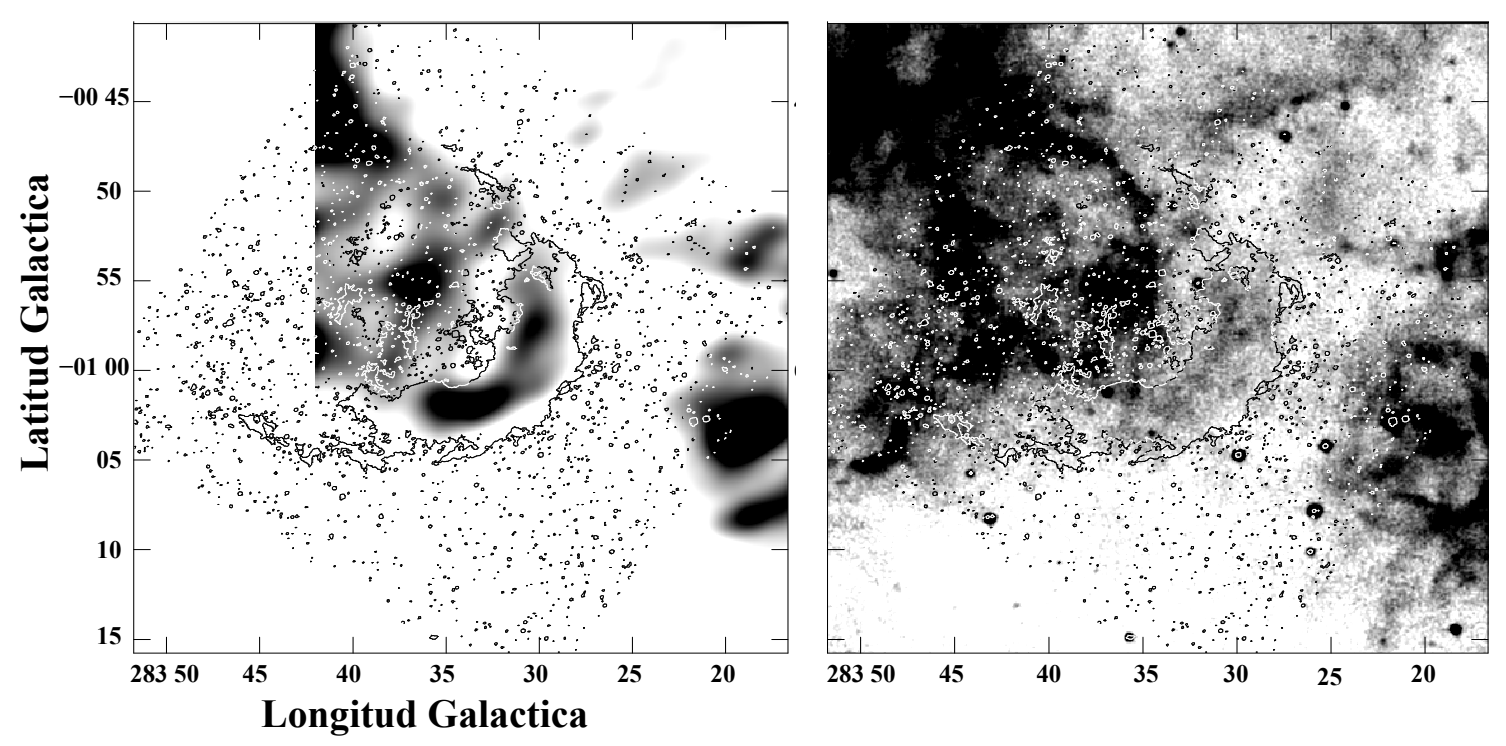

Figura 5.10: Distribución de la emisión IR en $60 \mu \mathrm{m}$ (HIRES) (panel izquierdo) y en 8,28 $\mu \mathrm{m}$ (MSX banda A) (panel derecho), ambas superpuestas con la emisión H $\alpha$ (contornos).

La distribución de emisión correspondiente a las bandas C, D y E del relevamiento MSX muestra similares características a la emisión de la banda A mostrada en la Figura 5.10 y no se presentarán. Lo mismo sucede con la emisión en $100 \mu \mathrm{m}$ obtenida del relevamiento IRAS de alta resolución. 


\subsection{Emisión del gas ionizado}

En la Figura 5.11 se muestra la distribución de la emisión de continuo en $5 \mathrm{GHz}$ obtenida del relevamiento de Parkes (Haynes et al. 1978). Cercano a la posición de WR 18, puede observarse una estructura que se extiende desde $(l, b) \sim\left(283^{\circ} 40^{\prime},-01^{\circ} 03^{\prime}\right)$ hasta $(l, b) \sim\left(283^{\circ} 35^{\prime},-00^{\circ} 50^{\prime}\right)$ que coincide en tamaño y forma con el $\mathrm{BBO}$, por lo que muy posiblemente represente la contraparte en continuo de radio del mismo. Existe otra estructura muy intensa que se extiende en longitud galáctica desde $l \sim 283^{\circ} 50^{\prime}$ a $l \sim 284^{\circ} 10^{\prime}$ y en latitud galáctica desde $b \sim-00^{\circ} 35^{\prime}$ hasta $b \sim-01^{\circ} 05^{\prime}$ que se corresponde con la emisión en IR pero no así con la emisión en $\mathrm{H} \alpha$. La intensidad máxima de esta región se observa en la posición $(l, b) \sim\left(283^{\circ} 59^{\prime},-00^{\circ} 55^{\prime}\right)$, la cual es coincidente con la ubicación de región de formación estelar Avedisova 2311.

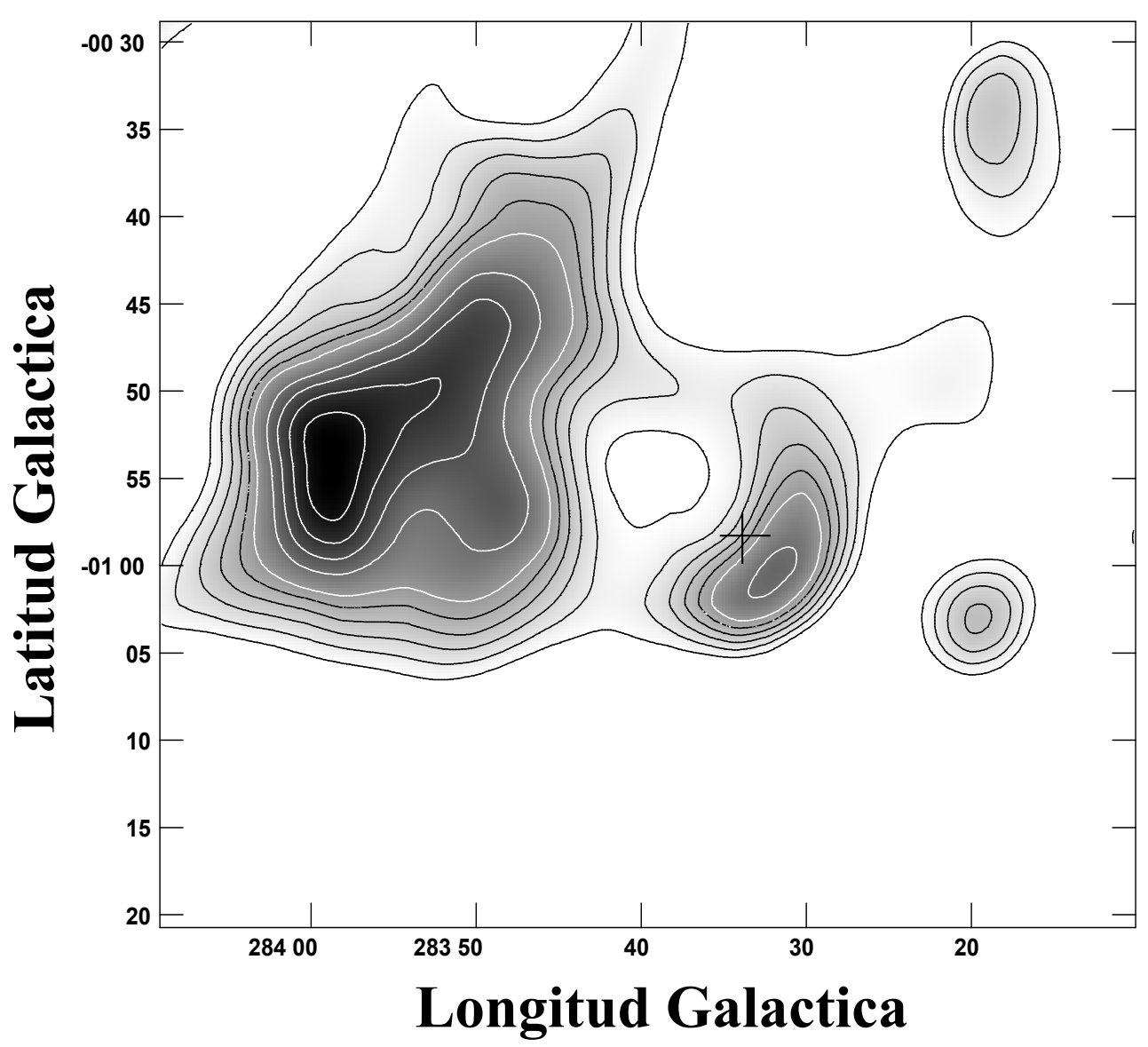

Figura 5.11: Distribución de la emisión en el continuo de radio en 5 GHz en NGC 3199. Los niveles de contorno están dados en $\mathrm{T}_{B}$ y van desde $2,5 \mathrm{~K}$ hasta $3,5 \mathrm{~K}$ en intervalos de $0,2 \mathrm{~K}$, a partir de 3,5 en intervalos de $0,3 \mathrm{~K}$. La posición de WR 18 se indica con la cruz. 
La distribución de emisión de continuo de radio en 2,4 GHz (Duncan et al. 1995) se muestra en la Figura 5.12.

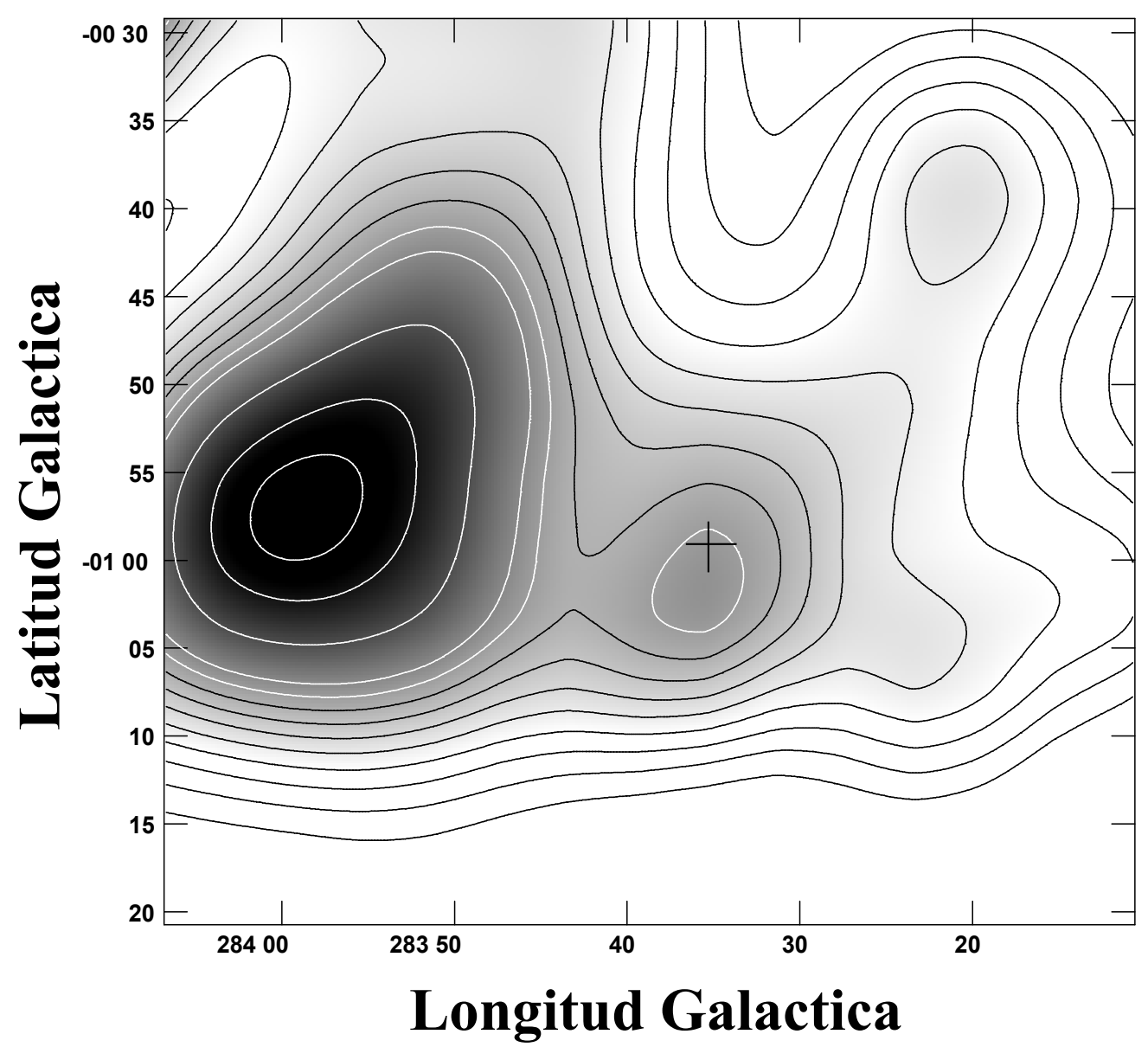

Figura 5.12: Distribución de la emisión en el continuo de radio en 2,4 GHz en NGC 3199. Los niveles de contorno van desde 4 hasta $13 \mathrm{Jy} / \mathrm{haz}$ en intervalos de $1 \mathrm{Jy} / \mathrm{haz}$, y a partir de $13 \mathrm{Jy} / \mathrm{haz}$ en intervalos de $3 \mathrm{Jy} / \mathrm{haz}$. La posición de WR 18 se indica con la cruz.

Como puede observarse, la emisión a esta frecuencia es muy similar a la observada en $5 \mathrm{GHz}$. A pesar de las diferencias en la resolución angular, puede distinguirse una estructura similar en tamaño y forma al BBO. Puede observarse también una emisión intensa extendida cuyo máximo se encuentra en $(l, b)=\left(283^{\circ} 58^{\prime},-00^{\circ} 57^{\prime}\right)$ y que muy probablemente represente también la contraparte en continuo de radio de la región de formación estelar Avedisova 2311. 


\subsection{Análisis y discusión}

Hasta aquí se ha presentado toda la información de la que se dispone, acerca del MIE en los alrededores de WR 18 y su nebulosa óptica asociada NGC 3199. En esta sección se discutirá dicha información con el fin de poder establecer un escenario adecuado para determinar la membresía a la nebulosa de las distintas componentes encontradas en todas las frecuencias así como también el estudio de sus propiedades.

\subsubsection{El gas ionizado asociado a NGC 3199}

Con el fin de determinar las características del material ionizado, fue necesario adoptar un modelo para explicar la distribución espacial observada en la emisión $\mathrm{H} \alpha$ así como también en continuo de radio en 5 y 2,4 GHz.

A comienzos de este capítulo se hizo referencia al modelo propuesto por Dyson \& Ghambari (1989) para explicar la morfología de NGC 3199, en el cual el BBO consiste en una semicáscara generada por la acción de una elevada velocidad espacial de WR 18 en un medio uniforme. A continuación nos proponemos poner a prueba este modelo estudiando la emisión observada en $\mathrm{H} \alpha$. Para tal fin se confeccionaron algunos perfiles de emisión a lo largo del eje de simetría del BBO a partir de la imagen $\mathrm{H} \alpha$. Dicho eje representaría también (de acuerdo al modelo de Dyson \& Ghambari, 1989) a la dirección de movimiento de WR 18. La imagen $\mathrm{H} \alpha$ de NGC 3199 fue convolucionada a un haz de 30 " con el fin de eliminar posibles fuentes puntuales que produzcan confusión. En la Figura 5.13 se muestran los perfiles mencionados así como también las direcciones en las que fueron tomados sobre la imagen $\mathrm{H} \alpha$ de la nebulosa. En todos los casos, WR 18 se encuentra en el centro.

En los perfiles de la Figura 5.13 la emisión correspondiente al BBO está indicada mediante llaves. En estos perfiles pueden resaltarse dos características generales de la emisión:

1. La emisión del BBO parece estar formada por lo que parecen ser dos picos, uno ancho sobre el borde interno de la nebulosa, y otro angosto sobre el borde externo.

2. La emisión del BBO parece ser ligeramente más abrupta en su lado interno que en el externo. Es decir que la pendiente de la emisión es levemente mayor en el borde que está próximo a la estrella. 

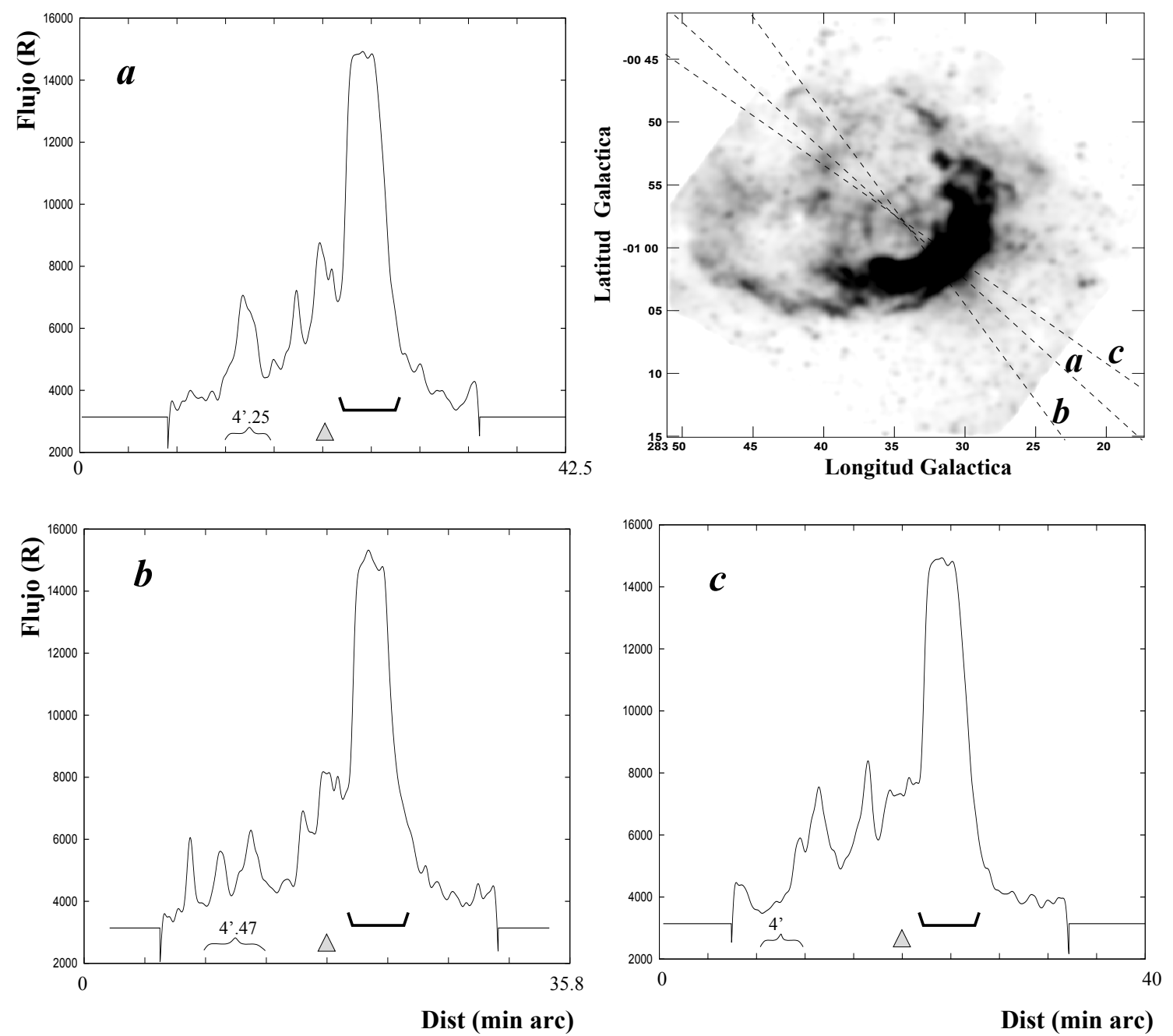

Figura 5.13: Perfiles de emisión H $\alpha$ de la nebulosa NGC 3199. Las direcciones en las que fueron obtenidos los perfiles están indicadas por las líneas de trazos $a, b$ y $c$ en el panel superior derecho. La llave y el triángulo en la parte inferior de cada perfil indican la emisión correspondiente al BBO y la posición de WR 18, respectivamente. El flujo está dado en Rayleighs (R) y la distancia angular en minutos de arco.

El primer modelo que se adoptó para representar esta emisión fue el de una semicáscara formada por un borde externo y otro interno ambos de geometría circular. Para reproducir la emisión de ésta se supuso que la intensidad de emisión es proporcional a la longitud del material emisor (material emisor ópticamente delgado). Estos perfiles fueron luego convolucionados a un haz de $30^{\prime \prime}$ de arco. En la Figura 5.14 se muestra un perfil obtenido con este modelo, el cual fue confeccionado considerando un radio para el borde interno del $40 \%$ del radio del borde externo. Como puede observarse, este modelo no resulta suficiente para explicar las dos características en la emisión que fueron resaltadas en el párrafo anterior, es decir no genera perfiles anchos en su ex- 
tremo con una morfología de doble pico, ni tampoco presenta una emisión más abrupta en el lado interno.

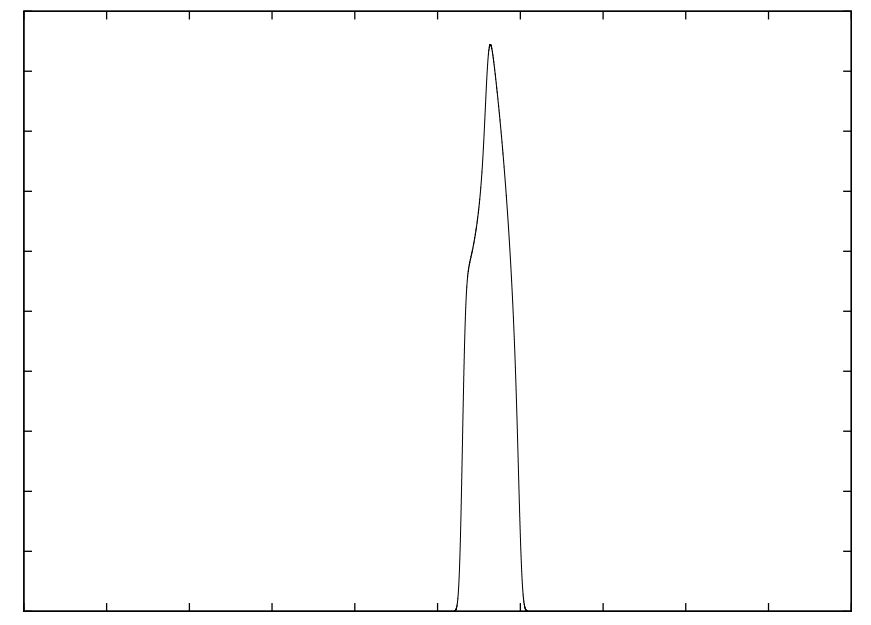

Figura 5.14: Perfil teórico de emisión obtenido suponiendo bordes circulares. El borde circular interno posee una distancia a la estrella que es un $40 \%$ de la distancia del borde externo.

Posteriormente se adoptó un modelo con similares características geométricas al descripto por Dyson \& Ghambari (1989) (ver Figura 5.15).

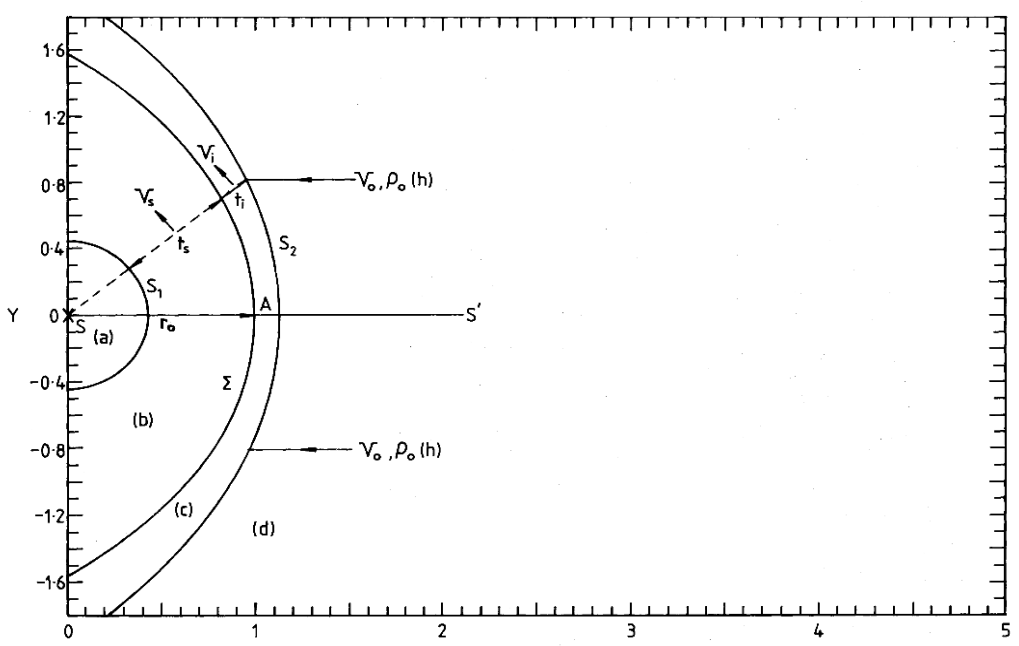

Figura 5.15: Diagrama esquemático propuesto por Dyson \& Ghambari (1989) para describir la distribución espacial del material ionizado en la nebulosa NGC 3199

Basados en dicho modelo se consideró una semicáscara formada por un borde interno circular y un borde externo hiperbólico que conforman una figura de revolución alrededor del eje de simetría, el cual es perpendicular 
a la dirección del observador. La extensión en longitud de la estructura está determinada por la distancia de corte, la cual puede ir desde la posición de WR 18 (distancia de corte máxima) hasta una distancia equivalente al radio interno (distancia de corte mínima) (ver Figura 5.16). El modelo de nebulosa está determinado entonces por tres variables: el radio interno $\left(\mathrm{R}_{\text {int }}\right)$, la distancia de corte $\left(\mathrm{d}_{c}\right)$ y la excentricidad del borde hiperbólico externo $\left(\mathrm{e}_{b h e}\right)$.

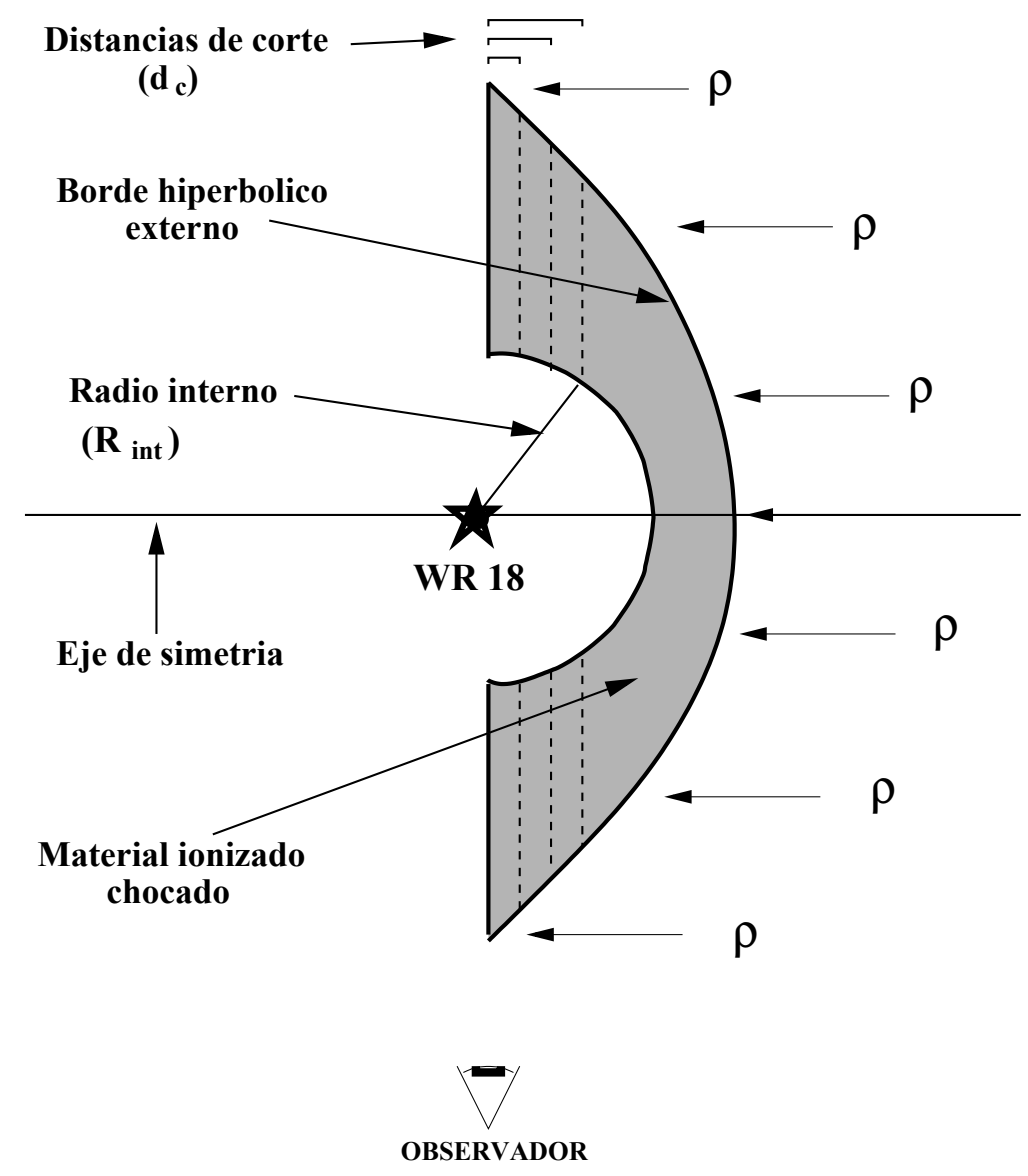

Figura 5.16: Segundo modelo propuesto para explicar la morfología y el perfil de emisión de la nebulosa NGC 3199.

Una morfología como esta puede originarse debido a una elevada velocidad espacial de WR 18, la cual ioniza y choca el material interestelar circundante de densidad constante $\rho$. Con este modelo es posible reproducir la componente ancha con los dos picos en la parte superior; la relación de intensidades entre los picos está determinada por la excentricidad del borde hiperbólico externo, mientras que la pendiente del borde externo está determinada por el radio interno. Para ajustar el modelo se utilizó el perfil $a$ de la Figura 5.13 ya que la dirección en la que fue tomado el mismo es la más cercana a la dirección de simetría de la nebulosa y por lo tanto la mejor representada por el modelo. El análisis de este perfil se basó en la determinación de dos parámetros: 1) 
distancia entre el máximo de emisión de la estrella $(\mathrm{I}=0,595)$ y el perfil $\left(\mathrm{d}_{e p}\right)$ en unidades del ancho del perfil para esta intensidad $\left(\mathrm{A}_{I=0,595}\right)$ y 2$)$ ancho del perfil para $\mathrm{I}=0,95\left(\mathrm{~d}_{I=0,95}\right)$ también en unidades de $\mathrm{A}_{I=0,595}$. En la Figura 5.17 se muestra el perfil $a$ en unidades de flujo normalizado vs. distancia angular en minutos de arco. En este perfil están indicados los dos parámetros mencionados anteriormente. Los valores de $\mathrm{d}_{e p} \mathrm{y} \mathrm{d}_{I=0,95}$ medidos del perfil $\mathrm{H} \alpha$ son: $\mathrm{d}_{e p}=0,521 \times \mathrm{A}_{I=0,595}$ y $\mathrm{d}_{I=0,95}=0,571 \times \mathrm{A}_{I=0,595}$.

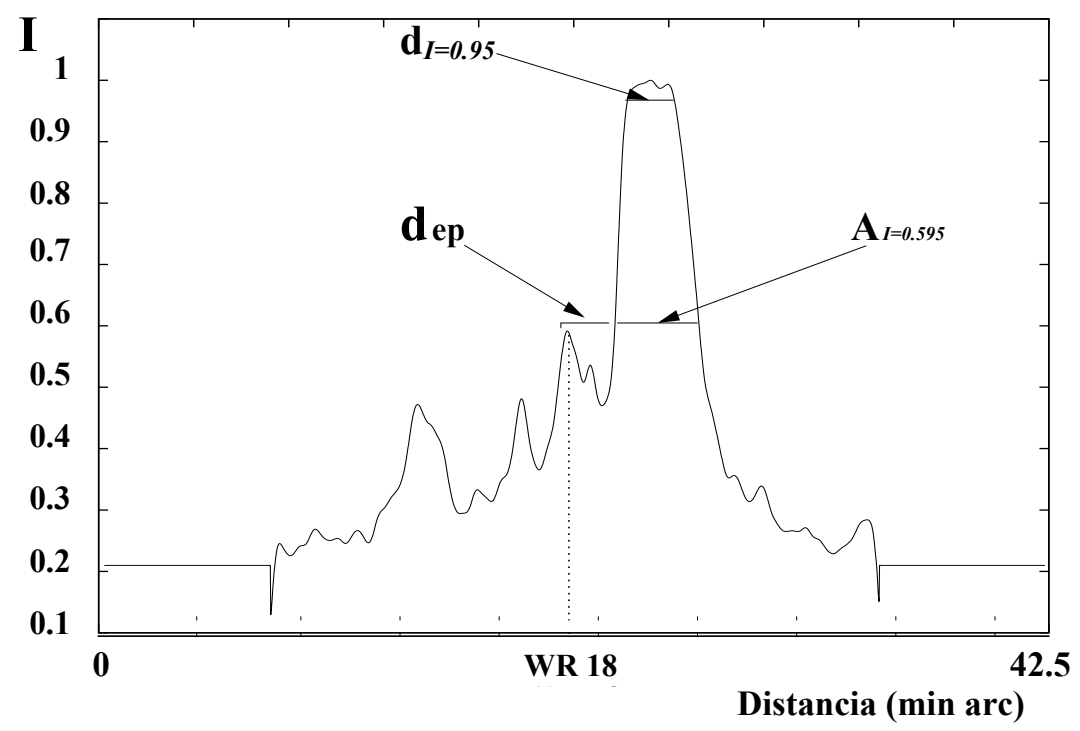

Figura 5.17: Perfil de emisión H $\alpha$ de NGC3199 donde se encuentran indicados los parámetros a ajustar con el modelo.

De esta manera, se hicieron numerosos ensayos con distintos valores de $\mathrm{R}_{i n t}, \mathrm{~d}_{c} \mathrm{y} \mathrm{e}_{b h e}$. El mejor ajuste se obtuvo para $\mathrm{R}_{i n t}=62 \%$ del radio externo, $\mathrm{d}_{c}=32 \%$ del radio externo y $\mathrm{e}_{b h e}=2$. Sin embargo la morfología del perfil obtenido para estos valores difiere notablemente de la del perfil observacional ya que el mínimo entre los dos picos es muy pronunciado. Modificando las variables del modelo se intentó disminuir este mínimo con una mínima variación de los parámetros de ajuste. El nuevo ajuste llevó a un modelo con $\mathrm{R}_{\text {int }}=53 \%$ del radio externo, $\mathrm{d}_{c}=32 \%$ del radio externo y $\mathrm{e}_{b h e}=2,8$. En la Figura 5.18 se esquematizan ambos modelos comparados con el perfil de emisión de NGC 3199 y convolucionados con un haz de $30^{\prime \prime}$. Como puede observarse, en el segundo modelo el tamaño del mínimo entre los picos ha descendido pero con esto se perdió ajuste del parámetro $\mathrm{d}_{I=0,95}$, ya que la pendiente en la mitad superior del borde externo disminuyó también.

Con el fin de solucionar el problema mencionado anteriormente, fue necesario introducir una segunda modificación al modelo. Para disminuir la profundidad del mínimo entre los dos picos, la morfología del borde interno y/o el borde externo debería ser algo distinta. La morfología circular del borde 


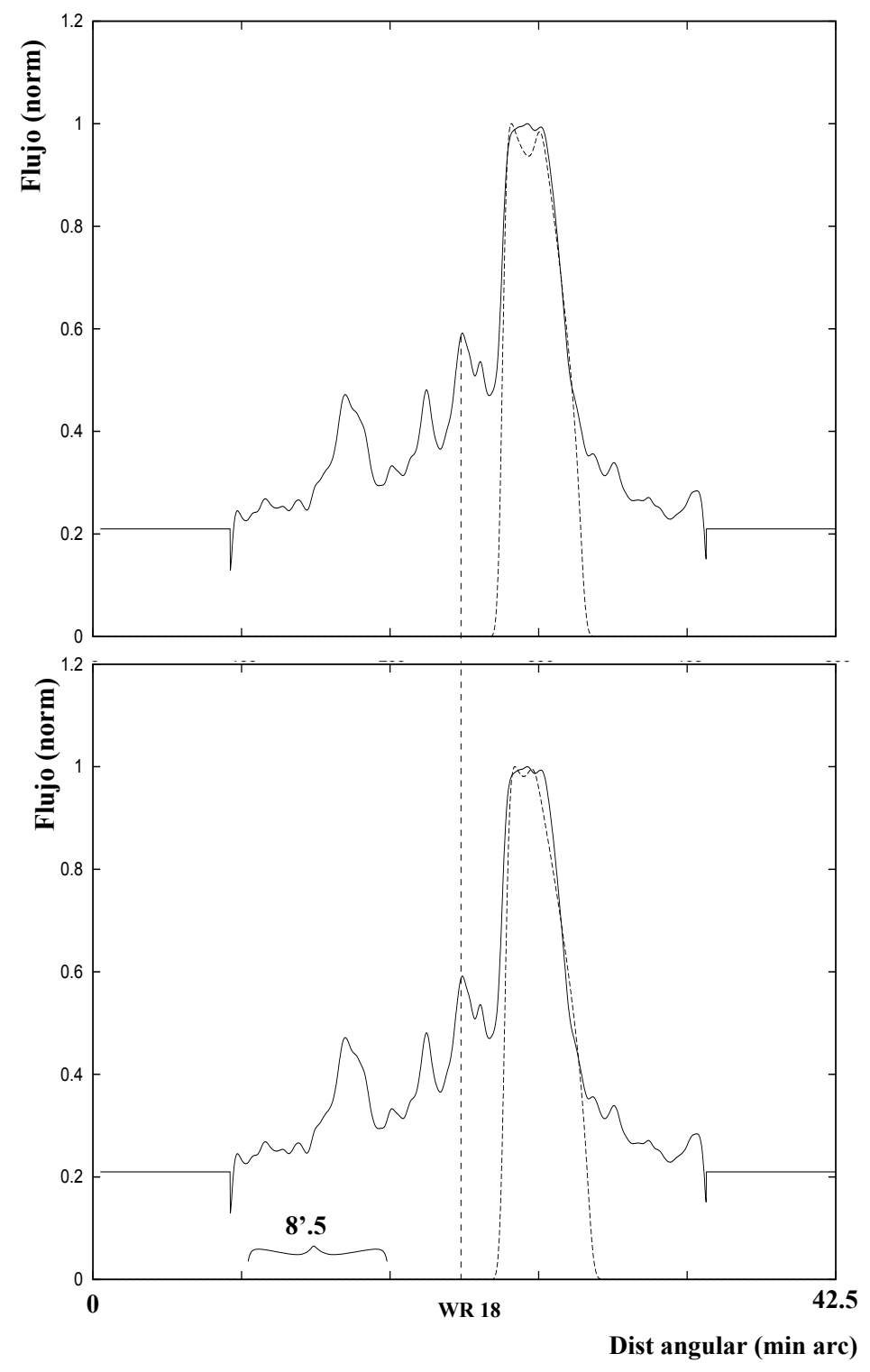

Figura 5.18: Panel superior: Ajuste realizado con $\mathrm{R}_{\text {int }}=62 \%$ del radio externo, $\mathrm{d}_{c}=32 \%$ del radio externo y $\mathrm{e}_{b h e}=2$. Panel inferior: Ajuste realizado con $\mathrm{R}_{i n t}=53 \%$ del radio externo, $\mathrm{d}_{c}=32 \%$ del radio externo y $\mathrm{e}_{b h e}=2.8$. Ambos modelos fueron convolucionados con un haz de $30^{\prime \prime}$ y ambos están superpuestos con el perfil observado de la emisión $\mathrm{H} \alpha$.

interno se asocia a una emisión isotrópica del viento de la estrella, por lo tanto no es seguro modificarla, por lo tanto la modificación se llevó a cabo en el borde externo, haciendo más pronunciados los extremos del mismo. Para lograr esto, el borde externo hiperbólico se reemplazó por uno elíptico (ver Figura 5.19). Una estructura de este tipo podría explicarse considerando una emisión isotrópica del viento de la estrella, moviéndose a alta velocidad e impactando el MIE, el cual tiene una densidad en los extremos de la nebulosa $\left(\rho_{1}\right)$ mayor 
que en el centro $\left(\rho_{2}\right)$.

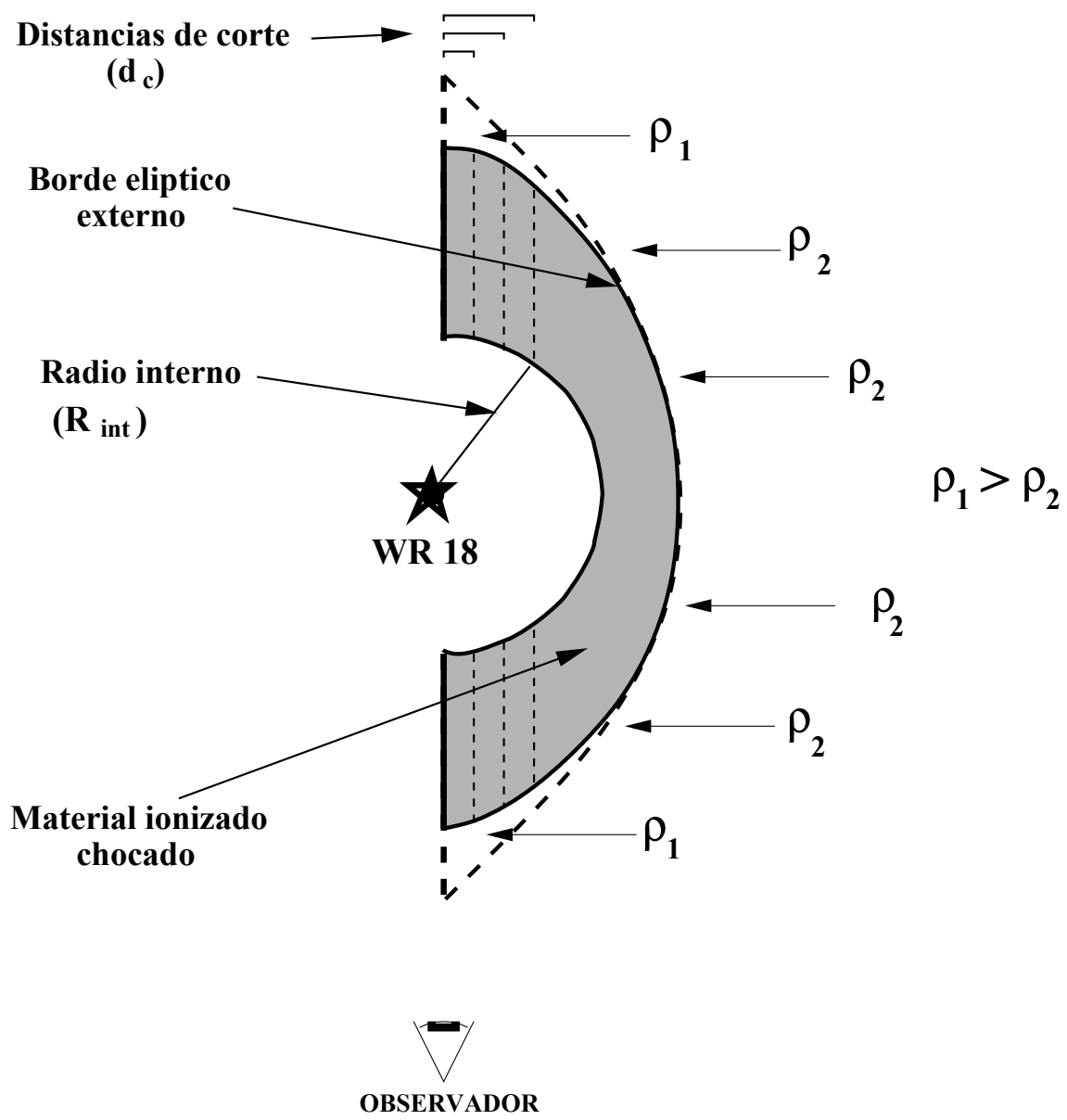

Figura 5.19: Tercer y último modelo propuesto para explicar la morfología y el perfil de emisión de la nebulosa NGC 3199

Con este cambio, la pendiente del pico ubicado en el lado interno es menos pronunciada, y por lo tanto la profundidad del mínimo entre los picos disminuye notablemente. Las variables del modelo son ahora, el radio interno $\left(\mathrm{R}_{\text {int }}\right)$, la distancia de corte $\left(\mathrm{d}_{c}\right)$ y el semieje mayor del borde elíptico $\left(\mathrm{s}_{m}\right)$ (para el semieje menor del borde elíptico se tomó un valor $=1)$. Con este nuevo modelo, el mejor ajuste se consiguió para $\mathrm{R}_{i n t}=65 \%$ del radio externo, $\mathrm{d}_{c}=30 \%$ del radio externo y $\mathrm{s}_{m}=2,8$. Los valores obtenidos para los parámetros de ajuste fueron: $\mathrm{d}_{e p}=0,516 \mathrm{~A}_{I=0,595} \mathrm{y} \mathrm{d}_{I=0,95}=0,568 \mathrm{~A}_{I=0,595}$. En otras palabras, los parámetros de ajuste difieren en menos del $1 \%$ con los obtenidos del perfil $\mathrm{H} \alpha$. En la Figura 5.20 se muestra la comparación de ambos perfiles.

En la Figura 5.21 se muestra la superposición de la nebulosa NGC 3199 en $\mathrm{H} \alpha$ con el modelo a escala obtenido anteriormente. Como puede observarse el modelo muestra buena correspondencia morfológica con la nebulosa, especialmente en la zona central. 


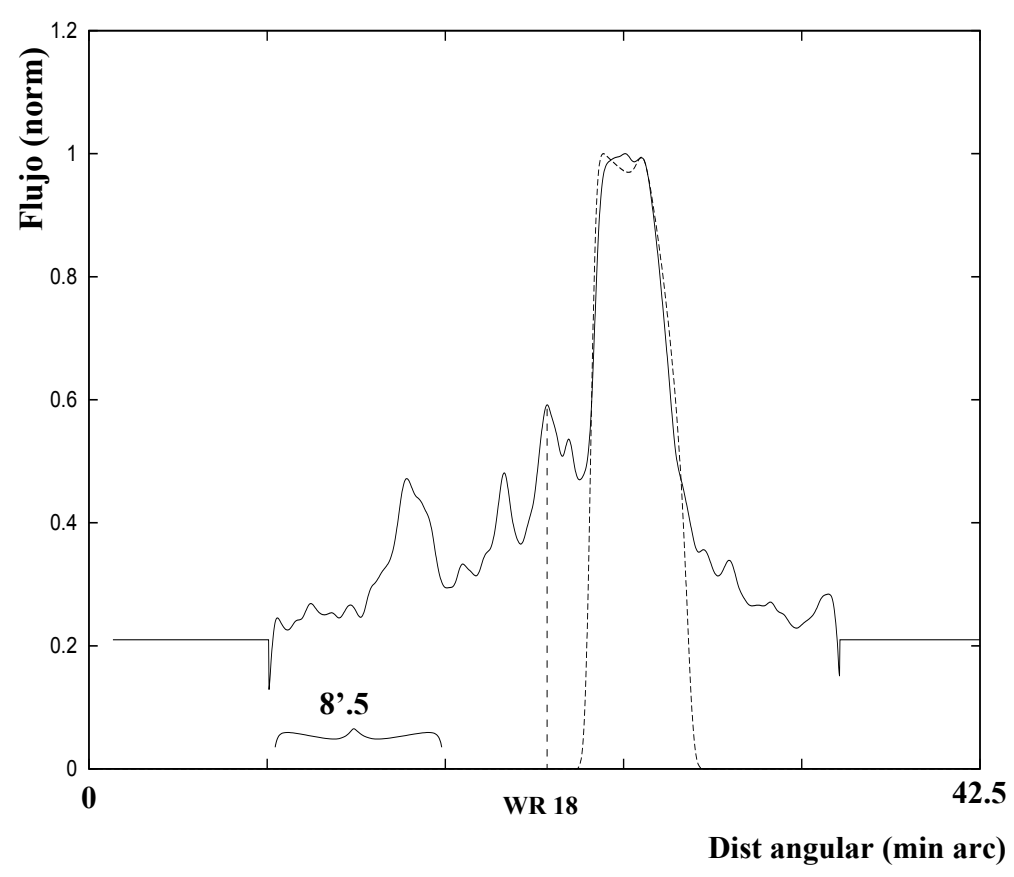

Figura 5.20: Modelo obtenido con $\mathrm{R}_{\text {int }}=65 \%$ del radio externo, $\mathrm{d}_{c}=30 \%$ del radio externo y $\mathrm{s}_{m}=2,8$, convolucionado con un haz de $30^{\prime \prime}$ y superpuesto con el perfil de emisión $\mathrm{H} \alpha$.

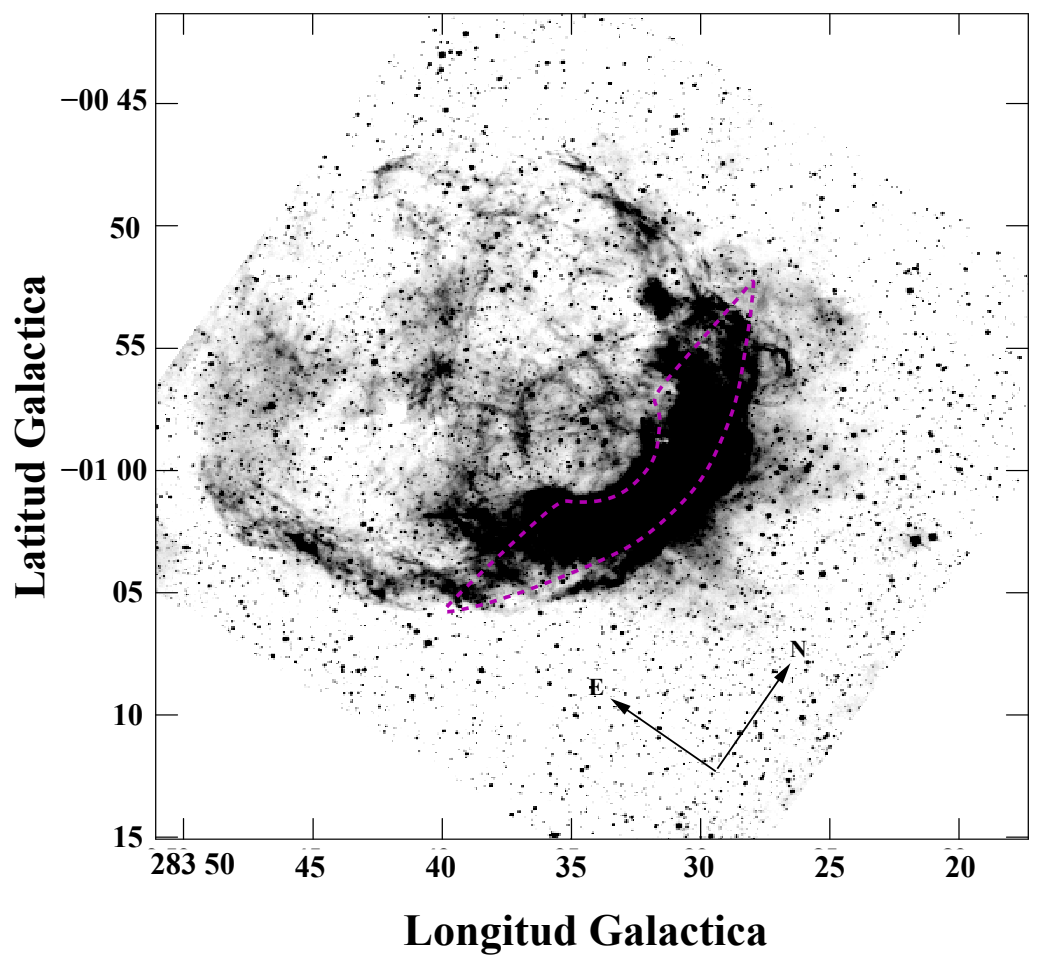

Figura 5.21: Superposición a escala del modelo obtenido con la imagen H $\alpha$ de NGC 3199. 
En la Tabla 5.1 se presentan los principales parámetros físicos obtenidos para NGC 3199 a partir de la emisión en el continuo de radio en 2,4 y 5 $\mathrm{GHz}$ y con los métodos explicados en el Capítulo 3. Las incertezas en los flujos a estas frecuencias provienen de la indeterminación del primer nivel de contorno. Para la determinación de la masa del gas ionizado $\left(M_{i o n}\right)$, la densidad electrónica $\left(n_{e}\right)$ y la medida de emisión máxima $\left(E M_{\max }\right)$ se consideró una temperatura electrónica $T_{e}=9500 \mathrm{~K}$ (Kwitter, 1984) y una simetría esférica con densidad electrónica homogénea $(f=1) . M_{i o n}$ fue multiplicada por 1,27 para considerar la presencia de Helio ionizado. El factor de llenado $f$ puede obtenerse a partir de los parámetros geométricos obtenidos a partir del modelo ajustado para el BBO. Utilizando la Ecuación 3.16 multiplicada por un factor 0,35, que representa el $70 \%$ de la semicáscara (debido a la distancia de corte del $30 \%$ del modelo) y adoptando $\mathrm{R}_{e x t}=4,2$ pc y $\mathrm{R}_{\text {int }}=2,7 \mathrm{pc}(\equiv 0,65 \times 4,2$ pc) el valor obtenido para el factor de llenado es $f=0,26$. El factor de llenado puede calcularse también considerando las densidades electrónicas calculadas de la espectroscopía óptica, a partir de $f=\left(\frac{n_{e}}{n_{e}^{\prime}}\right)^{0,5}$. Adoptando $n_{e}^{\prime}=140 \mathrm{~cm}^{-3}$ (Kwitter, 1984), el valor obtenido es $f=0,96$. En base a lo expuesto se puede afirmar que $f$ se encuentra entre los valores 0,26 y 0,96 .

Tabla 5.1: Principales parámetros físicos correspondientes al gas ionizado en NGC 3199

\begin{tabular}{lr}
\hline \hline & \\
Parámetro & Valor \\
\hline & \\
$S_{2,4 \text { GHz }}(J y)$ & $28 \pm 3$ \\
$S_{5}$ GHz $(J y)$ & $25 \pm 2$ \\
Indice espectral $(\alpha)$ & $-0,15 \pm 0,11$ \\
$n_{e}(f=1)\left(\mathrm{cm}^{-3}\right)$ & $130_{-50}^{+100}$ \\
$n_{e}(f=0,26-0,96)\left(\mathrm{cm}^{-3}\right)$ & $255-132$ \\
$M_{\text {ion }}(f=1)\left(\mathrm{M}_{\odot}\right)$ & $271_{-230}^{+630}$ \\
$M_{\text {ion }}(f=0,26-0,96)\left(\mathrm{M}_{\odot}\right)$ & $137-264$ \\
$E M_{\max }(f=1)\left(10^{4} \mathrm{pc} \mathrm{cm}^{-6}\right)$ & $9,1 \pm 4,5$ \\
$E M_{\max }(f=0,26-0,96)\left(10^{4} \mathrm{pc} \mathrm{cm}^{-6}\right)$ & $5,8-8,9$ \\
$N_{\text {lyc }}\left(10^{49} \mathrm{seg}^{-1}\right)$ & $\sim 1,1$ \\
\end{tabular}

Como puede observarse de la Tabla 5.1 el valor obtenido para el el índice espectral a partir de los flujos en 2,4 y $5 \mathrm{GHz}$, indica que la nebulosa NGC 3199 posee una emisión típicamente térmica. 


\subsubsection{Emisión del polvo en NGC 3199}

Para la determinación de las características y propiedades físicas del polvo en la nebulosa NGC 3199 se utilizaron las mediciones realizadas sobre los relevamientos IRAS y MSX en todas sus bandas.

En la Tabla 5.2 se presentan los flujos medidos en las cuatro bandas del relevamiento IRAS y en las bandas A $(8,28 \mu \mathrm{m}), \mathrm{D}(14,65 \mu \mathrm{m})$ y $\mathrm{E}(21,3 \mu \mathrm{m})$ del relevamiento MSX y los principales parámetros físicos obtenidos a partir de los mismos. El flujo correspondiente a la banda $\mathrm{C}(12,13 \mu \mathrm{m})$ del relevamiento MSX no se incluye debido a la dificultad en la determinación del primer nivel de contorno de la nebulosa en dicha frecuencia. La temperatura del polvo indicada se obtuvo a partir de los valores del flujo en 60 y $100 \mu \mathrm{m}, \mathrm{y}$ fue calculada considerando dos valores posibles para el índice de emisividad $m$.

Tabla 5.2: Principales parámetros físicos infrarrojos correspondientes a NGC 3199

\begin{tabular}{lr}
\hline \hline & \\
Parámetro & Valor \\
& \\
\hline$S_{8,28 \mu m}(J y)$ & $77 \pm 35$ \\
$S_{12 \mu m}(J y)$ & $256 \pm 108$ \\
$S_{14,65 \mu m}(J y)$ & $144 \pm 47$ \\
$S_{21,3 \mu m}(J y)$ & $202 \pm 81$ \\
$S_{25 \mu m}(J y)$ & $416 \pm 160$ \\
$S_{60 \mu m}(J y)$ & $2014 \pm 496$ \\
$S_{100 \mu m}(J y)$ & $5300 \pm 1700$ \\
$F_{I R}\left(W / m^{2}\right)$ & $2,7 \times 10^{-10}$ \\
$L_{I R}\left(L_{\odot}\right)$ & $4.1 \times 10^{4}$ \\
$T_{p o l v o}(\mathrm{~K})(m=1)$ & $32 \pm 6$ \\
$T_{\text {polvo }}(\mathrm{K})(m=1,5)$ & $28 \pm 5$ \\
$M_{\text {polvo }}\left(M_{\odot}\right)$ & $\sim 11$ \\
& \\
\hline
\end{tabular}

En la Figura 5.22 se muestra la distribución espectral de energía (SED) obtenida para el infrarrojo medio y lejano, considerando una emisión del polvo de la forma $\nu^{m} \times \mathrm{B}_{\nu}\left(T_{\text {polvo }}\right)$ (Ecuación 3.9) y una temperatura $T_{\text {polvo }}=32 \mathrm{~K}$. En esta figura están también indicados los flujos correspondientes a las cuatro bandas IRAS (rectángulos) y a las bandas A, D y E del relevamiento MSX (círculos).

En la Figura 5.22 puede observarse que los valores de flujo correspondientes 


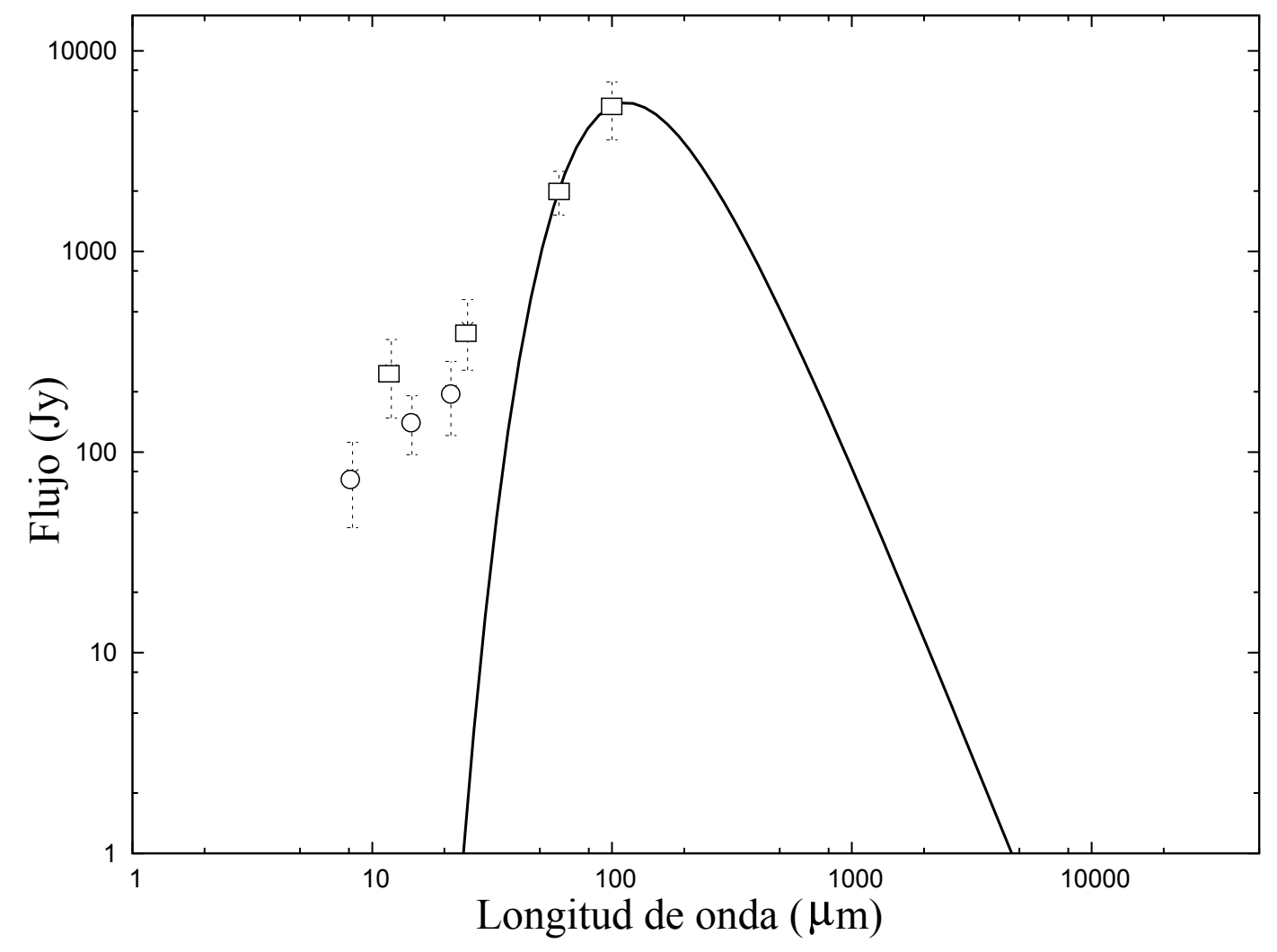

Figura 5.22: Distribución espectral de energía en la región del IR medio y lejano obtenida para una temperatura $T_{\text {polvo }}=32 \mathrm{~K}$. Los cuadrados indican los flujos en las cuatro bandas IRAS y los círculos indican los flujos en las bandas A, D y E de MSX.

al relevamiento IRAS en 25 y $12 \mu \mathrm{m}$ y las 3 bandas del relevamiento MSX exceden los valores de flujo calculados por nuestro modelo. Este exceso de flujo puede ser originado por la emisión de líneas nebulares que emiten en el IR medio. Otra posible explicación puede ser que la emisión del polvo en NGC 3199 requiera más de una temperatura $T_{\text {polvo }}$ para su modelado. Puede observarse también que el flujo medido para $\lambda=12 \mu \mathrm{m}$ del relevamiento IRAS excede los flujos medidos para $\lambda=14,65$ y $21,3 \mu \mathrm{m}$ del relevamiento MSX. Este exceso de flujo puede ser el resultado de una muy mala determinación del primer nivel de contorno, ya que no se dispuso de imágenes de alta resolución angular (HIRES) para esta $\lambda$.

\subsubsection{Movimiento de WR 18}

El modelo de Dyson \& Ghambari (1989) intentó explicar la morfología de la nebulosa NGC 3199 como el resultado de la interacción entre el MIE y los vientos de WR 18 la cual se movería a gran velocidad produciendo una estructura de tipo "bow shock". Esta posibilidad fue desestimada posteriormente 
por Marston (2001) principalmente debido a las direcciones del movimiento propio de WR 18 obtenidas del catálogo Hipparcos las cuales indicaban un movimiento aparente en una dirección perpendicular al eje de simetría del BBO.

En este trabajo, considerando datos de movimiento propio obtenidos del catálogo Tycho para WR 18 se calculará el módulo de la velocidad espacial de WR 18 respecto del MIE así como también las direcciones de movimiento reales de la estrella al sustraer los efectos de movimiento solar, movimiento del LSR y movimiento del MIE local a la estrella. De acuerdo al catálogo de Tycho, los valores del movimiento propio para WR 18 son (en milisegundos de arco por año): $\mu_{\alpha} \cos \delta=-4,7 \pm 2,6$ y $\mu_{\delta}=4 \pm 2,4$. Siguiendo el procedimiento desarrollado por Moffat et al. (1998), obtuvimos los siguientes valores del movimiento propio referidos al sistema de coordenadas galácticas: $\mu_{l}=-9,5 \pm$ 4,3 marcsec/año y $\mu_{b}=-1,6 \pm 3,3$ marcsec/año.

Posteriormente se utilizó el método desarrollado por van der Sluys \& Lamers (2003) adaptado al cuarto cuadrante galáctico, con el fin de obtener las componentes de la velocidad de WR 18 (respecto del MIE) en la dirección de la longitud galáctica $\left(\mathrm{v}_{l}\right)$ y en la dirección de la latitud galáctica $\left(\mathrm{v}_{b}\right)$. Para esto, los valores $\mathrm{v}_{l}$ y $\mathrm{v}_{b}$ debieron ser corregidos por movimiento del LSR (220 $\mathrm{km} / \mathrm{seg}$ alrededor del centro galáctico), por el movimiento del Sol respecto del LSR $(10,0 \pm 1,3 \mathrm{~km} / \mathrm{seg}$ en direccion al centro galáctico, 13,9 $\pm 3,7 \mathrm{~km} / \mathrm{seg}$ en la dirección de rotación galáctica y $7,4 \pm 2,6 \mathrm{~km} / \mathrm{seg}$ en la dirección al polo norte galáctico) y por el propio movimiento del MIE en la dirección de la estrella. Los valores obtenidos fueron:

$$
v_{l_{W R 18(M I E)}}=-30 \pm 45 \mathrm{~km} / \mathrm{seg} \quad v_{W_{W R 18(M I E)}}=-5 \pm 35 \mathrm{~km} / \mathrm{seg}
$$

El módulo de la velocidad espacial de WR 18 respecto del MIE, corregido por movimiento del Sol y del LSR será:

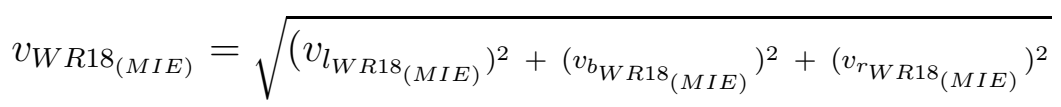

No se encontraron en la bibliografía valores medidos para la velocidad radial de WR $18\left(\mathrm{v}_{r}\right)$, pero por otro lado se puede afirmar que:

$$
v_{W R 18(M I E)} \geq \sqrt{(-30 \mathrm{~km} / \mathrm{seg})^{2}+(-5 \mathrm{~km} / \mathrm{seg})^{2}}=30 \mathrm{~km} / \mathrm{seg}
$$

Considerando los errores en $\mathrm{v}_{l_{W R 18_{(M I E)}}} \mathrm{y}_{\mathrm{V}_{W R 18_{(M I E)}}}$, el valor obtenido para $\mathrm{v}_{W R 18_{(M I E)}}$ puede superar los $80 \mathrm{~km} / \mathrm{seg}$. Este valor es ligeramente más alto que el deducido por Dyson \& Ghanbari (1989) ( $60 \mathrm{~km} / \mathrm{seg})$, es decir que la estrella podría estar moviéndose respecto del MIE a una velocidad que sería lo suficientemente alta como para producir una estructura de tipo "bow shock". Una estimación de la velocidad radial puede hacerse considerando los datos de velocidad radial obtenidos por Chu (1982) en la posición en la que se 
observa un desdoblamiento de la línea $\mathrm{H} \alpha$ (posición de WR 18); este fenómeno fue explicado por la autora como el resulatdo de la observación de dos capas de material ionizado alejándose de WR 18 originando líneas a velocidades positivas y negativas. Calculando el promedio de las velocidades de alejamiento y acercamiento utilizando líneas de $\mathrm{H} \alpha$ (tomadas con una apertura de $2^{\prime}$ en un área de $3^{\prime}$ ) alrededor de WR 18, encontramos que:

$$
v_{\text {alej }}=20,1 \pm 3,5 \mathrm{~km} / \mathrm{seg} \quad v_{\text {acerc }}=-13,5 \pm 1,5 \mathrm{~km} / \mathrm{seg}
$$

De esta manera promediando estos valores es posible encontrar una velocidad radial sistémica de la capa ionizada en expansión que podría aproximarse a la velocidad radial de la estrella. El valor obtenido fue:

$$
v_{r(\text { sist } W R 18)}=3,3 \pm 3,8 \mathrm{~km} / \mathrm{seg}
$$

La introducción de esta velocidad en las fórmulas desarrolladas anteriormente no introduce grandes cambios en el módulo de la velocidad espacial de la estrella respecto del MIE, ya que la distancia a WR 18 es muy cercana a la distancia del punto tangente en esta dirección (ver van der Sluys \& Lamers, 2003)

Las correcciones anteriormente mencionadas introducen también cambios en la dirección de movimiento aparente; con estas correcciones la dirección real del movimiento de la estrella respecto al MIE puede verse en la Figura 5.23. Como puede observarse, la dirección del movimiento estelar está en buen acuerdo con la morfología de NGC 3199, ya que la estrella parecería estar moviéndose en dirección hacia la zona más brillante de la nebulosa.

Es importante destacar que en la dirección de movimiento de WR 18 indicada en la Figura 5.23 no se han considerado los errores obtenidos para

$\mathrm{v}_{l_{W R 18(M I E)}} \mathrm{y}_{b_{W R 18(M I E)}}$ ya que los mismos generan una gran dispersión de direcciones de la velocidad.

\subsubsection{Componentes moleculares y atómicas asociadas a NGC 3199}

Considerando la posibilidad del modelo de bow shock como explicación a la morfología del BBO en la nebulosa NGC 3199, es necesario establecer cuáles de todas las componentes de gas atómico y molecular encontradas anteriormente serían las involucradas en este modelo y/o si existe alguna evidencia de la interacción entre las mismas y WR 18.

De todas las componentes moleculares y atómicas encontradas en las cercanías de NGC 3199, la componente de HI visible en el intervalo de velocidades de 8,2 a $13,2 \mathrm{~km} / \mathrm{seg}$ (ver Figura 5.9) es la única que presenta una excelente correspondencia morfológica con el BBO de NGC 3199 (aunque el intervalo de 


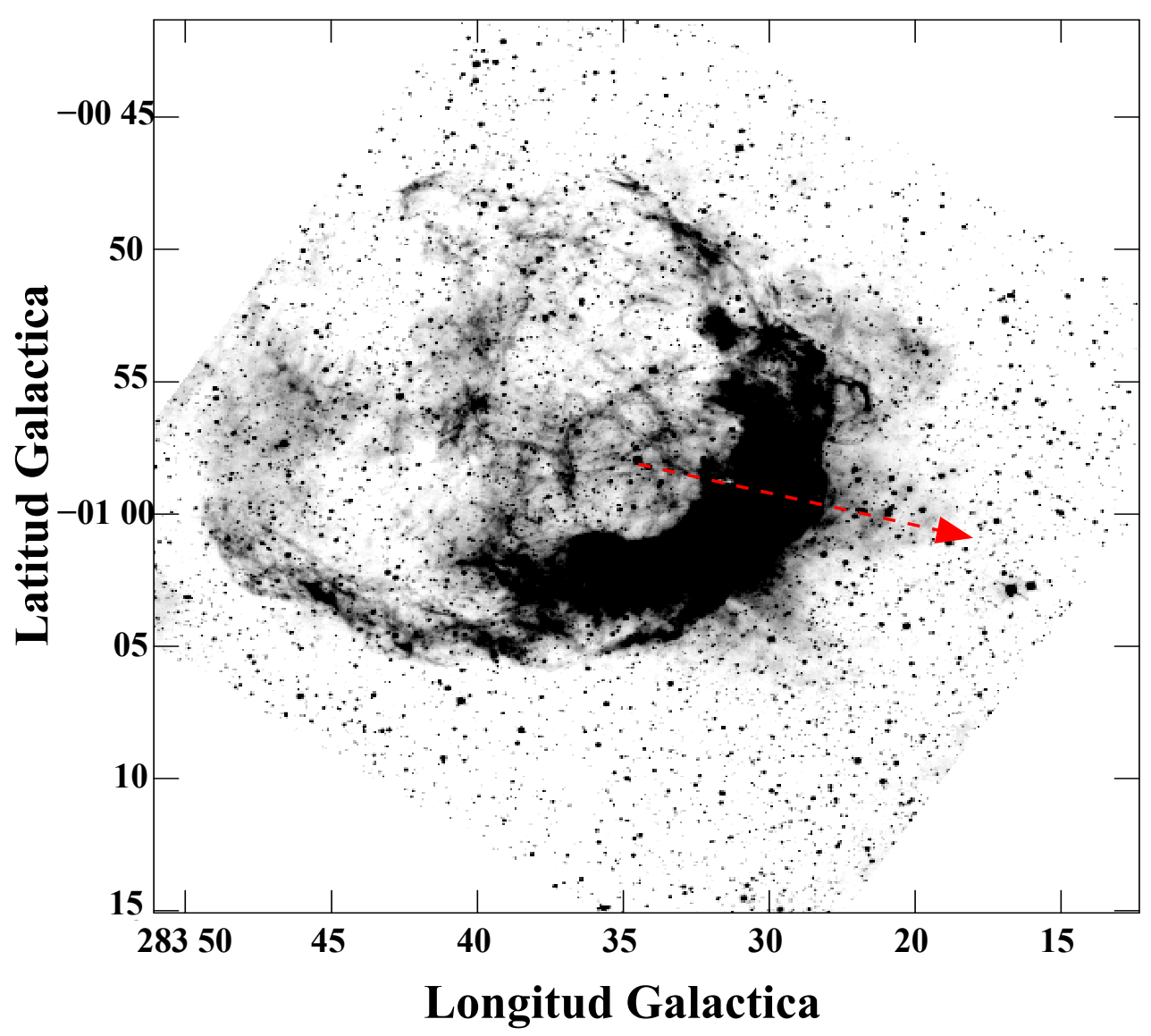

Figura 5.23: Dirección de movimiento de WR 18 repecto de la nebulosa NGC 3199, corregida por movimiento del LSR y movimiento solar

velocidades en el que se ésta se encuentra difiere de las velocidades encontradas en la línea $\mathrm{H} \alpha$ por $\mathrm{Chu}, 1982)$. La masa de HI calculada para esta componente es $M_{H I}=57 \pm 20 M_{\odot}$. Sumando este valor al valor encontrado para la masa ionizada obtenido a partir del flujo medido a $5 \mathrm{GHz}\left(M_{i o n}=137 \mathrm{M}_{\odot}\right.$, con $f=0,26)$ se obtiene una masa total $M_{t o t} \approx 194 M_{\odot}$. Este valor es muy similar al que se obtendría utilizando el modelo de Dyson \& Ghanbari (1989) (ver Ecuación 11 de dicho trabajo) reduciendo la distancia a $2,2 \mathrm{kpc}$ y tomando los valores de $n_{e} \mathrm{y} \mathrm{v}_{W R 18_{(M I E)}}$ calculados en esta Tesis Doctoral. El valor obtenido según este modelo sería $\mathrm{M}_{t o t} \approx 220 \mathrm{M}_{\odot}$.

No existe una componente molecular que presente una clara correpondencia en su morfología con el BBO, pero en el rango de velocidades 5,7 a 8,3 km/seg se ve una estructura molecular que fue descripta en la Sección 5.2.2 y que fue denominada subcomponente D3 (ver Figura 5.7). Esta subcomponente se extiende desde $(l, b)=\left(283^{\circ} 37^{\prime},-01^{\circ} 05^{\prime}\right)$ hasta $(l, b)=\left(283^{\circ} 25^{\prime},-01^{\circ} 07^{\prime}\right)$, en una dirección casi perpendicular a la dirección de movimiento de la estrella y 
que podría ser material molecular chocado por los vientos de la misma.

Aproximadamente en el mismo intervalo de velocidades, se encuentran las subcomponentes D1 y D2 (ver Figura 5.7). Como ya se describió en la Sección 5.2 .2 , estas subcomponentes se ubican entre los filamentos externos e internos en la región este de NGC 3199. Esta anticorrespondencia morfológica hace suponer que tales filamentos podrían ser en realidad los bordes de dichas subcomponentes moleculares que están siendo ionizadas por WR 18 y/o alguna otra estrella en la zona. De esta manera podrían no existir una cáscara "interna" y otra "externa" como se mencionó en la Sección 4.1, sino sólo una cáscara que rodea a la cavidad conformada por el material ionizado y neutro del BBO y la nube molecular conformada por las subcomponentes D1 y D2; la forma elongada de la misma podría deberse al efecto del movimiento de WR 18 (ver Figuras 5.7 y 5.8). La disposición y morfología de las componentes moleculares D1 y D2 coinciden notablemente con un vacío en la emisión del HI en el mismo intervalo de velocidades (ver Figura 5.9), lo cual tal vez indique una asociación física entre el gas molecular y el gas neutro a estas velocidades.

La subcomponente A2 es la única cuya morfología posee cierta correspondencia con la morfología observada en la emisión H $\alpha$ de la nebulosa NGC 3199. Esta se ve claramente en los filamentos ubicados en la zona norte y noreste del BBO (ver Figuras 5.3 y 5.4); además es también la única componente molecular cuyo intervalo de velocidad concuerda con las velocidades encontradas por Chu (1982) en esta posición. Este hecho así como también la elevada velocidad espacial observada para esta componente hacen suponer que el origen de este material molecular es distinto al de las otras componentes, siendo tal vez material molecular creado en la atmósfera de la estrella en alguna fase anterior en la cual la temperatura superficial es más fría (RSG o LBV) y que más tarde fue expulsado por los intensos vientos de la fase WR.

La subcomponente denominada como A3, coincide en posición y velocidad con la componente molecular encontrada por Marston (2001), la cual fue interpretada como el borde molecular externo de una cáscara en expansión que está siendo disociada e ionizada por la estrella. Como puede observarse de la Figura 5.3, esta interpretación no parecería ser del todo correcta y refleja las consecuencias de realizar un muestreo incompleto en la zona de estudio.

En la Sección 4.2.2, se mostró que las componentes B y C están proyectadas en la dirección de la posición de WR 18. Estas componentes moleculares exhiben velocidades radiales similares a las encontradas por Marston (2001) en la misma dirección y muy posiblemente correspondan a las mismas estructuras. Dada la extensión y morfología de las mismas, es altamente improbable que representen material molecular eyectado por WR 18 en alguna fase anterior a la fase WR, como Marston (2001) propone. Estas componentes (o al menos una de ellas) podrían ser las responsables de la absorción en el visual $\left(\mathrm{A}_{v}\right)$ 
encontrada para WR 18. Tomando un promedio de las $A_{V}$ recopiladas por van der Hucht (2001) en la dirección de la estrella WR 18, encontramos que la $\overline{A_{V}}=2,9 \pm 0,5 \mathrm{mag}$. Como se mencionó en el capítulo anterior, la relación entre la densidad de columna total de $\mathrm{H}$ y $\mathrm{A}_{V}$ está dada por:

$$
A_{V}=R_{V} \times 1,72 \times 10^{-22} \times N_{H}
$$

siendo los valores de $\mathrm{R}_{V}$ entre 3,1 y 5 (dependiendo de la densidad del medio

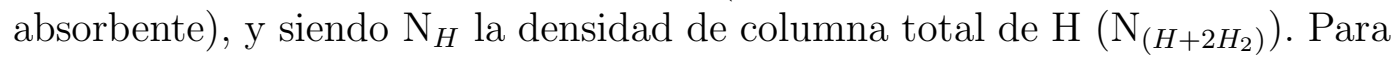
la densidad de columna de $\mathrm{H}$ se despreciará la componente atómica con lo cual $\mathrm{N}_{H}$ sólo será la correspondiente al material molecular.

La densidad de columna del gas molecular de la componente B en la dirección de WR 18 es $N_{H_{2}}=1,66 \times 10^{21}$ moléculas $/ \mathrm{cm}^{2}$, la que produciría una absorción en el visual $\mathrm{A}_{V} \sim 1,4 \mathrm{mag}$. Por otro lado, la densidad de columna del gas molecular de la componente $\mathrm{C}$ en la dirección de WR 18 es $N_{H_{2}}=9,5$ $\times 10^{20}$ moléculas $/ \mathrm{cm}^{2}$, la que produciría una absorción en el visual $\mathrm{A}_{V} \sim 0,8$ mag. Considerando un valor de absorción del MIE de 0,8 mag/kpc (Allen's, Astrophysical Quantities), la absorción total producida por estas dos componentes y por el MIE sería:

$$
A_{V(B+C+M I E)}=1,4+0,8+2,2 \mathrm{kpc} \times 0,8 \mathrm{mag} / \mathrm{kpc}=3,96 \mathrm{mag}
$$

Este valor excede al valor de absorción visual promedio obtenido de la literatura para WR 18. Por otro lado, considerando sólo la componente B y el MIE, el valor obtenido para la absorción visual es:

$$
A_{V(B+M I E)}=3,16 \mathrm{mag}
$$

Este último valor se encuentra dentro del rango de las absorciones visuales obtenidas de la literatura para WR 18. Es decir que la absorción producida por la componente molecular B (sumada a la producida por el MIE) alcanzaría para explicar la absorción visual observada en WR 18. En vista de este resultado la componente B podría ubicarse por delante de WR 18 mientras que la componente $\mathrm{C}$ por detrás de la misma.

Al observar la Figura 5.5, se puede apreciar una notable anticorrespondencia entre la componente molecular B y el BBO. Esta característica podría sugerir que dicha componente molecular se encuentra por delante de la nebulosa absorbiendo la emisión del gas ionizado de una estructura cuya extensión excede a la del BBO. Esta alternativa puede ser descartada al observar la emisión de la nebulosa en el IR medio y lejano, ya que no se detecta emisión en la dirección del centro de NGC 3199 para estas frecuencias.

\subsection{Resumen y conclusiones}

En este capítulo se analizaron las componentes del gas molecular, atómico e ionizado, así como también la emisión del polvo asociados a la nebulosa óptica 
NGC 3199.

La componente de gas ionizado fue estudiada a través de su emisión en el continuo de radio en 2,4 y $5 \mathrm{GHz}$. La masa y densidad obtenidas indican que el origen de la misma es interestelar. La morfología observada en el gas ionizado sugiere que la nebulosa se ha desarrollado por la interacción entre la estrella WR 18 (la cual se mueve a una elevada velocidad en la dirección de NGC 3199), y el gas neutro del MIE (el cual fue posteriormente calentado e ionizado). Este hecho parece estar corroborado por los perfiles de emisión observados en $\mathrm{H} \alpha$, los cuales pueden modelarse por medio de una cáscara cuya superficie interna posee simetría esférica y su superficie externa simetría elíptica/hiperbólica características de estructuras de tipo "bow shock". La detección de una estructura de HI a velocidades radiales entre $\sim 8$ y $13 \mathrm{~km} / \mathrm{seg}$ con similares características morfológicas que NGC 3199, indica que el gas neutro en esta nebulosa no ha sido completamente ionizado.

Las componentes moleculares detectadas en las cercanías de NGC 3199 se encuentran distribuidas en el intervalo de velocidades de $\sim-21$ a $14 \mathrm{~km} / \mathrm{seg}$. Cada una de estas parecen estar asociadas morfológica y/o cinemáticamente a distintas regiones de la nebulosa:

- Las componentes A1, A2 y A3, que podrían estar asociadas a la región norte y noreste de NGC 3199.

- Las componentes B y C que podrían estar ubicándose por delante y por detrás de la estrella WR 18 respectivamente. Estas componentes podrían estar siendo ionizadas por la estrella, generando las componentes de emsión $\mathrm{H} \alpha$ en -16 y 11,4 km/seg detectadas por Chu (1982) en la dirección de la estrella. Es improbable que estas componentes moleculares estén físicamente asociadas al BBO de NGC 3199.

- Las componentes D1, D2 y D3. Estas componentes muy probablemente se encuentren cinemáticamente asociadas con la nebulosa y la estrella. Las componentes D1 y D2 podrían estar conformando el límite este y sureste de NGC 3199 y su disposición espacial en la dirección norestesuroeste estar relacionada con la dirección de movimiento de la estrella. Los dos filamentos visibles en $\mathrm{H} \alpha$ ubicados en el extremo este de NGC 3199 podrían representar los bordes ionizados de las componentes D1 y D2.

Es importante destacar las diferencias entre las conclusiones obtenidas por Marston (2001) y las obtenidas en esta Tesis Doctoral en lo concerniente al estudio del gas molecular en esta nebulosa. Este es un buen ejemplo de lo erróneo que puede resultar hacer observaciones de gran resolución angular a expensas de perder campo de observación. 


\subsection{Bibliografía}

- Allens's, Astrophysical Quantities, Cuarta Edición. Editor: Arthur N. Cox

- Chu, Y.-H., 1981, ApJ, 249, 195C

- Chu, Y.-H., 1982, ApJ, 254, 578C

- Deharveng, L.; Maucherat, M., 1974 A\&A, 34, 465D

- Dyson, J. E.; Ghanbari, J., 1989, A\&A, 226, 270D

- Duncan, A. R.; Stewart, R. T.; Haynes, R. F.; Jones, K. L., 1995, MNRAS, 277,36D

- Haynes, R. F.; Caswell, J. L.; Simons, L. W. J., 1978, AuJPA, 45, 1H

- Kwitter, K. B., 1984, ApJ, 287, 840K

- Lundstrom, I.; Stenholm, B., 1982, IAUS, 99, 289L

- Marston, A. P. 2001, ApJ, 563, 875M

- Moffat, A. F. J., Marchenko, S. V., Seggewiss, W., van der Hucht, K. A., Schrijver, H., Stenholm, B., Lundstrom, I., Gunawan, D. Y. A. Setia, Sutantyo, W., van den Heuvel, E. P. J., 1998, A\&A, 331, 949

- Shaver, P. A.; Goss, W. M. 1970, AuJPA, 14, $133 \mathrm{~S}$

- Smith, Lindsey F., 1968MNRAS, 140, 409S

- Smith, Lindsey F.; Batchelor, R. A., 1970 AuJPh, 23, 203S

- van der Hucht, K. A., 1981mms, conf, 157V

- van der Hucht, K. A., 2001, NewAR, 45, 135V

- van der Sluys, M. V.; Lamers, H. J. G. L. M., 2003, A\&A, 398, 181V

- Whitehead, M. J.; Meaburn, J.; Goudis, C. D., 1988, A\&A, 196, 261W 


\section{Capítulo 6}

\section{Las nebulosas ópticas alrededor de WR 55 y WR 68.}

\subsection{RCW 78, morfología y antecedentes.}

RCW 78 (Rodgers, Campbell \& Whiteoak, 1960) es una nebulosa óptica irregular que rodea a la estrella WR 55 (HD117688). Esta nebulosa es claramente observable en la banda óptica, especialmente en la línea $\mathrm{H} \alpha$. La parte más brillante de la misma posee un diámetro de aproximadamente $20^{\prime}$. Una imagen $\mathrm{H} \alpha$ completa de la nebulosa puede encontrarse en el trabajo de Chu et al. (1983). En la Figura 6.1 se muestra la imagen $\mathrm{H} \alpha$ de la zona más brillante de RCW 78 obtenida del relevamiento SuperCOSMOS. En la misma se observan tres regiones de interés: 1) La indicada como A (delimitada con una línea continua), conforma una estructura filamentaria que rodea en forma incompleta a la estrella WR 55. Esta estructura ha sido dividida en tres subregiones, de acuerdo al brillo observado de las mismas: la región A1, que tiene una extensión de $\sim 12^{\prime}$ en la dirección noreste a suroeste, y es la más brillante; la región A2, que se extiende a lo largo de $\sim 12^{\prime}$ en la dirección este a oeste, y la región A3, extendida a lo largo de $\sim 6^{\prime}$ en la dirección sureste a noroeste, que es la menos intensa. En la Figura 6.1 las regiones A1, A2 y A3 están divididas entre sí por las líneas de trazos ubicadas a lo largo de $l=307^{\circ} 52^{\prime} 30^{\prime \prime}$ y $b=00^{\circ} 06^{\prime}$. Perteneciente a la región A1 se destaca otra estructura muy brillante que se extiende desde $(l, b)=\left(307^{\circ} 49^{\prime}, 00^{\circ} 13^{\prime}\right)$ hasta $(l, b)=\left(307^{\circ} 46^{\prime}, 00^{\circ} 11^{\prime}\right)$ y cuya posición angular es muy cercana a la estrella WR 55. Esta estructura está indicada en la Figura 6.1 como la "barra"; 2) La estructura identificada como B, que es extendida y posee una geometría cuasi triangular. Ésta se extiende hacia el oeste superponiéndose con A1. En la Figura 6.1 la estructura B se encuentra delimitada por la línea de puntos gruesa; 3) La estructura indicada como C. La misma se ubica entre B y A2 y es una región de intensa absorción en la banda óptica. La estructura C está delimitada en la Figura 6.1 por la línea de puntos delgada. 


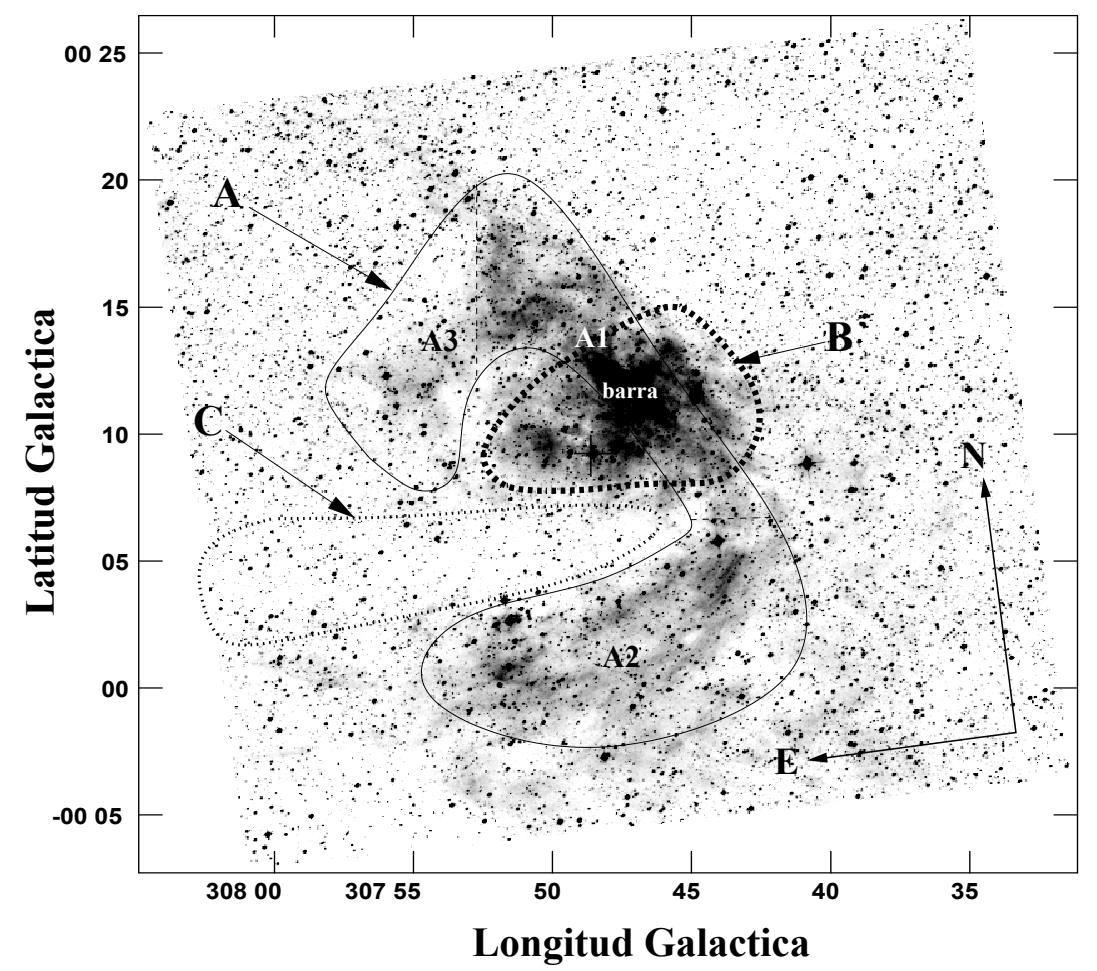

Figura 6.1: Imagen $\mathrm{H} \alpha$ de la nebulosa RCW 78 obtenida del relevamiento SuperCOSMOS. La posición de WR 55 está indicada por la cruz en el centro del campo. La orientación del sistema ecuatorial está dada por las flechas que indican las direcciones $\mathrm{N}$ y E en el extremo inferior derecho.

En la región comprendida por la nebulosa RCW 78, existen numerosos objetos cuyas posiciones coinciden con algunas de las estructuras mencionadas anteriormente. HD 117704 es una estrella de coordenadas $(l, b)=\left(307^{\circ} 48^{\prime} 32,4^{\prime \prime}\right.$, $\left.00^{\circ} 09^{\prime} 14,4^{\prime \prime}\right)$ y cuyo tipo espectral varía entre O9 y B2. La estrella HD 117797 se ubica en $(l, b)=\left(307^{\circ} 51^{\prime} 33,6^{\prime \prime}, 00^{\circ} 02^{\prime} 41,2^{\prime \prime}\right)$, su tipo espectral es O8Ib(f) (Walborn 1982) y su distancia es de 3,9 kpc (Turner \& Forbes, 2005). En la posición $(l, b)=\left(307^{\circ} 51^{\prime} 44,6^{\prime \prime}, 00^{\circ} 01^{\prime} 40,3^{\prime \prime}\right)$ se ubica el cúmulo abierto C1331622. El mismo posee un diámetro de $\sim 7^{\prime}$ (Días+2002-2007) y está compuesto principalmente por estrellas de tipo espectral A y F. La fuente IRAS 133166210 se ubica en la posición $(l, b)=\left(307^{\circ} 57^{\prime}, 00^{\circ} 01^{\prime} 12^{\prime \prime}\right)$. Esta fuente fue catalogada como la región de formación estelar Avedisova 307.95+0.02. En la Figura 6.2 se muestra la ubicación de los objetos mencionados anteriormente. De dicha figura puede observarse que parte de la emisión $\mathrm{H} \alpha$ proveniente de la región A2 hacia mayores longitudes galácticas posiblemente sea originada en el cúmulo C1331-622.

Chu \& Treffers (1981) estudiaron la línea $\mathrm{H} \alpha$ en las cercanías de WR 55 (en la zona central de RCW 78). Las velocidades radiales de la línea de $\mathrm{H} \alpha$ encontradas en este trabajo varían desde $-44 \mathrm{~km} / \mathrm{seg}$ en las cercanías de WR 


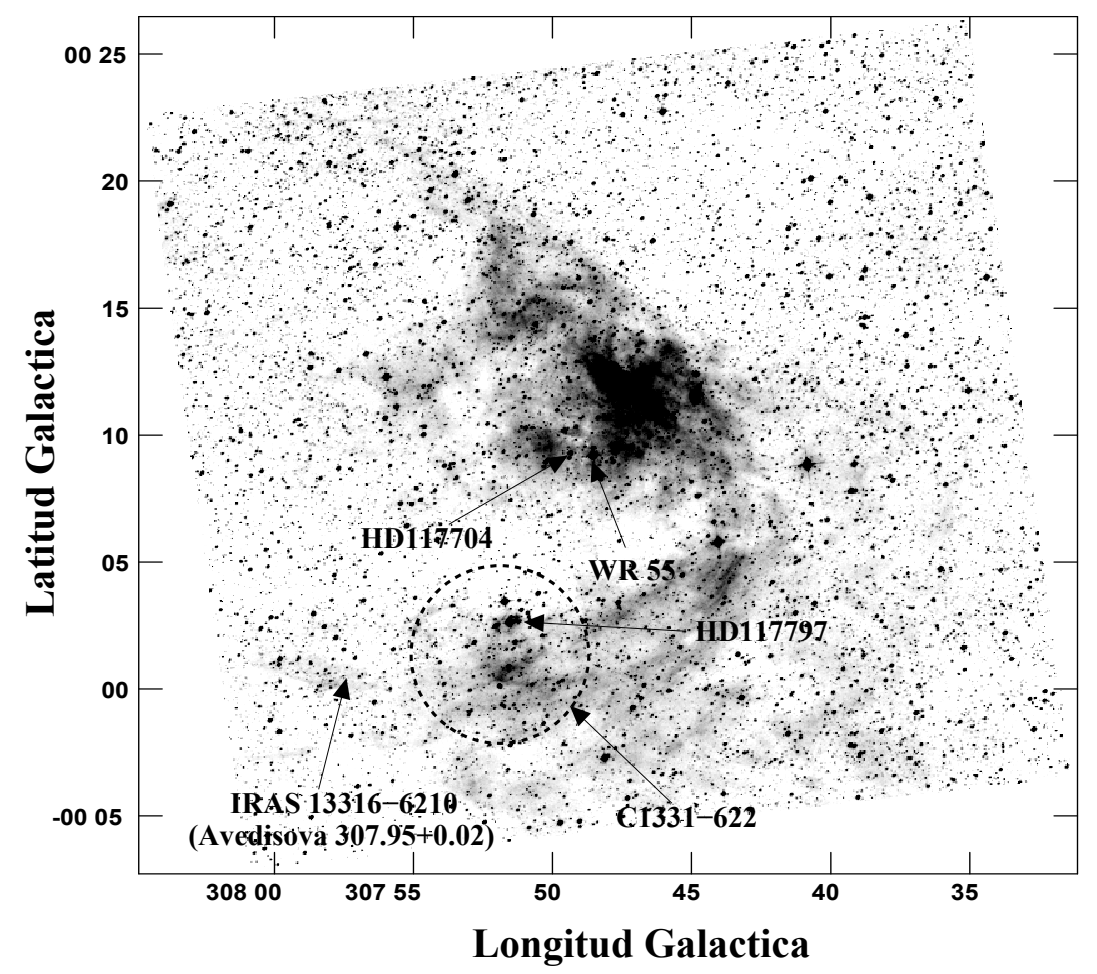

Figura 6.2: Imagen $\mathrm{H} \alpha$ de la nebulosa $\mathrm{RCW} 78$ donde están indicadas las posiciones de los objetos ubicados en este campo (ver texto).

55 hasta $-53 \mathrm{~km} / \mathrm{seg}$ unos $7^{\prime}$ al norte de la estrella. A pesar de este gradiente, los autores no encontraron movimientos sistemáticos que sean consistentes con una cáscara en expansión o con eyecciones estelares. Por este motivo la nebulosa fue considerada por los autores como una "región HII". El gradiente de velocidades observado fue explicado considerando una ionización producida sobre la superficie de una nube molecular, lo que causaría un "outflow" similar al observado en la nebulosa de Orión. Los autores proponen que la falta de indicios de movimientos de expansión podría deberse a que los vientos de la estrella WR 55 han empezado a actuar recientemente.

Esteban et al. (1990) realizaron un estudio espectroscópico de alta resolución en RCW 78. Las abundancias de oxígeno, de nitrógeno y de helio derivadas por los autores indican un bajo nivel de enriquecimiento de estos elementos. Posteriormente, Esteban et al. (1993) concluyeron que la fotoionización es la principal fuente de excitación en la nebulosa.

Cappa et al. (2009), realizaron un estudio del gas molecular utilizando observaciones de alta resolución angular de las transiciones $\mathrm{J}=1 \rightarrow 0$ y $\mathrm{J}=2 \rightarrow 1$ $\left(\mathrm{HPBW}=44^{\prime \prime}\right.$ y $22^{\prime \prime}$ respectivamente) y resolución angular intermedia de la línea $\mathrm{J}=1 \rightarrow 0\left(\mathrm{HPBW}=2^{\prime}, 6\right)$ y encontraron una estructura molecular de forma anular a velocidades entre $-52,5 \mathrm{a}-43,5 \mathrm{~km} / \mathrm{seg}$ que se corresponde morfológi- 
camente con la estructura filamentaria de la nebulosas (llamada estructura A en esta Tesis). También encontraron una estructura molecular en el rango de velocidades entre $-43,5$ a $-39,5 \mathrm{~km} / \mathrm{seg}$ que posiblemente está asociada con la región este de la nebulosa. Las autoras proponen que RCW 78 se ha formado sobre la superficie de la componente molecular asociada a RCW 78 como resultado de la ionización provocada por la estrella WR 55.

\subsection{Observaciones de CO de NANTEN}

En la Figura 6.3 se muestran los perfiles de emisión de ${ }^{12} \mathrm{CO}$ en la dirección de siete puntos de la nebulosa RCW 78, cada uno de ellos identificado con letras minúscula en el borde superior izquierdo.

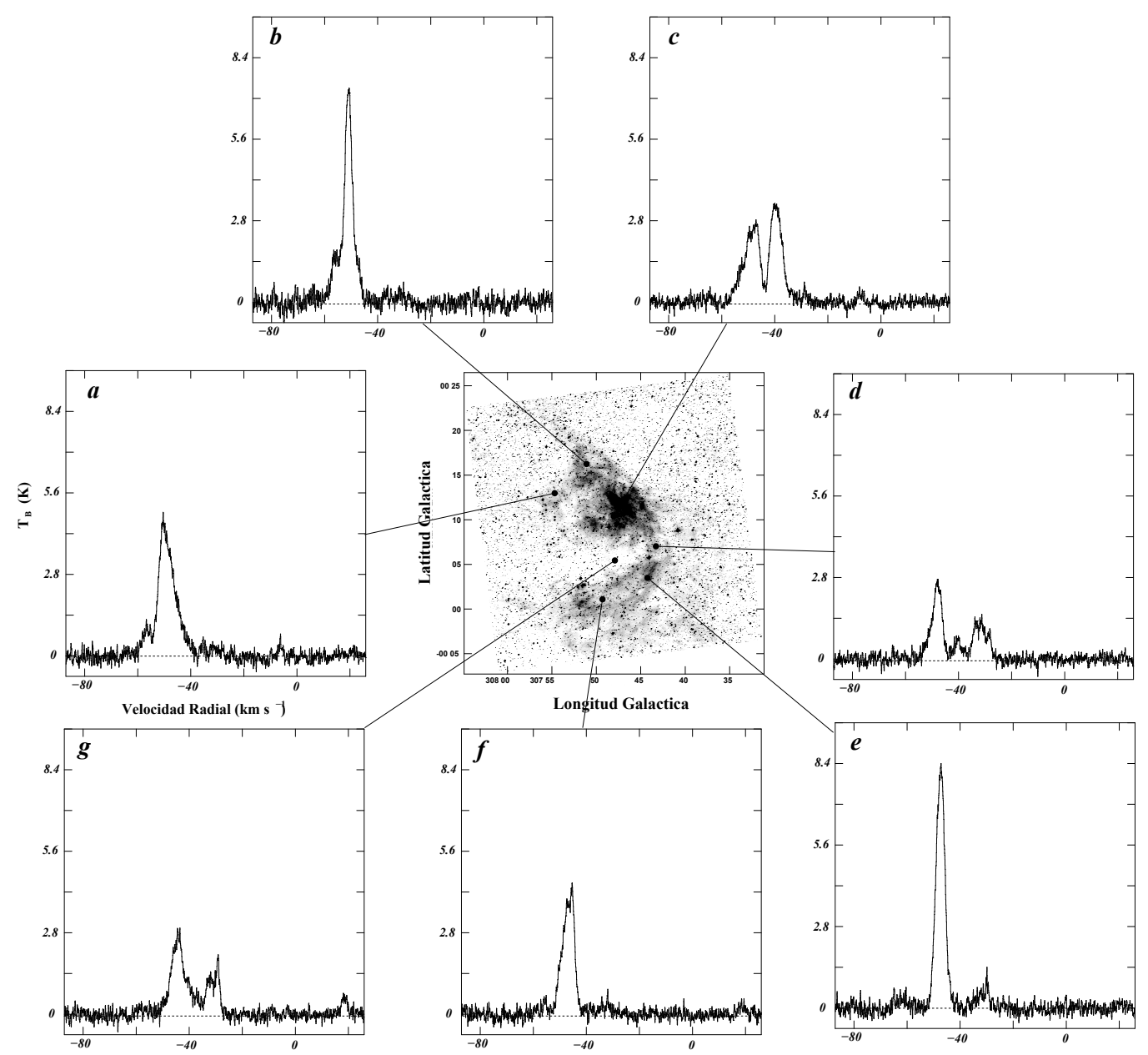

Figura 6.3: Perfiles de emisión del ${ }^{12} \mathrm{CO}$ en temperatura de brillo (K) vs velocidad radial $(\mathrm{km} / \mathrm{seg})$ en dirección a siete regiones de la nebulosa RCW 78 .

Los perfiles $a$ y $b$ fueron tomados en la dirección de la estructura $\mathrm{H} \alpha$ A3 y 
A1, respectivamente. La componente molecular detectada en ambas direcciones se ubica a velocidades entre $\sim-54 \mathrm{a}-48 \mathrm{~km} / \mathrm{seg}$. La intensidad pico de la componente molecular observada en el perfil $a$ es $\mathrm{T}_{B} \sim 4,2 \mathrm{~K}$ y la extensión en velocidad de la misma es de $\sim 20 \mathrm{~km} / \mathrm{seg}$. La componente del perfil $b$ posee una intensidad pico $\mathrm{T}_{B} \sim 7 \mathrm{~K}$ y su extensión en velocidad es $\sim 15 \mathrm{~km} / \mathrm{seg}$. En ambos se observa un pequeño hombro o sobreemisión a $\sim-55 \mathrm{~km} / \mathrm{seg}$. En el perfil $a$ la temperatura máxima de este hombro no alcanza los $\sim 1,4 \mathrm{~K}$, mientras que en el perfil $b$ posee mayor intensidad.

El perfil $c$ fue tomado en la dirección de la zona más brillante de RCW 78. En el mismo se distinguen dos componentes moleculares. La primera de ellas se encuentra a velocidades levemente más positivas que la encontrada en los perfiles $a$ y $b$, y posee en su extremo de velocidades más positivas varios picos de menor intensidad. La segunda componente se encuentra a velocidades entre $\sim-41 \mathrm{a}-35 \mathrm{~km} / \mathrm{seg}$. La intensidad máxima de ambas componentes no supera los $4 \mathrm{~K}$.

El perfil $d$ corresponde a una posición intermedia entre las estructuras $\mathrm{H} \alpha$ A1 y A2. En el mismo se pueden observar dos componentes. La primera de ellas en un intervalo de velocidades similar al de la componente encontrada en los perfiles $a, b$ y $c$, con una intensidad máxima que no supera los $2,8 \mathrm{~K}$. La segunda se encuentra en el rango de velocidades $\sim-38$ a $-35 \mathrm{~km} / \mathrm{seg}$, siendo su intensidad máxima de $\sim 1,4 \mathrm{~K}$. Esta componente muestra estructura en velocidad. Existe una tercer componente muy poco intensa $\left(\mathrm{T}_{B}(\right.$ pico $)<0,7$ $\mathrm{K} \equiv 2 \sigma$ ) a una velocidad de $\sim-40 \mathrm{~km} / \mathrm{seg}$.

En los perfiles $e$ y $f$, se muestra la emisión molecular correspondiente a dos posiciones del filamento $\mathrm{H} \alpha$ denominado A2. En estos perfiles puede observarse nuevamente la presencia de una componente en un intervalo de velocidades similar al encontrado en los perfiles $a$ y $b$. La intensidad de la componente detectada en el perfil $e\left(\mathrm{~T}_{B} \sim 8,4 \mathrm{~K}\right)$ es superior a la del perfil $f\left(\mathrm{~T}_{B} \sim 4,2 \mathrm{~K}\right)$. En el perfil $e$ puede observarse la presencia de una componente débil $\left(\mathrm{T}_{B}\right.$ (pico) $<1,4 \mathrm{~K} \equiv 4 \sigma$ ) en el rango de velocidades -35 a $-30 \mathrm{~km} / \mathrm{seg}$.

El perfil $g$ fue tomado en la zona de intensa absorción óptica denominada C. En este perfil se observan dos componentes. La componente más intensa $\left(T_{B}(\right.$ pico $\left.) \sim 2,8 \mathrm{~K}\right)$ está ubicada en un intervalo de velocidades similar al de las componentes encontradas en los perfiles $a$ hasta $f$ pero ligeramente corridos hacia velocidades más positivas. La componente menos intensa $\left(\mathrm{T}_{B}(\right.$ pico $) \sim$ $2 \mathrm{~K})$ se encuentra en el intervalo de velocidades de $\sim-33$ a $-28 \mathrm{~km} / \mathrm{seg}$ y parecería estar formada por dos componentes.

A pesar de la complejidad y diversidad en las velocidades e intensidades encontradas en el gas molecular, existen principalmente tres componentes moleculares en la dirección de la nebulosa RCW 78, que se encuentran aproximadamente en los siguientes intervalos de velocidad: i) -54 a $-48 \mathrm{~km} / \mathrm{seg}$ (presente en los perfiles $a$ a $g$ ), ii) $-39 \mathrm{a}-35 \mathrm{~km} / \mathrm{seg}$ (perfil $c$ y probablemente d) e iii) -33 a $-28 \mathrm{~km} / \mathrm{seg}$ (perfiles $d$ y $\mathrm{g}$ ). En la Figura 6.4 se muestra la 
distribución del $\mathrm{CO}$ en los rangos de velocidad mencionados anteriormente. También se observa dicha emisión del CO superpuesta con la emisión $\mathrm{H} \alpha$.
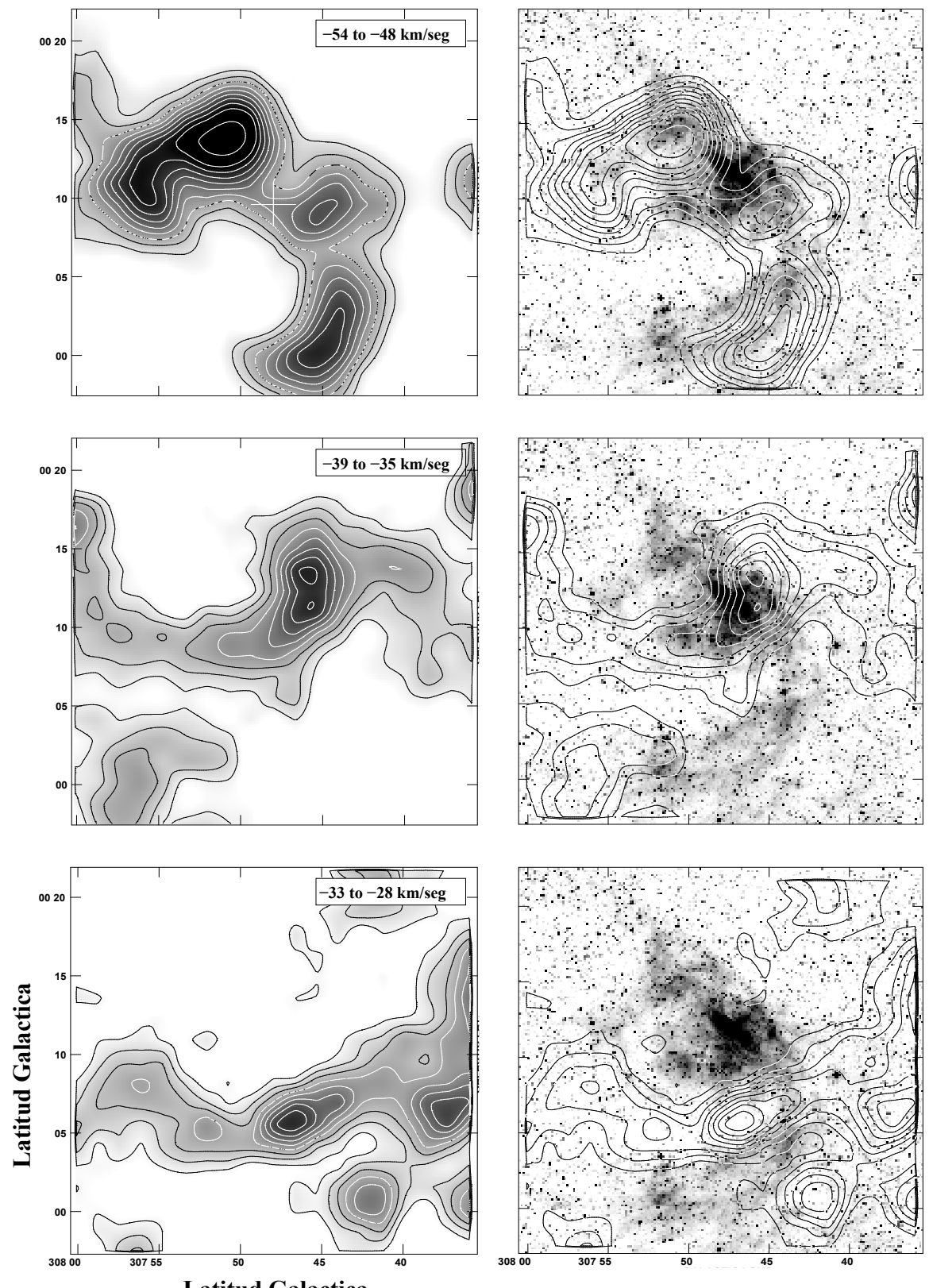

Figura 6.4: Distribución espacial del CO en los tres rangos de velocidad mencionados. Los mismos están indicados en el borde superior derecho de los paneles de la izquierda. En los paneles de la derecha se muestra dicha emisión molecular pero superpuesta con la emisión $\mathrm{H} \alpha$ (tonos de grises). En el rango de velocidad $-54 \mathrm{a}-48 \mathrm{~km} / \mathrm{seg}$, los niveles de contorno van desde $0,7 \mathrm{~K}(\sim 21 \sigma)$ en intervalos de $0,35 \mathrm{~K}$. En el rango de velocidad -39 a -35 $\mathrm{km} / \mathrm{seg}$, los niveles de contorno van desde $0,56 \mathrm{~K}(\sim 14 \sigma)$ en intervalos de $0,35 \mathrm{~K}$. En el rango de velocidad -33 a $-28 \mathrm{~km} / \mathrm{seg}$, los niveles de contorno van desde $0,42 \mathrm{~K}(\sim 11 \sigma)$ en intervalos de $0,21 \mathrm{~K}$. 
En la Figura 6.4 puede observarse que la distribución espacial del CO es muy diferente en cada intervalo de velocidad. Cada una de estas componentes guarda cierta correspondencia en su morfología con las distintas regiones de la nebulosa RCW 78 mencionadas en la Figura 6.1. En el intervalo de velocidad de $-54 \mathrm{a}-48 \mathrm{~km} / \mathrm{seg}$ el gas molecular muestra una estructura semielíptica similar a la estructura filamentaria de la nebulosa (estructura A). Esta componente molecular fue encontrada por Cappa et al. (2009). En el rango de velocidad -39 a $-35 \mathrm{~km} / \mathrm{seg}$ el CO está confinado a una región delimitada por $307^{\circ} 35^{\prime}$ $<l<307^{\circ} 55^{\prime}$ y $00^{\circ} 05^{\prime}<b<00^{\circ} 18^{\prime}$, y en base a su morfología podría estar relacionado con la emisión extendida de RCW 78 (estructura B). La emisión de CO observada en $l>307^{\circ} 55^{\prime}$ es un remanente del material molecular observado en el rango de velocidad de $-43 \mathrm{a}-38 \mathrm{~km} / \mathrm{seg}$ y posiblemente no se encuentre asociado a la nebulosa. En el rango de velocidad -33 a $-28 \mathrm{~km} / \mathrm{seg}$, el gas molecular está proyectado sobre la región de absorción óptica (estructura C).

A continuación se presentará un análisis más detallado de estas componentes moleculares a fin de intentar comprender su cinemática y su posible relación con el material ionizado de RCW 78.

En la Figura 6.5, se muestra la distribución de emisión del CO (contornos) en el rango de velocidades $-57,7$ a $-45,7 \mathrm{~km} / \mathrm{seg}$ presentado en imágenes integradas en intervalos de $2 \mathrm{~km} / \mathrm{seg}$. A los fines de este estudio se identificaron ciertas estructuras moleculares denominadas C1, C2, C3 y C4. La identificación de las mismas se realiza en las posiciones e intervalos de velocidad en los que cada una alcanza su máxima temperatura de emisión.

La componente $\mathrm{C} 1$ es detectada en el rango de velocidades de $\sim-57,7$ a $-53,7 \mathrm{~km} / \mathrm{seg}$. Esta componente alcanza su máxima emisión $(3,8 \mathrm{~K})$ en el intervalo de velocidades comprendido entre $-57,7$ a $-55,7 \mathrm{~km} / \mathrm{seg}$, en la posición $(l, b)=\left(307^{\circ} 52^{\prime}, 09^{\circ} 02^{\prime}\right)$. Dicha posición es coincidente con la ubicación del cúmulo abierto C1331-622. En el rango de velocidades de $-55,7$ a $-53,7$ $\mathrm{km} / \mathrm{seg}$ el máximo de intensidad en la distribución de CO (3,8 K) se encuentra desplazado hacia latitudes galácticas mayores, más precisamente en la posición $(l, b)=\left(307^{\circ} 54^{\prime}, 00^{\circ} 07^{\prime}\right)$, pudiéndose observar una emisión residual de intensidad significativa $\left(\mathrm{T}_{B}>0,7 \mathrm{~K}\right)$ en la región comprendida por C1331-622.

La emisión correspondiente a la componente C2 comienza a hacerse visible en el rango de velocidades de $-55,7$ a $-53,7 \mathrm{~km} / \mathrm{seg}$ y alcanza su máxima emisión $(7 \mathrm{~K})$ en el intervalo de velocidades de $-51,7$ a $-49,7 \mathrm{~km} / \mathrm{seg}$ en la posición $(l, b)=\left(307^{\circ} 50^{\prime}, 00^{\circ} 14^{\prime}\right)$. Esta componente molecular se extiende en la dirección este, y posee cierta correpondencia posicional con la subestructuras $\mathrm{H} \alpha$ denominadas A3 y la región norte de A1. La componente C2 es detectable hasta velocidades $\sim-47 \mathrm{~km} / \mathrm{seg}$.

La componente C3 comienza a detectarse en el intervalo de velocidades de $-55,7$ a $-53,7 \mathrm{~km} / \mathrm{seg}$ y alcanza su emisión máxima $(\sim 3,3 \mathrm{~K})$ en la posición $(l, b)=\left(307^{\circ} 45^{\prime}, 00^{\circ} 09^{\prime}\right)$ en el rango de velocidades $-51,7 \mathrm{a}-49,7 \mathrm{~km} / \mathrm{seg}$. La emisión de C3 permanece detectable hasta una velocidad $\sim-47,7 \mathrm{~km} / \mathrm{seg}$. 

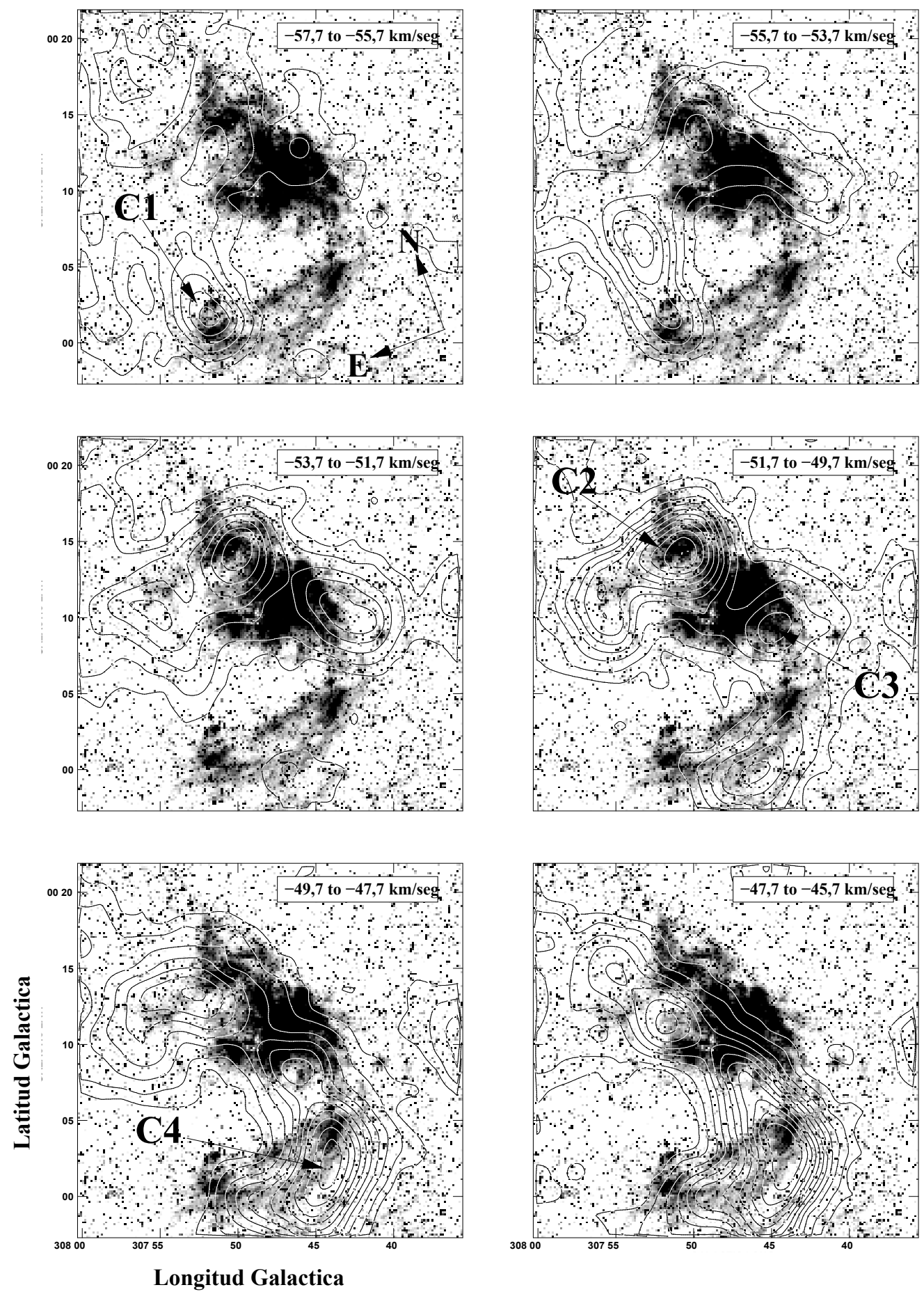

Figura 6.5: Superposición de la emisión integrada de CO (contornos) con la emisión H $\alpha$ (tonos de grises). El intervalo de velocidad se encuentra en el extremo superior derecho de cada imagen. Los niveles de contornos van desde $0,7 \mathrm{~K}(\sim 12 \sigma)$ en intervalos de $0,7 \mathrm{~K}$. La orientación del sistema ecuatorial está dada por las flechas que indican las direcciones norte $(\mathrm{N})$ y este (E) en el extremo inferior derecho de la primera imagen. 
La componente denominada $\mathrm{C} 4$ es detectada en el rango de velocidades de $-51,7 \mathrm{a}-45,7 \mathrm{~km} / \mathrm{seg}$. Esta componente molecular comienza a detectarse en el intervalo de velocidades de $-51,7$ a $-49,7 \mathrm{~km} / \mathrm{seg}$, aunque posiblemente la emisión de intensidad $\mathrm{T}_{B}>0,7 \mathrm{~K}$ observada en $(l, b)=\left(307^{\circ} 46^{\prime},-00^{\circ} 59^{\prime}\right)$ en el intervalo de velocidades de $-53,7$ a $-51,7 \mathrm{~km} / \mathrm{seg}$ pertenezca también a la misma. La componente C4 alcanza su máximo de intensidad $(\sim 7,9 \mathrm{~K})$ en el intervalo de velocidades $-47,7$ to $-45,5 \mathrm{~km} / \mathrm{seg}$. Esta componente molecular desarrolla una morfología extendida en la dirección sureste a noroeste superponiéndose en posición con la emisión de la subestructura $\mathrm{H} \alpha$ denominada A2. Cabe destacar que la disposición espacial de la componente C4 se encuentra levemente corrida hacia latitudes galácticas menores respecto de la subestructura A2, es decir que los máximos de emisión en ambas longitudes de onda no se encuentran exactamente en la misma posición.

Del análisis realizado en la Figura 6.5 no es posible encontrar alguna componente molecular que pudiera estar asociada a la estructura $\mathrm{H} \alpha$ brillante denominada la "barra". En el intervalo de velocidades de $-55,7$ a $-53,7 \mathrm{~km} / \mathrm{seg}$ el gas molecular adopta una disposición espacial en la misma dirección que la barra, y con líneas de contornos intensas $(\sim 2,1 \mathrm{~K})$ en la posición de la misma. Las integraciones en intervalos muy extensos de velocidad pueden contribuir a la pérdida de definición de estructuras moleculares que abarquen rangos cortos de velocidad. En la Figura 6.6 se muestra la distribución espacial del ${ }^{12} \mathrm{CO}$ en el intervalo de velocidades de $-55,30 \mathrm{a}-54,97 \mathrm{~km} / \mathrm{seg}$ obtenidas de los datos con la resolución en velocidad original $(0,055 \mathrm{~km} / \mathrm{seg})$ y superpuestas con la imagen de $\mathrm{H} \alpha$ en la zona central de RCW 78. En éstas se aprecian algunos detalles en la distribución espacial de esta componente molecular que no fueron detectados anteriormente y que le otorgan cierta similitud morfológica con la barra $\mathrm{H} \alpha$. Esta estructura visible en $\mathrm{H} \alpha$ posee detalles cuyas extensiones angulares no exceden los $2^{\prime}$, por este motivo las observaciones con una resolución angular (HPBW) de $2^{\prime} .7$ no son las más apropiadas para encontrar su contraparte de gas molecular.

En la Figura 6.7 se muestra la distribución del CO en la zona central de la nebulosa en el rango de velocidades de $-38,6$ a $-35,6 \mathrm{~km} / \mathrm{seg}$, presentado en imágenes integradas en intervalos de velocidad de $0,5 \mathrm{~km} / \mathrm{seg}$. La emisión molecular está superpuesta con la emisión $\mathrm{H} \alpha$. Como ya se indicó anteriormente, la distribución espacial del $\mathrm{CO}$ en este intervalo de velocidades parece coincidir morfológicamente con la emisión extendida $\mathrm{H} \alpha$ central de RCW 78 identificada como estructura B. En el material molecular presente en este rango de velocidades se indicaron dos componentes, identificadas en la Figura 6.7 como C5 y C6. Al igual que en la Figura 6.5 la identificación de estas componentes moleculares se realizó en las posiciones e intervalos de velocidad en los cuales la intensidad de su emisión es máxima. La componente C5 es visible en todo el rango de velocidades y alcanza su máxima intensidad de emisión ( $\mathrm{T} \sim$ $3,5 \mathrm{~K})$ entre $-38,6$ y $-38,1 \mathrm{~km} / \mathrm{seg}$ en la posición $(l, b)=\left(307^{\circ} 46^{\prime}, 00^{\circ} 11^{\prime}\right)$; esta 

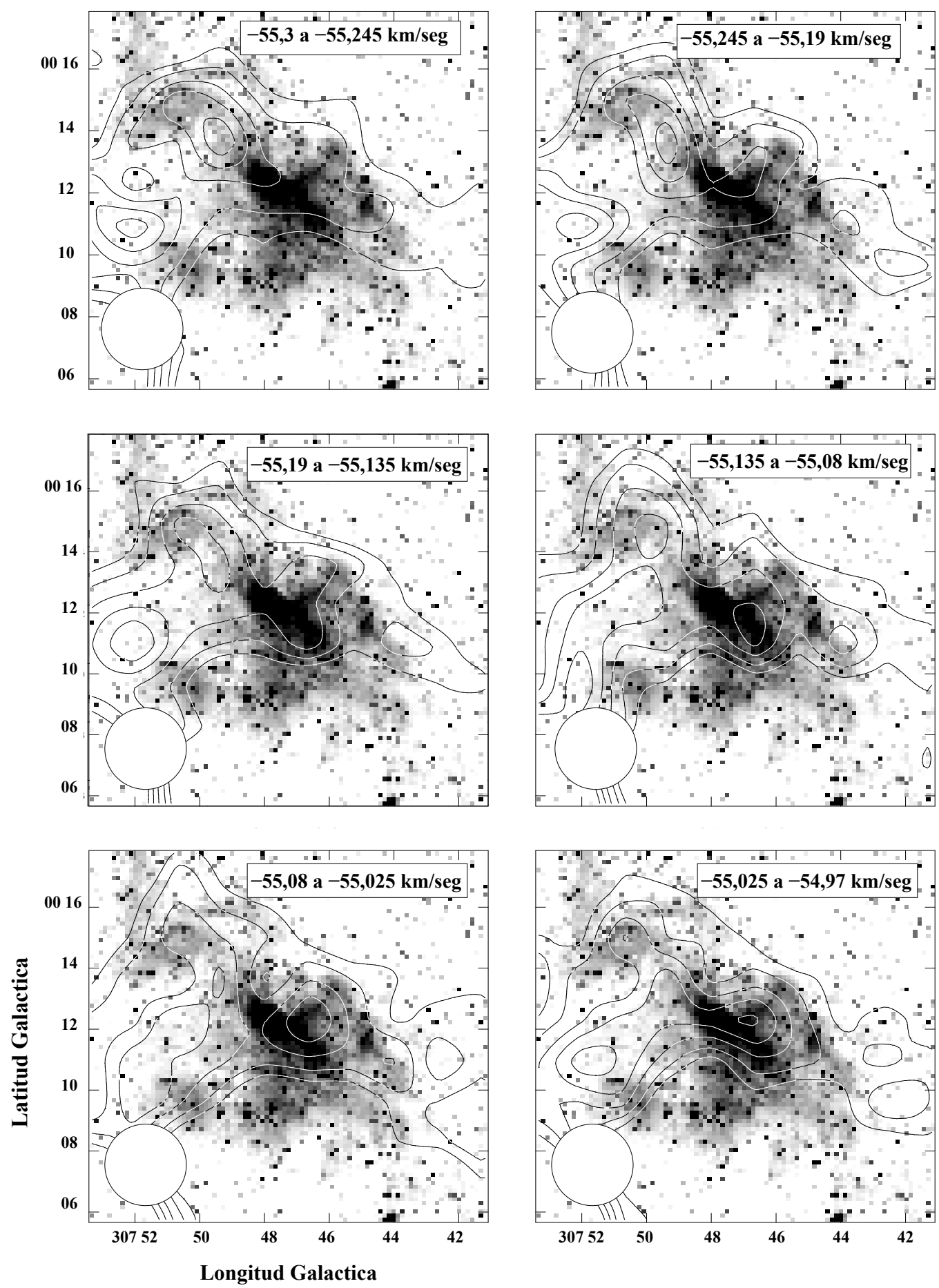

Figura 6.6: Distribución del ${ }^{12} \mathrm{CO}$ (contornos) superpuesto con la emisión $\mathrm{H} \alpha$ (tonos de grises) en la zona central de RCW 78. El intervalo de velocidad de cada imagen está indicado arriba a la derecha. Los niveles de contorno van de $0,84 \mathrm{~K}(\sim 2,7 \sigma)$ en intervalos de 0,42 K. El haz de observación está indicado abajo a la izquierda de cada imagen. 
componente se extiende desde esta última posición en dirección hacia el este atravesando en forma casi perpendicular a la "barra" y delineando una estructura extendida $\mathrm{H} \alpha$ intensa que está comprendida entre $307^{\circ} 44^{\prime}<l<307^{\circ} 49^{\prime}$ y $00^{\circ} 07^{\prime}<b<00^{\circ} 14^{\prime}$. A partir de $-35,6 \mathrm{~km} / \mathrm{seg}$ la emisión extendida de esta componente desaparece y el remanente del material molecular se extiende en forma casi paralela a la "barra" (esta estructura remanente podrá observarse en el intervalo de velocidades de $-33,8 \mathrm{a}-32,8 \mathrm{~km} / \mathrm{seg}$ de la Figura 6.8). La emisión correspondiente a la componente indicada como C6 es visible en el rango de velocidades de $-38,6$ a $-36,6 \mathrm{~km} / \mathrm{seg}$. Esta componente guarda una excelente similitud en su morfología con la zona este de la estructura $\mathrm{H} \alpha$ denominada $\mathrm{B}$, en la región comprendida entre $307^{\circ} 49^{\prime}<l<307^{\circ} 52^{\prime}$ y $00^{\circ} 07^{\prime}<$ $b<00^{\circ} 11^{\prime}$, especialmente con una estructura $\mathrm{H} \alpha$ intensa de morfología esférica centrada en $(l, b)=\left(308^{\circ} 51^{\prime}, 00^{\circ} 10^{\prime}\right)$. La mejor correspondencia morfológica entre la componente C6 y esta estructura esférica se observa en el rango de velocidades $-37,6$ a $-36,6 \mathrm{~km} / \mathrm{seg}$. La temperatura de brillo pico de $\mathrm{CO}$ en C6 es $\mathrm{T} \sim 1,95 \mathrm{~K}$.

En la Figura 6.4 se mostró que la morfología del material molecular observado en el rango de velocidades de -33 a $-28 \mathrm{~km} / \mathrm{seg}$, se corresponde notablemente con una intensa franja de absorción en la banda óptica denominada $\mathrm{C}$, la cual está ubicada entre las componentes $\mathrm{H} \alpha$ denominadas B y A2. En la Figura 6.8 se muestra la distribución del $\mathrm{CO}$ en el rango de velocidades de $-33,8$ a $-27,8 \mathrm{~km} / \mathrm{seg}$, presentado en imágenes integradas en intervalos de velocidad de $0,5 \mathrm{~km} / \mathrm{seg}$. La emisión molecular está superpuesta con la emisión $\mathrm{H} \alpha$. El gas molecular en este intervalo de velocidad se extiende en forma casi perpendicular a la nebulosa RCW 78 desde $(l, b)=\left(307^{\circ} 57^{\prime}, 00^{\circ} 10^{\prime}\right)$ hasta $(l, b)$ $=\left(307^{\circ} 40^{\prime}, 00^{\circ} 08^{\prime}\right)$. En la Figura 6.4 se han destacado dos componentes moleculares que fueron denominadas C7 y C8. La componente C7 adquiere su máxima intensidad $(\mathrm{T} \sim 2,7 \mathrm{~K}$ ) en el intervalo de velocidades de $-30,8 \mathrm{a}-29,8 \mathrm{~km} / \mathrm{seg}$ en la posición $(l, b)=\left(307^{\circ} 52^{\prime}, 00^{\circ} 05^{\prime}\right)$. La componente $\mathrm{C} 8$ se ubica en $(l, b)=$ $\left(307^{\circ} 47^{\prime}, 00^{\circ} 05^{\prime}\right)$. Esta componente comienza a hacerse visible en el intervalo de velocidades $-32,8$ a $-31,8 \mathrm{~km} / \mathrm{seg}$, para desvanecerse en el intervalo de $-31,8$ a $-29,8 \mathrm{~km} / \mathrm{seg}$ y luego alcanzar su máxima intensidad ( $\mathrm{T} \sim 3,7 \mathrm{~K}$ ) en el intervalo $-29,8$ a $-28,8 \mathrm{~km} / \mathrm{seg}$. En la posición $(l, b)=\left(307^{\circ} 46^{\prime}, 00^{\circ} 15^{\prime} 20^{\prime \prime}\right)$ se puede observar la presencia de una componente molecular intensa. Esta componente es un remanente de la componente C5 anteriormente descripta. Lo mismo sucede con el material molecular comprendido entre $308^{\circ}<l<307^{\circ} 55^{\prime}$ y $00^{\circ} 03^{\prime}<b<00^{\circ} 10^{\prime}$ en el intervalo de velocidades de $-33,8 \mathrm{a}-30,8 \mathrm{~km} / \mathrm{seg}$, el cual representa emisión de CO remanente de una estructura molecular presente en el intervalo de velocidades de $-43 \mathrm{a}-34 \mathrm{~km} / \mathrm{seg}$. 

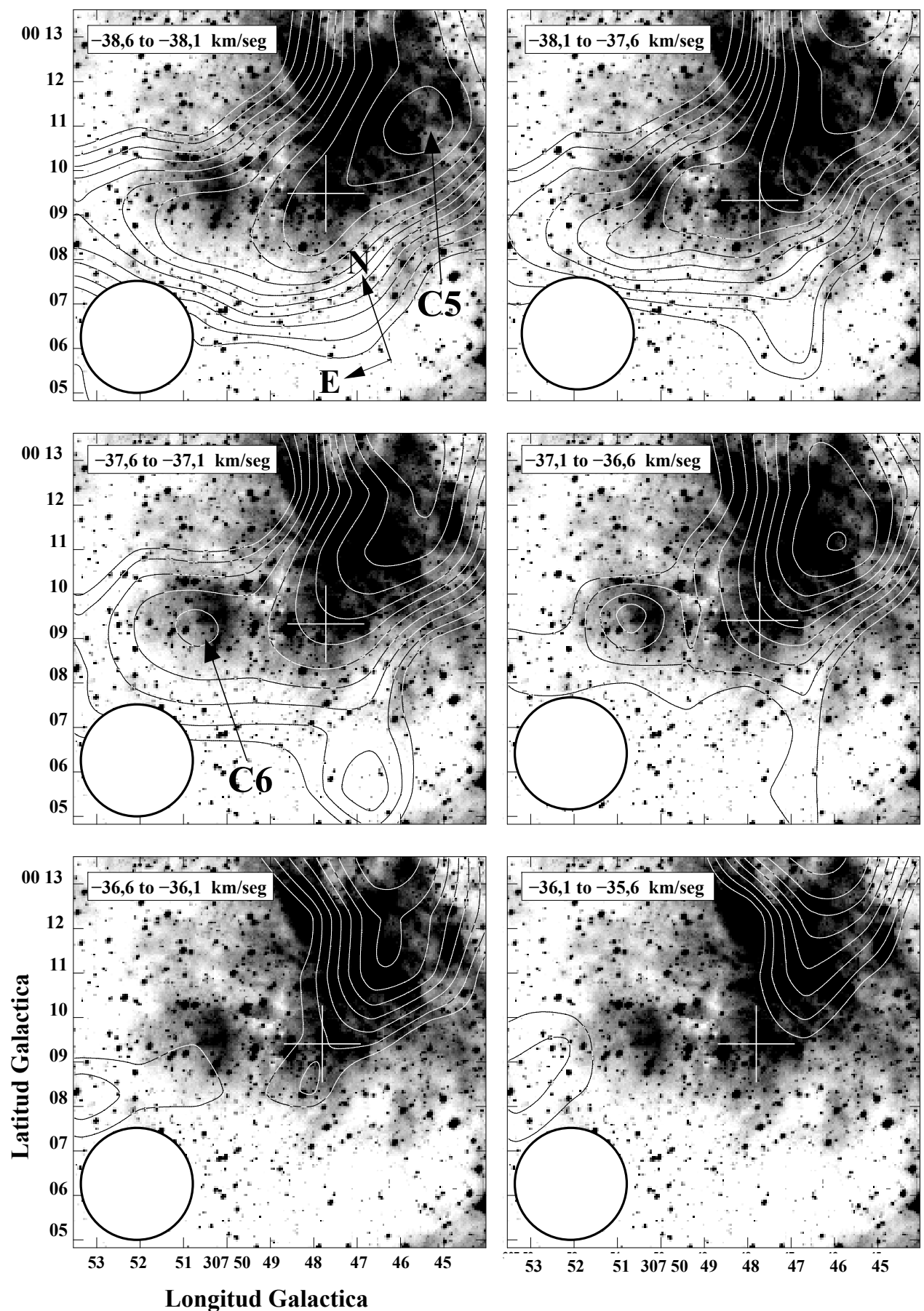

Figura 6.7: Distribución del ${ }^{12} \mathrm{CO}$ (contornos) superpuesto con la emisión $\mathrm{H} \alpha$ (tonos de grises) en el intervalo $-38,6 \mathrm{a}-35,6 \mathrm{~km} / \mathrm{seg}$. El intervalo de velocidad se encuentra en el borde superior izquierdo de cada imagen. Los niveles de contornos van desde 0,9 K $(\sim 8 \sigma)$ hasta $2,15 \mathrm{~K}$ en intervalos de $0,21 \mathrm{~K}$, y desde $2,15 \mathrm{~K}$ en intervalos de $0,35 \mathrm{~K}$. La posición de WR 55 está indicada por la cruz blanca. El haz de observación de CO está indicado en el borde inferior izquierdo de cada imagen. 

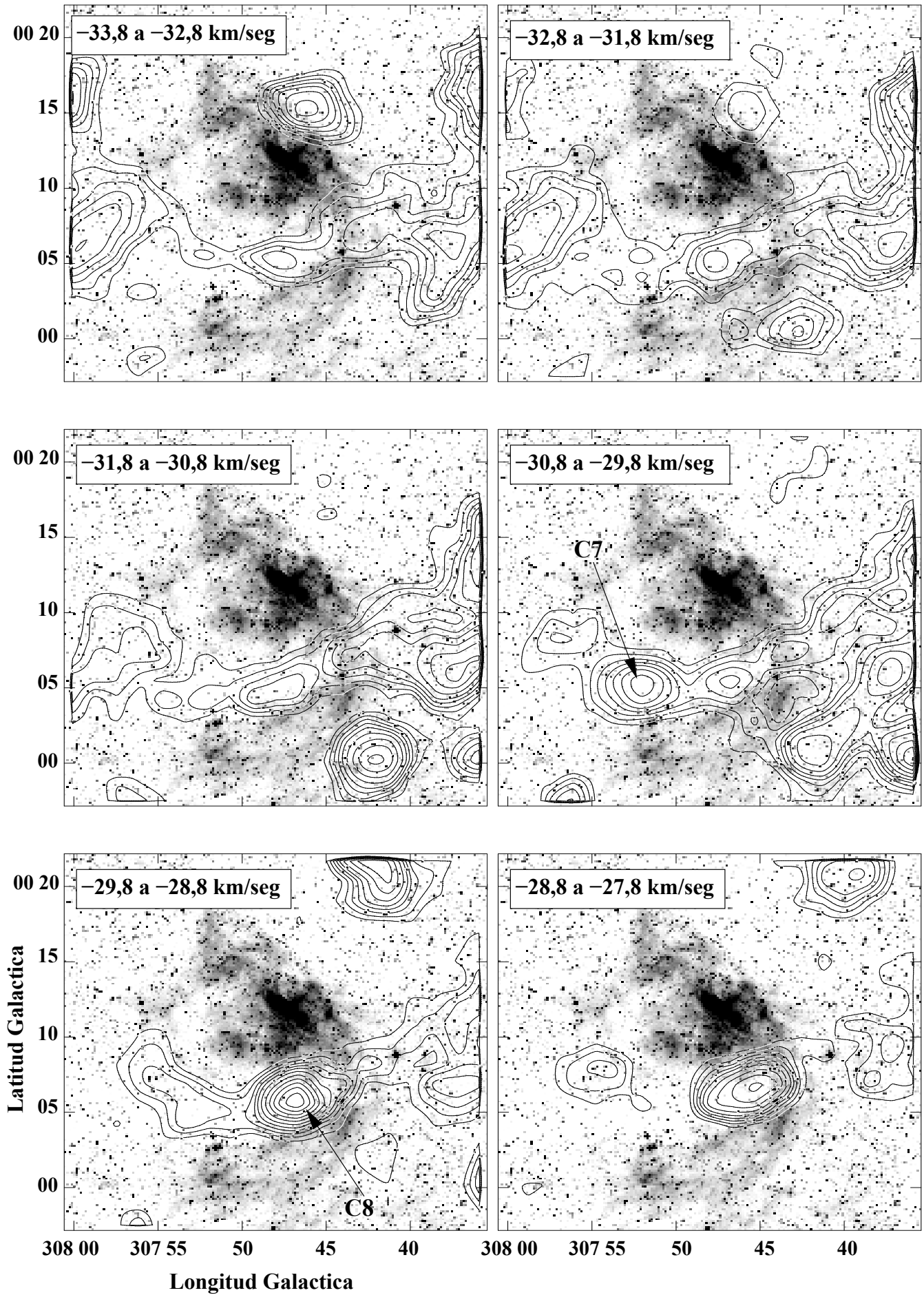

Figura 6.8: Distribución del ${ }^{12} \mathrm{CO}$ (contornos) superpuesto con la emisión $\mathrm{H} \alpha$ en el rango de velocidad $-33,8$ a $-27,8 \mathrm{~km} / \mathrm{seg}$. El rango de velocidad de cada mapa está indicada arriba a la izquierda. Los niveles de contorno van desde $0,42 \mathrm{~K}(\sim 5 \sigma)$ hasta $1,8 \mathrm{~K}$ en intervalos de $0,3 \mathrm{~K}$, y desde $1,8 \mathrm{~K}$ en intervalos de $0,5 \mathrm{~K}$. 


\subsection{La nebulosa RCW 78 en el continuo de radio e infrarrojo}

La Figura 6.9 muestra la distribución del continuo de radio en 4,85 GHz, obtenida del relevamiento de Parkes-MIT-NRAO (PMN) Southern Radio Survey (Condon et al, 1993).
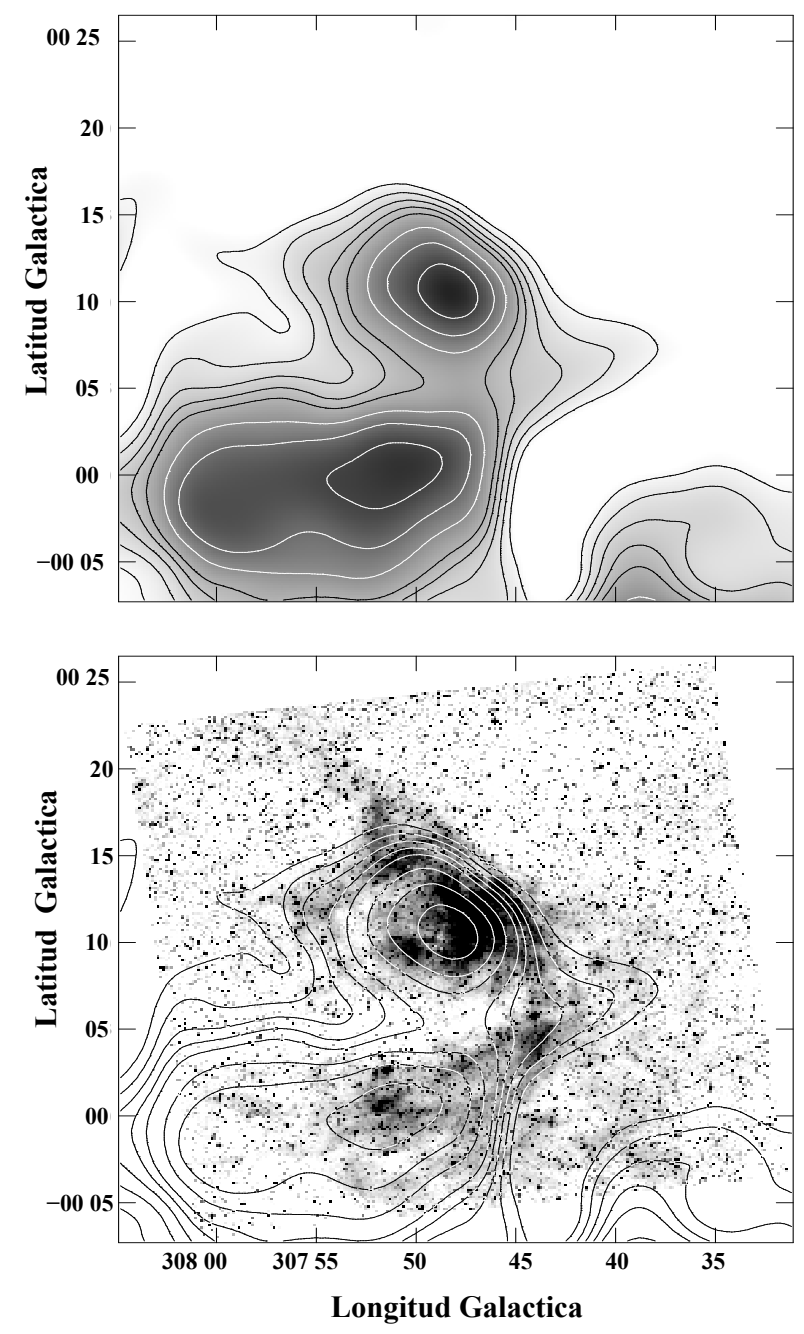

Figura 6.9: Panel superior: Emisión del continuo de radio en 4,85 GHz. Los niveles de contorno van de 0,01 Jy/haz a 0,11 Jy/haz en intervalos de 0,02 Jy/haz. Panel inferior: Distribución de la emisión en 4,85 GHz (contornos) superpuesta con la emisión $\mathrm{H} \alpha$ de la nebulosa RCW 78.

La emisión en esta frecuencia muestra una estructura muy intensa en la posición de la "barra" H $\alpha$ que podría estar originada por el gas ionizado de la misma estructura. Puede observarse que existe emisión en una zona coincidente con la estructura $\mathrm{H} \alpha$ identificada como A2, aunque la posición del máximo observado en $(l, b)=\left(307^{\circ} 52^{\prime}, 00^{\circ} 01^{\prime}\right)$ coincide con la posición del cúmulo abierto 
C1331-622 y la estrella HD 117797, por lo que el origen de esta emisión no puede ser determinado con exactitud (ver Sección 6.4). Lo mismo sucede con la emisión localizada alrededor de $(l, b)=\left(307^{\circ} 59^{\prime},-00^{\circ} 01^{\prime}\right)$, la cual es muy próxima a la ubicación de la fuente IRAS 13316-6210.

La distribución de la emisión IR en $60 \mu \mathrm{m}$ obtenida del relevamiento IRAS de alta resolución (HIRES) se muestra en la Figura 6.10.
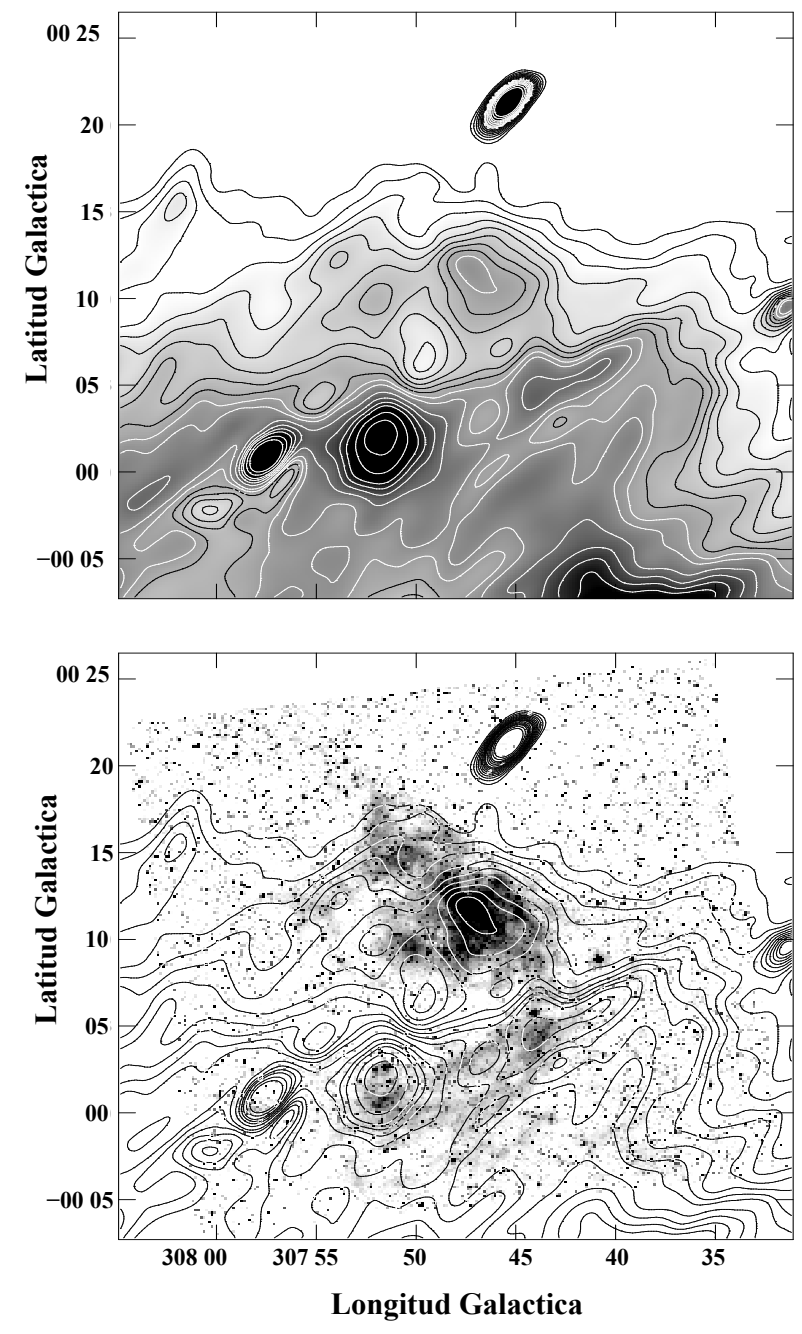

Figura 6.10: Panel superior: Distribución de la emisión en $60 \mu \mathrm{m}$. Los niveles de contorno van de 400 a $750 \mathrm{MJy} /$ ster en intervalos de $50 \mathrm{MJy} /$ ster. Panel inferior: Distribución de la emisión en $60 \mu \mathrm{m}$ (contornos) superpuesta con la emisión $\mathrm{H} \alpha$ de la nebulosa RCW 78.

La emisión en $60 \mu \mathrm{m}$ muestra una pequeña zona de emisión en el centro del campo en la dirección norte a sur que coincide en posición y tamaño con la emisión H $\alpha$ de la "barra". Para contornos de intensidad mayores a 800 $\mathrm{MJy} /$ ster, existe una estructura que se extiende desde $(l, b)=\left(307^{\circ} 40^{\prime}, 00^{\circ} 08^{\prime}\right)$ hasta $(l, b)=\left(307^{\circ} 48^{\prime}, 00^{\circ} 02^{\prime}\right)$ en superposición con la estructura $\mathrm{H} \alpha$ denominada $\mathrm{A} 2$. Al igual que en la emisión en continuo de radio en 4,85 GHz, existen 
dos estructuras muy intensas que se destacan. Una de ellas en la dirección del cúmulo C1331-622 y la estrella HD 117797 y la otra en la posición de la fuente IRAS 13316-6210.

\subsection{Análisis y discusión}

\subsubsection{La componente molecular entre $\sim-58$ y $-45 \mathrm{~km} / \mathrm{seg}$}

Como fuera destacado en las Figuras 6.4 y 6.5, la morfología del material molecular en el intervalo de velocidades entre $\sim-58$ y $-45 \mathrm{~km} / \mathrm{seg}$, posee una notable similitud con la estructura filamentaria de RCW 78 (estructura A). En el material molecular en este intervalo de velocidades fueron identificadas cuatro subcomponentes moleculares denominadas C1, C2, C3 y C4, las cuales están ubicadas en distintas posiciones en la nebulosa. Como pudo observarse de la Figura 6.5 existe un gradual incremento en las velocidades radiales observadas desde la componente $\mathrm{C} 1$ hasta la componente $\mathrm{C} 4$. En la Figura 6.11 se muestra una imagen Latitud Galáctica-Velocidad radial obtenida integrando en un rango de longitud galáctica $307^{\circ} 35^{\prime}<l<308^{\circ} 00^{\prime}$. Las posiciones de las componentes C1, C2, C3 y C4 están indicadas.

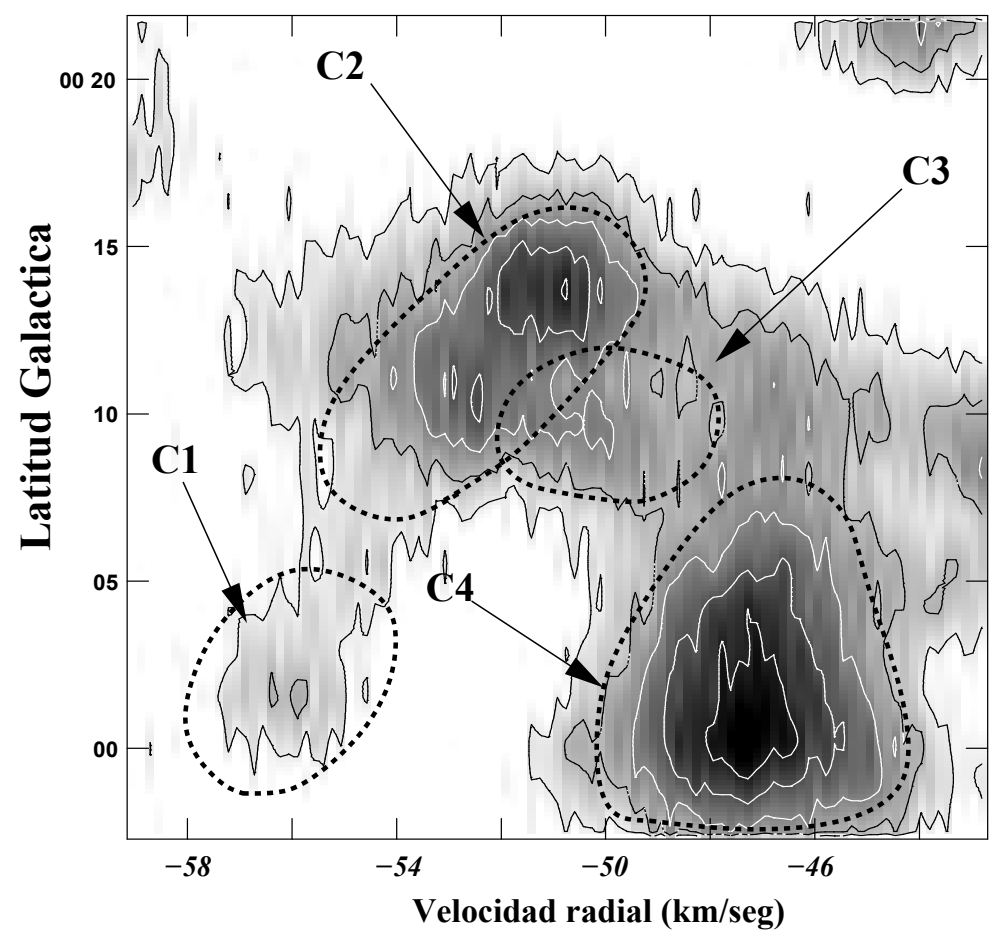

Figura 6.11: Imagen Latitud Galáctica-Velocidad radial del CO en el rango $307^{\circ} 35^{\prime}<$ $l<308^{\circ}$. Los niveles de contorno van desde 0,56 K $(\sim 5 \sigma)$ en intervalos de 0,56 K. Las posiciones de C1, C2, C3 y C4 están indicadas por las línea de trazos. 
De la Figura 6.11 puede corroborarse que las subcomponentes $\mathrm{C} 1, \mathrm{C} 2, \mathrm{C} 3$ y $\mathrm{C} 4$ se encuentran separadas tanto en posición como en velocidad. En vista de lo destacado anteriormente, dos interrogantes surgen en relación al material molecular observado en el intervalo de velocidades de $\sim-58$ y $-45 \mathrm{~km} / \mathrm{seg}: 1$ ) ¿Son las subcomponentes C1, C2, C3 y C4 estructuras físicamente relacionadas entre sí? 2) ¿Cuál es la relación de las subcomponentes C1, C2, C3 y C4 con la nebulosa RCW 78?

En la Figura 6.12 se muestra la distribución de CO integrada en el rango de velocidades desde -58 a $-56 \mathrm{~km} / \mathrm{seg}$, en el cual la subcomponente C1 es observada. La emisión de CO está superpuesta con la de $\mathrm{H} \alpha$, IR en $60 \mu \mathrm{m}$ y continuo de radio en $4,85 \mathrm{GHz}$
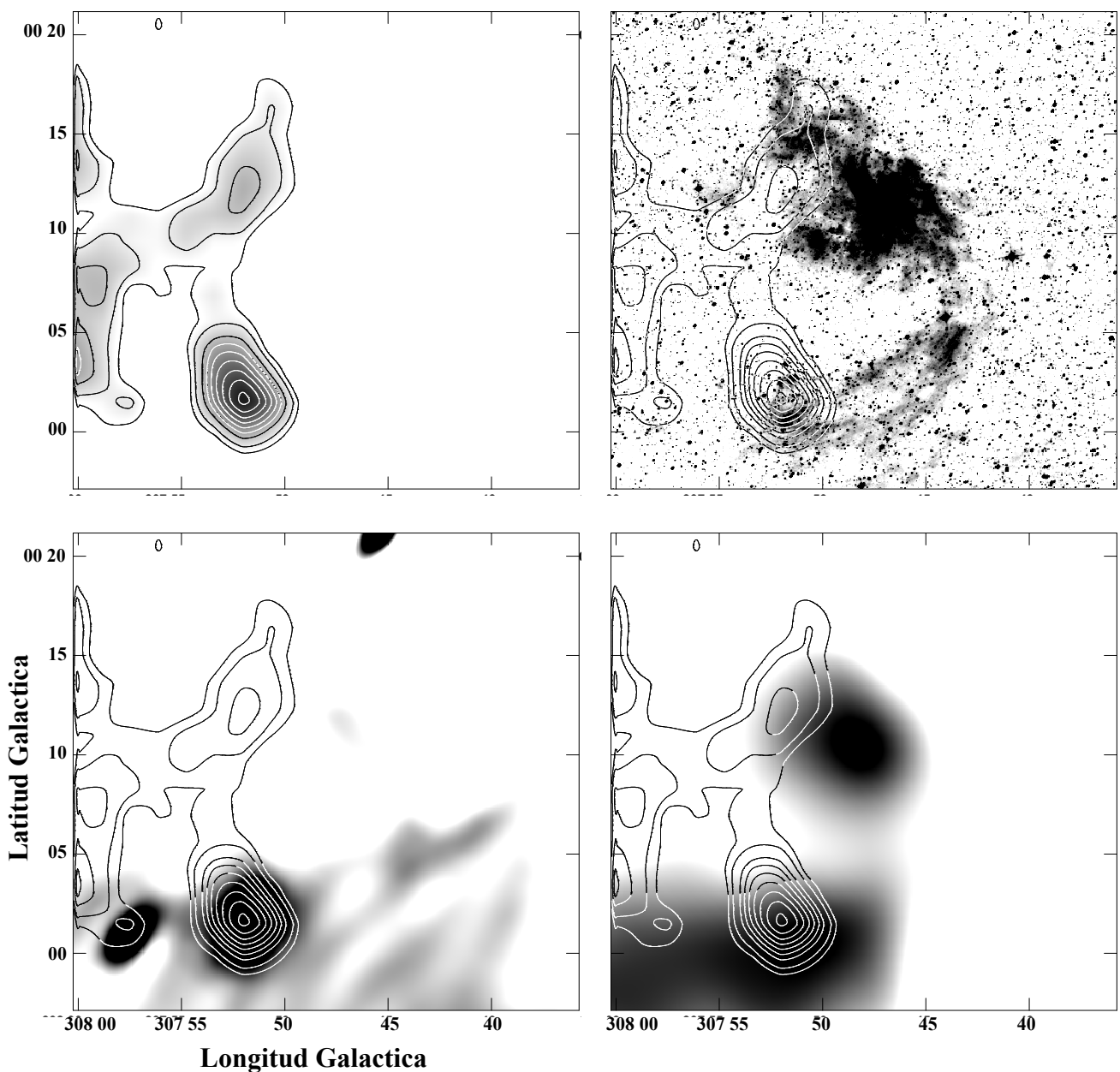

Figura 6.12: Panel superior izquierdo: Distribución de CO en el rango de velocidades de $-58 \mathrm{a}-56 \mathrm{~km} / \mathrm{seg}$. Los niveles de contorno van desde $0,9 \mathrm{~K}(\sim 23 \sigma)$ hasta $3,4 \mathrm{~K}$ en intervalos de 0,28 K. Panel superior derecho: Superposición de la emisión de CO con la emisión H $\alpha$. Panel inferior izquierdo: Superposición de la emisión de CO con la emisión IR en $60 \mu \mathrm{m}$. Panel inferior derecho: Superposición de la emisión de CO con la emisión en continuo de radio en $4,85 \mathrm{GHz}$. 
La Figura 6.12 muestra que la posición y extensión de la subcomponente C1 es coincidente con una intensa emisión observada en las tres bandas, especialmente en $\mathrm{H} \alpha$ y $60 \mu \mathrm{m}$. Como ya se mencionó en la Sección 6.2, la posición de C1 concuerda con la ubicación del cúmulo abierto C1331-622. Cappa et al. (2009) encontraron una elevada concentración de objetos estelares jóvenes (YSOs) en esta posición. Esto podría significar que el cúmulo se ha formado recientemente y por lo tanto podría estar conservando aún su componente molecular. El cúmulo C1331-622 ha sido recientemente catalogado y muy poco estudiado por lo que no se contó con información acerca de su velocidad radial. Turner \& Forbes (2005) determinaron para el cúmulo C1331-622 una distancia espectrofotométrica de $819 \pm 26$ pc. Utilizando el modelo de rotación galáctica de Brand \& Blitz (1993), la velocidad radial obtenida para una longitud galáctica $l=307^{\circ} .8$ y para una distancia de $820 \mathrm{pc}$ es $\sim-12 \mathrm{~km} / \mathrm{seg}$. Esta velocidad es $\sim 45 \mathrm{~km} / \mathrm{seg}$ superior a la velocidad observada para la subcomponente C1. Es decir que desde el punto de vista cinemático no se puede afirmar que la subcomponente $\mathrm{C} 1$ represente una componente molecular asociada al cúmulo abierto C1331-622, pero en virtud de las similitudes morfológicas destacadas anteriormente es una posibilidad que no puede ser descartada.

Del análisis morfológico realizado al gas molecular en la Figura 6.5, pudo observarse que la subcomponente molecular denominada $\mathrm{C} 2$, que está presente en el intervalo de velocidad $-55,7 \mathrm{a}-47,7 \mathrm{~km} / \mathrm{seg}$, parece correlacionarse morfológicamente con las estructuras $\mathrm{H} \alpha$ A3 y parte de la A1 (posiblemente también la "barra"); la subcomponente C3 por otra parte, presente en el intervalo $-53,7$ a $-47,7 \mathrm{~km} / \mathrm{seg}$ podría estar relacionada con la región Sur de A1. Finalmente, la subcomponente C4 muestra una clara similitud en su morfología con la estructura A2. Si bien la notable correspondencia morfológica entre el material molecular conformado por las subcomponentes $\mathrm{C} 2$, C3 y C4 y la estructura $\mathrm{H} \alpha$ denominada A hace que una relación física entre ellos sea muy probable, deseamos proponer un modelo geométrico simple que nos permita entender en forma cualitativa las características de la emisión $\mathrm{H} \alpha$ y de $\mathrm{CO}$ observadas. Si C2, C3 y C4 conforman una única estructura molecular, dicho modelo debe ser el idóneo para explicar la diferencia de velocidades observado entre estas subcomponentes. Como ya se mencionó al principio de este capítulo Chu \& Treffers (1981) observaron un gradiente de velocidades en la zona central de la nebulosa, pero el mismo no fue atribuido por los autores a un fenómeno de expansión, sino más bien a un "outflow" provocado por la ionización generada por la estrella WR 55. Este gradiente fue también detectado en el CO hacia la zona central de RCW 78 por Cappa et al. (2009). Sería deseable también que nuestro modelo fuera capaz de explicar las diferencias en las intensidades de emisión observadas entre las estructuras A1, A2 y A3.

A continuación se presenta el modelo propuesto para explicar las características del complejo molecular conformado por las subcomponentes C2, C3 y C4 (que desde ahora será llamado CM234). 


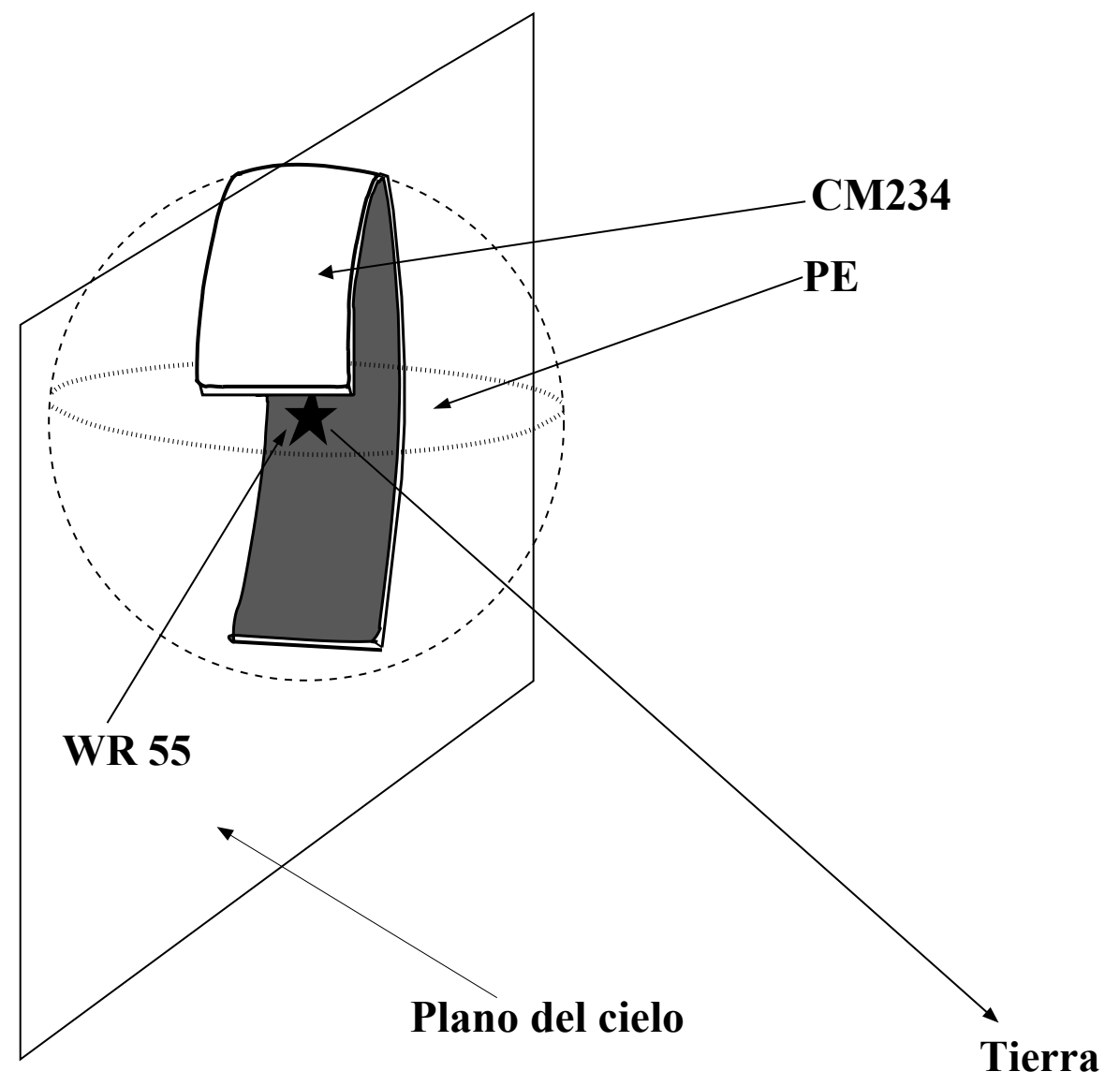

Figura 6.13: Esquema del modelo propuesto para explicar la cinemática de CM234, mostrado desde una perspectiva lateral superior a la del observador (Tierra).

En el modelo presentado en la Figura 6.13, CM234 está representado por una "faja" o "cinta" que se expande radialmente respecto de la posición de WR 55. La perspectiva mostrada en la Figura 6.13 corresponde a una posición lateral y levemente superior a la observada desde la Tierra. La expansión radial permite ubicar a CM234 a lo largo de la superficie de una esfera (línea a rayas) cuyo centro corresponde a la posición de WR 55. En dicha esfera puede definirse un plano ecuatorial (línea de puntos), el cual es ortogonal a la extensión de CM234 y coplanar con la Tierra. Dicho plano está indicado en la Figura 6.13 como PE.

A continuación, en la Figura 6.14 se presenta un esquema del modelo explicado anteriormente pero en la perspectiva del observador (figura superior) y en una perspectiva superior (figura inferior). Las posiciones tentativas correspondientes a las subcomponentes C2, C3 y C4 están indicadas. El movimiento de expansión puede explicarse prestando atención a las distintas velocidades observadas para las subcomponentes C2, C3 y C4. 

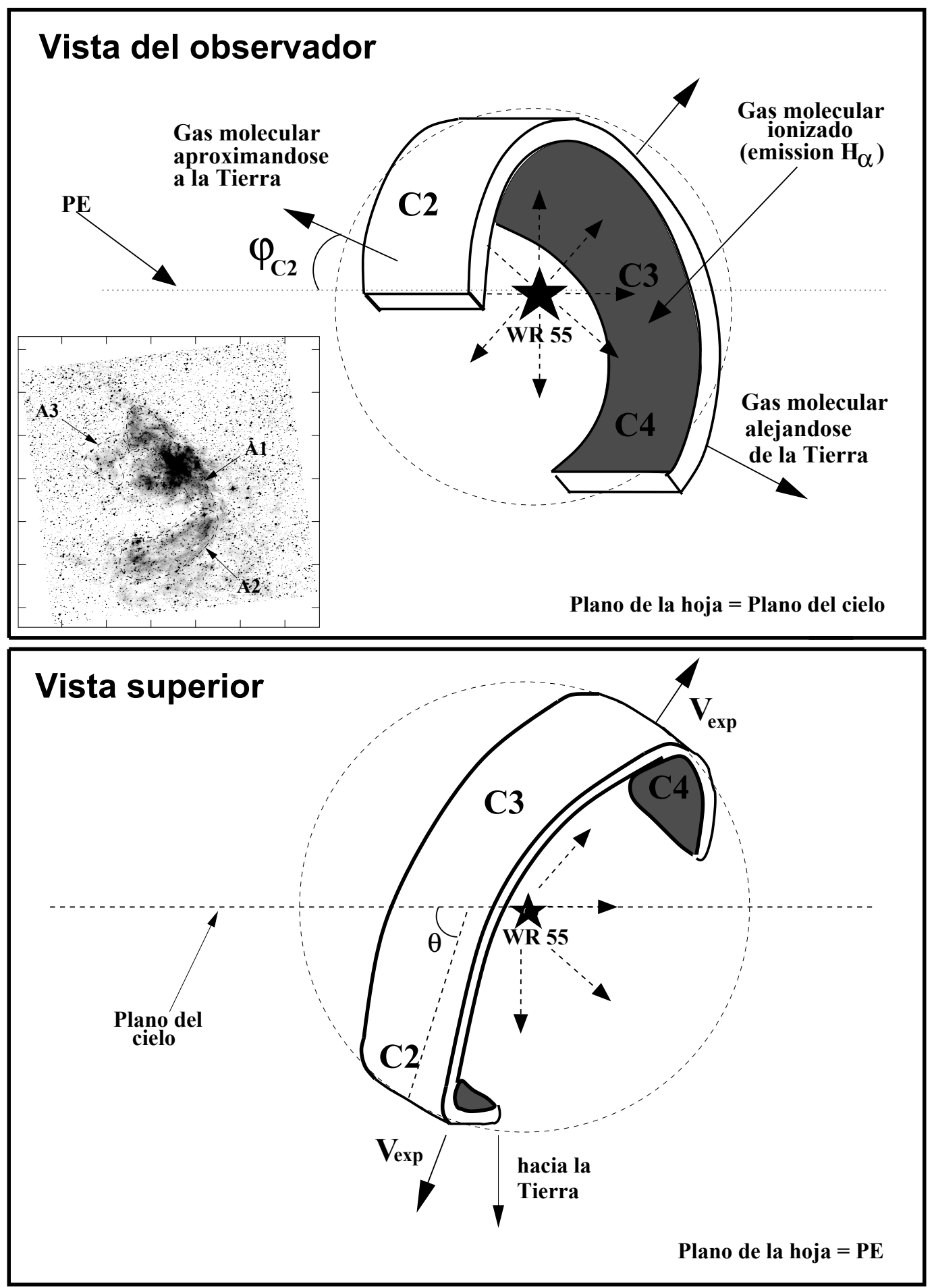

Figura 6.14: Panel superior Esquema del modelo propuesto para explicar la cinemática de CM234, según la visión del observador (coplanar a PE). Las flechas en líneas continuas representan el movimiento del gas molecular y las flechas en lineas de trazos representan los vientos de WR 55. Panel inferior: Idem, pero observado desde una posición superior a la del observador (perpendicular al plano PE). Las posiciones relativas de las subcomponentes $\mathrm{C} 2$, C3 y C4 en la estructura del modelo fueron indicadas. 
En el modelo propuesto se observa que un sector de CM234 se acerca hacia el observador (velocidad radial más negativa), el cual estaría representando a la parte de la componente C2 morfológicamente correlacionada con la estructura $\mathrm{H} \alpha$ denominada A3. Por otro lado, el sector de CM234 que se aleja del observador (velocidad radial más positiva) estaría representando a las subcomponentes $\mathrm{C} 4$, C3 y a la parte de $\mathrm{C} 2$ morfológicamente correlacionada con A1. La expansión de CM234 podría estar siendo producida por los intensos vientos de la estrella WR 55, que impactan la cara interna de la misma. Sobre esta cara interna no sólo actuarían los vientos de la estrella, sino también su intensa radiación, la cual provocaría la ionización del material molecular. El material molecular ionizado en la cara interna de la componente molecular (representado por las zonas oscuras en la Figura 6.14) sería el responsable de la emisión de la línea $\mathrm{H} \alpha$ que da origen a la morfología de la nebulosa $\mathrm{RCW}$ 78. Para una mejor comprensión de las características explicadas, en la Figura 6.15 se presenta una superposición de la estructura correspondiente al modelo propuesto para CM234, con la emisión del CO integrada en el intervalo de velocidades de $-57,7$ a $-45,7$ y con la emisión $\mathrm{H} \alpha$ de la nebulosa RCW 78 . Las posiciones de las componentes $\mathrm{C} 2, \mathrm{C} 3$ y $\mathrm{C} 4$ fueron indicadas.

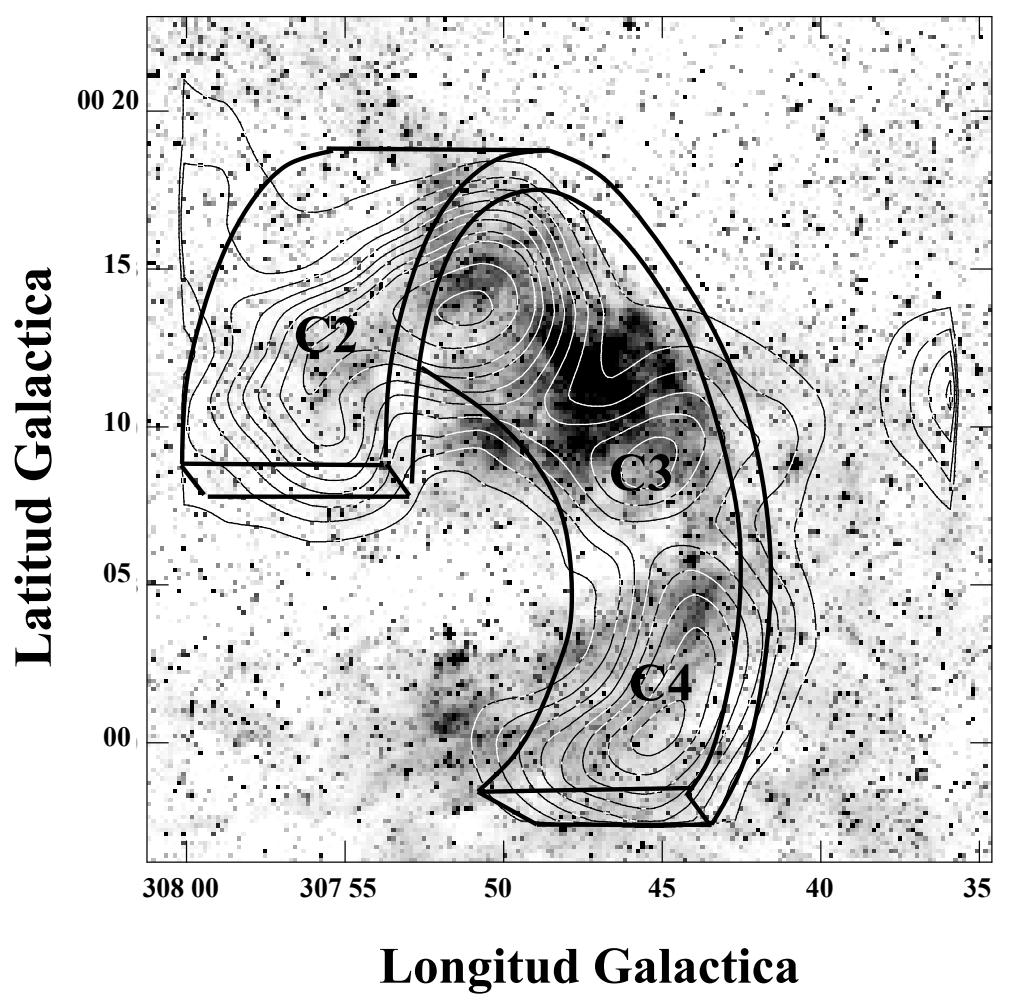

Figura 6.15: Superposición del CO integrado en el intervalo de velocidades de $-57,7$ a $-45,7 \mathrm{~km} / \mathrm{seg}$ (contornos delgados) con la imagen $\mathrm{H} \alpha$ de RCW 78 (tonos de grises) y con la estructura geométrica del modelo propuesto para explicar la cinemática de CM234 (contornos gruesos). 
Una característica importante del modelo propuesto está relacionada con las diferencias en la intensidad de emisión de la línea $\mathrm{H} \alpha$ entre las estructuras A1, A2 y A3. Como ya fuera mencionado, la intensidad de emisión de la estructura A3 es inferior a la de la estructura A2 y sobre todo a la de la estructura A1. De acuerdo a nuestro modelo, el material molecular de la subcomponente C2 (que se está acercando hacia la Tierra y que se corresponde morfológicamente con A3) se encuentra por delante del material ionizado por la estrella. En este caso el material molecular estaría dando origen a la absorción que haría aparecer la emisión $\mathrm{H} \alpha$ de esta zona más débil. Esto no ocurriría con las componentes C3, C4 y parte de la subcomponente C2 que se corresponde morfológicamente con A1, las cuales al estar alejándose del observador exponen su cara interna ionizada sin sufrir éstas ningún tipo de absorción por parte del material molecular. La estructura denominada "barra" (perteneciente a A1) es la más brillante y su intensa emisión podría ser ocasionada por la cercanía del material molecular ionizado a la estrella WR 55.

Como puede apreciarse, la subcomponente C1 fue arbitrariamente excluida de nuestro modelo, aunque no pueda ser confirmado si la misma está físicamente asociada CM234 o si es una estructura molecular ubicada en la dirección de RCW 78 que representa la contraparte molecular de otro objeto (por ejemplo el cúmulo C1331-622)

Si bien el modelo descripto permite explicar en forma cualitativa los gradientes de velocidad observados en CM234, no es posible a priori explicar los mismos en forma cuantitativa sin hacer algunas suposiciones y aproximaciones adicionales. Esto se debe principalmente a que es necesario introducir en el modelo tres valores que no se conocen: 1 ) la velocidad de expansión $\left(\mathrm{V}_{\text {exp }}\right)$ de CM234 (o de las subcomponentes C2, C3 y C4), 2) el ángulo de inclinación del vector $\mathrm{V}_{\text {exp }}$ de CM234 respecto del plano del plano del cielo (indicado en la Figura 6.14 por $\theta$ ) y 3 ) el ángulo de inclinación del vector $\mathrm{V}_{\text {exp }}$ de las subcomponentes $\mathrm{C} 2$, C3 y C4 respecto del plano PE (indicado en la Figura 6.14 por $\varphi$ ). Cabe destacar que de acuerdo al modelo, el ángulo $\theta$ posee el mismo valor para todas subcomponentes $\mathrm{C} 2, \mathrm{C} 3$ y $\mathrm{C} 4$, a diferencia del ángulo $\varphi$ que es distinto para cada componente. Es decir que existen los valores $\varphi_{C 2}, \varphi_{C 3}$ y $\varphi_{C 4}$. En la Figura 6.14 sólo está indicado $\varphi_{C 2}$.

Una estimación de $\theta$ puede realizarse considerando las propiedades geométricas del modelo propuesto. Por lo explicado hasta aquí, la morfología cuasi elíptica de CM234 puede interpretarse como el resultado de la proyección sobre el plano del cielo de una "faja" o "cinta" de simetría circular. Dicha faja se encuentra inclinada un ángulo $\theta$ con respecto del plano del cielo (ver Figuras 6.14 y 6.16). Por efectos de proyección la faja toma el aspecto de una elipse para un observador externo. El semieje mayor de la elipse está identificado en la Figura 6.16 con la letra "A" y el semieje menor con la letra "B". Como puede observarse, el semieje menor es simplemente el resultado de la proyección del radio (semieje mayor) en el plano del cielo; por lo tanto el ángulo de 
inclinación de la faja respecto del plano del cielo estará dado por la relación entre $\mathrm{A}$ y $\mathrm{B}$ dada por $\cos (\theta)=\mathrm{B} / \mathrm{A}$. De la Figura 6.16 puede obtenerse que $\mathrm{B} / \mathrm{A} \sim 0,55$ por lo tanto $\theta \sim 56^{\circ}$.

La velocidad radial observada para cada componente $\mathrm{C} i(i=2,3,4)$ será la proyección de la velocidad de expansión $\left(\mathrm{V}_{\text {exp }}\right)$ en la dirección del observador $\left(\mathrm{V}_{\exp } \times \operatorname{sen} \theta \times \cos \varphi_{C i}\right)$. Por otro lado el intervalo de velocidades total del CM234 $\left(\Delta v_{o b s}\right)$, será la diferencia entre las velocidades radiales más positivas restada de la más negativa, entonces $\Delta v_{o b s}=v_{o b s ~} C_{4}-v_{o b s} C 2$, o sea:

$$
\Delta v_{o b s}=V_{e x p} \times \operatorname{sen}(\theta) \times \cos \left(\varphi_{C 4}\right)-V_{e x p} \times \operatorname{sen}(\theta) \times \cos \left(\varphi_{C 2}\right)
$$

De las características geométricas observables para CM234, se puede considerar para las componentes $\mathrm{C} 2$ y C4 que $\varphi_{C 4} \approx \varphi_{C 2}+180^{\circ}$, entonces:

$$
\Delta v_{o b s}=V_{\text {exp }} \times \operatorname{sen}(\theta) \times \cos \left(\varphi_{C 2}+180^{\circ}\right)-V_{e x p} \times \operatorname{sen}(\theta) \times \cos \left(\varphi_{C 2}\right)
$$

Desarrollando, reagrupando y considerando valores absolutos, el intervalo total de velocidades de CM234 está dado entonces por:

$$
\Delta v_{o b s}=2 \times V_{e x p} \times \operatorname{sen}(\theta) \times \cos \left(\varphi_{C 2}\right)
$$

Debido a la dificultad en la determinación en forma exacta de $\varphi_{C 2}$, se considerará para este ángulo un rango de valores determinado a partir de las mencionadas características morfológicas. Podemos entonces considerar para $\varphi_{C 2}$ valores extremos de:

$$
20^{\circ}<\varphi_{C 2}<50^{\circ}
$$

De esta manera, adoptando los valores $\Delta v_{\text {obs }} \approx 12 \mathrm{~km} / \mathrm{seg}, \theta=56^{\circ}$ y el rango de valores de $\varphi_{C 2}$ indicado anteriormente se puede inferir que la velocidad de expansión se encuentra entre los valores

$$
7,8 \mathrm{~km} / \mathrm{seg}<V_{\exp }<11,5 \mathrm{~km} / \mathrm{seg}
$$

Es importante destacar que debido a la forma en la que fue definida la subcomponente $\mathrm{C} 2$, el valor de $\varphi_{C 2}$ puede superar los $90^{\circ}$ (ya que hay una parte de esta componente que se está alejando), pero a los efectos del cálculo anterior sólo se consideró la región de la misma que más rápidamente se acercaba al observador, y por lo tanto con el valor de $\varphi_{C 2}$ más pequeño.

La expansión de CM234 permite inferir una velocidad sistémica para el mismo. El intervalo de velocidad de esta estructura va desde $\sim-57,7$ a $-45,7$ $\mathrm{km} / \mathrm{seg}$, por lo que puede adoptarse una velocidad sistémica de $\sim-51 \mathrm{~km} / \mathrm{seg}$. En el análisis a seguir se considerará que la estrella WR 55 se encuentra a una distancia de $5 \pm 1 \mathrm{kpc}$ (Cappa et al., 2009). En la Figura 6.17 se muestra la curva de rotación obtenida del modelo de Brand \& Blitz (1993) para $l=$ $307^{\circ}, 8$. En esta curva puede observarse que para una velocidad radial de $\sim-51$ 

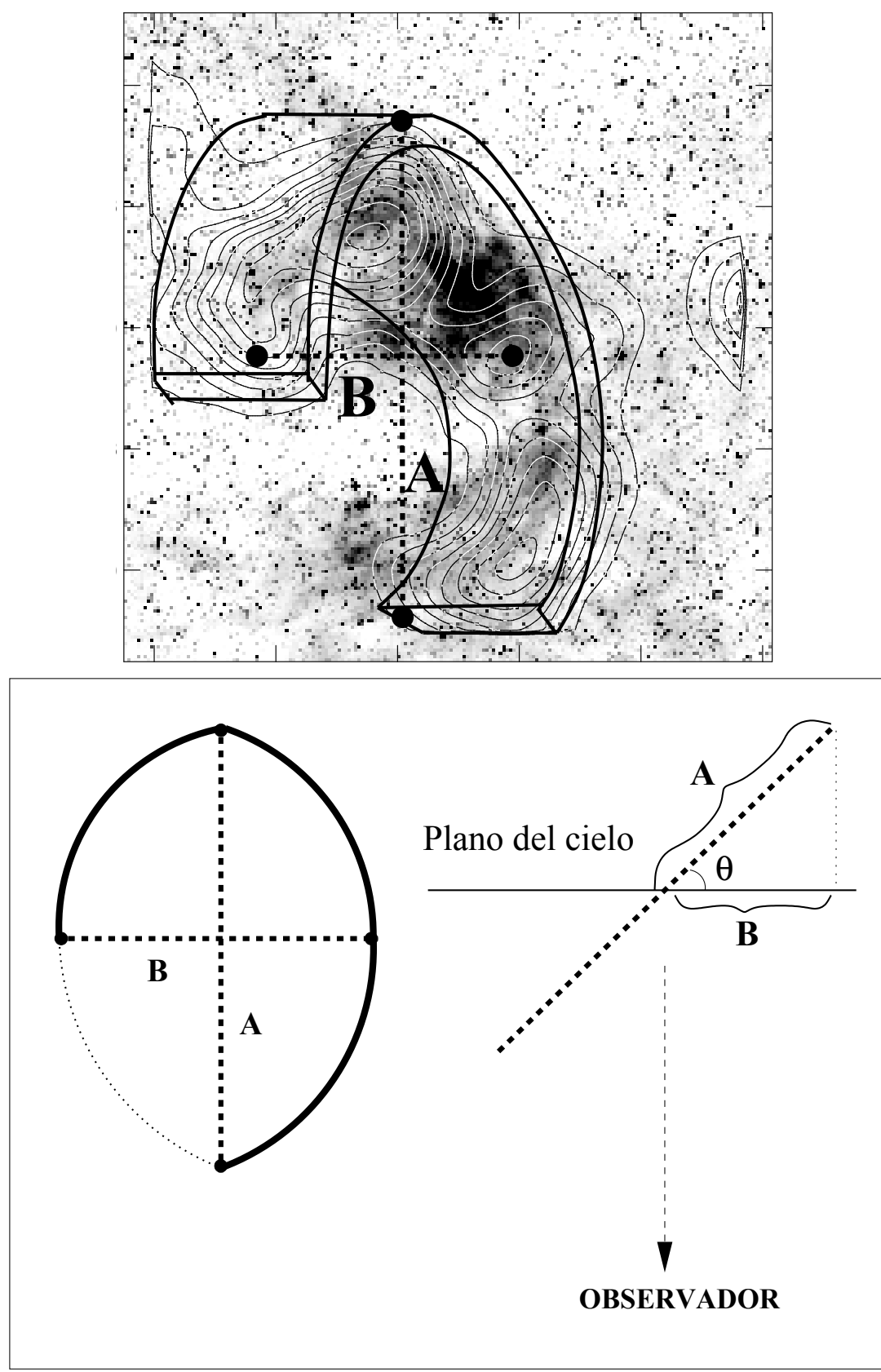

Figura 6.16: Panel superior: Modelo propuesto para el CM234. Panel inferior: Interpretación geométrica de la proyección de CM234 en el plano del cielo.

$\mathrm{km} / \mathrm{seg}$ no existe una distancia posible para el modelo ya que esta velocidad es levemente inferior a la del punto tangente para esta longitud galáctica. El valor de velocidad radial para el punto tangente es de $-47,3 \mathrm{~km} / \mathrm{seg}$, al cual le corresponde una distancia cinemática de 5,2 kpc (ver Figura 6.17).

Brand \& Blitz (1993) demostraron que en la Vía Lactea existen objetos 


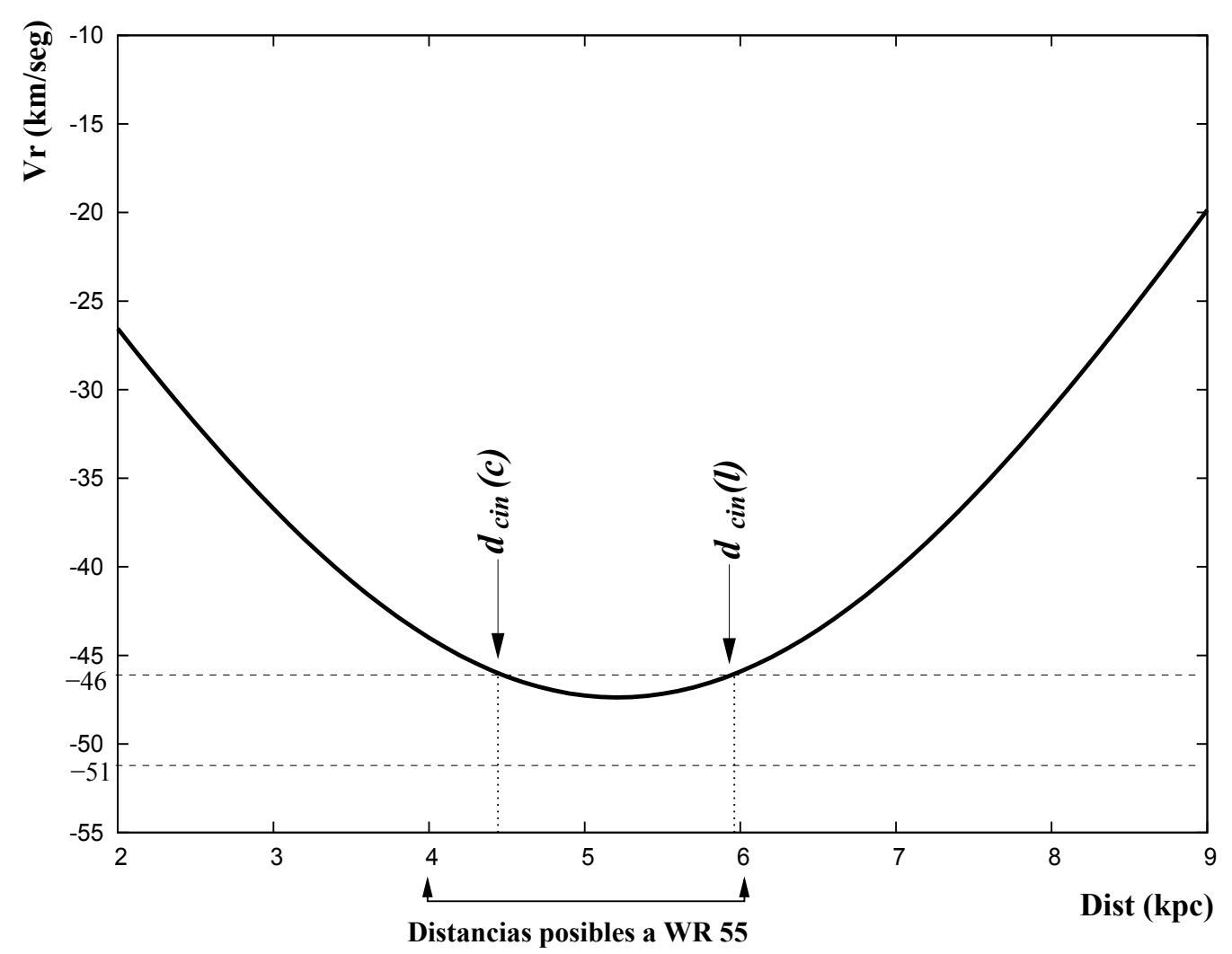

Figura 6.17: Curva de rotación galáctica en la dirección de WR 55

cuyos movimientos se alejan del movimiento estrictamente circular predicho por el modelo de rotación galáctico. Estos movimientos dan origen a una "velocidad residual", que es la diferencia entre la velocidad radial "observada" y la velocidad radial "esperada" $\left(v_{r e s}=v_{o b s}-v_{e s p}\right)$. En la Figura 10 del trabajo de Brand \& Blitz (1993) están indicadas las velocidades residuales para distintas longitudes galácticas a distintas distancias. En dicha figura puede observarse que para $l \sim 308^{\circ}$, a distancias superiores a $1 \mathrm{kpc}$, las velocidades residuales son negativas. Esto significa que la velocidad radial esperada para el movimiento circular del CM234 podría ser mayor que la velocidad radial observada. Más exactamente, para $l=308^{\circ}$ y a una distancia de $\sim 5 \mathrm{kpc}$ se obtiene una velocidad residual levemente inferior a $-5 \mathrm{~km} / \mathrm{seg}$. Por lo tanto, haciendo estas correcciones la velocidad esperada de acuerdo al movimiento de rotación galáctico para CM234 podría llegar a los -46 km/seg. Las distancias cinemáticas cercanas y lejanas correspondientes a esta velocidad radial son $d_{c i n}(\mathrm{c}) \approx 4,4 \mathrm{kpc} \mathrm{y} d_{c i n}(\mathrm{l}) \approx 6 \mathrm{kpc}$, respectivamente. De esta manera, la distancia cinemática cercana se encuentra en el rango de distancias posibles a la estrella WR 55 (ver Figura 6.17).

En base a lo expuesto hasta ahora, muy posiblemente la emisión $\mathrm{H} \alpha$ y la emisión del CO de CM234 provienen de las mismas estructuras. La emisión 
H $\alpha$ podría haberse originado de la ionización de la región interna del material molecular. Cappa et al. (2009), usando datos de la emisión en el continuo de radio en $4,85 \mathrm{GHz}$, calcularon una masa de gas ionizado en la nebulosa $M_{\text {ion }}=$ $(3-5) \times 10^{3} \mathrm{M}_{\odot}$ y una densidad electrónica $n_{e} \sim 6-15 \mathrm{~cm}^{-2}$. Estas cantidades indican que fue necesaria la presencia de una gran cantidad de gas molecular para ser ionizado, por lo que dicho gas molecular sea muy posiblemente de origen interestelar. En la Tabla 6.1 se detallan los principales parámetros físicos asociados a las subcomponentes C2, C3 y C4. La densidad de columna fue calculada haciendo uso de la Ecuación 3.4. La energía cinética de las componentes fue calculada usando una velocidad de expansión intermedia a las encontradas $(\sim 9,6 \mathrm{~km} / \mathrm{seg})$. El valor de la extinción visual $\left(\mathrm{A}_{V}\right)$ fue obtenido haciendo uso de la relación $\mathrm{N}_{H_{2}} / \mathrm{A}_{V}=0,94 \times 10^{21} \mathrm{~cm}^{-2} \mathrm{mag}^{-1}$ (Bohlin et al., 1978).

Tabla 6.1: Principales parámetros físicos asociados a las subcomponentes moleculares C2, C3 y $\mathrm{C} 4$

\begin{tabular}{|c|c|c|c|}
\hline Parametro & $\mathrm{C} 2$ & C3 & $\mathrm{C} 4$ \\
\hline Centro $(l, b)\left({ }^{\circ} \prime \prime \prime\right)$ & $\left(307^{\circ} 51^{\prime}, 0^{\circ} 14^{\prime}\right)$ & $\left(307^{\circ} 44^{\prime}, 0^{\circ} 10^{\prime}\right)$ & $\left(307^{\circ} 44^{\prime}, 0^{\circ} 00^{\prime}\right)$ \\
\hline$\Delta v(\mathrm{~km} / \mathrm{seg})$ & $\sim 10$ & $\sim 8$ & $\sim 7$ \\
\hline $\mathrm{I}_{C O}(K \mathrm{~km} / \mathrm{seg})$ & 34,8 & 20,1 & 36,2 \\
\hline$\Omega\left(10^{-6}\right.$ ster $)$ & 6,9 & 3,3 & 5,4 \\
\hline$N_{H_{2}}\left(10^{21} \mathrm{~cm}^{-2}\right)$ & $5,5 \pm 0,1$ & $3,0 \pm 0,1$ & $5,1 \pm 0,2$ \\
\hline$M_{\text {tot } H_{2}}^{(\dagger)}\left(10^{3} M_{\odot}\right)$ & $20 \pm 8$ & $5 \pm 2$ & $15 \pm 6$ \\
\hline$A_{v}(m a g)$ & $5,8 \pm 0,1$ & $3,2 \pm 0,1$ & $5,4 \pm 0,2$ \\
\hline$E_{\text {cin }}\left(10^{48}\right.$ erg $)$ & $\sim 18$ & $\sim 5$ & $\sim 14$ \\
\hline
\end{tabular}

(†) Valor calculado utilizando una distancia $\mathrm{d}=5 \pm 1 \mathrm{kpc}$ (Cappa et al., 2009)

En la Tabla 6.2 se presentan algunos parámetros geométricos y dinámicos calculados para el complejo molecular CM234.

La energía cinética de expansión de CM234 es $\sim 3,7 \times 10^{49}$ ergios (valor 
Tabla 6.2: Principales parámetros geométricos y dinámicos determinados para el complejo molecular CM234

\begin{tabular}{lr}
\hline \hline Parámetro & Valor \\
\hline Semieje mayor $\left(^{\prime}\right)$ & 7,5 \\
Semieje mayor lineal $(p c)$ & 10,9 \\
Semieje menor $\left(^{\prime}\right)$ & 6 \\
Extensión en velocidad $(\mathrm{km} / \mathrm{seg})$ & 12 \\
Velocidad de expansión $(\mathrm{km} / \mathrm{seg})$ & 7,8 a 11,5 \\
Velocidad sistémica $(\mathrm{km} / \mathrm{seg})$ & -51 \\
Energía cinética $\left(10^{49} \mathrm{erg}\right)$ & $\sim 3,7$ \\
\hline
\end{tabular}

calculado sumando las energías cinéticas individuales de $\mathrm{C} 2, \mathrm{C} 3$ y C4). A partir de este valor es posible calcular qué fracción de la energía mecánica inyectada por los vientos de WR 55 fue convertida en energía cinética del CM234, es decir cúal fue su eficiencia en la conversión de la energía mecánica en cinética (indicada por el coeficiente $\epsilon=\mathrm{E}_{\text {cin } C M 234} / \mathrm{E}_{m e c} W R 55$ ). De acuerdo al modelo explicado anteriormente, CM234 no rodea en forma completa a la estrella. Realizando una simple proyección geométrica es posible inferir cuál sería la energía cinética que tendría una estructura molecular de similares características pero que rodea a WR 55 en forma completa. En la Figura 6.18 se muestra un esquema comparativo de las dimensiones aproximadas del modelo propuesto para CM234 (cuyo semieje mayor posee un valor S), con una esfera de radio $\mathrm{R}$. Notar que necesariamente $\mathrm{S}=\mathrm{R}$. La base de CM234 está indicada por $\mathrm{W}$, y su proyección en el plano del cielo por $\mathrm{W}^{\prime}$. Es decir que $\mathrm{W}^{\prime}=\cos \left(90^{\circ}-\right.$ $\theta) \times \mathrm{W}=0,83 \times \mathrm{W}$. De la geometría observada, puede estimarse que $\mathrm{W}^{\prime} \approx 0,7 \times \mathrm{S}$ $=0,7 \times \mathrm{R}$. Por lo tanto $\mathrm{W} \approx 0,84 \times \mathrm{R}$. De la geometría, puede inferirse además que CM234 tiene una extensión en longitud (o altura $\mathrm{H}$ ) que lo hace rodear a la esfera en un $\sim 60 \%\left(30^{\circ}<\varphi_{C 2}+\varphi_{C 3}+\varphi_{C 4}<240^{\circ}\right)$, es decir que $\mathrm{H} \sim 0,6 \times 2 \pi \mathrm{R}$. Por lo tanto el área de CM234 $(\mathrm{H} \times \mathrm{W})$ es $\approx 0,84 \mathrm{R} \times 0,6 \times 2 \pi \mathrm{R}=\pi \mathrm{R}^{2}$.

Comparando el valor obtenido para el área de CM234 con el valor del área de la esfera $\left(4 \pi R^{2}\right)$, puede observarse que el área de la esfera es $\sim 4$ veces mayor que el área de la estructura molecular. Haciendo una proyección 


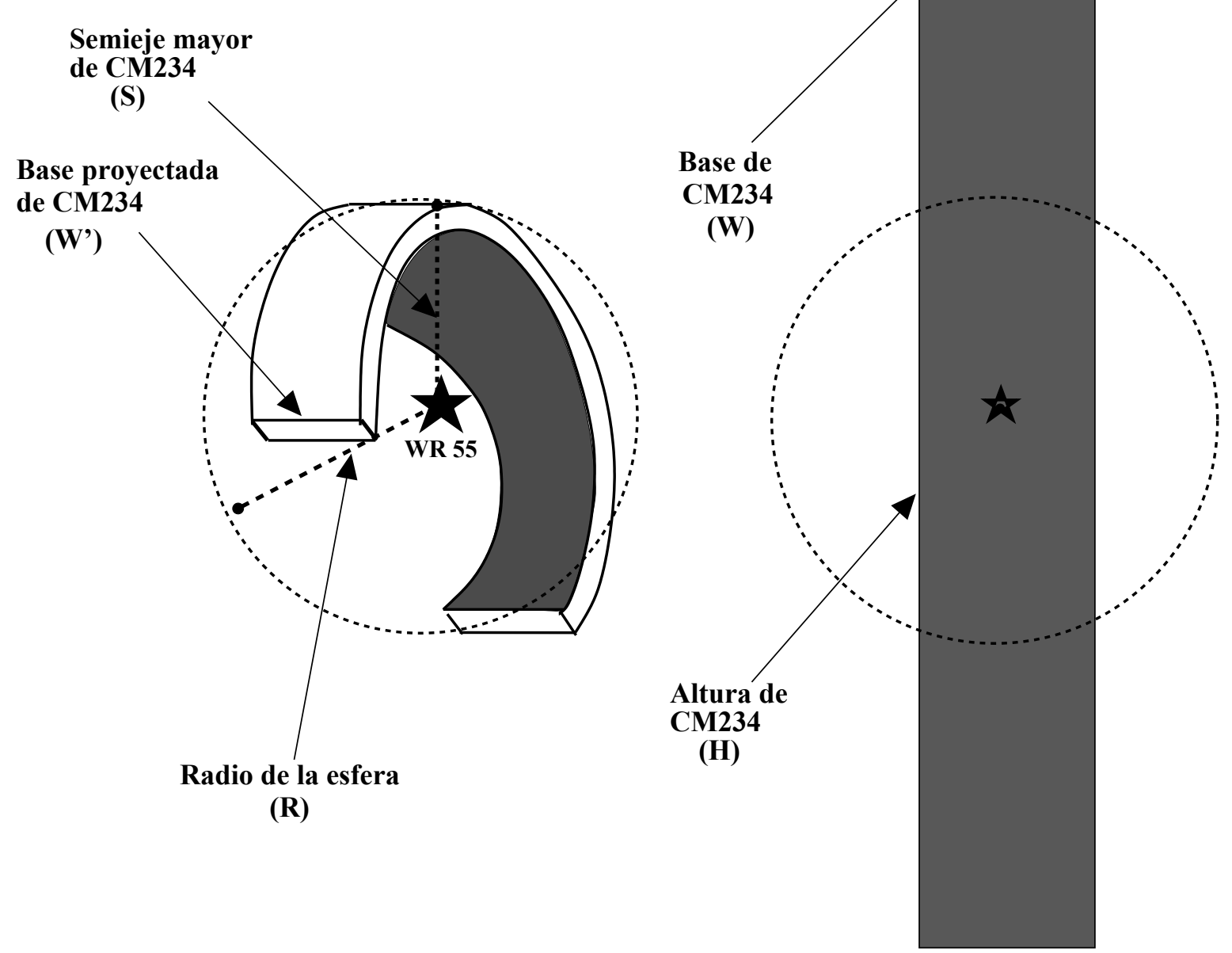

Figura 6.18: Modelo propuesto para el complejo molecular CM234 y su comparación con una esfera de radio igual al semieje mayor

de esta relación a las energías cinéticas involucradas, entonces una estructura molecular de similares características a CM234 pero que rodea por completo a la estrella y se expande en forma isotrópica respecto de ella, tendrá una energía cinética $\sim 4$ veces mayor a la encontrada; es decir que una estructura molecular de estas características se expandiría con una energía cinética de $\sim 1,5 \times 10^{50}$ ergios. Considerando que WR 55 es una estrella de tipo espectral WN7, la tasa de pérdida de masa para este tipo espectral (suponiendo abundancias metálicas solares) es $\log (\dot{M})=-4,69$ y su velocidad terminal $\mathrm{v}_{\infty}=1960 \mathrm{~km} / \mathrm{seg}$ (Smith et al., 2002). Utilizando estos valores, la luminosidad mecánica entregada al medio por los vientos de la estrella es de $\mathrm{L}_{w} \sim 2,5 \times 10^{37} \mathrm{erg} / \mathrm{seg}$. Si consideramos para WR 55 una masa inicial entre 40 y $60 \mathrm{M}_{\odot}$ y un tiempo de vida en la fase WN de $\sim 3 \times 10^{5}$ años (Maeder \& Maynet, 2003), la energía mecánica entregada al 
MIE por los vientos de la estrella es $\sim 2 \times 10^{50}$ ergs. De manera que la fracción de energía mecánica de los vientos de WR 55 convertida en energía cinética de CM234 es $\epsilon \approx 0,75$. Este valor resulta muy elevado comparado con los valores obtenidos de los modelos teóricos de BI $\left(\epsilon_{\text {teor }}<0,2\right)$ y aun más comparado con los valores obtenidos de la observación $\left(\epsilon_{o b s} \sim 0,03\right)$

El elevado valor encontrado para $\epsilon$ respecto de los valores teóricos y observacionales hace suponer que los vientos de la fase WN de WR 55 pudieron no haber sido suficientes para explicar la energía cinética observada para CM234. Además, el tiempo de vida dinámico obtenido para CM234 es $t_{d} \approx 1 \times 10^{6}$ años, el cual es tres veces superior al tiempo de vida de una estrella en la fase WN. Por lo tanto, es muy posible que los vientos de la estrella en alguna fase previa (posiblemente la fase $\mathrm{O}$ ) puedan haber contribuido también al desarrollo de la cinemática observada en el complejo molecular CM234.

\subsubsection{La "barra" $\mathrm{H} \alpha$}

En la Sección 6.1 se destacó la presencia de una zona de emisión en $\mathrm{H} \alpha$ muy brillante de $\sim 5^{\prime}$ de largo que se extiende de norte a sur en la zona central de RCW 78, y que fue denominada "barra".

En la Sección 6.2 se mostró que existen dos componentes moleculares que morfológicamente tienen una gran similitud con la barra $\mathrm{H} \alpha$. En las Figura 6.6 puede observarse que un sector de la componente $\mathrm{C} 2$ parece corresponderse con la barra a velocidades entre $-55,3$ a $-55 \mathrm{~km} / \mathrm{seg}$, aunque este intervalo puede extenderse hacia velocidades levemente superiores e inferiores, en los cuales el material molecular mantiene una disposición espacial en la misma dirección que la barra y por detrás de ésta. La otra componente molecular se encuentra en un rango de velocidades entre -37 a $-35 \mathrm{~km} / \mathrm{seg}$ y parece ser una extensión de la componente molecular C5. Chu \& Treffers (1981) estudiaron ocho posiciones alrededor de la zona central de RCW 78 en la línea $\mathrm{H} \alpha$ y encontraron emisión en la región de la barra a velocidades entre -48 y -51,6 (ver Figura 6.19, panel superior). Si la emisión $\mathrm{H} \alpha$ es originada por la ionización de material molecular neutro por parte de WR 55, sería esperable que el material ionizado y el molecular no posean velocidades radiales muy distintas. Por este motivo proponemos que el material molecular ubicado entre las componentes C2 y C3 a velocidades $\sim-55 \mathrm{~km} / \mathrm{seg}$ sea la contraparte molecular de la barra.

En la Tabla 6.3 se presentan algunos parámetros físicos calculados para la barra utilizando la emisión en continuo de radio, infrarrojo y molecular.

Para el cálculo de la masa del gas molecular asociado a esta estructura se realizó una integración de los mapas de ${ }^{12} \mathrm{CO}$ en un intervalo de velocidad alrededor de $-56,7 \mathrm{a}-54,7 \mathrm{~km} / \mathrm{seg}$, intervalo en el cual la distribución del gas molecular se mantiene paralela a la barra (Figura 6.19, panel inferior). Debido a que las resoluciones angulares del relevamiento SuperCOSMOS en la línea $\mathrm{H} \alpha$ y 
nuestras observaciones de ${ }^{12} \mathrm{CO}$ son muy distintas no es sencillo determinar cuál es la línea de contorno que determina los límites de la contraparte molecular de la barra $\mathrm{H} \alpha$. Por este motivo se calculó una masa promedio considerando varios posibles niveles de contorno, así como también una dispersión de masas debido a esta incertidumbre.
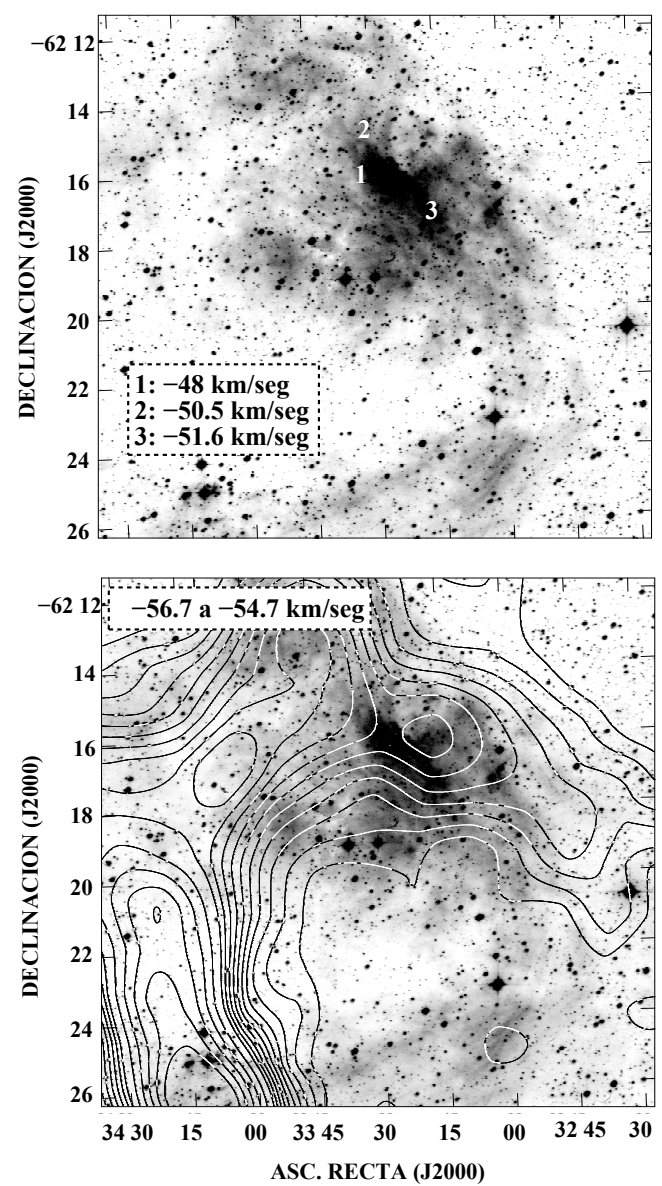

Figura 6.19: Panel superior: Posiciones de los espectros $\mathrm{H} \alpha$ tomados por Chu \& Treffers (1981). En el borde inferior izquierdo se encuentran las velocidades medidas en estas posiciones por dichos autores. Panel inferior: Distribución del material molecular en el intervalo de velocidad $-56,7$ a $-54,7 \mathrm{~km} / \mathrm{seg}$. Los niveles de contorno van de $0,175 \mathrm{~K}(\sim 3 \sigma)$ a $3,5 \mathrm{~K}$ en intervalos de $0,175 \mathrm{~K}$, y a partir de $3,5 \mathrm{~K}$ en intervalos de $0,35 \mathrm{~K}$.

Los parámetros del gas ionizado se obtuvieron a partir de la emisión de continuo de radio en $4,85 \mathrm{GHz}$ y considerando una temperatura electrónica $\mathrm{T}_{e}=10.000 \mathrm{~K}$. Para el cálculo de densidad electrónica, la masa de gas ionizado y la medida de emisión se utilizaron las Ecuaciones 3.13, 3.14 y 3.15 respectivamente. La masa ionizada fue multiplicada por 1,27 para considerar la presencia del helio ionizado una vez. Estos valores fueron calculados considerando densidades electrónicas homogéneas $(f=1)$ e inhomogéneas $(f<1)$, adoptando $\mathrm{n}_{e}^{\prime}<100 \mathrm{~cm}^{-3}$ (Esteban et al., 1990). 
Tabla 6.3: Principales parámetros físicos correspondientes a la "barra" $\mathrm{H} \alpha$ en la zona central de RCW 78

\begin{tabular}{|c|c|}
\hline \multicolumn{2}{|l|}{ Continuo de radio } \\
\hline $\begin{array}{l}S_{4,85 \mathrm{GHz}}(\mathrm{Jy}) \\
n_{e}(f=1)\left(\mathrm{cm}^{-3}\right) \\
n_{e}(f=0,37)\left(\mathrm{cm}^{-3}\right) \\
M_{\text {ion }}(f=1)\left(M_{\odot}\right) \\
M_{\text {ion }}(f=0,37)\left(M_{\odot}\right) \\
E M_{\max }(f=1)\left(10^{6} \mathrm{pc} \mathrm{cm}^{-6}\right) \\
E M_{\max }(f=0,37)\left(10^{6} \mathrm{pc} \mathrm{cm}^{-6}\right) \\
N_{\text {lym }}\left(10^{48} \mathrm{seg}^{-1}\right)\end{array}$ & $\begin{aligned} 0,8 & \pm 0,3 \\
14 & \pm 1 \\
& \sim 23 \\
510 & \pm 250 \\
\sim & 300 \\
2,1 & \pm 0,4 \\
& \sim 1,5 \\
& 1,6\end{aligned}$ \\
\hline \multicolumn{2}{|l|}{ IR } \\
\hline $\begin{array}{l}S_{60 \mu m}(J y) \\
S_{100 \mu m}(J y) \\
T_{\text {polvo }}(\mathrm{K})(m=1,5) \\
M_{\text {polvo }}\left(M_{\odot}\right)\end{array}$ & $\begin{aligned} 480 & \pm 280 \\
1100 & \pm 800 \\
30 & \pm 5 \\
& \sim 16\end{aligned}$ \\
\hline \multicolumn{2}{|l|}{$\mathrm{CO}$} \\
\hline $\begin{array}{l}\Delta v(\mathrm{~km} / \mathrm{seg}) \\
I_{C O} K \mathrm{~km} / \mathrm{seg} \\
\Omega\left(10^{-6} \text { ster }\right) \\
N_{\mathrm{H}_{2}}\left(10^{20} \mathrm{~cm}^{-2}\right) \\
M_{t o t} \mathrm{H}_{2}\left(\mathrm{M}_{\odot}\right) \\
A_{v}(\mathrm{mag})\end{array}$ & $\begin{array}{r}\sim 2 \\
1,8 \pm 0,1 \\
1,8 \pm 0,6 \\
3,4 \pm 0,5 \\
340 \pm 140 \\
0,4 \pm 0,1\end{array}$ \\
\hline
\end{tabular}

\subsubsection{La estructura B}

La estructura $\mathrm{H} \alpha$ denominada $\mathrm{B}$ parece tener su contraparte molecular a velocidades entre $\sim-39 \mathrm{y}-35 \mathrm{~km} / \mathrm{seg}$ (ver Sección 6.2, Figura 6.7). Si bien las componentes moleculares C5 y C6 parecen estar conectadas a velocidades entre $-38,6$ y $-36,6 \mathrm{~km} / \mathrm{seg}$, la componente C5 es visible hasta velocidades de $\sim-32,8 \mathrm{~km} / \mathrm{seg}$ (ver Figura 6.8) .

Como ya se indicó, existe una notable similitud morfológica entre la componente C6 y una pequeña condensación de emisión $\mathrm{H} \alpha$ ubicada en $(l, b)=$ $\left(308^{\circ} 51^{\prime}, 00^{\circ} 09^{\prime}\right)$. La componente C5 por otro lado parece corresponderse con la emisión extendida $\mathrm{H} \alpha$ de morfología triangular que se extiende en dirección 
este-oeste.

La particular disposición espacial de la estructura B, y de sus posibles componentes moleculares asociadas (C5 y C6), hacen dudar de la posible relación entre éstas con el brazo A y sus componentes moleculares asociadas. Dos preguntas surgen de aquí:

a)¿Es la estructura B el resultado de la ionización de las componentes C5 y C6 por parte de la radiación proveniente de WR 55?

b) ¿Es la elevada velocidad radial de C5 y C6 el resultado de la interacción entre ellas y los intensos vientos de WR 55?

A continuación se intentará adaptar al modelo propuesto para explicar las velocidades radiales observadas del complejo molecular CM234 a las componentes moleculares C5 y C6 con el fin de explicar las elevadas velocidades radiales que se observan para estas últimas. Las componentes C5 y C6 se ubican en la dirección de WR 55, por lo tanto el ángulo $\theta$ respecto del plano del cielo que podría considerarse para las mismas sería $\sim 270^{\circ}$. Es decir que si estas estructuras moleculares se están expandiendo debido a los vientos de WR 55 considerando la máxima velocidad de expansión posible $(11,5 \mathrm{~km} / \mathrm{seg})$, su velocidad radial observada debería ser $\sim-39,5 \mathrm{~km} / \mathrm{seg}$ (ver Figura 6.20). Es decir que los valores de velocidad radial obtenidos según nuestro modelo para C5 y C6, no alcanzan los valores observados para las mismas.

Algunas explicaciones posibles pueden ser:

1. El ángulo $\theta$ determinado para el complejo molecular CM234 es menor que $56^{\circ}$. La consecuencia directa de esto resulta en una mayor velocidad de expansión.

2. El ángulo $\varphi_{C 2}$ podría ser mayor que $50^{\circ}$. Esto también tiene por consecuencia una mayor velocidad de expansión para el complejo molecular CM234.

3. Las componentes C5 y C6 no tienen ninguna asociación física con CM234. Esto podría significar que la estructura $\mathrm{H} \alpha$ denominada $\mathrm{B}$, no está relacionada con la estructura $\mathrm{H} \alpha$ denominada $\mathrm{A}$, es decir que las mismas son sólo dos nebulosas distintas ubicadas en la misma dirección de la visual.

En vista de la última posibilidad, se prestó atención a algunas características morfológicas observadas en la componente B. De la Figura 6.7 puede observarse que la pequeña condensación $\mathrm{H} \alpha$ ubicada en $(l, b)=\left(307^{\circ} 51^{\prime}, 00^{\circ} 09^{\prime} 30^{\prime \prime}\right)$, la cual posee una notable correspondencia morfológica con la componente C6, no muestra una distribución uniforme en la emisión $\mathrm{H} \alpha$. El brillo es más intenso sobre el borde oeste de la misma, en la dirección de WR 55. En vista de estas características, la componente B podría interpretarse como el resultado 


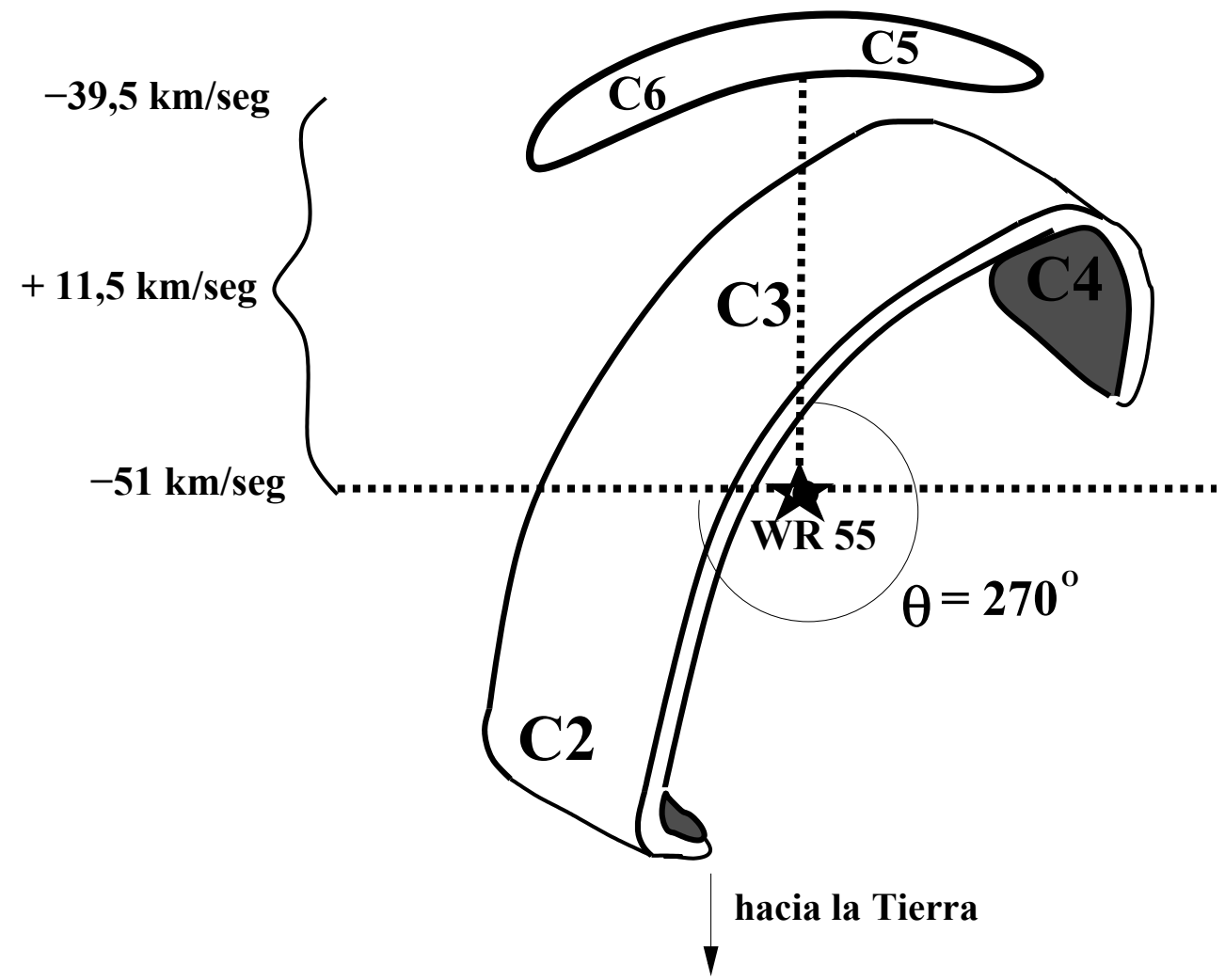

Figura 6.20: Adaptación de las componentes C5 y C6 al modelo propuesto para explicar la cinemática de CM234.

de la ionización de las componentes C5 y C6 por parte de una fuente de radiación ubicada entre éstas y además necesariamente a la misma distancia, o al menos a una distancia muy cercana.

La ubicación de WR 55 en una posición interior a estas estructuras sugiere que ésta podría ser la responsable de la ionización de C5 y C6, pero como ya se detalló anteriormente, esto está en contradicción con el modelo cinemático propuesto para CM234. Por este motivo, se realizó una búsqueda en diversos catálogos, de fuentes estelares cuyas coordenadas estén entre las posiciones de C5 y C6 y que pudieran ser a su vez las responsables de su ionización. Esta búsqueda tuvo como resultado a la estrella HD 117704. Esta estrella está ubicada muy próxima a WR 55, en la posición $(l, b)=\left(308^{\circ} 49^{\prime} 12^{\prime \prime}, 00^{\circ} 09^{\prime}\right)$, y su tipo espectral varía entre una O tardía y una B temprana (Loden+ 1976, Jaschek, 1978, Canon+ 1918-1924 ADC 1989, Reed, 2005). En la Figura 6.21 se muestra una imagen de las componentes moleculares C5 y C6 integradas en el rango de velocidades de $-37,6 \mathrm{a}-36,6 \mathrm{~km} / \mathrm{seg}$, superpuestas con la imagen H $\alpha$ de RCW 78. Las posiciones de las estrellas WR 55 y HD 117704 están indicadas.

El $2^{d o}$ Catálogo de Velocidades Radiales y Datos Astrométricos (Kharchenko+ 2007) indica para esta estrella una velocidad radial heliocéntrica $\mathrm{V}_{\mathrm{Hel}}=-21$ 


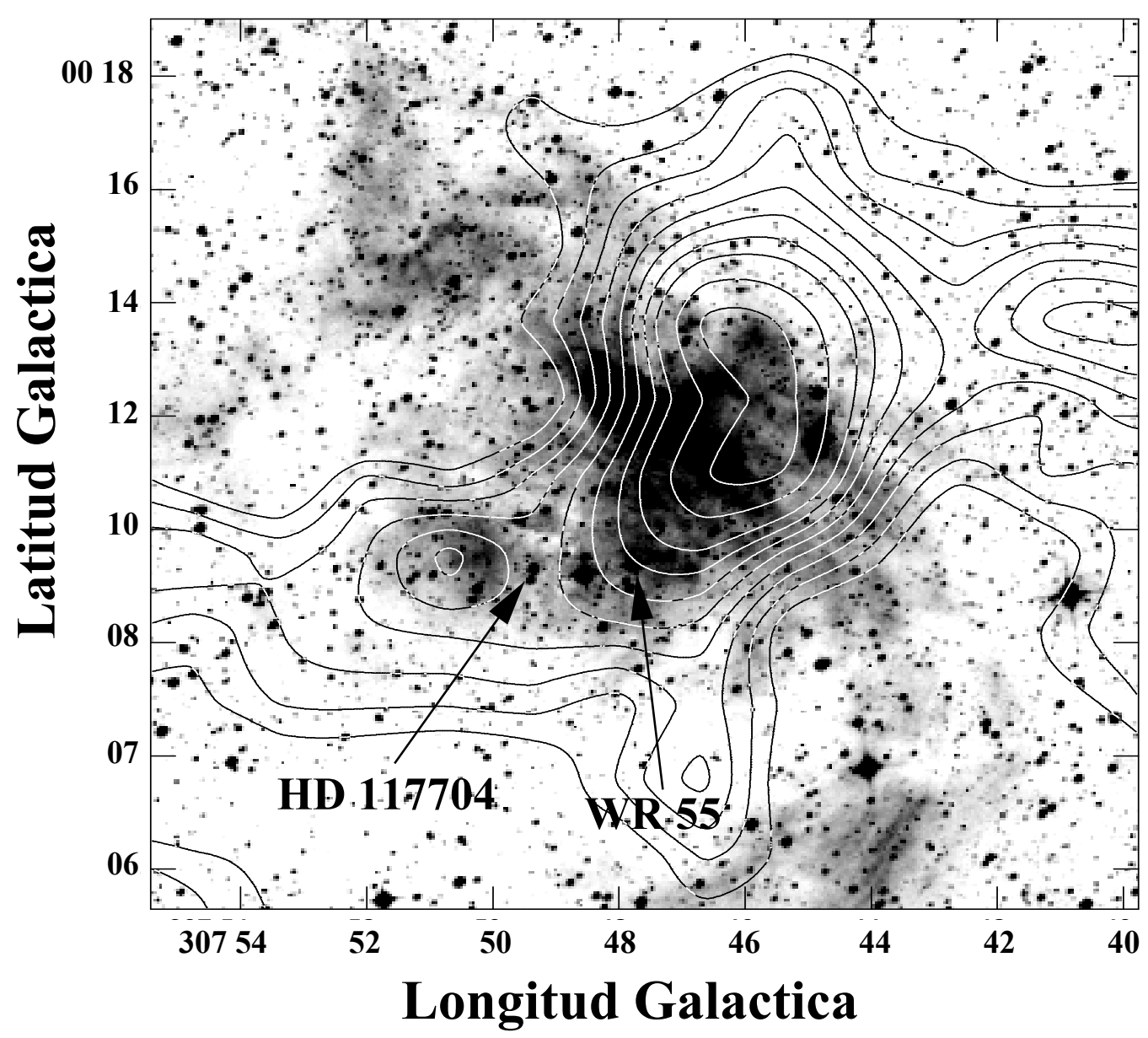

Figura 6.21: Componentes moleculares C5 y C6 integradas en el rango de velocidad $-37,6$ a $-36,6 \mathrm{~km} / \mathrm{seg}$ (contornos), superpuestos con la emisión H $\alpha$ de RCW 78 (tonos de grises). Las posiciones de las estrellas WR 55 y HD 117704 están indicadas.

$\mathrm{km} / \mathrm{seg}$, la cual llevada al sistema LSR tiene un valor de $\mathrm{V}_{L S R}=-36,8 \mathrm{~km} / \mathrm{seg}$. Esta velocidad radial es notablemente similar a la observada para las componentes C5 y C6, lo que podría indicar una asociación entre estos objetos.

Si bien la evidencia presentada hasta aquí, habla en favor de una asociación física entre la estructura B y las componentes C5 y C6, así como también de una posible independencia física y cinemática de las mismas respecto de la estructura filamentaria de RCW 78 (estructura A), son necesarias más observaciones de mejor calidad (ópticas y en radio) para obtener datos que puedan ser concluyentes. 


\subsection{El modelo propuesto para CM234. ¿Es posible encontrar este tipo de estructuras alrededor de otras estrellas WR?}

En la Sección 6.4.1 se explicó la morfología y la cinemática del complejo molecular CM234 proponiendo que éste consiste en una estructura anular incompleta con un cierto ángulo de inclinación respecto del cielo. Esta estructura se expande respecto de la posición de WR 55 y además es ionizada por la misma estrella. La búsqueda de estructuras moleculares de estas características podría aportar información valiosa para el estudio de las nebulosas anillo y/o el material molecular en las mismas.

La detección de esta clase de estructuras moleculares alrededor de otras nebulosas ópticas podría permitir explicar las morfologías no esféricas que muchas de ellas presentan. A continuación se analizará un posible caso de una nebulosa anillo alrededor de una estrella WR en la cual el material molecular presenta similares características que en el caso de la nebulosa RCW 78 y para la cual podría adaptarse el modelo mencionado anteriormente.

\subsubsection{La nebulosa óptica alrededor de WR 68}

Utilizando la base de datos del relevamiento SuperCOSMOS en la línea $\mathrm{H} \alpha$, se encontraron algunos objetos cuyas morfologías podrían explicarse con el modelo descripto anteriormente. Uno de ellos es la nebulosa anillo alrededor de la estrella WR 68. En la Figura 6.22 se muestra la imagen $\mathrm{H} \alpha$ de la misma. La nebulosa presenta una morfología elíptica con la estrella cerca de su centro. Una característica interesante de esta nebulosa anillo consiste en que uno de sus bordes es muy brillante mientras que el otro es casi imperceptible. Utilizando las observaciones de ${ }^{12} \mathrm{CO}$ de NANTEN se investigó la distribución del material molecular en las cercanías de WR 68. Las observaciones de ${ }^{12} \mathrm{CO}$ para este objeto fueron realizadas con un espaciado de $5^{\prime} .4$, el cual resulta insuficiente para llevar a cabo un estudio morfológico y cinemático del material molecular con gran detalle, pero suficiente para realizar un estudio a gran escala del mismo.

$\mathrm{Al}$ analizar el material molecular alrededor de WR 68 se encontraron dos componentes moleculares que podrían estar asociadas a la nebulosa anillo. Una de ellas parece corresponderse morfológicamente con el borde oscuro de la nebulosa y se extiende en un intervalo de velocidad que va de $\sim-46$ a -42 $\mathrm{km} / \mathrm{seg}$; la otra, que presenta cierta similitud con el borde brillante, se extiende en el intervalo de velocidad que va de $\sim-40 \mathrm{a}-37 \mathrm{~km} / \mathrm{seg}$. Estas componentes 


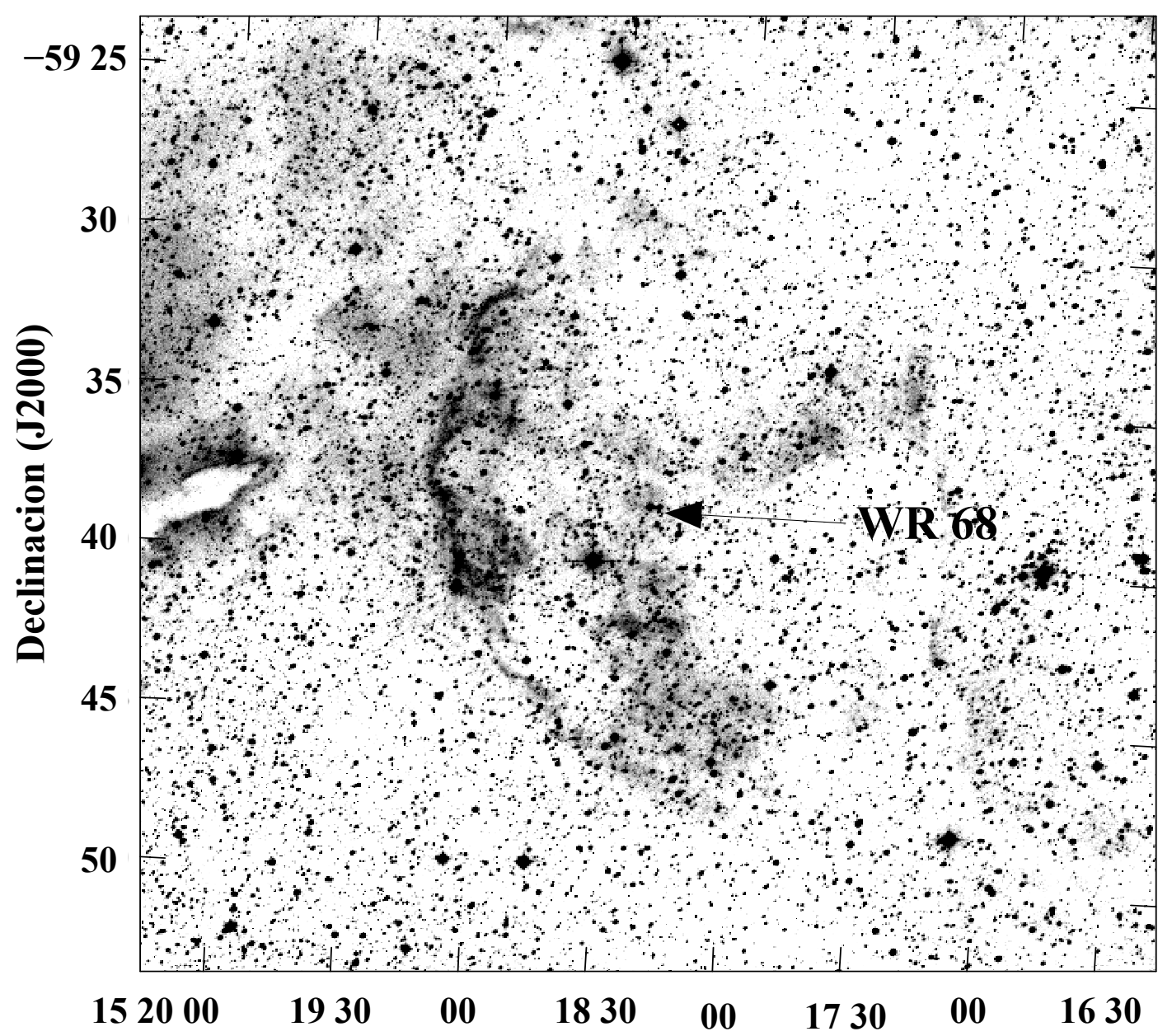

Asc. Recta (J2000)

Figura 6.22: Nebulosa anillo $\mathrm{H} \alpha$ alrededor de la estrella WR 68. La posición de la estrella está indicada por la flecha.

moleculares están mostradas en las Figuras 6.23 y 6.24. Las imágenes están integradas en intervalos de $0,22 \mathrm{~km} / \mathrm{seg}$, pero dichos intervalos no son contiguos ni están equiespaciados en velocidad ya que fueron seleccionados de manera tal que la correspondencia morfológica con la nebulosa $\mathrm{H} \alpha$ resulte más clara.

Considerando para estas componentes moleculares una velocidad sistémica $\mathrm{v}_{\text {sist }} \approx-41 \mathrm{~km} / \mathrm{seg}$ y utilizando el modelo de rotación circular galáctico (Brand \& Blitz, 1993), los valores obtenidos para la distancia cinemática cercana y lejana son $d_{c e r c}=2,8 \mathrm{kpc}$ y $d_{l e j}=10,3 \mathrm{kpc}$, respectivamente. Por otro lado, la distancia a WR 68 es de 3,27 kpc (van der Hucht, 2001), aunque este valor puede tener un error del $50 \%$. Es decir, que la distancia cinemática cercana derivada para las componentes moleculares observadas en la dirección de WR 
68 concuerda con la distancia espectrofotométrica obtenida para dicha estrella (dentro de los errores).

Las componentes moleculares encontradas alrededor de WR 68 presentan cierta similitud respecto de las encontradas en RCW 78. La componente a velocidades entre $-46 \mathrm{a}-42 \mathrm{~km} / \mathrm{seg}$ (componente que se acerca) parecería estar asociada a la emisión $\mathrm{H} \alpha$ débil de la nebulosa; por otro lado el material molecular antre -40 y $-37 \mathrm{~km} / \mathrm{seg}$ (componente que se aleja) parecería estar relacionada con la emisión $\mathrm{H} \alpha$ más intensa. Por lo tanto, las características observadas alrededor de la estrella WR 68 y su nebulosa anillo pueden ser explicadas de la misma manera que en el caso de WR 55 y la nebulosa RCW 78. Es decir, que la emisión $\mathrm{H} \alpha$ podría haber sido originada por la ionización en la cara interna del gas molecular por parte de WR 68. La emisión H $\alpha$ sólo es visible sobre la componente molecular que se aleja, mientras que la componente molecular que se acerca estaría absorbiendo dicha emisión, haciendo que la misma se observe menos intensa.

Observaciones moleculares con mejor resolución angular permitirían realizar un estudio más detallado de estas componentes moleculares para obtener resultados más concluyentes. 

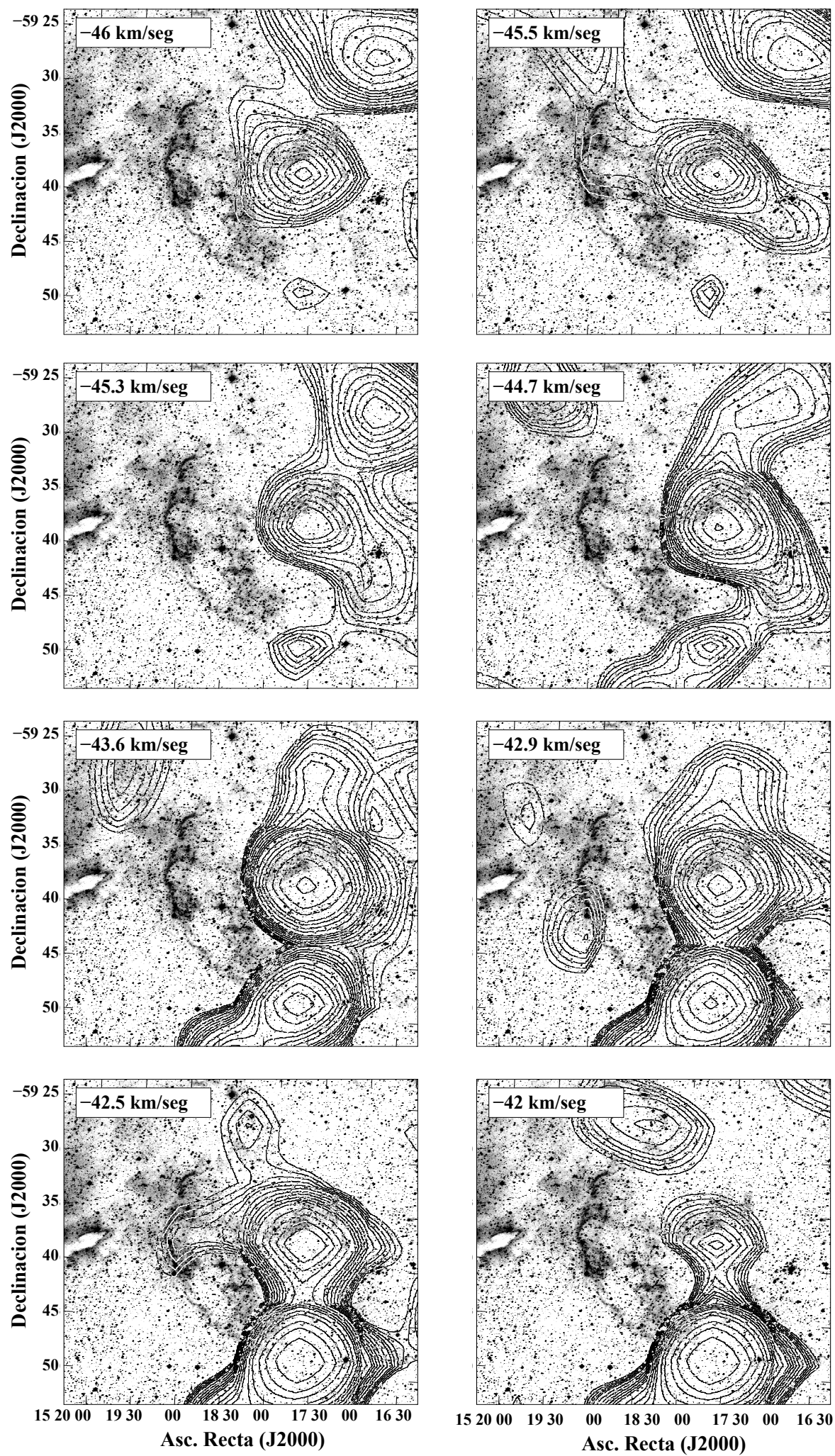

Figura 6.23: Distribución de ${ }^{12} \mathrm{CO}$ alrededor de WR 68 en el intervalo -46 a $-42 \mathrm{~km} / \mathrm{seg}$. Las imágenes están integradas en intervalos de $0,22 \mathrm{~km} / \mathrm{seg}$. La velocidad central está indicada arriba a la izquierda. El primer nivel de contorno es $0,3 \mathrm{~K}(\sim 3 \sigma)$. 

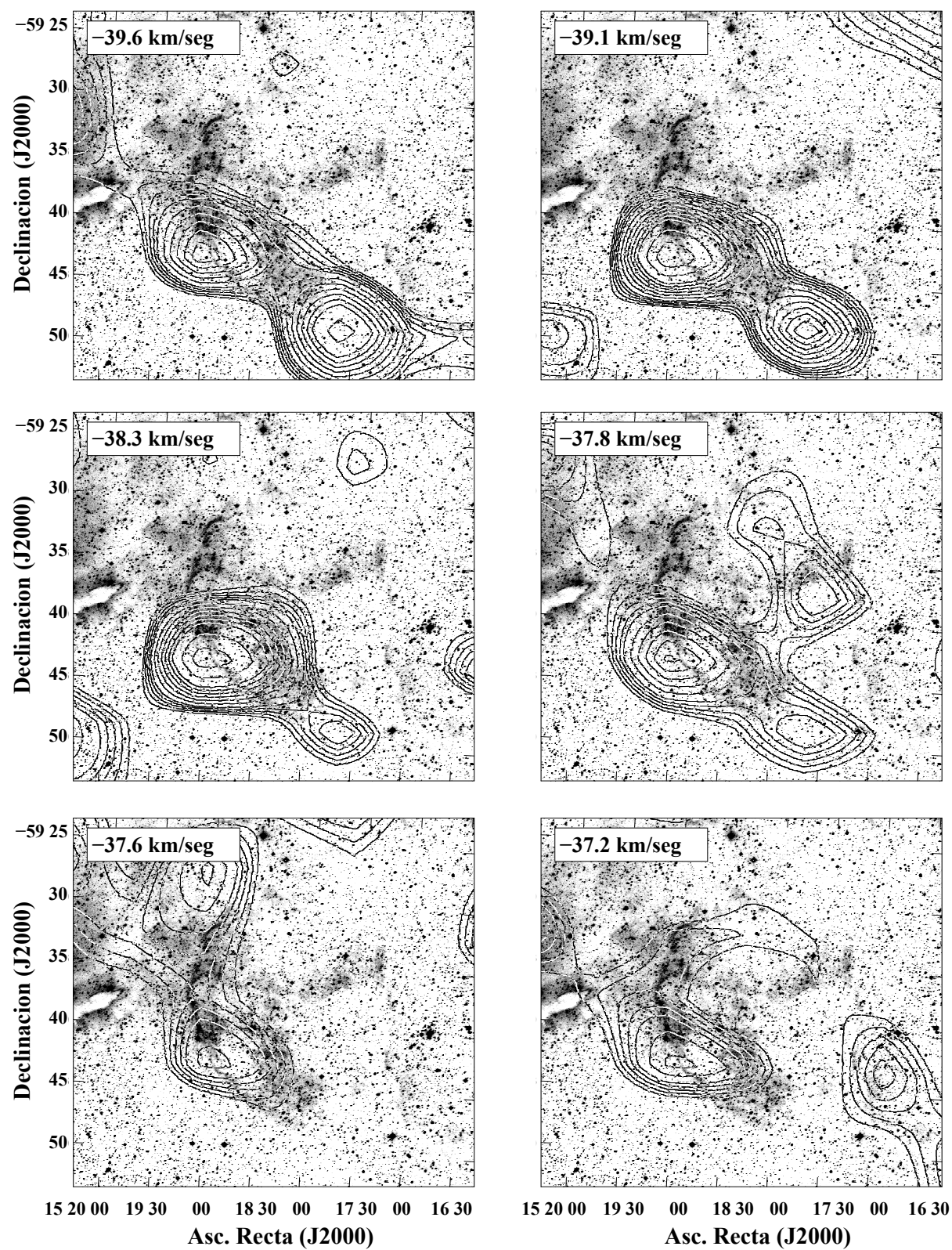

Figura 6.24: Distribución de ${ }^{12} \mathrm{CO}$ alrededor de WR 68 en el intervalo $-39,6$ a $-37,2$ $\mathrm{km} / \mathrm{seg}$. Las imágenes están integradas en intervalos de $0,22 \mathrm{~km} / \mathrm{seg}$. La velocidad central está indicada arriba a la izquierda. El primer nivel de contorno es $0,3 \mathrm{~K}(\sim 3 \sigma)$. 


\subsection{Resumen y conclusiones}

El análisis de la emisión del ${ }^{12} \mathrm{CO}$ en la nebulosa óptica RCW 78 alrededor de la estrella WR 55, reveló la presencia de tres componentes moleculares que aportan en forma separada a distintas características morfológicas de la nebulosa.

1. El complejo molecular CM234, presente en el rango de velocidades de $\sim-57,7$ a $-45,7 \mathrm{~km} / \mathrm{seg}$. Dicho complejo estaría asociado con la parte filamentaria de la nebulosa $\mathrm{H} \alpha \mathrm{RCW} 78$, tambien llamada componente A.

2. La estructura molecular compuesta por las componentes C5 y C6 en el rango de velocidades de $\sim-39$ a $-35 \mathrm{~km} / \mathrm{seg}$. Esta estructura estaría asociada a la emisión $\mathrm{H} \alpha$ extendida en el centro de RCW 78, denominada estructura B.

3. La estructura molecular formada por las componentes $\mathrm{C} 7 \mathrm{y} \mathrm{C} 8$, en el intervalo de velocidades $\sim-33 \mathrm{a}-28 \mathrm{~km} / \mathrm{seg}$. Esta estructura se ubica a lo largo de la intensa franja de absorción que se observa en la zona central de la nebulosa, llamada estructura C.

El gradiente de velocidades observado para el complejo molecular CM234 pudo explicarse considerando un modelo en el cual dicho complejo conforma un anillo incompleto expandiéndose respecto de la posición de la estrella WR 55. La estrella sería responsable de la expansión, así como de la ionización de la cara interna de esta estructura. Esta ionización del gas molecular sería la responsable de la emisión en $\mathrm{H} \alpha$ de la estructura filamentaria de RCW 78 (componente A), así como también de su emisión en el continuo de radio. El origen del gas molecular que conforma CM234 es interestelar. Por este motivo la nebulosa óptica RCW 78 puede considerarse simplemente una "región HII" expandiéndose alrededor de WR 55. La existencia de gas molecular de origen estelar mezclado con CM234 no puede ser descartada. La estructura molecular encontrada en la nebulosa óptica alrededor de WR 68 parece poseer similares características que el complejo molecular CM234. De ser esto confirmado, estructuras moleculares como éstas permitirían explicar la morfología elíptica de algunas nebulosas ópticas alrededor de estrellas de gran masa.

La velocidad radial observada para las componentes C5 y C6 no concuerda con la esperada según el modelo propuesto para CM234, por lo que posiblemente estas componentes, al igual que la estructura B, no estén asociadas con 
la estructura filamentaria de RCW 78. Es decir, que nebulosa RCW 78 podría ser la conjunción de dos nebulosas que se encuentran en la misma dirección de la visual, pero que no están vinculadas físicamente.

Las componentes $\mathrm{C} 7$ y C8 podrían ser en parte, las responsables de la franja de absorción observada en la región media de RCW 78. 


\subsection{Bibliografía}

- Brand, J.; Blitz, L., 1993, A\&A, 275, 67B

- Condon, J. J.; Griffith, Mark R.; Wright, Alan E., 1993, 106, 1095C

- Cappa, C. E.; Rubio, M.; Martín, M. C.; Romero, G. A., 2009, A\&A, $508,759 \mathrm{C}$

- Chu, Y.-H.; Treffers, R. R., 1981, ApJ, 250, 615C

- Chu, Y.-H.; Treffers, R. R.; Kwitter, K. B.,1983, ApJS, 53, 937C

- Días+ 2002-2007, Optically visible open clusters and Candidates

- Esteban, C.; Vilchez, J. M.; Manchado, A.; Edmunds, M. G. 1990, A\&A, $227,515 \mathrm{E}$

- Esteban, C.; Smith, L. J.; Vilchez, J. M.; Clegg, R. E. S., 1993, A\&A, $272,299 \mathrm{E}$

- Henry Draper Catalogue and Extension (Cannon+ 1918-1924; ADC 1989)

- Jaschek, M., 1978, BICDS, 15, 121J

- Kharchenko, N. V.; Scholz, R.-D.; Piskunov, A. E.; Roeser, S.; Schilbach, E., 2007yCat, 3254, 0K

- Loden, L. O.; Loden, K.; Nordstrom, B.; Sundman, A., 1976, A\&AS, 23, $283 \mathrm{~L}$

- Maeder, A.; Meynet, G., 2003, A\&A, 411, 543M

- Mezger, P. G.; Henderson, A. P., 1967, ApJ, 147, 471M

- Reed, C., 2005yCat, 5125, 0R

- Rodgers A. W., Campbell C. T., Whiteoak J. B., 1960, MNRAS, 121, 123

- Smith, Linda J.; Norris, Richard P. F.; Crowther, Paul A., 2002, MNRAS, 337, 1309S

- Turner, D. G.; Forbes, D., 2005, PASP, 117, 967T

- van der Hucht, K. A., 2001, NAR, 45, 135

- Walborn, N., 1982, AJ, 87, 1300 


\section{Capítulo 7}

\section{El gas molecular asociado a las regiones HII RCW 121 y $\mathrm{RCW}$ 122. Su relación con las estrellas WR 87, WR 89, WR 91 y el cúmulo abierto HM 1}

\subsection{Resumen}

En este capítulo se presentan los resultados obtenidos del análisis multifrecuencia realizado en los alrededores de las regiones de formación estelar RCW 121 y RCW 122. Este análisis se basó fundamentalmente en los datos de la línea $\mathrm{J}=1 \rightarrow 0$ de la molécula ${ }^{12} \mathrm{CO}$ obtenidos con el radiotelescopio NANTEN. El objetivo de este análisis fue verificar la posible relación existente entre las estrellas del cúmulo abierto HM1, WR 87, WR 89 y WR 91 con las regiones de formación estelar RCW 121 y RCW 122. Como resultado se encontró la presencia de un complejo molecular gigante $\left(M \sim 1,2 \times 10^{6} M_{\odot}\right)$ dentro del cual existen dos concentraciones mas pequeñas asociadas a RCW 121 y RCW 122. Estas concentraciones poseen contrapartes muy intensas en infrarrojo medio y lejano (MSX y IRAS) así como también en continuo de radio entre 2,4 y 14,35 $\mathrm{GHz}(\mathrm{RCW} 121)$ y 0,408 y $300 \mathrm{GHz}$ (RCW 122) las que indican una emisión de origen térmico. El análisis llevado a cabo no indica relación alguna existente entre las estrellas del cúmulo y las estrellas WR 87, WR 89 y WR 91 con las regiones de formación estelar RCW 121 y RCW 122 y su complejo molecular asociado.

Como resultado de este estudio se confeccionó un trabajo que fue publicado en la revista Astronomy \& Astrophysics (2008, A\&A, 486, 807A). Mi partici- 
pación en el mismo consistió en la reducción y el análisis de los datos de CO; también participé activamente en el análisis de los datos de IR y continuo de radio. También estuvieron a mi cargo la confección de las figuras publicadas.

A continuación se presenta el trabajo como fue aceptado para su publicación. Al finalizar el mismo y a modo de completitud, se desarrollan algunos conceptos y figuras relacionados al análisis realizado a la componente molecular asociada a las regiones HII RCW 121 y RC 122 y que no pudieron ser presentados en dicha publicación. Estos conceptos no fueron desarrollados en forma general en el Capítulo 3, ya que los mismos sólo fueron empleados para el estudio de las regiones HII mencionadas anteriormente. 


\subsection{Algunos conceptos adicionales del análi- sis realizado a la componente molecular asociada a RCW 121 y RCW 122}

El análisis cinemático, tanto cualitativo como cuantitativo de la componente molecular asociada a RCW 121 y RCW 122, se basó fundamentalmente en el estudio de los momentos de la línea de CO.

Los momentos estudiados fueron:

- Momento de orden 0 (Area debajo de la línea):

$$
M^{0}=\int_{v_{1}}^{v_{2}} T_{b}(v) d v \quad\left(K k m s^{-1}\right)
$$

- Momento de orden 1 (Velocidad de la línea):

$$
M^{1}=<V>=\frac{\int_{v_{1}}^{v_{2}} v T_{b}(v) d v}{\int_{v_{1}}^{v_{2}} T_{b}(v) d v} \quad\left(k m s^{-1}\right)
$$

- Momento de orden 2 (Ancho de la línea):

$$
M^{2}=\left\langle V^{2}>^{1 / 2}=\left(\frac{\int_{v_{1}}^{v_{2}}(v-<V>)^{2} T_{b}(v) d v}{\int_{v_{1}}^{v_{2}} T_{b}(v) d v}\right)^{1 / 2} \quad\left(k m s^{-1}\right)\right.
$$

- Momento de orden 3 (Sesgamiento o asimetría de la línea):

$$
M^{3}=\left\langle V^{3}>^{1 / 3}=\left(\frac{\int_{v_{1}}^{v_{2}}(v-<V>)^{3} T_{b}(v) d v}{\int_{v_{1}}^{v_{2}} T_{b}(v) d v}\right)^{1 / 3} \quad\left(k m s^{-1}\right)\right.
$$

Para encontrar los momentos correspondientes a la línea de CO se utilizó la tarea MOMNT del paquete AIPS. Esta tarea realiza un despliegue espacial en graduación cromática en tono de grises de los distintos momentos de la línea molecular para distintos intervalos de integración en velocidad.

\section{Momento de orden 0:}

Este momento resultó muy útil a la hora de calcular las masas de las componentes moleculares asociadas a RCW 121 y RCW 122 y RCW 122C. Estas componentes moleculares (denominadas en la publicación Feature B, A y C respectivamente) se encuentran ubicadas sobre otra emisión molecular extendida subyacente (denominada plateau). Para el cálculo de las masas de los Features A, B y C es necesario sustraer la emisión extendida del plateau. En la Figura 7.1, se muestra la distribución del material molecular en la zona de RCW 121 y RCW 122 integrado en el rango de velocidad de -23 a $-8 \mathrm{~km} / \mathrm{seg}$. 


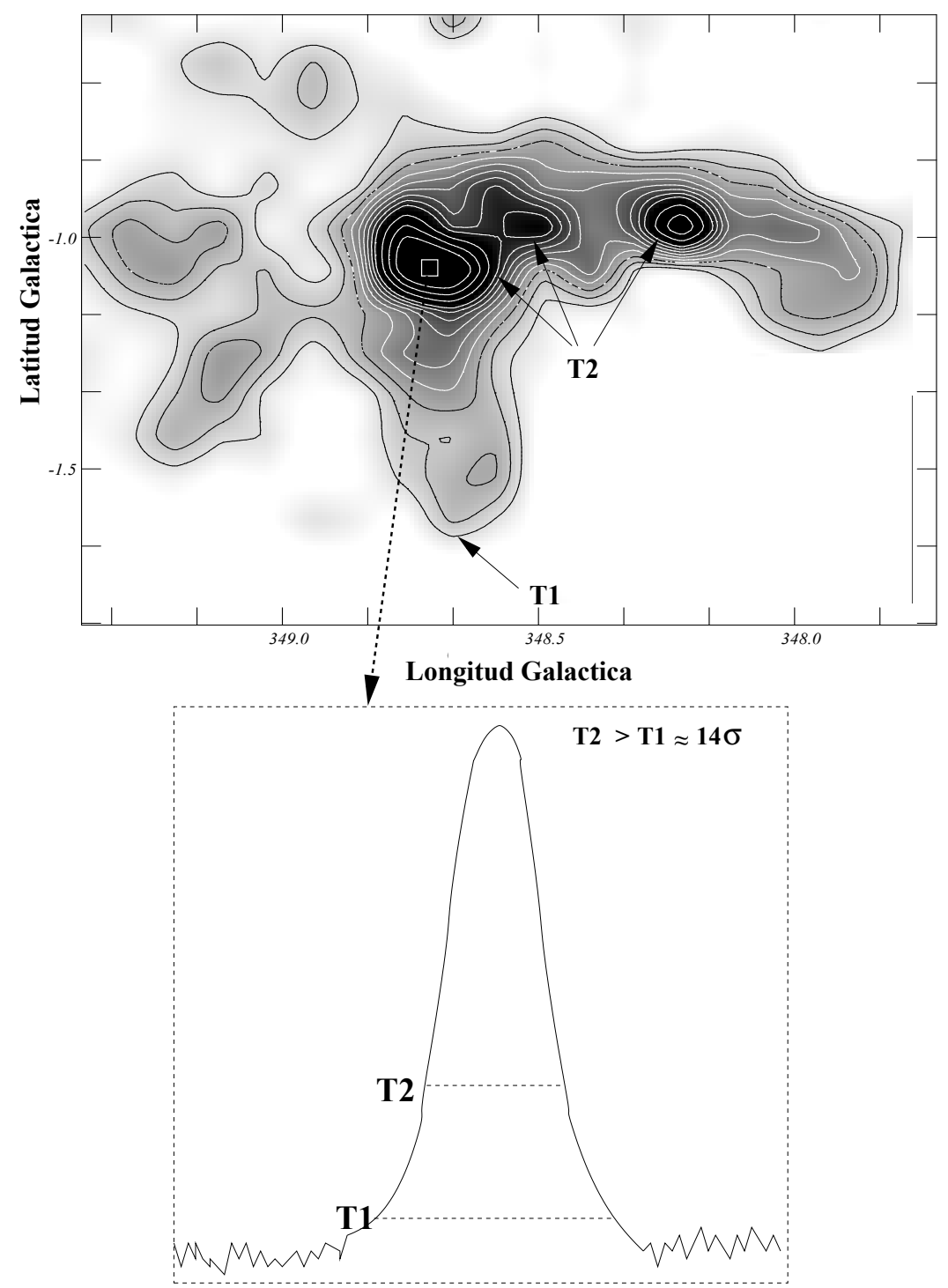

Figura 7.1: Panel superior: Complejo molecular asociado a las regiones HII RCW $121 \mathrm{y}$ RCW 122, integrado en el rango de velocidades -23 a $-8 \mathrm{~km} / \mathrm{seg}$. La temperatura T1 ( $14 \sigma$ ) es la temperatura que delimita la emisión del plateau y T2 es la que delimita la nube moleculares asociadas a las regiones HII inmersas en ella. Panel inferior: Perfil de línea que se observaría en la dirección de una de las nube moleculares internas.

En la misma pueden apreciarse las componentes moleculares asociadas a RCW 121, RCW 122 y RCW 122c, así como la emisión del plateau.

La temperatura T1 es la que se adoptó como límite para el plateau ( $14 \sigma$ ) mientras que la temperatura T2 es el primer nivel de temperatura que delimita las componentes moleculares correspondientes a RCW 121 RCW 122 y RCW 122c en el intervalo de velocidades de integración. En la parte inferior de la figura se muestra en forma esquemática las temperaturas T1 y T2 en un perfil tomado en la dirección de una de las componentes moleculares. Como 
se vio anteriormente: $N_{H_{2}}=$ cte $\times \int_{v_{1}}^{v_{2}} T_{C O}(v) d v$ con $\int_{v_{1}}^{v_{2}} T_{C O}(v) d v=$ área debajo de la línea entre las velocidades $v_{1} \mathrm{y} v_{2}$, siendo $v_{2}-v_{1}=\Delta v$ el intervalo de velocidades en el que se encuentra la estructura molecular (en este caso $v_{1}=$ $-23 \mathrm{~km} / \mathrm{seg}$ y $v_{2}=-8 \mathrm{~km} / \mathrm{seg}$ ). El área debajo de la línea puede calcularse a partir del mapa de momento de orden 0, o más precisamente con el valor promedio del momento de orden 0 dentro de la superficie ocupada por la nube molecular de interés por medio de TVSTAT. A este valor se le debe restar el valor del área debajo de la línea correpondiente a la emisión extendida. En la Figura 7.2 se esquematiza brevemente el procedimiento llevado a cabo.

La Figura 7.2a muestra el área total de la línea correspondiente a la estructura (componente molecular + emisión extendida); la Figura 7.2b muestra el área de la línea correspondiente sólo a la componente molecular; la Figura 7.2c el área de la línea correspondiente sólo a la emisión extendida. El parámetro ICUT de la tarea MOMNT representa un parámetro de corte en las mismas unidades que la imagen de entrada, es decir que valores más pequeños que ICUT serán ignorados en la imagen. El valor que se usó para para ICUT en este trabajo fue el menor valor de temperatura que encerraba a la nube molecular de interés en el intervalo de velocidades correspondiente (o sea T2 en la Figura 7.1); con este valor, el área de la línea calculada con el momento de orden 0 en la tarea MOMNT está representada en la Figura 7.2d. Es decir que el valor del área de la línea correspondiente sólo a la componente molecular es igual al valor del área calculado por MOMNT con ICUT=T2 menos el rectángulo de área $\mathrm{T} 2 \times \Delta v^{\prime}$. A diferencia de $\Delta v$, el valor de $\Delta v^{\prime}$ no se conoce, pero se lo puede calcular. Utilizando un valor de ICUT $=-\mathrm{T} 2$, el área que MOMNT calcula ahora con el momento de orden 0 para la línea, es la representada en la Figura 7.2e mientras que el ancho de la línea (calculado con el momento de orden 2) tiene un valor $\Delta v^{\prime \prime}$. Así, $\Delta v^{\prime}=\Delta v-\Delta v^{\prime \prime}$, esta última operación puede hacerse con la tarea COMB; por lo tanto la densidad de columna correspondiente sólo a la nube molecular es igual a:

$$
\mathrm{N}\left(\mathrm{H}_{2}\right)=1,9 \times 10^{20} \times\left[\text { momento orden } 0(\text { icut }=\mathrm{T} 2)-\left(\Delta v^{\prime} \times \mathrm{T} 2\right)\right]
$$

Las masas de las componentes moleculares se obtuvieron a partir de la densidad de columna como se vio anteriormente. Es importante destacar que este proceso debió hacerse para cada componente molecular en cada uno de los intervalos de velocidades en los que éstas se encontraban, para evitar la contaminación de otras estructuras que pudieran aparecer en esa misma dirección pero a otras velocidades.

\section{Momento de orden 1:}

Este momento representa el valor medio de velocidad del perfil (velocidad radial media). Considerando una línea cuya morfología pueda aproximarse a una gaussiana, este valor coincide con el valor de velocidad al cual la línea posee 


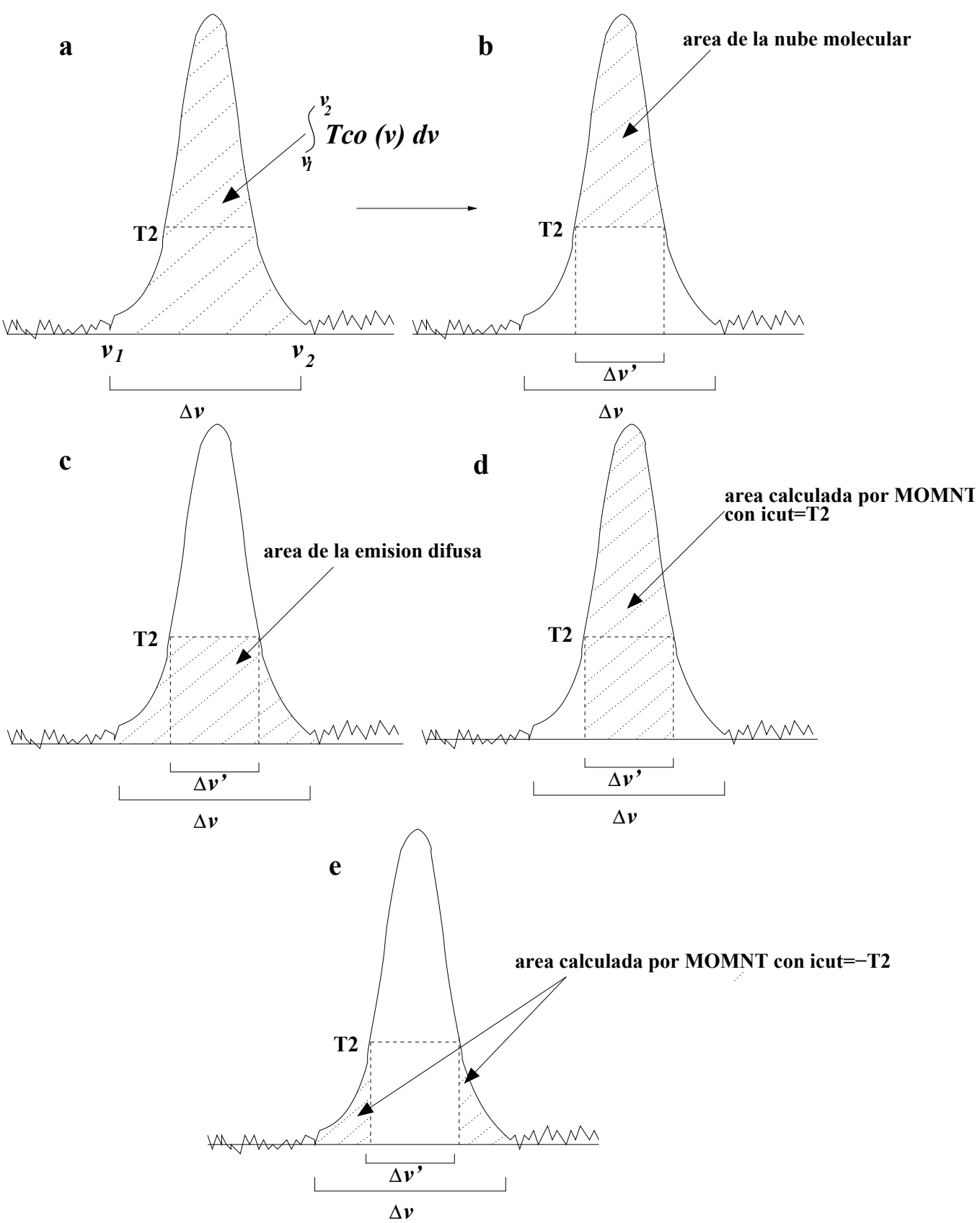

Figura 7.2: a). Área total de la línea calculada por la integral. b) Área de la línea correspondiente a la nube molecular. c) Área de la línea correspondiente a la emisión extendida. d) Área de la línea correspondiente a la nube molecular calculada con MOMNT usando ICUT=T2. e) Área de la línea correspondiente a la nube molecular calculada usando ICUT $=-\mathrm{T} 2$

su máxima temperatura (ver Figura 7.3, panel superior). La tarea MOMNT, por medio de los mapas de momento de orden 1, permite realizar imágenes de distribución de velocidades radiales medias o también llamados "perfiles de velocidad" de una componente molecular. Estas son herramientas útiles a la 
hora de estudiar la cinemática de una nube molecular.

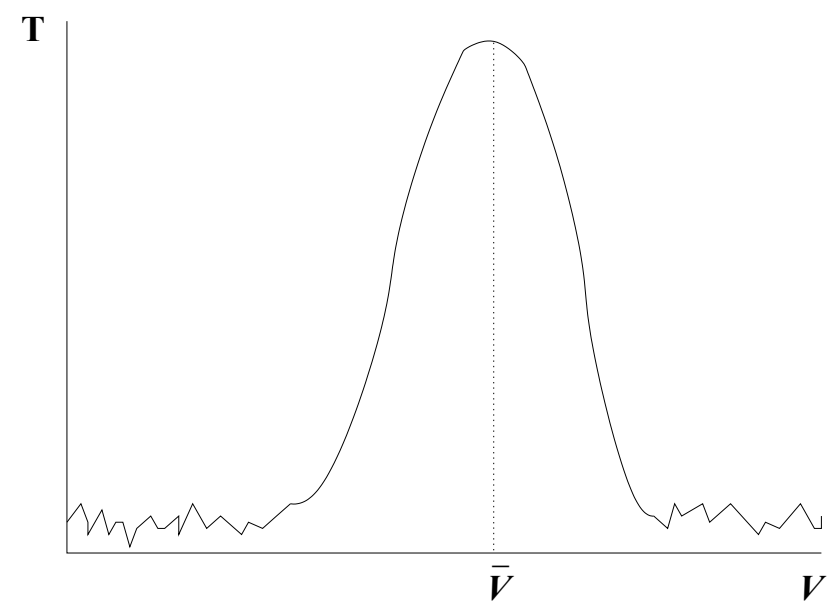

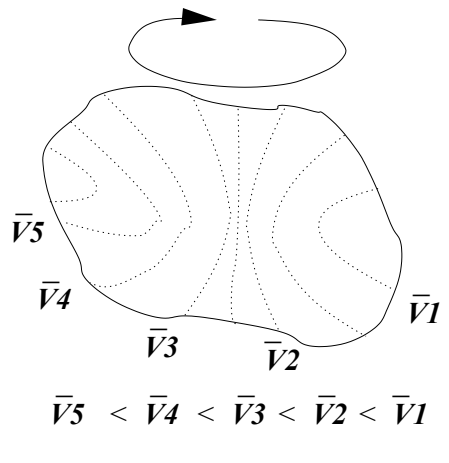

ROTACION

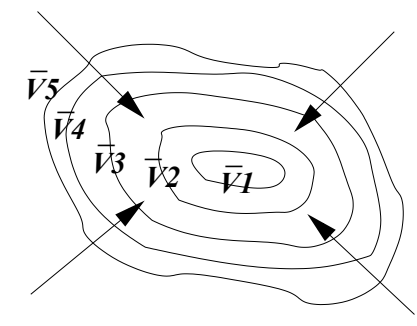

$\bar{V} 5<\overline{V 4}<\bar{V} 3<\overline{V 2}<\bar{V} 1$

CONTRACCION

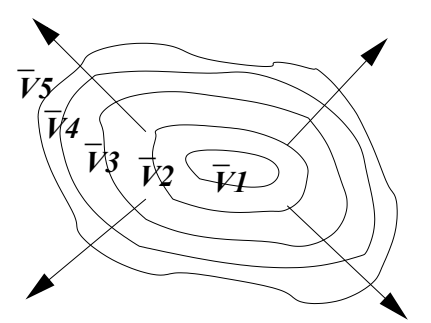

$\bar{V} 5>\bar{V} 4>\bar{V} 3>\bar{V} 2>\bar{V} 1$

EXPANSION

Figura 7.3: Panel superior: Momento de orden 1 o velocidad media del perfil. Paneles inferiores: Representación esquemática e interpretación de distintos tipos de gradientes de velocidad radial.

Al realizar un mapa de distribución de velocidades radiales medias, se pueden confeccionar sobre éstas, curvas de nivel que unan puntos de la nube con idéntica velocidad radial. Si estas curvas se distribuyen en forma paralela existe un "gradiente de velocidad". La morfología de estos gradientes permite inferir características importantes del movimiento de una nube molecular. En la Figura 7.3 (paneles inferiores), se muestran distintos gradientes de velocidad radial media y la interpretación dinámica de los mismos. Si las líneas de velocidad radial se ubican paralelamente en forma inconexa, este gradiente puede interpretarse como una rotación (Figura 7.3, panel inferior izquierdo). Por el contrario, si las líneas de velocidad radial se ubican paralelamente pero de forma conexa, este gradiente puede interpretarse como una expansión o una contracción, dependiendo hacia dónde crezcan las velocidades (Figura 7.3 paneles inferiores al medio y a la derecha)

En la Figura 7.4 se muestra el perfil de velocidad obtenido para el complejo 
molecular encontrado en la dirección de RCW 121 y RCW 122 a velocidades entre -23 y $-8 \mathrm{~km} / \mathrm{seg}$. La graduación cromática de grises representa puntos con igual velocidad radial media dentro del complejo molecular. Los valores de velocidad radial están indicados por las curvas de nivel.

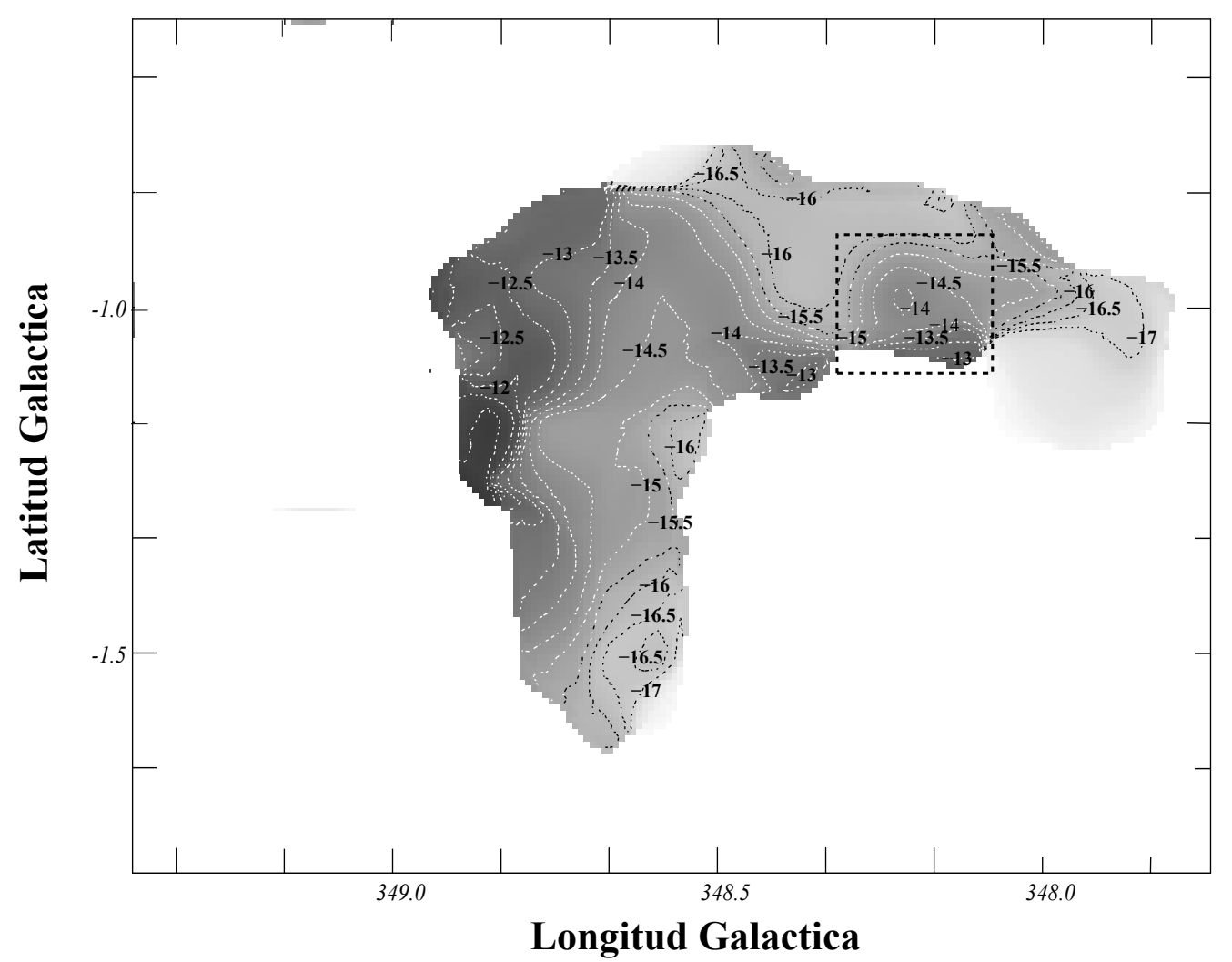

Figura 7.4: Perfil de velocidad radial (distribución de momento de orden 1) confeccionado para el complejo molecular entre -23 y $-8 \mathrm{~km} / \mathrm{seg}$.

Como puede observarse en la Figura 7.4, existen numerosas regiones en las cuales existen diversos gradientes en velocidad radial. Una de las más interesantes es tal vez la región correspondiente a RCW 121, la cual está indicada con un rectángulo en líneas de trazos. Como puede observarse, las curvas de velocidades radiales en esta región tienden a cerrarse hacia velocidades radiales más positivas. Como fue explicado, este comportamiento en la distribución espacial de la velocidad radial puede ser interpretado como una evidencia de contracción en el material molecular de la región de formación estelar.

\section{Momento de orden 2}

Este momento representa el ancho de la línea espectral. La distribución de momento de orden 2 en un determinado intervalo de velocidades permite la 
visualización de regiones en las que existe ensanchamiento de la línea. El ensanchamiento térmico de una línea espectral puede estar directamente asociado a la presencia de regiones en las cuales el campo radiativo es intenso. Por este motivo la distribución de momento de orden 2 es una excelente herramienta para la búsqueda de componentes moleculares en las que se esté desarrollando la formación estelar. En la Figura 7.5 se muestra la distribución de momento de orden 2 para el complejo molecular en la región de RCW 121 y RCW 122 a velocidades entre -23 y $-8 \mathrm{~km} / \mathrm{seg}$. En la misma puede observarse que las zonas en las cuales el ensanchamiento de la línea espectral de CO es mayor coinciden en posición y tamaño con RCW 121, RCW 122 y RCW 122c.

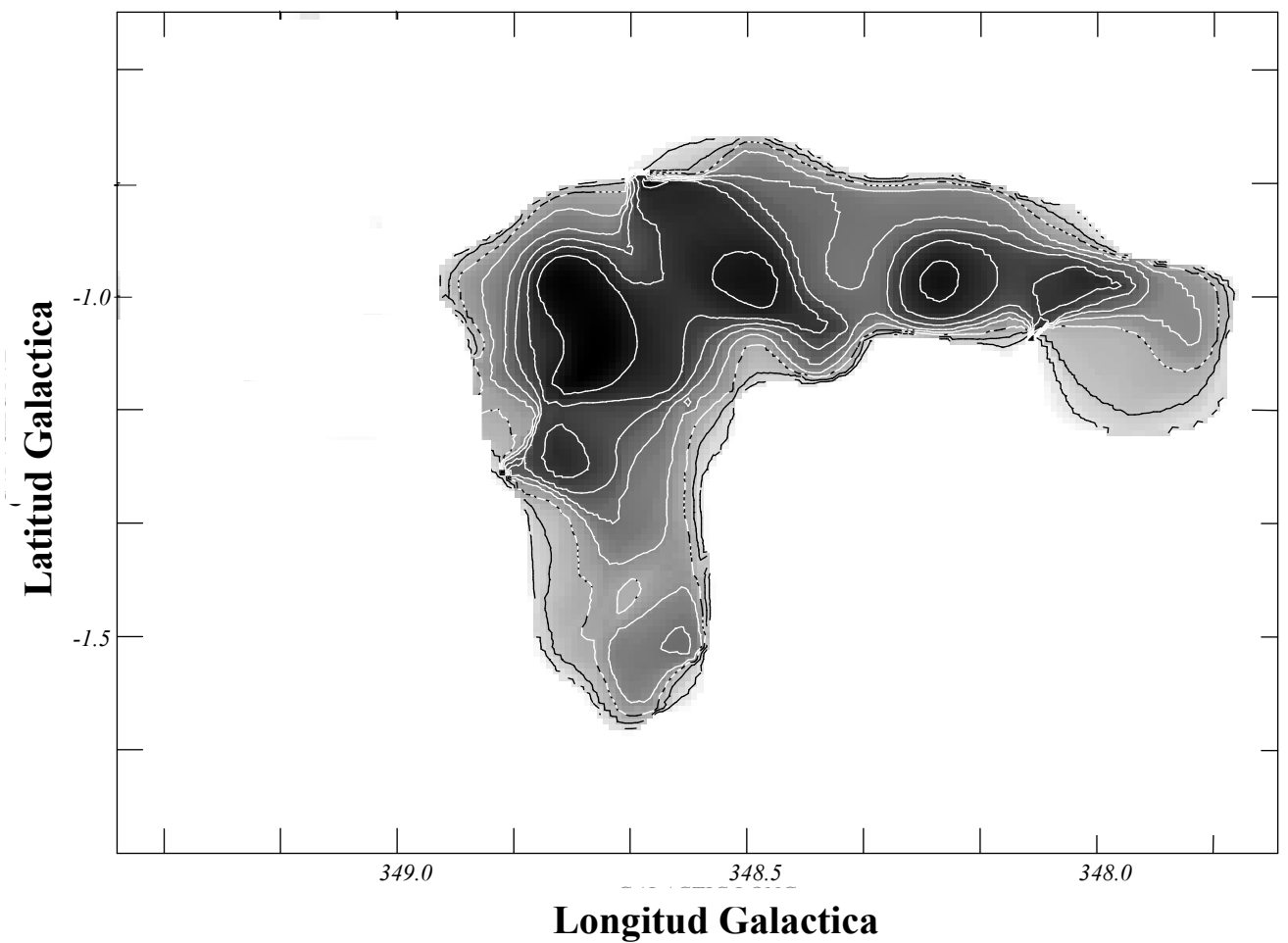

Figura 7.5: Distribución del Momento de orden 2 del complejo molecular entre -23 y -8 $\mathrm{km} / \mathrm{seg}$.

\section{Momento de orden 3}

Ésta es una cantidad mediante la cual se puede cuantificar el sesgamiento o asimetría de la línea espectral respecto del valor medio de la misma. Es otra herramienta importante en el estudio de la dinámica de una nube molecular. En la Figura 7.6 se muestra la interpretación geométrica en los perfiles de línea para los diferentes signos del momento de orden 3. A diferencia de lo que sucede con la velocidad media del perfil (momento de orden 2), un gradiente en la asimetría del perfil no tiene una interpretación directa y puede ser consecuencia de factores cinemáticos y/o instrumentales. 


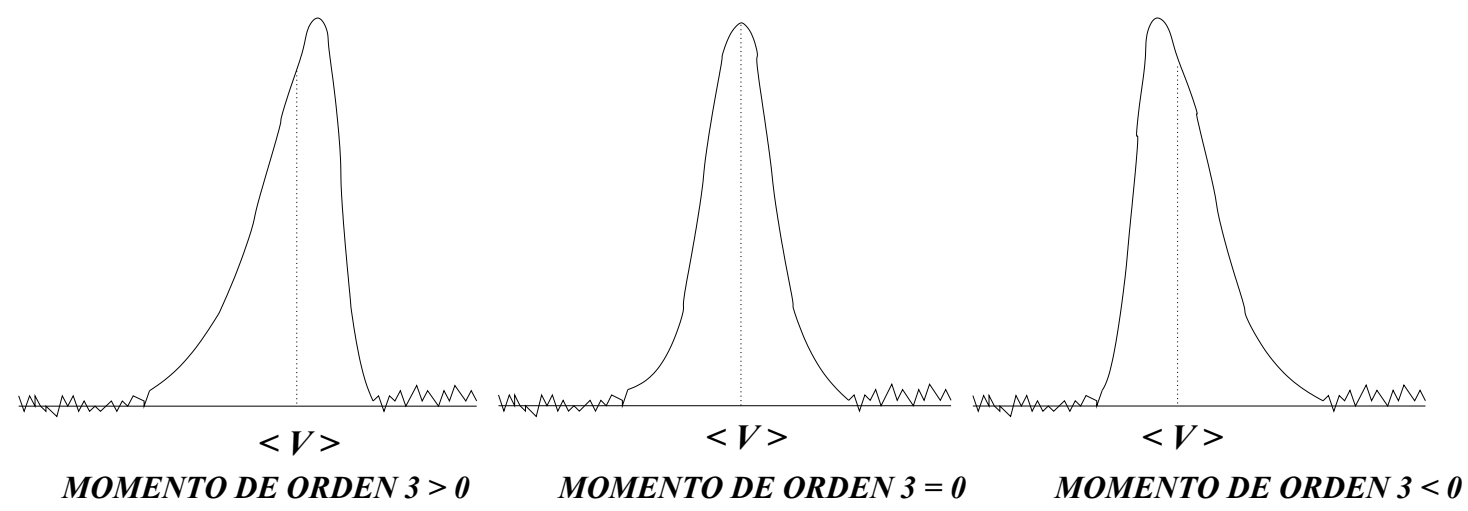

Figura 7.6: Posibles morfologías de una línea espectral acorde a distintos valores del momento de orden 3 .

En la Figura 7.7 se muestra la distribución de momento de orden 3 para el complejo molecular asociado a RCW 121 y RC 122.

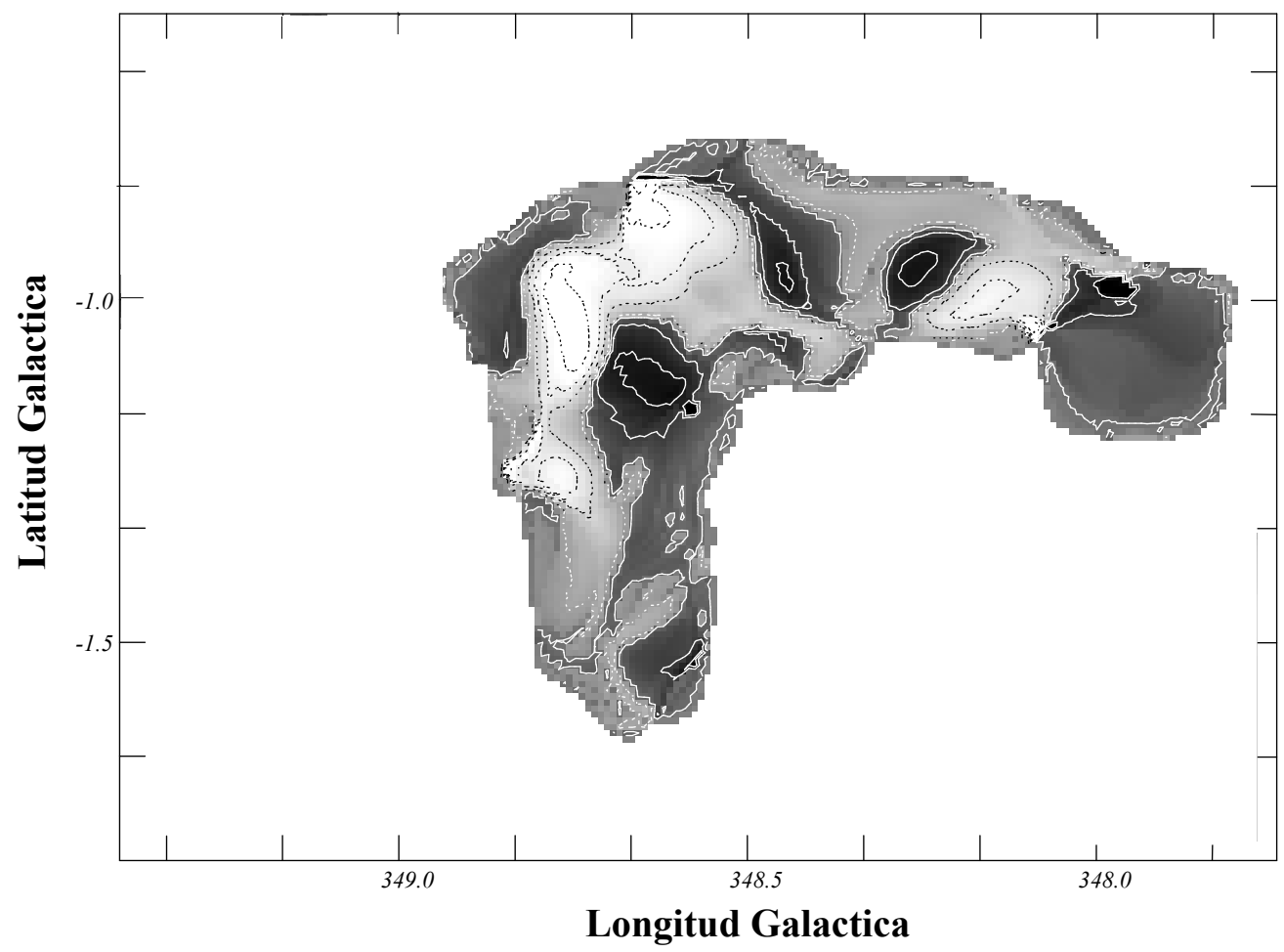

Figura 7.7: Distribución del Momento de orden 3 para el complejo molecular entre -23 y $-8 \mathrm{~km} / \mathrm{seg}$. Las regiones oscuras representan valores positivos y las zonas claras valores negativos.

Como puede observarse de la Figura 7.7, en las regiones del complejo molecular en las que se encuentran RCW 121, RCW 122 y RCW 122c, existe un gradiente notorio en el sesgamiento de la línea espectral. 


\section{Capítulo 8}

\section{El gas molecular detectado en los alrededores de las estrellas WR 14, WR 75 y WR 103}

Como fue mencionado en el Capítulo 1, los alrededores de diez estrellas WR fueron analizados en la línea $\mathrm{J}=1 \rightarrow 0$ del ${ }^{12} \mathrm{CO}$ en busca de material molecular que pudiera estar físicamente asociado a la/s estrella/s en cuestión. Algunos casos se han presentado hasta aquí, en los cuales el material molecular detectado alrededor de la estrella evidencia una posible interacción tanto con la radiación como con los vientos estelares.

A continuación se presenta un breve resumen del estudio del MIE realizado en los alrededores de las estrellas WR 14, WR 75 y WR 103, en los cuales se detectó también la presencia de gas molecular, pero que a diferencia de lo observado para WR 16, WR 18 y WR 55, no pudieron encontrarse (al menos con los datos disponibles) evidencias concluyentes de interacción entre dichas estrellas y el gas molecular detectado.

\subsection{WR 14 y la nebulosa RCW 38}

La estrella WR 14 (HD 76536), es una estrella de tipo espectral WC7 y su distancia es de $2 \mathrm{kpc}$ (van der Hucht, 2001). La estrella WR 14 se encuentra ubicada en la zona del objeto conocido como "Nebulosa de Gum". Si bien esta región es muy compleja desde el punto de vista cinemático y de emisión, la estrella se encuentra relativamente aislada de otros objetos estelares. A $\sim 40^{\prime}$ al norte de WR 14 se encuentra la región HII RCW 38 (Rodgers, Campbell \& Whiteoak, 1960). La distancia a esta nebulosa fue determinada por varios autores: Radhakrishnan et al.(1972) ( $d=1,5 \mathrm{kpc}$ ), Muzzio (1979) $(d=1,7$ kpc) y Beck, Fisher \& Smith (1991) $(d=1,7 \pm 0,9 \mathrm{kpc})$.

En la Figura 8.1 se muestra la imagen obtenida del relevamiento MSX 
banda A $(8,28 \mu \mathrm{m})$ de una zona de $\sim 86^{\prime}$ de lado centrado en la posición de WR 14.

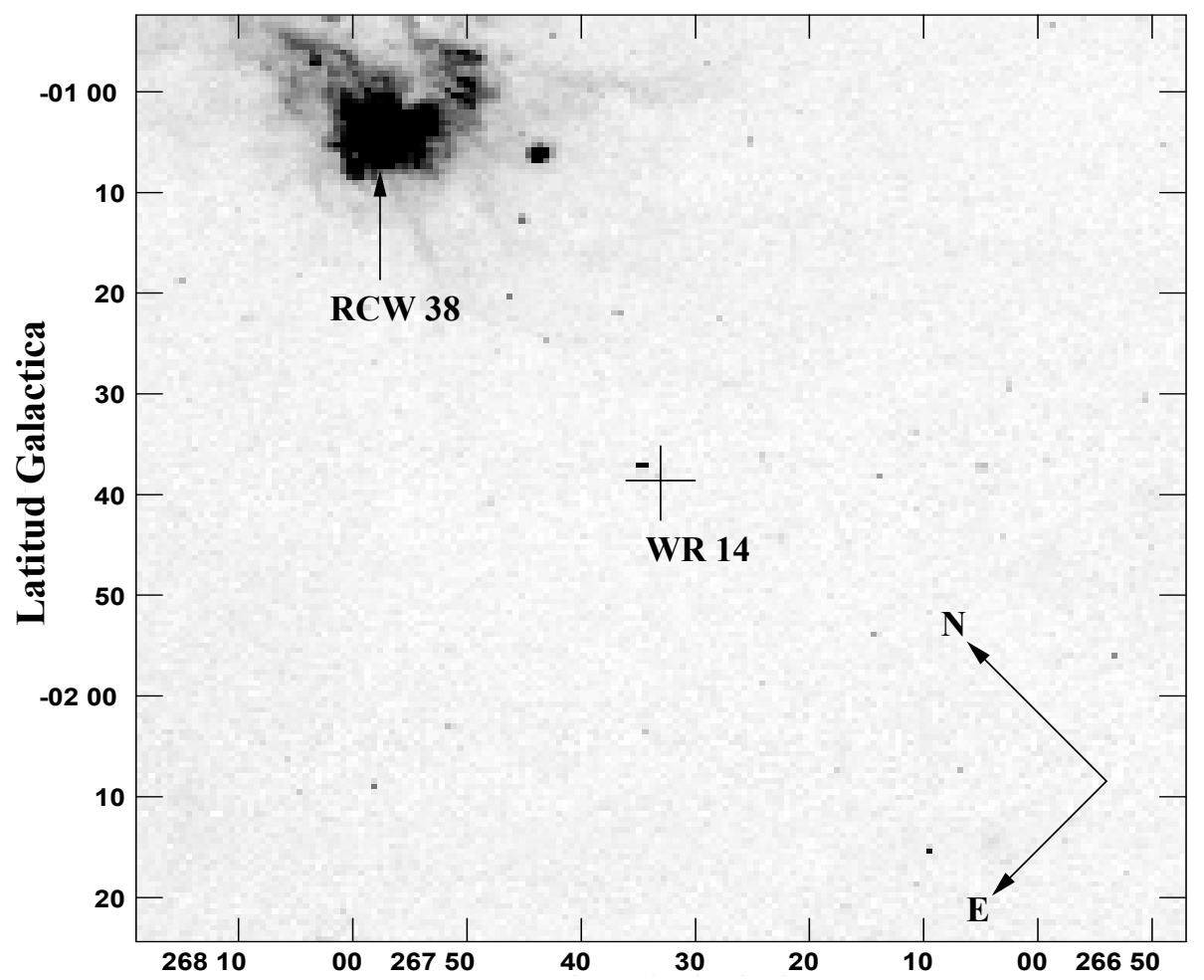

\section{Longitud Galactica}

Figura 8.1: Imagen MSX (banda A) de la zona alrededor de WR 14. La posición de la estrella y de la región HII RCW 38 están indicadas. La dirección de los ejes del sistema ecuatorial está indicada por las flechas N y E.

El análisis del MIE en los alrededores de WR 14 en el IR lejano (relevamiento IRAS) y en el continuo de radio no reveló la presencia de material ionizado y/o emisión de polvo que pudiera estar directamente asociado al campo radiativo de la estrella.

El análisis de los datos de CO muestra la presencia de material molecular a velocidades entre -6 y $20 \mathrm{~km} / \mathrm{seg}$. En la Figura 8.2 se muestra el perfil de emisión promedio obtenido en el mismo campo que la Figura 8.1, donde puede distinguirse claramente la componente molecular mencionada anteriormente. En la Figura 8.3 se muestra la distribución del CO superpuesta con la emisión MSX (banda A) integrada en intervalos de velocidad de $2 \mathrm{~km} / \mathrm{seg}$. En estas imágenes se puede observar una condensación molecular que coincide en tamaño y forma con la nebulosa RCW 38. Esta condensación es visible en el rango de velocidades de -3 a $9 \mathrm{~km} / \mathrm{seg}$. En el intervalo de velocidades de 1 a $7 \mathrm{~km} / \mathrm{seg}$, dicha condensación aparece superpuesta sobre una nube molecular 
extendida que parece rodear hacia el este, norte y oeste a la estrella WR 14.

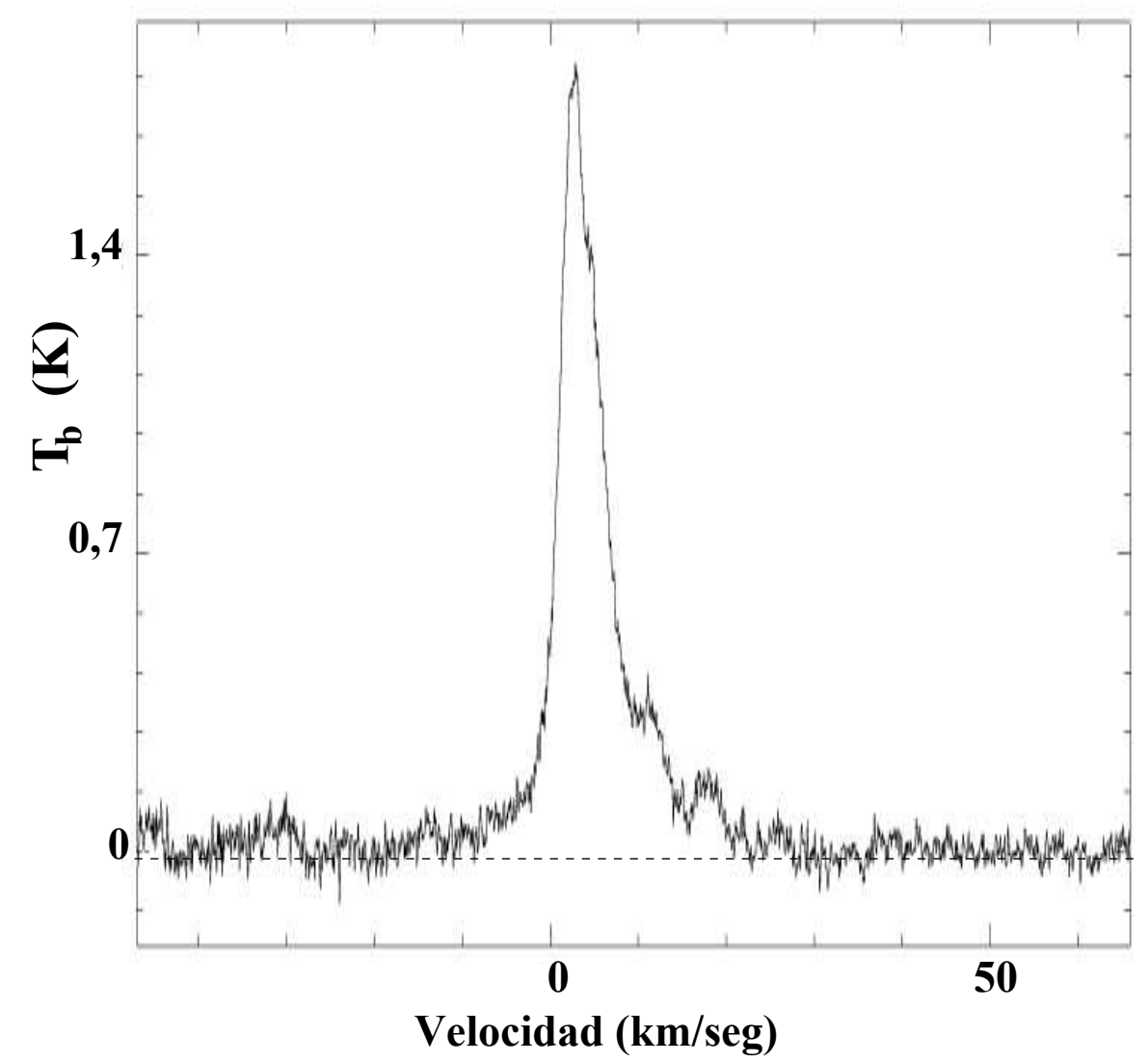

Figura 8.2: Perfil de emisión promedio del ${ }^{12} \mathrm{CO}$ en una zona de $\sim 86^{\prime}$ de lado centrada en la posición de la estrella WR 14.

El intervalo de velocidades en el que se encuentra la componente molecular que coincide con RCW 38 está en buen acuerdo con las velocidades observadas para distintas líneas en la dirección a dicha nebulosa en la bibliografía: Wilson

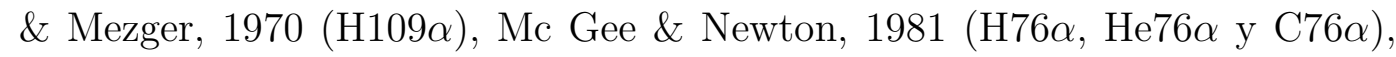
Witheoak \& Gardner, $1974\left(\mathrm{H}_{2} \mathrm{CO}\right)$, Gillespie et al., 1979 (CO J=1 $\rightarrow 0$ ), White \& Phillips, $1983(\mathrm{CO} \mathrm{J}=2 \rightarrow 1$ ), Zinchenko et al., 1995 (CS J=2 $\rightarrow 1$ ). Por lo expuesto anteriormente puede concluirse que el gas molecular detectado en el intervalo de velocidades de $\sim-3$ a $9 \mathrm{~km} / \mathrm{seg}$ muy posiblemente se encuentre asociado a la nebulosa RCW 38.

No se encontraron en la bibliografía estudios relacionados a la búsqueda de una asociación física entre la nebulosa RCW 38 y la estrella WR 14 (formación estelar secuencial?). Aunque una asociación entre ambos objetos no puede ser descartada a priori ya que las distancias a los mismos son muy similares, nuevas observaciones moleculares (preferentemente con una mayor área de cobertura) serían de gran utilidad para confirmar esta posibilidad. 

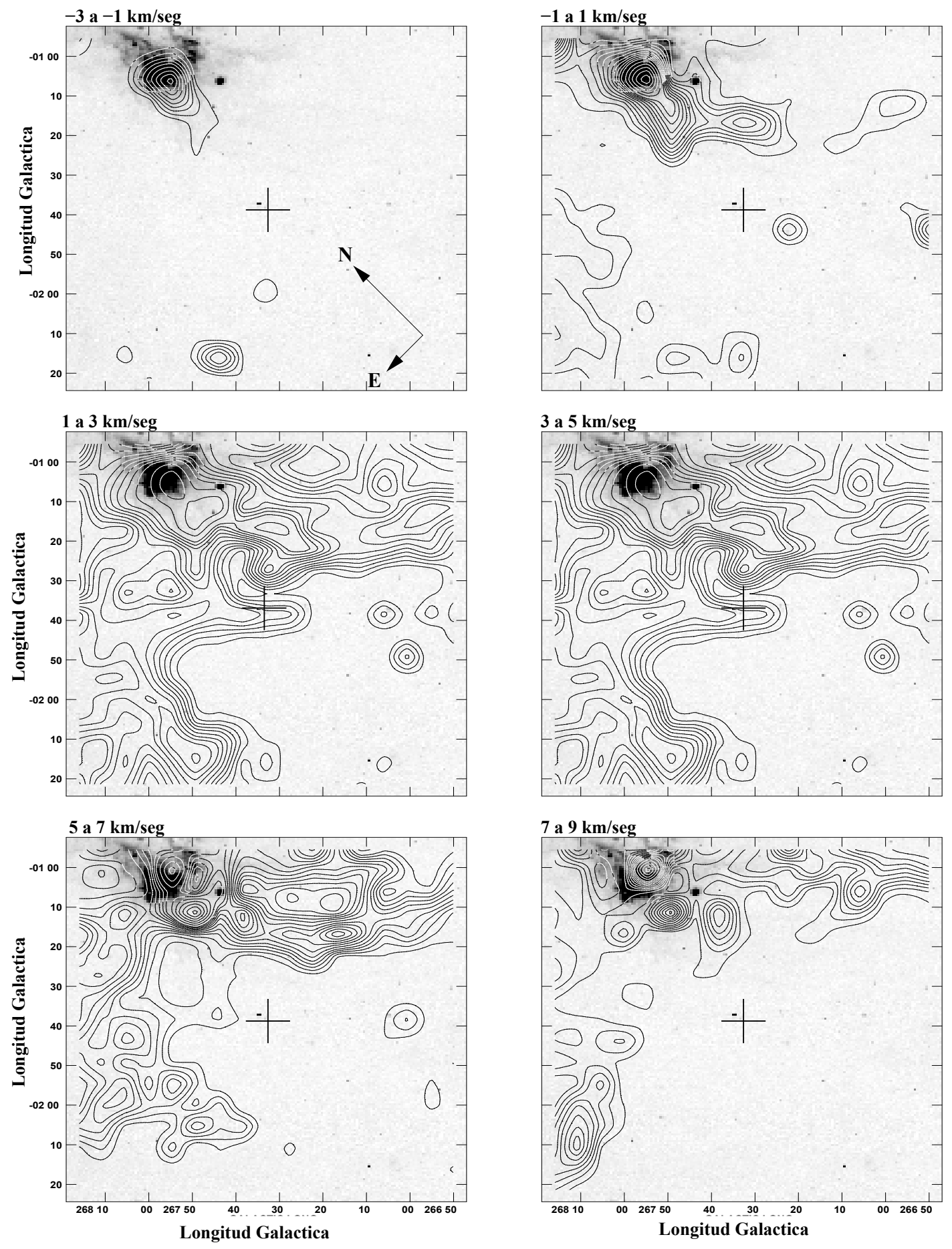

Figura 8.3: Distribución de ${ }^{12} \mathrm{CO}$ (contornos) en el rango de velocidades de -3 a $9 \mathrm{~km} / \mathrm{seg}$ superpuesto con la emisión MSX (banda A) (tono de grises). El intervalo de velocidad de cada imagen se indica arriba a la izquierda. La posición de WR 14 está indicada con la cruz. La dirección de los ejes del sistema ecuatorial está indicada por las flechas $\mathrm{N}$ y E en la imagen superior izquierda. 


\subsection{WR 75 y la nebulosa RCW 104}

La estrella WR 75 presenta evidencias de una posible interacción con el MIE, ya que se encuentra rodeada por la nebulosa RCW 104, la cual está mostrada en la Figura 8.4, obtenida del relevamiento SuperCOSMOS.

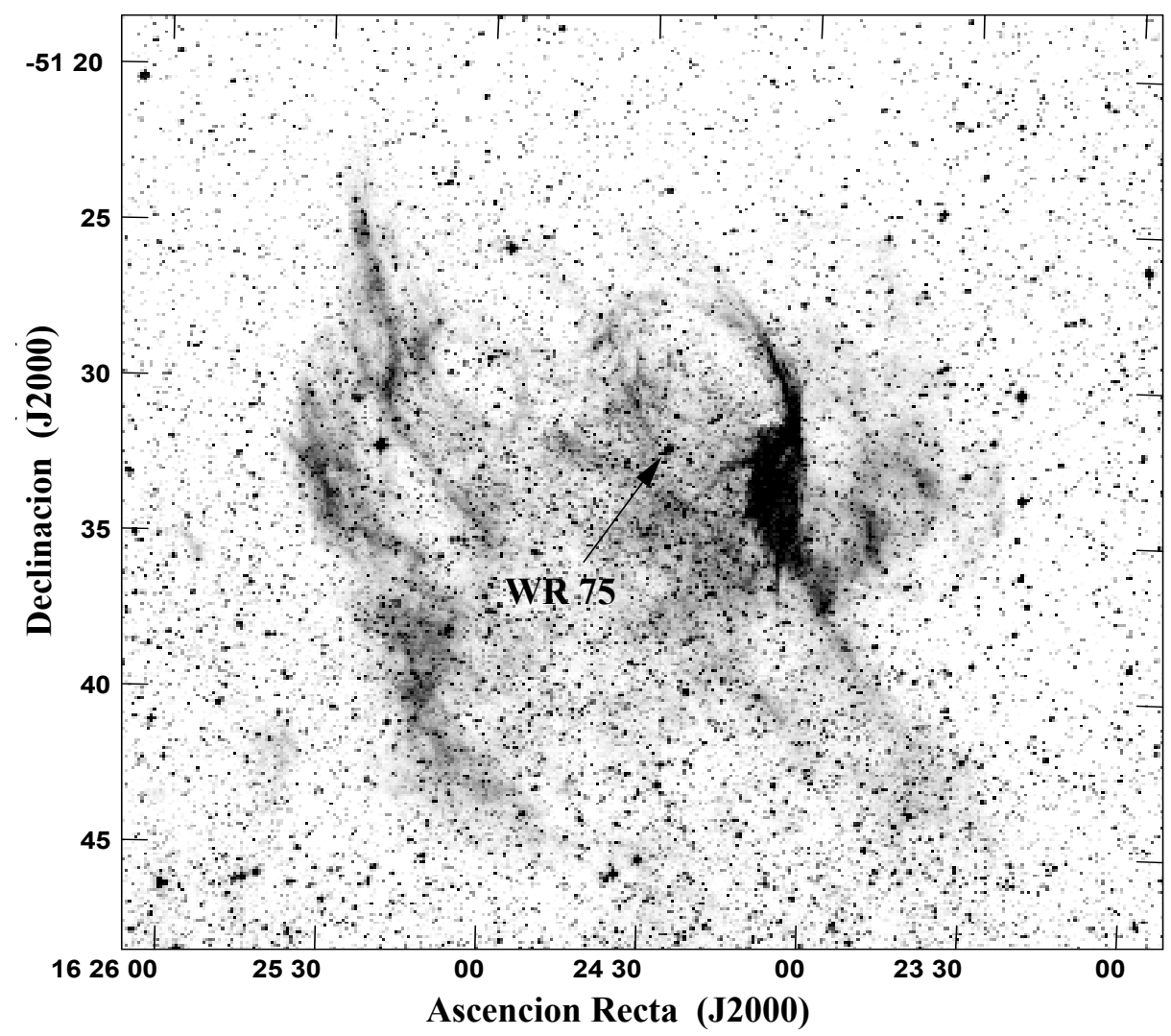

Figura 8.4: Imagen H $\alpha$ de la nebulosa RCW 104 obtenida del relevamiento SuperCOSMOS.

La nebulosa RCW 104 fue estudiada por medio de espectroscopía óptica por Chu (1982), Chu et al. (1983) y Goudis et al. (1988). Estos últimos encontraron una componente de baja velocidad a $-39 \mathrm{~km} / \mathrm{seg}\left(\mathrm{V}_{H e l}=-50 \mathrm{~km} / \mathrm{seg}\right)$ y otra de alta velocidad entre $-89 \mathrm{~km} / \mathrm{seg}\left(\mathrm{V}_{\mathrm{Hel}}=-100 \mathrm{~km} / \mathrm{seg}\right)$ y $-159 \mathrm{~km} / \mathrm{seg}$ $\left(\mathrm{V}_{H e l}=-170 \mathrm{~km} / \mathrm{seg}\right)$. Goudis et al. (1988) plantean que una simple expansión no es suficiente explicación y proponen que existen flujos de masa estelar generando choques (bow shocks) alrededor de núcleos densos que rodean a la nebulosa. Proponen también que habría gas difuso ionizado por WR 75 . Como fue mencionado en el Capítulo 1, Marston et al. (1999) estudiaron la distribución del $\mathrm{CO}$ en los alrededores de WR 75 utilizando observaciones del radiotelescopio SEST. Estos autores encontraron que el gas molecular estaba presente en dos componentes cuyos intervalos de velocidad eran similares a los observados por Goudis et al. (1988). 

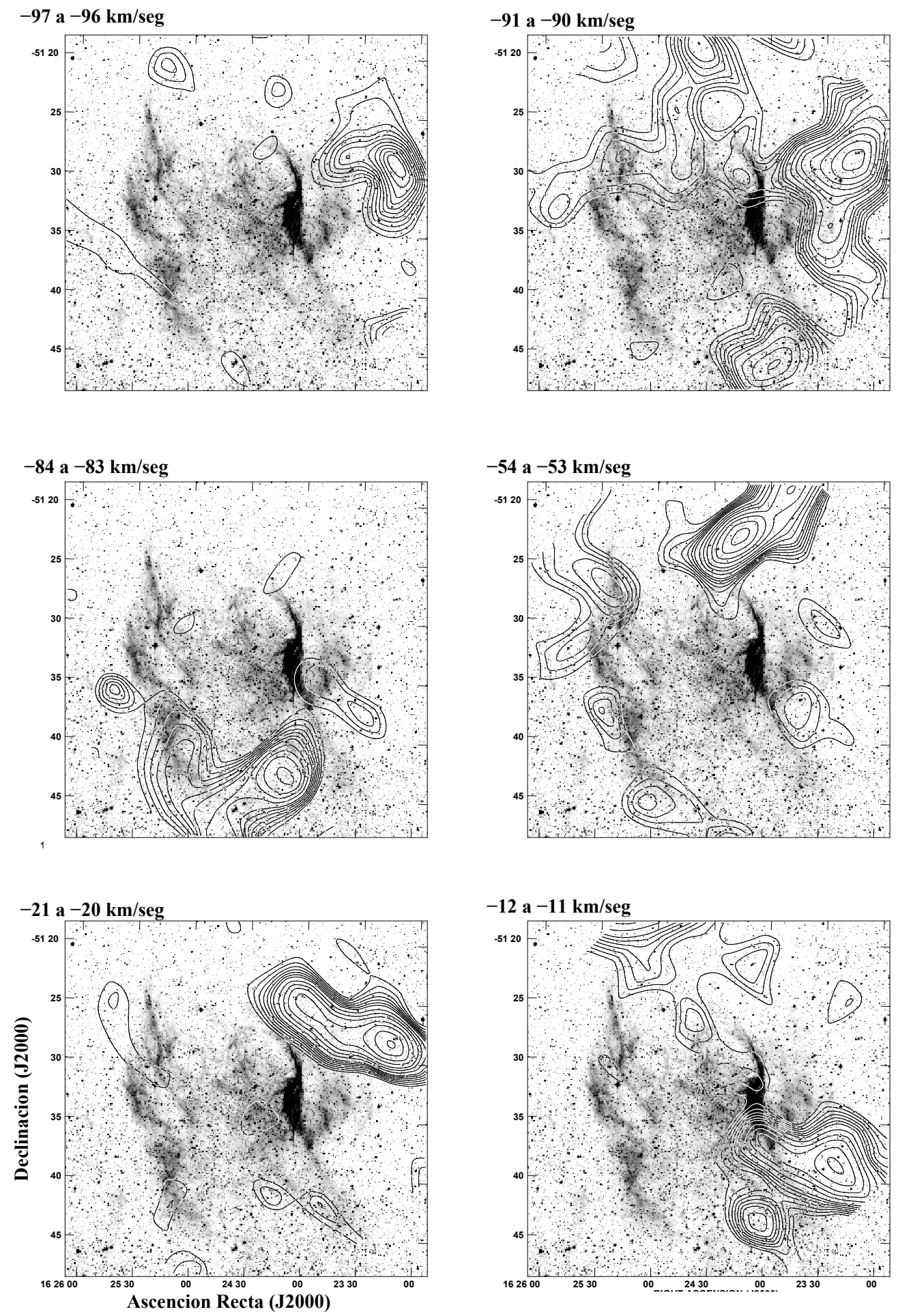

Figura 8.5: Imágenes de la emisión integrada de $\mathrm{CO}$ en intervalos de velocidad de $1 \mathrm{~km} / \mathrm{seg}$, superpuestos con la emisión $\mathrm{H} \alpha$ de RCW 104. Los niveles de contorno van de $0,2 \mathrm{~K}(\sim 5 \sigma)$ hasta $0,7 \mathrm{~K}$ en intervalos de $0,07 \mathrm{~K}$, y desde $1 \mathrm{~K}$ en intervalos de $0,14 \mathrm{~K}$. 
El análisis del CO realizado con los datos de NANTEN revela la presencia de numerosas componentes moleculares en la posición de la nebulosa RCW 104 en un rango de velocidades que va desde -100 hasta $10 \mathrm{~km} / \mathrm{seg}$. Muchas de estas componentes están presentes en intervalos de velocidad muy pequeños $(\sim$ $0,5 \mathrm{~km} / \mathrm{seg}$ ). En la Figura 8.5 se muestran imágenes de la distribución espacial de CO integradas en intervalos de velocidad de $1 \mathrm{~km} / \mathrm{seg}$ superpuestas con la imagen $\mathrm{H} \alpha$ de RCW 104, para aquellas componentes moleculares que están presentes en intervalos de velocidad más extensos ( $\sim 2 \mathrm{~km} / \mathrm{seg}$ o más).

La observación de otras líneas moleculares permitiría un estudio más completo del gas molecular en las cercanías de RCW 104. Observaciones de la línea $\mathrm{J}=1 \rightarrow 0$ del ${ }^{13} \mathrm{CO}$ podrían complementarse con las ya existentes de la línea $\mathrm{J}=1 \rightarrow 0$ del ${ }^{12} \mathrm{CO}$ con el fin de determinar sin ambigüedad las masas de las componentes moleculares encontradas y así poder establecer de forma más exacta el origen de las mismas (estelar o interestelar?). Por otro lado, observaciones de la línea $\mathrm{J}=2 \rightarrow 1$ del ${ }^{12} \mathrm{CO}$ podrían también complementarse con las de $\mathrm{J}=1 \rightarrow 0$ del ${ }^{12} \mathrm{CO}$ para estudiar las condiciones de excitación de las nubes moleculares detectadas (Sakamoto et al., 1997). Ante la posibilidad de la obtención en un futuro de las observaciones moleculares anteriormente descriptas, el estudio de esta nebulosa fue postergado para una etapa posterior al desarrollo de esta Tesis Doctoral.

\subsection{WR 103}

$\mathrm{Al}$ igual que en todos los casos presentados hasta aquí, el MIE en los alrededores de la estrella WR 103 fue analizado en distintas frecuencias con el fin de encontrar evidencias de interacción entre esta estrella y el medio circundante.

El análisis de los datos de CO de NANTEN, reveló la presencia de una única componente molecular, en el intervalo de velocidad comprendido entre 0 y $10 \mathrm{~km} / \mathrm{seg}$. En la Figura 8.6 se muestra el perfil de emisión promedio en un área de $\sim 90^{\prime}$ de lado centrada en la estrella WR 103 donde puede apreciarse la componente molecular mencionada anteriormente. En la Figura 8.7 se muestra la distribución espacial del CO integrada en el intervalo de velocidad de 4 a $8 \mathrm{~km} / \mathrm{seg}$. En dicha figura puede observarse que la distribución espacial del material molecular en este rango de velocidades rodea en forma parcial a la estrella WR 103, la cual está ubicada en el centro del campo.

No pudieron encontrarse estructuras en el IR lejano (relevamiento IRAS) o medio (relevamiento MSX) que pudieran ser relacionadas con la estrella. La búsqueda de gas ionizado por medio del análisis de la emisión en el continuo de radio y en la línea $\mathrm{H} \alpha$ arrojó también resultados negativos. El mismo resultado 
se obtuvo en el análisis de la línea de $\lambda=21 \mathrm{~cm}$ del HI.

La particular morfología de la componente molecular observada en el intervalo de velocidad de 4 a $8 \mathrm{~km} / \mathrm{seg}$ en las cercanías de WR 103 podría sugerir una posible interacción entre el gas molecular y los vientos de la estrella, similar a la encontrada entre la estrella WR 16 y la componente molecular denominada AME, o también a la encontrada entre la estrella WR 55 y el complejo molecular denominado CM234.

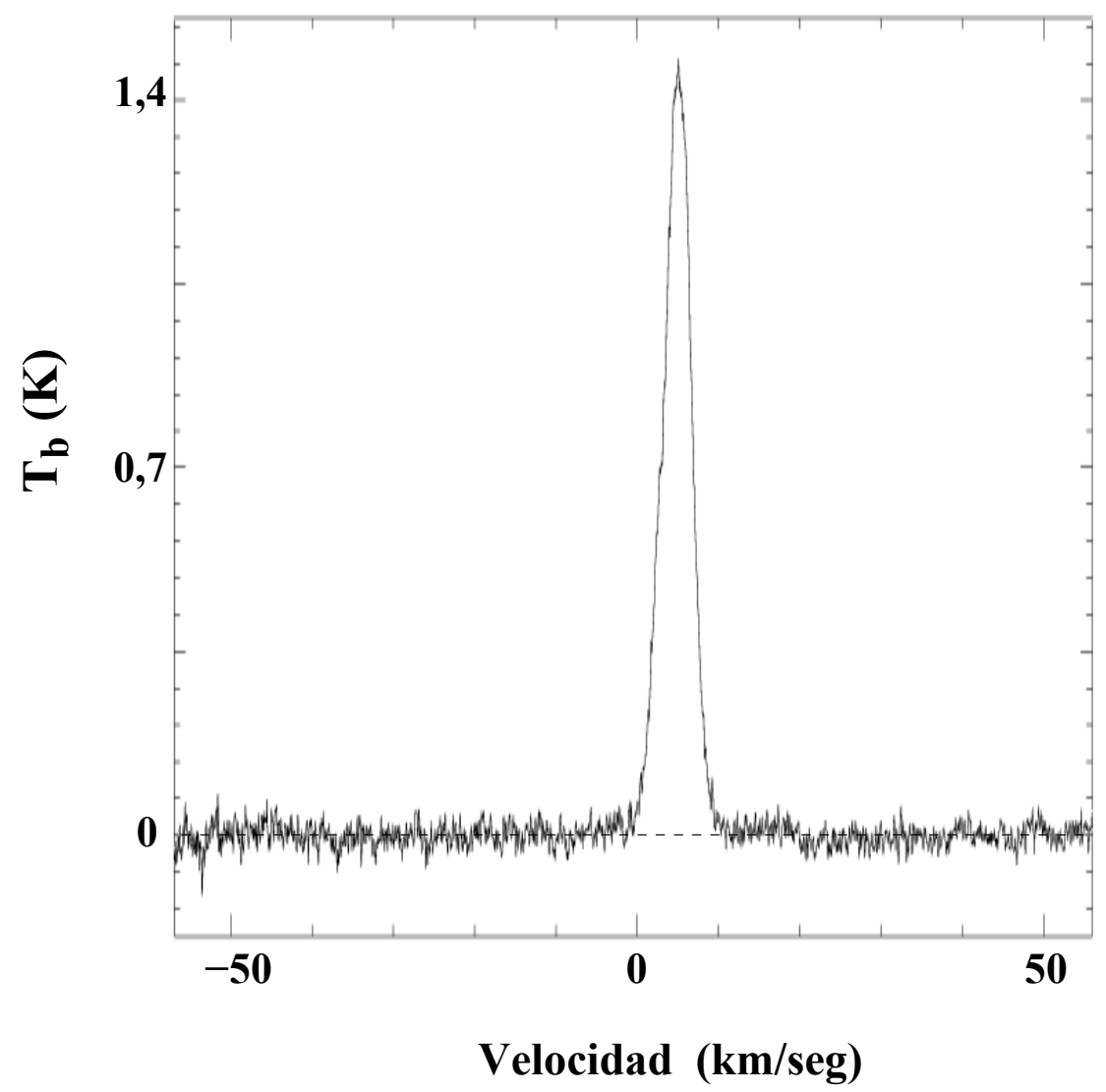

Figura 8.6: Emisión promedio de ${ }^{12} \mathrm{CO}$ en un área de $\sim 86^{\prime}$ de lado centrada en la posición de la estrella WR 103

La falta de emisión detectable en otras frecuencias alrededor de WR 103, hace que sea muy difícil establecer la existencia de una posible interacción entre esta estrella y la componente molecular mencionada anteriormente. Además, debido a la posición de la estrella casi en la dirección del centro galáctico $(l=$ $\left.358^{\circ} 29^{\prime} 05^{\prime \prime}, b=-04^{\circ} 53^{\prime} 29^{\prime \prime}\right)$, no se puede determinar una distancia cinemática confiable para la componente molecular utilizando la curva de rotación galáctica, ya que la misma posee grandes fuentes de error en esta dirección. Por este 
motivo, no es posible hacer una comparación de distancias entre la estrella y la compoente molecular.

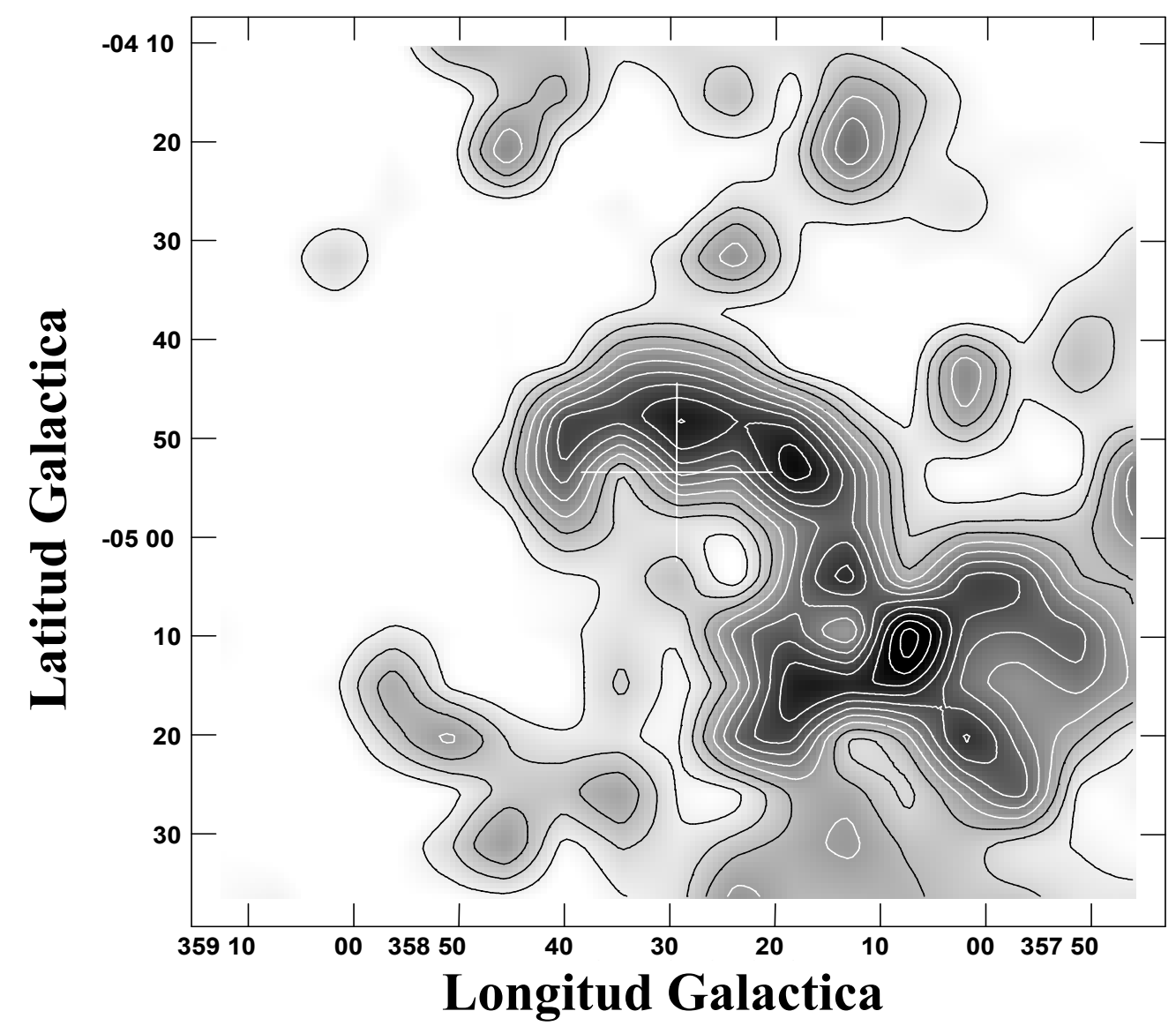

Figura 8.7: Distribución del ${ }^{12} \mathrm{CO}$ integrada en el rango de velocidad 4 a $8 \mathrm{~km} / \mathrm{seg}$. La posición de WR 103 está indicada por la cruz en el centro del campo. 


\subsection{Bibliografía}

- Beck S. C., Fischer J., Smith H. A., 1991, ApJ, 383,336

- Chu, Y.-H., 1982, ApJ, 254, 578C

- Chu, Y.-H.; Treffers, R. R.; Kwitter, K. B., 1983, ApJS, 53, 937C

- Gillespie, A. R.; White, G. J.; Watt, G. D., 1979, MNRAS, 186, 383G

- Goudis, C. D.; Meaburn, J.; Whitehead, M. J., 1988, A\&A, 191, 341G

- Marston, A. P.; Welzmiller, J. T.; Bransford, M. A.; Black, J. H.; Bergman, P., 1999, IAUS, 193, 370M

- McGee, R. X.; Newton, L. M., 1981, MNRAS, 196, 889M

- Muzzio J. C., 1979, AJ, 84, 639

- Radhakrishnan V., Goss W. M., Murray J. D., Brook J. W., 1972, ApJS, 24,49

- Rodgers A. W., Campbell C. T., Whiteoak J. B., 1960, MNRAS, 121, 123

- Sakamoto S., Hasegawa T., Handa T., Hayashi M., Oka T., 1997, ApJ, 486, 276.

- van der Hucht, K. A., 2001, NAR, 45, 135

- Wilson, T. L.; Mezger, P. G.; Gardner, F. F.; Milne, D. K., 1970, A\&A, $6,364 \mathrm{~W}$

- White, G. J.; Phillips, J. P., 1983, MNRAS, 202, 255W

- Whiteoak, J. B.; Gardner, F. F., 1974, A\&A, 37, 389W

- Zinchenko, I.; Lapinov, A.; Mattila, K.; Toriseva, M., 1995, Ap\&SS, 224, $585 \mathrm{Z}$ 


\section{Capítulo 9}

\section{Resumen general y Conclusiones}

A lo largo de esta Tesis Doctoral, se ha analizado el MIE en los alrededores de diez estrellas WR galácticas mediante un estudio multifrecuencia del mismo, prestando especial atención a la emisión del gas molecular a través del estudio de la línea rotacional $\mathrm{J}=1 \rightarrow 0$ de la molécula de ${ }^{12} \mathrm{CO}$ como trazadora. El objetivo de este análisis fue estudiar el medio circundante a dichas estrellas a fin de comparar los resultados obtenidos con los predichos por las teorías vigentes de la interacción de las estrellas de gran masa con el medio interestelar.

A continuación se presenta un breve resumen de los resultados obtenidos y posteriormente se expondrán las conclusiones e implicancias que de estos pueden desprenderse.

\subsection{Resumen}

En la Tabla 9.1 se presentan las características generales observadas del MIE en los alrededores de las estrellas estudiadas. En la misma se detalla la existencia o no existencia de nebulosas ópticas asociadas (emisión $\mathrm{H} \alpha$ ), emisión en continuo de radio y continuo infrarrojo, así como también la presencia de estructuras de gas atómico y/o molecular que pudieran estar físicamente asociadas a la estrella en cuestión.

De manera general, puede resumirse que:

- De las diez estrellas estudiadas, siete de ellas exhiben nebulosas ópticas asociadas, lo cual indica una interacción de la radiación estelar con el MIE circundante. En el caso de la nebulosa observada alrededor de WR 87 y WR 89, la formación de la misma puede estar más posiblemente asociada a las otras estrellas de gran masa pertenecientes al cúmulo HM1. 
Tabla 9.1: Características generales del MIE en los alrededores de las estrellas estudiadas.

\begin{tabular}{|c|c|c|c|c|c|c|}
\hline Estrella & $\begin{array}{l}\text { Óptico } \\
(\mathrm{H} \alpha)\end{array}$ & $\begin{array}{c}\text { Cont. } \\
\text { de radio }\end{array}$ & Infrarrojo & $\begin{array}{c}\mathrm{HI} \\
(\lambda=21 \mathrm{~cm})\end{array}$ & $\begin{array}{l}\mathrm{CO}\left(\mathrm{H}_{2}\right) \\
\text { (estelar) } \\
\end{array}$ & $\begin{array}{c}\mathrm{CO}\left(\mathrm{H}_{2}\right) \\
\text { (interestelar) }\end{array}$ \\
\hline WR 16 & $x$ & & $x$ & & $x$ & $x$ \\
\hline WR 14 & X & & & & & $?^{(\dagger)}$ \\
\hline WR 18 & $x$ & $x$ & $x$ & $x$ & $\mathrm{P}$ & $x$ \\
\hline WR 55 & $x$ & $x$ & $x$ & & $\mathrm{P}$ & $x$ \\
\hline WR 68 & $x$ & & $x$ & & $\mathrm{P}$ & $\mathrm{P}$ \\
\hline WR 75 & $x$ & & $x$ & & $\mathrm{P}$ & $\mathrm{P}$ \\
\hline WR 87 & $\mathrm{P}^{(\ddagger)}$ & $\mathrm{P}^{(\ddagger)}$ & $\mathrm{P}^{(\ddagger)}$ & & & \\
\hline WR 89 & $\mathrm{P}^{(\ddagger)}$ & $P^{(\ddagger)}$ & $\mathrm{P}^{(\ddagger)}$ & & & \\
\hline WR 91 & & & & & & \\
\hline WR 103 & & & & & $\mathrm{P}$ & $\mathrm{P}$ \\
\hline
\end{tabular}

$X:$ Presente

P: Probable

?: Dudoso

$(\dagger)$ : Material molecular posiblemente asociado a RCW 38.

(†): Emisión posiblemente asociada al cúmulo abierto HM1. 
- El origen de la emisión de las nebulosas ópticas encontradas alrededor de las estrellas WR 16 y WR 55, proviene de la ionización directa del gas molecular en las cercanías de dichas estrellas. Además, las características cinemáticas encontradas en dichas componentes moleculares sugieren una interacción entre las mismas y el viento estelar. Similares podrían ser los casos de WR 68 y WR 75.

- En el caso de WR 18 la ionización observada en la zona más intensa de la nebulosa asociada (NGC 3199) no parece originarse en el gas molecular sino más bien en el gas neutro (HI) que se encuentra en la dirección del movimiento de la estrella. Este es el único caso en el que se encontró una componente de gas neutro asociada a la nebulosa óptica.

- En el caso de WR 16 se pudo determinar la presencia inequívoca de componentes moleculares de origen estelar e interestelar espacialmente separadas, debido a las características morfológicas y cinemáticas de las mismas. Estas componentes sugieren que la evolución de esta estrella se llevó a cabo en varias etapas, cada una de las cuales posee distintas características. Este hecho puede corroborarse también por la presencia de una nebulosa anillo múltiple alrededor de la estrella.

- La nebulosa asociada a las estrellas WR 87, WR 89 y al cúmulo HM1 no posee una contraparte neutra y/o molecular. Por otro lado, el gas molecular observado hacia menores latitudes galácticas está asociado con las regiones de formación estelar RCW 121 y RCW 122; es decir que no existen pruebas que indiquen que las regiones de formación estelar RCW 121 y RCW 122 son el resultado de un proceso de formación estelar inducido por WR 87, WR 89 y HM1.

- Las regiones HII RCW 121 y RCW 122 constituyen dos regiones de formación estelar separadas espacialmente pero pertenecientes a un mismo complejo molecular gigante. El gas molecular correspondiente a estas nebulosas presenta interesantes características dinámicas y cinemáticas muy probablemente originadas por procesos físicos que están ocurriendo en su interior.

\subsection{Conclusiones}

A continuación se presentan las principales conclusiones que pudieron ser derivadas a partir de los resultados obtenidos a lo largo de esta Tesis Doctoral. 
En forma general puede concluirse que:

a) El gas molecular asociado a nebulosas ópticas alrededor de estrellas WR presenta una gran complejidad en su movimiento. Un análisis minucioso de la línea rotacional $\mathrm{J}=1 \rightarrow 0$ del ${ }^{12} \mathrm{CO}$ (la cual es una excelente trazadora de la distribución del $\mathrm{H}_{2}$ ) permite concluir que la dificultad observada en la cinemática de la misma excede a la de una cáscara en expansión planteada por la teoría de BI.

b) La íntima asociación morfológica existente entre el gas molecular y el gas ionizado (observado a través de emisión de la línea $\mathrm{H} \alpha$ y en el continuo de radio) en las nebulosas alrededor de estrellas WR, permite concluir que las mismas (o al menos una parte de ellas) puedan ser originadas por la ionización directa de componentes de gas molecular de origen estelar o interestelar que están ubicadas próximas a la estrella. La ionización puede originarse también del gas interestelar neutro.

Esto podría significar que la detección de nebulosas ópticas alrededor de estrellas WR (o estrellas de gran masa) podría depender de la existencia de gas molecular capaz de ser ionizado en las cercanías de las mismas.

c) La observación de líneas moleculares alrededor de estrellas WR permite además estudiar la componente molecular de las eyecciones provenientes de la estrella en etapas más tempranas de su evolución.

d) En base a lo expuesto en a) y b) y c) podría concluirse que el estudio de líneas moleculares en los alrededores de estrellas WR (o estrellas de gran masa) es indicado para entender los efectos a "pequeña escala" producidos por la estrella en el MIE local.

\subsection{Trabajos a futuro}

A partir de los resultados obtenidos y discutidos en esta Tesis Doctoral, nuestra intención es continuar investigando con más y mejores observaciones el entorno de las estrellas de gran masa, así como también las regiones de formación estelar de nuestra galaxia. Particularmente, algunos objetivos a futuro son:

- Estudiar en mayor detalle el gas molecular observado en las nebulosas ópticas alrededor de las estrellas WR 16, WR 40, WR 75 y WR 68. Observaciones de las líneas rotacionales $\mathrm{J}=1 \rightarrow 0$ de las moléculas de ${ }^{12} \mathrm{CO}$ y 
${ }^{13} \mathrm{CO}$ con mejor resolución angular $\left(\mathrm{HPBW} \sim 15^{\prime \prime}\right.$ ) permitirían una mejor comprensión de las propiedades físicas de dichas nebulosas, especialmente su cinemática. Por otro lado, la observación de líneas rotacionales superiores $(\mathrm{J}=2 \rightarrow 1)$ de dichas moléculas, así como la observación de otras moléculas ( $\left.\mathrm{CS}, \mathrm{HCO}^{+}, \mathrm{HCN}\right)$ permitirían un mayor entendimiento de los procesos físicos que allí se están llevando a cabo.

La nebulosa anillo alrededor de la estrella WR 40 (RCW 58), no fue estudiada en esta Tesis Doctoral, pero su particular morfología (ver Figura 1.7) plantea interesantes interrogantes, especialmente en lo referente a su cinemática.

- Continuar con el estudio del gas molecular en las regiones HII RCW 121 y RCW 122. La obtención de nuevas observaciones moleculares permitirían lograr una mejor comprensión de las características físicas y cinemáticas observadas en estas regiones de formación estelar (gradientes de velocidad y sesgamiento).

Además se está realizando en la actualidad un estudio de formación estelar en RCW 122 basado en observaciones fotométricas en la banda espectral correspondiente al infrarrojo cercano.

- Realizar un estudio del gas molecular en regiones de formación estelar de nuestra galaxia que no pudieron ser estudiadas es esta Tesis Doctoral y para las que se cuenta con observaciones de NANTEN (NGC 3503, RCW 49). 


\section{Agradecimientos}

Cada desafío que decidimos enfrentar a lo largo de nuestras vidas, nos exige lo mejor de nosotros mismos y por lo tanto alcanzar las metas que esos desafíos nos proponen nos llena de orgullo. A medida que vamos creciendo comenzamos a entender que en esos logros que tanta satisfacción nos producen, no somos los únicos protagonistas. A lo largo de estos cinco años he tenido a mi lado a un montón de personas que me han ayudado y han sabido guiarme (tanto en mi profesión como en la vida), por lo que finalizar sin agradecerles haría que este trabajo esté más que incompleto.

Me gustaría comenzar agradeciendo a mi director Marcelo Arnal, por la confianza, el tiempo y la paciencia invertidos en mí desde un principio y por toda su ayuda y su guía a lo largo de este trabajo.

A mis grandes amigos/colegas, Javi V., Diego A. y Diego B (en orden de distancias), con quienes he compartido no sólo estudio y trabajo, sino también muchísimos lindos momentos de mi vida. Su cálida e incondicional amistad son los bienes más preciados que he obtenido de mi incursión en la Astronomía.

A TODO el personal de Instituto Argentino de Radioastronomía, por la ayuda y apoyo otorgados a lo largo de mi Doctorado y Licenciatura. Ahí van: a Gisela, Cristina Cappa, Ricardo, Fede, Marcelo, Kiko, Fernando, Guillermina, Carlitos, Claudia, Mariela, Laura, Paula, Gustavo, Anabella, Lucía, Oscar, Palo, Cristina Martín. No quisiera olvidarme de todos los chicos de ingeniería que tantas veces y tan gentilmente me han ahorrado kilómetros de caminatas.

Al personal del Observatorio, especialmente al Grupo de Estrellas Masivas: a Guille por haberme dado tan gentilmente un lugar para trabajar y a Vero y Ceci, por su buena onda, su calidez y por aguantarme de compañero de oficina, lo que demuestra que nos une una amistad de fierro ya que muchas veces no soy fácil de aguantar.

A Mire, Juan, Euge e Ivan (Altamiranos), mi familia "adoptiva" platense. Por abrirme las puertas de su casa y brindarme en todo momento su cálida amistad. Ojalá todo el mundo pudiera tener amigos como ellos.

Por último y muy especialmente, a mi familia. A mi madre, a mi padre y a mi hermana. Por estar siempre conmigo, por ayudarme siempre y por apoyarme en todos los momentos de mi vida. Nada de lo que he logrado y he conseguido a lo largo de toda mi vida lo podría haber hecho sin su ayuda. Todo lo que soy se lo debo a ellos.

A todos ellos, muchas gracias. 